\title{
EXTRAÇÃO DA ÁGUA DO SOLO POR PLANTAS: DESENVOLVIMENTO E VALIDAÇÃO DE UM MODELO
}

\author{
QUIRIJN DE JONG VAN LIER \\ Engenheiro Agrônomo
}

Orientador: Prof. Dr. PAULO LEONEL LIBARDI

Tese apresentada à Escola Superior de Agricultura "Luiz de Queiroz", da Universidade de São Paulo, para obtenção do título de Doutor em Agronomia. Área de concentração: Solos e Nutrição de Plantas.

PIRACICABA

Estado de São Paulo - Brasil

janeiro de 1994 
Ficha catalogrefica preparada pela Seço de Livros da Divisăo de Fiblioteca e Documentaçăo - FCLQ/USP

J49e

Jong Van Lier, Ruirijn de Extraça da água do solo por plantas: desenvolvi mento validafar de um modelo. Firacicaba, 1994. 9tp. ilus.

Tese - ESALQ

Bibliogratia.

1. Agua do solo - Extragão - Modelo matemático 2. Condutividade hidraulica 3. Modelo matemático

4. Raiz - Agua - Absorfzo I. Escola Superior de Agricultura Luiz de Queiroz, Firacicaba.

$$
\text { CDD } 631.432
$$




\section{EXTRAÇÃO DA ÁGUA DO SOLO POR PLANTAS: DESENVOLVIMENTO E VALIDAÇÃO DE UM MODELO}

QUIRIJN DE JONG VAN LIER

Aprovada em 03 de março de 1994

Comissão julgadora:

1. Prof. Dr. Paulo Augusto Manfron

UFSM

2. Dr. Sílvio Crestana

EMBRAPA/São Carlos

3. Prof. Dr. Sérgio Oliveira Moraes

ESALQ/USP

4. Prof. Dr. Zilmar Ziller Marcos

ESALQ/USP

5. Prof. Dr. Paulo Leonel Libardi

ESALQ/USP

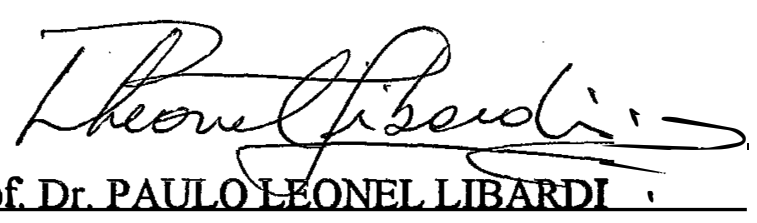

Orientador 


\section{AGRADECIMENTOS}

O autor agradece a todas as pessoas que de alguma forma colaboraram com a realização deste trabalha, em especial

ao Prof. Paulo Leonel Libardi pela orientação,

ao Prof. Sérgio Oliveira Moraes pela colaboração e as boas sugestões,

ao Prof. Virgílio Franco do Nascimento Filho pela colaboração na cessão do equipamento de radiação $\gamma$,

ao Prof. Gerd Sparovek pela ajuda na coleta, no pré-tratamento e na análise da terra,

ao Engenheiro Agrônomo Oscar Vieira pelas sugestões e valioso auxílio na elaboração do experimento,

aos funcionários Luiz Fernando Novello e Francisco Bernardo Dias pela ajuda na parte experimental,

a Iara e Maíra, pela paciência.

Agradece também à Coordenadoria de Aperfeicoamento de Pessoal de Nível Superior (CAPES) pela bolsa de estudos concedida. 


\section{SUMÁRIO}

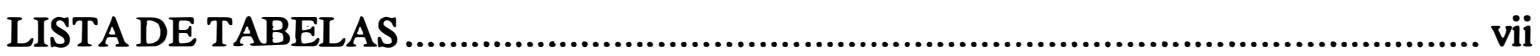

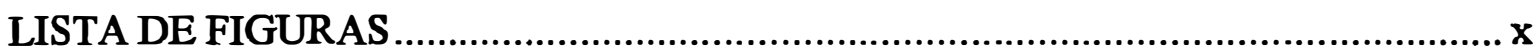

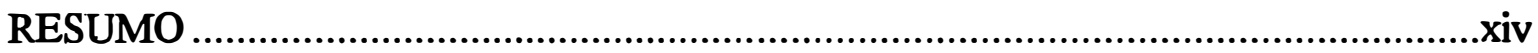

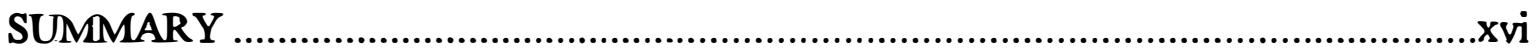

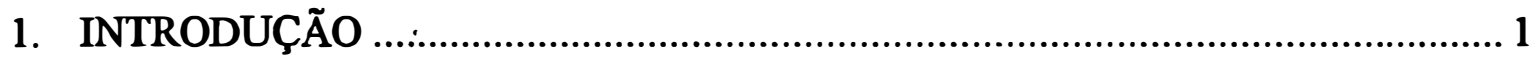

2. REVISÃO DE LITERATURA ................................................................. 4

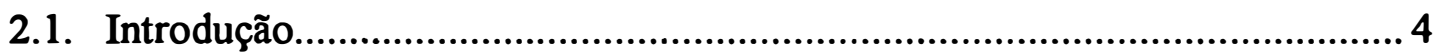

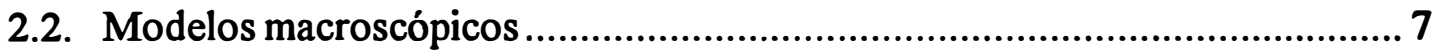

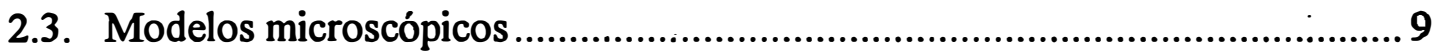

2.4. Limitações à extração de água do solo pelas raízes ................................... 12

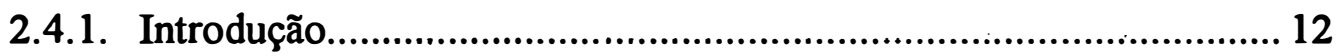

2.4.2. Condutividade hidráulica do solo ................................................. 13

2.4.3. Condutividade hidráulica do tecido vegetal .................................. 14

2.4.4. Condutividade hidráulica da interface solo-raiz ............................ 15

( 2.5. Distribuição espacial das raízes.................................................................. 16

$\succ$ 2.6. Atividade das raízes em função da profundidade ......................................... 16

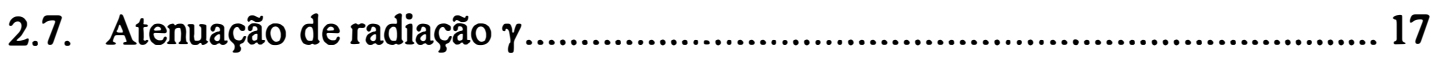




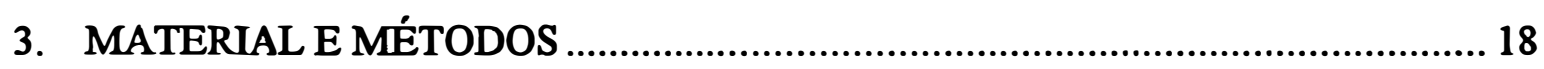

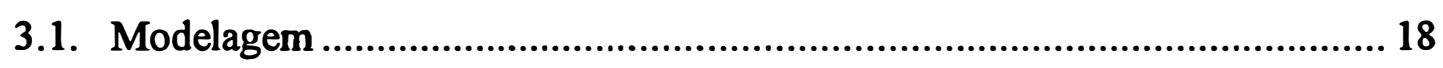

3.1.1. Absorção de água por uma raiz isolada ............................................ 18

3.1.1.1. Teoria para um sistema tridimensional ................................. 19

3.1.1.1.1. Condutividade hidráulica ........................................... 23

3.1.1.1.2. Curva de retenção .................................................... 24

3.1.1.2. Teoria para um sistema bidimensional................................... 27

3.1.2. Ajuste das umidades medidas à teoria ................................................ 28

3.1.3. Absorção de água por um sistema radicular completo ....................... 28

3.2. Delineamento experimental.......................................................................... 30

3.2.1. Terra: coleta e pretratamento.......................................................... 30

3.2.2. Planta ....................................................................................... 31

3.2.3. Unidades experimentais ............................................................... 32

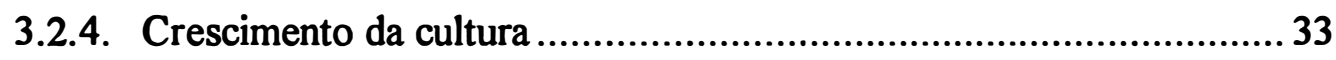

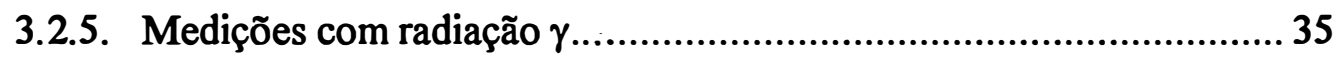

3.2.6. Estimativa da evapotranspiração ………………………………....... 39

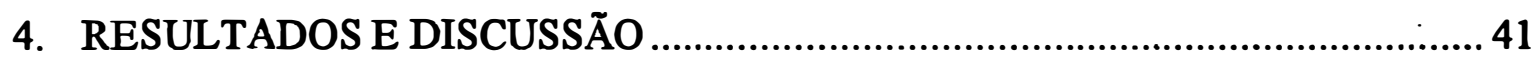

4.1. Curvas de retenção................................................................................... 41

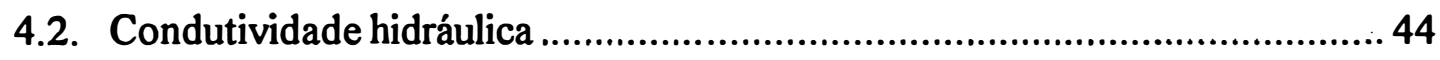

4.3. Coeficiente de atenuação da radiação $\gamma$ pela água ………………………..... 47

4.4. Medições da umidade através da atenuação de radiação $\gamma$............................. 48

4.4.1. Estimativa da evapotranspiração ..................................................... 48

4.4.2. Ajuste do modelo proposto às umidades medidas............................ 49

4.5. Extrapolação do modelo a um sistema radicular............................................ 71

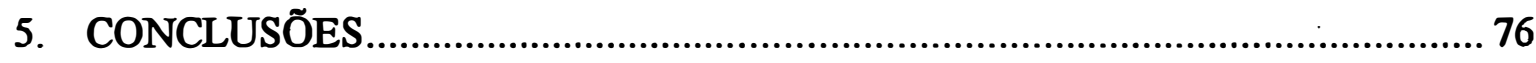




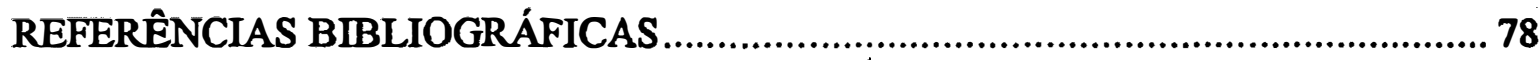

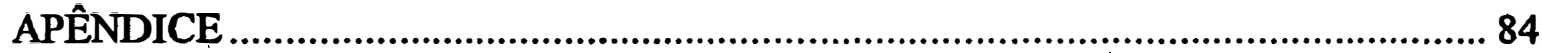




\section{LISTA DE TABELAS}

Tabela 1 - Resultados da análise quimica do material dos solos LE e LV antes da

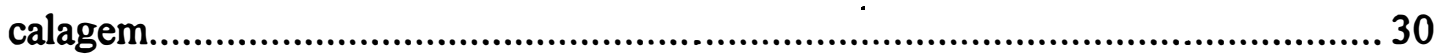

Tabela 2 - Resultados da análise quimica do material dos solos LE e LV depois da calagem.

Tabela 3 - Resultados da análise fisica do material dos solos LE e LV.

Tabela 4 - Composição da solução nutritiva completa, conforme SARRUGE (1975).

Tabela 5 - Umidades volumétricas obtidas no material dos solos LV e LE para as

14 tensões aplicadas.

Tabela 6 - Parâmetros da equação de VAN GENUCHTEN (1980) (equação (22)) e parâmetros estatísticos da regressão para o material dos solos LV e LE 42

Tabela 7 - Avanço da frente de molhamento em função do tempo para o material dos solos LV e LE no experimento de difusão.

Tabela 8 -Resultados da regressão linear de $x$ versus 00,5 e umidades determinadas e no experimento de difusão para o material dos solos LV e LE. 46

Tabela 9 - Taxas de evapotranspiração $\left(10^{-8} \cdot \mathrm{m}^{3} \cdot \mathrm{m}^{-2} \cdot \mathrm{s}^{-1}\right)$ estimadas com base nas umidades medidas nas 9 datas para as duas repetições dos materiais dos solos LV e LE. 
Tabela 10 - Transpiração $\left(T, 10^{-8} \mathrm{~m}^{3} \cdot \mathrm{m}^{-2} \cdot \mathrm{s}^{-1}\right)$, zona influenciada $\left(R_{t}, \mathrm{~m}\right)$, umidade do solo na zona não influenciada $\left(\theta_{\text {solo }}, \mathrm{m}^{3} \cdot \mathrm{m}^{-3}\right)$, potencial na raiz $\left(\psi_{\text {raiz }}\right.$, $\mathrm{kPa}$ ) e coeficientes de ajuste (c.a.), para o material do solo $\mathrm{LV}, \mathrm{1}^{\mathrm{a}}$ repetição, a $0,04 \mathrm{~m}$ de profundidade, para as 9 datas de leitura.

Tabela 11 - Transpiração $\left(T, 10^{-8} \mathrm{~m}^{3} \cdot \mathrm{m}^{-2} \cdot \mathrm{s}^{-1}\right)$, zona influenciada $\left(R_{t}, \mathrm{~m}\right)$, umidade do solo na zona não influenciada $\left(\theta_{\text {solo }}, \mathrm{m}^{3} \cdot \mathrm{m}^{-3}\right)$, potencial na raiz $\left(\psi_{\text {raiz }}\right.$, $\mathrm{kPa}$ ) e coeficientes de ajuste (c.a.), para o material do solo $\mathrm{LV}, \mathbf{1}^{\mathrm{a}}$ repetição, a $0,05 \mathrm{~m}$ de profundidade, para as 9 datas de leitura

Tabela 12 - Transpiração $\left(T, 10^{-8} \mathrm{~m}^{3} \cdot \mathrm{m}^{-2} \cdot \mathrm{s}^{-1}\right)$, zona influenciada $\left(R_{t}, \mathrm{~m}\right)$, umidade do solo na zona não influenciada $\left(\theta_{\text {solo }}, \mathrm{m}^{3} \cdot \mathrm{m}^{-3}\right)$, potencial na raiz $\left(\psi_{\text {raiz }}\right.$, $\mathrm{kPa}$ ) e coeficientes de ajuste (c.a.), para o material do solo $\mathrm{LV}, 1^{\mathrm{a}}$ repetição, a 0,06 $\mathrm{m}$ de profundidade, para as 9 datas de leitura.

Tabela 13 - Transpiração $\left(T, 10^{-8} \mathrm{~m}^{3} \cdot \mathrm{m}^{-2} \cdot \mathrm{s}^{-1}\right)$, zona influenciada $\left(R_{t}, \mathrm{~m}\right)$, umidade do solo na zona não influenciada $\left(\theta_{\text {solo }}, \mathrm{m}^{3} \cdot \mathrm{m}^{-3}\right)$, potencial na raiz $\left(\psi_{\text {raiz }}\right.$, $\mathrm{kPa}$ ) e coeficientes de ajuste (c.a.), para o material do solo LV, $2^{\underline{a}}$ repetição, a 0,04 $\mathrm{m}$ de profundidade, para as 9 datas de leitura.

Tabela 14 - Transpiração $\left(T, 10^{-8} \mathrm{~m}^{3} \cdot \mathrm{m}^{-2} \cdot \mathrm{s}^{-1}\right)$; zona influenciada $\left(R_{t}, \mathrm{~m}\right)$, umidade do solo na zona não influenciada $\left(\theta_{\text {solo }}, \mathrm{m}^{3} \cdot \mathrm{m}^{-3}\right)$, potencial na raiz $\left(\psi_{\text {raiz }}\right.$, $\mathrm{kPa}$ ) e coeficientes de ajuste (c.a.), para o material do solo LV, $2^{\underline{a}}$ repetição, a $0,05 \mathrm{~m}$ de profundidade, para as 9 datas de leitura.

Tabela 15 - Transpiração $\left(T, 10^{-8} \mathrm{~m}^{3} \cdot \mathrm{m}^{-2} \cdot \mathrm{s}^{-1}\right)$, zona influenciada $\left(R_{t}, \mathrm{~m}\right)$, umidade do solo na zona não influenciada $\left(\theta_{\text {solo }}, \mathrm{m}^{3} \cdot \mathrm{m}^{-3}\right)$, potencial na raiz $\left(\psi_{\text {raiz }}\right.$, $\mathrm{kPa}$ ) e coeficientes de ajuste (c.a.), para o material do solo $\mathrm{LV}, 2^{\mathrm{a}}$ repetição, a $0,06 \mathrm{~m}$ de profundidade, para as 9 datas de leitura.

Tabela 16 - Transpiração $\left(T, 10^{-8} \mathrm{~m}^{3} \cdot \mathrm{m}^{-2} \cdot \mathrm{s}^{-1}\right)$, zona influenciada $\left(R_{t}, \mathrm{~m}\right)$, umidade do solo na zona não influenciada $\left(\theta_{\text {solo }}, \mathrm{m}^{3} \cdot \mathrm{m}^{-3}\right)$, potencial na raiz $\left(\psi_{\text {raiz }}\right.$, $\mathrm{kPa}$ ) e coeficientes de ajuste (c.a.), para o material do solo LE, $1^{\mathrm{a}}$ repetição, a $0,04 \mathrm{~m}$ de profundidade, para as 9 datas de leitura. 
Tabela 17 - Transpiração $\left(T, 10^{-8} \mathrm{~m}^{3} \cdot \mathrm{m}^{-2} \cdot \mathrm{s}^{-1}\right)$, zona influenciada $\left(R_{t}, \mathrm{~m}\right)$, umidade do solo na zona não influenciada $\left(\theta_{\text {solo }}, \mathrm{m}^{3} \cdot \mathrm{m}^{-3}\right)$, potencial na raiz $\left(\psi_{\text {raiz }}\right.$, $\mathrm{kPa}$ ) e coeficientes de ajuste (c.a.), para o material do solo LE, $1^{\underline{a}}$ repetição, a $0,05 \mathrm{~m}$ de profundidade, para as 9 datas de leitura........................... 55

Tabela 18 - Transpiração $\left(T, 10^{-8} \mathrm{~m}^{3} \cdot \mathrm{m}^{-2} \cdot \mathrm{s}^{-1}\right)$, zona influenciada $\left(R_{t}, \mathrm{~m}\right)$, umidade do solo na zona não influenciada $\left(\theta_{\text {solo }}, \mathrm{m}^{3} \cdot \mathrm{m}^{-3}\right)$, potencial na raiz $\left(\psi_{\text {raiz }}\right.$, $\mathrm{kPa}$ ) e coeficientes de ajuste (c.a.), para o material do solo LE, $1^{\mathrm{a}}$ repetição, a 0,06 $\mathrm{m}$ de profundidade, para as 9 datas de leitura.

Tabela 19 - Transpiração $\left(T, 10^{-8} \mathrm{~m}^{3} \cdot \mathrm{m}^{-2} \cdot \mathrm{s}^{-1}\right)$, zona influenciada $\left(R_{t}, \mathrm{~m}\right)$, umidade do solo na zona não influenciada $\left(\theta_{\text {solo }}, \mathrm{m}^{3} \cdot \mathrm{m}^{-3}\right)$, potencial na raiz $\left(\psi_{\text {raiz }}\right.$, $\mathrm{kPa}$ ) e coeficientes de ajuste (c.a.), para o material do solo LE, $2^{\underline{a}}$ repetição, a 0,04 $\mathrm{m}$ de profundidade, para as 9 datas de leitura.

Tabela 20 - Transpiração $\left(T, 10^{-8} \mathrm{~m}^{3} \cdot \mathrm{m}^{-2} \cdot \mathrm{s}^{-1}\right)$, zona influenciada $\left(R_{t}, \mathrm{~m}\right)$, umidade do solo na zona não influenciada $\left(\theta_{\text {solo }}, \mathrm{m}^{3} \cdot \mathrm{m}^{-3}\right)$, potencial na raiz $\left(\psi_{\text {raiz }}\right.$, $\mathrm{kPa}$ ) e coeficientes de ajuste (c.a.), para o material do solo $\mathrm{LE}, 2^{\mathrm{a}}$ repetição, a 0,05 $\mathrm{m}$ de profundidade, para as 9 datas de leitura.

Tabela 21 - Transpiração $\left(T, 10^{-8} \mathrm{~m}^{3} \cdot \mathrm{m}^{-2} \cdot \mathrm{s}^{-1}\right)$, zona influenciada $\left(R_{t}, \mathrm{~m}\right)$, umidade do solo na zona não influenciada $\left(\theta_{\text {solo }}, \mathrm{m}^{3} \cdot \mathrm{m}^{-3}\right)$, potencial na raiz $\left(\psi_{\text {raiz }}\right.$, $\mathrm{kPa}$ ) e coeficientes de ajuste (c.a.), para o material do solo LE, $2^{-}$ repetição, a 0,06 $\mathrm{m}$ de profundidade, para as 9 datas de leitura.

Tabela 22 - Médias da transpiração $\left(T, 10^{-8} \mathrm{~m}^{3} \cdot \mathrm{m}^{-2} \cdot \mathrm{s}^{-1}\right)$, da zona influenciada $\left(R_{t}\right.$, $\mathrm{m})$, da umidade do solo na zona não influenciada $\left(\theta_{\text {solo }}, \mathrm{m}^{3} . \mathrm{m}^{-3}\right)$ e do potencial na raiz $\left(\psi_{\text {raiz }}, \mathrm{kPa}\right)$, bem como os respectivos coeficientes de variação (c.v., \%), para o material do solo LV para as 9 datas de leitura.

Tabela 23 - Médias da transpiração $\left(T, 10^{-8} \mathrm{~m}^{3} \cdot \mathrm{m}^{-2} \cdot \mathrm{s}^{-1}\right)$, da zona influenciada $\left(R_{t}\right.$, $\mathrm{m})$, da umidade do solo na zona não influenciada $\left(\theta_{\text {solo }}, \mathrm{m}^{3} \cdot \mathrm{m}^{-3}\right)$ e do potencial na raiz $\left(\psi_{\text {raiz }}, \mathrm{kPa}\right)$, bem como os respectivos coeficientes de variação (c.v., \%), para o material do solo LE para as 9 datas de leitura. 58 


\section{LISTA DE FIGURAS}

Figura 1 - Representação gráfica do potencial mátrico em função da distância da raiz.

Figura 2 - Desenho esquemático, com dimensões aproximadas, da unidade experimental de acrílico com placas porosas, utilizada para medir o fluxo de água ao sistema radicular.

Figura 3 - Espectro do ${ }^{241}$ Am obtido com o equipamento utilizado. 35

Figura 4 - Corte transversal, mostrando esquematicamente o posicionamento da unidade experimental de acrilico entre a fonte e o detector de radiação

Figura 5 - Curva de retenção do material do solo LV. A linha é resultado do ajuste da equação (22) às umidades medidas (pontos).

Figura 6 - Curva de retenção do material do solo LE. A linha é resultado do ajuste da equação (22) às umidades medidas (pontos).

Figura 7 - Condutividade hidráulica $\left(\log (K), \log \left(\mathrm{m}^{2} \cdot \mathrm{kPa}^{-1} \cdot \mathrm{s}^{-1}\right)\right)$ em função da umidade volumétrica, calculada através da equação (26) e com base nos resultados apresentados na Tabela 8 para o material dos solos LV e LE. 
Figura 8 - Umidades volumétricas $\left(\mathrm{m}^{3} \cdot \mathrm{m}^{-3}\right)$ em função da distância $(\mathrm{m})$ da placa porosa, medidas (pontos) e calculadas através de regressão (linhas) para o material do solo $\mathrm{LV}, \mathrm{I}^{\mathrm{a}}$ repetição, a $0,04 \mathrm{~m}$ de profundidade, para as 9 datas de leitura. Valores negativos para a distância indicam o lado A, valores positivos o lado $B$.

Figura 9 - Umidades volumétricas $\left(\mathrm{m}^{3} \cdot \mathrm{m}^{-3}\right)$ em função da distância $(\mathrm{m})$ da placa porosa, medidas (pontos) e calculadas através de regressão (linhas) para o material do solo $L V$, 1 a repetição, a $0,05 \mathrm{~m}$ de profundidade, para as 9 datas de leitura. Valores negativos para a distância indicam o lado A, valores positivos o lado $B$.

Figura 10 - Umidades volumétricas $\left(\mathrm{m}^{3} \cdot \mathrm{m}^{-3}\right)$ em função da distância $(\mathrm{m})$ da placa porosa, medidas (pontos) e calculadas através de regressão (linhas) para 0 material do solo $\mathrm{LV}, \mathbf{1}^{\mathrm{a}}$ repetição, a $0,06 \mathrm{~m}$ de profundidade, para as 9 datas de leitura. Valores negativos para a distância indicam o lado $\mathrm{A}$, valores positivos o lado $\mathrm{B}$.

Figura 11 - Umidades volumétricas $\left(\mathrm{m}^{3} \cdot \mathrm{m}^{-3}\right)$ em função da distância $(\mathrm{m})$ da placa porosa, medidas (pontos) e calculadas através de regressão (linhas) para 0 material do solo $\mathrm{LV}, 2$ a repetição, a $0,04 \mathrm{~m}$ de profundidade, para as 9 datas de leitura. Valores negativos para a distância indicam o lado $\mathrm{A}$, valores positivos o lado $B$ :

Figura 12 - Umidades volumétricas $\left(\mathrm{m}^{3} \cdot \mathrm{m}^{-3}\right)$ em função da distância $(\mathrm{m})$ da placa porosa, medidas (pontos) e calculadas através de regressão (linhàs) para 0 material do solo $\mathrm{LV}$; 2 a repetição, a $0,05 \mathrm{~m}$ de profundidade, para as 9 datas de leitura. Valores negativos para a distância indicam o lado A, valores positivos o lado $B$.

Figura 13 - Umidades volumétricas $\left(\mathrm{m}^{3} \cdot \mathrm{m}^{-3}\right)$ em função da distância $(\mathrm{m})$ da placa porosa, medidas (pontos) e calculadas através de regressão (linhas) para 0 material do solo $\mathrm{LV}, 2^{2}$ repetição, a $0,06 \mathrm{~m}$ de profundidade, para as 9 datas de leitura. Valores negativos para a distância indicam o lado A, valores positivos o lado $B$. 
Figura 14 - Umidades volumétricas $\left(\mathrm{m}^{3} \cdot \mathrm{m}^{-3}\right)$ em função da distância $(\mathrm{m})$ da placa porosa, medidas (pontos) e calculadas através de regressão (linhas) para o material do solo $\mathrm{LE}, 1^{\text {a }}$ repetição, a $0,04 \mathrm{~m}$ de profundidade, para as 9 datas de leitura. Valores negativos para a distância indicam o lado A, valores positivos o lado $B$.

Figura 15 - Umidades volumétricas $\left(\mathrm{m}^{3} \cdot \mathrm{m}^{-3}\right)$ em função da distância $(\mathrm{m})$ da placa porosa, medidas (pontos) e calculadas através de regressão (linhas) para o

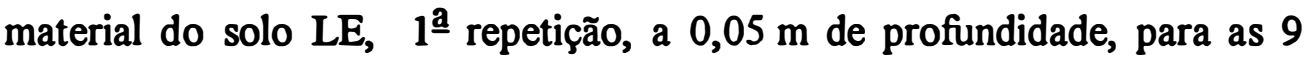
datas de leitura. Valores negativos para a distância indicam o lado A, valores positivos o lado $B$.

Figura 16 - Umidades volumétricas $\left(\mathrm{m}^{3} \cdot \mathrm{m}^{-3}\right)$ em função da distância $(\mathrm{m})$ da placa porosa, medidas (pontos) e calculadas através de regressão (linhas) para 0 material do solo $\mathrm{LE}$, $1^{\text {a }}$ repetição, a $0,06 \mathrm{~m}$ de profundidade, para as 9 datas de leitura. Valores negativos para a distância indicam o lado A, valores positivos o lado $B$

Figura 17 - Umidades volumétricas $\left(\mathrm{m}^{3} \cdot \mathrm{m}^{-3}\right)$ em função da distância $(\mathrm{m})$ da placa porosa, medidas (pontos) e calculadas através de regressão (linhas) para o material do solo $\mathrm{LE}, 2$ a repetição, a $0,04 \mathrm{~m}$ de profundidade, para as 9 datas de leitura. Valores negativos para a distância indicam o lado A, valores positivos o lado $B$.

Figura 18 - Umidades volumétricas $\left(\mathrm{m}^{3} \cdot \mathrm{m}^{-3}\right)$ em função da distância $(\mathrm{m})$ da placa porosa, medidas (pontos) e calculadas através de regressão (linhas) para o material do solo $\mathrm{LE}, 2$ a repetição, a $0,05 \mathrm{~m}$ de profundidade, para as 9 datas de leitura. Valores negativos para a distância indicam o lado $\mathrm{A}$, valores positivos o lado $B$

Figura 19 - Umidades volumétricas $\left(\mathrm{m}^{3} \cdot \mathrm{m}^{-3}\right)$ em função da distância $(\mathrm{m})$ da placa porosa, medidas (pontos) e calculadas através de regressão (linhas) para o material do solo LE, 2a repetição, a $0,06 \mathrm{~m}$ de profundidade, para as 9 datas de leitura. Valores negativos para a distância indicam o lado A, valores positivos o lado $B$. 
Figura 20 - Potencial total necessário nas raizes de uma planta de $0,01 \mathrm{~m}^{2}$ com profundidade efetiva do sistema radicular de $0,3 \mathrm{~m}$ e comprimento total do sistema radicular de 7,0 m no material do solo LV (a) e LE (b) com umidade inicial correspondente ao potencial mátrico de $-10 \mathrm{kPa}$, para manter um fluxo de água de acordo com a taxa de transpiração de 3.10$8 \mathrm{~m}^{3} \cdot \mathrm{m}^{-2} \cdot \mathrm{s}^{-1}(3), 6 \cdot 10^{-8} \mathrm{~m}^{3} \cdot \mathrm{m}^{-2} \cdot \mathrm{s}^{-1}(6)$, e $12.10^{-8} \mathrm{~m}^{3} \cdot \mathrm{m}^{-2} \cdot \mathrm{s}^{-1}$ (12).

Figura 21 - Potencial total necessário nas raizes de uma planta de $0,01 \mathrm{~m}^{2} \mathrm{com}$ profundidade efetiva do sistema radicular de $0,3 \mathrm{~m}$ e comprimento total do sistema radicular de $0,7 \mathrm{~m}(0,7)$ e $7,0 \mathrm{~m}(7,0)$ no material do solo LV (a) e LE (b) com umidade inicial correspondente ao potencial mátrico de $-10 \mathrm{kPa}$, para manter um fluxo de água de acordo com a taxa de transpiração de $6.10^{-8} \mathrm{~m}^{3} \cdot \mathrm{m}^{-2} \cdot \mathrm{s}^{-1}$. 


\title{
EXTRAÇÃO DA ÁGUA dO SOLO POR PLANTAS: \\ DESENVOLVIMENTO E VALIDAÇÃO DE UM MODELO
}

\author{
Autor: QUIRIJN DE JONG VAN LIER \\ Orientador: Prof. Dr. PAULO LEONEL LIBARDI
}

\section{RESUMO}

O conhecimento do processo de fluxo de água no solo em direção a uma raiz, é essencial para o manejo racional da irrigação de culturas. Um modelo foi desenvolvido para a descrição fisica desse processo, baseado na contabilização do fluxo de água na zona circundante à raiz e na demanda tránspiratória. $\mathbf{O}$ modelo foi aferido num experimento com plantas de arroz (Oryza sativa L.) no material de dois solos, um Latossolo Vermelho Amarelo álico A moderado, textura média (LV) e um Latossolo Vermelho Escuro álico A moderado, textura muito argilosa (LE), ambos do município de Piracicaba (SP). Criou-se um ambiente artificial, simulando a presença de uma só raiz através da utilização de placas porosas de cerâmica. A umidade em função da distância da raiz e em função do tempo foi medida utilizando a técnica de atenuação de radiação $\gamma$.

$O$ experimento conduzido não permitiu, para o material do solo $L V$, de alta condutividade hidráulica, validar o modelo desenvolvido, devido ao avanço excessivamente rápido da faixa influenciada pela extração de água pelas raízes. Para o material do solo LE, com uma condutividade hidráulica menor, pôde-se observar o esgotamento de água próxima às placas porosas, de acordo com o modelo desenvolvido. 
Em conseqüência da aceitação do modelo concluiu-se que a extração da água do solo pelo sistema radicular de plantas depende das propriedades hidráulicas do solo. Durante a secagem do solo o potencial para manter o fluxo neceśsário de água em direção às raizes diminui, e muito mais rapidamente em solos com condutividade hidráulica baixa. Introduziu-se o termo potencial-limite, o potencial mais baixo que uma planta consegue manter nas suas raizes. Quando o potencial-limite das raizes é atingido, a umidade média do solo corresponde à crítica. $\mathrm{O}$ tempo para se chegar ao potencial-limite é função da umidade inicial do solo, da condutividade hidráulica do solo, da demanda transpiratória e da distribuição espacial das raizes.

As limitações do modelo proposto dizem respeito às simplificações feitas para desenvolvê-lo, como a desconsideração das variações na taxa de transpiração durante um dia, a suposição que todas as raizes têm o mesmo raio e que a água nas suas superficies possui o mesmo potencial total, a hipótese de que, ao extrair água do solo, não há interação entre raizes e a desconsideração da variabilidade espacial : das características do solo. 


\title{
EXTRACTION OF SOIL WATER BY PLANTS: DEVELOPMENT AND VALIDATION OF A MODEL
}

\author{
Author: QUIRIN DE JONG VAN LIER \\ Adviser: Prof. Dr. PAULO LEONEL LIBARDI
}

\section{SUMMARY}

The knowledge of the process of soil water movement in direction of a root is essential for the understanding of the control of irrigation practices. A model was developed to physically describe this process, based on the calculation of water fluxes in the surroundings of a root as a function of atmospheric transpiration demand. The model was checked in an experiment with rice (Oryza sativa L.), planted in the material of two soils, a medium textured oxisol and a very clayey oxisol, both from the township of Piracicaba, São Paulo State, Brazil. An artificial environment was created in order to simulate the presence of only one root, using ceramic porous plates. Soil water content as a function of root distance and as a function of time was measured using the technique of attenuation of a $\gamma$-beam.

For the medium textured material with a relatively high hydraulic conductivity, the experiment did not permit the validation of the developed model, because of the very quick advance of the drying front. For the very clayey material, with a lower hydraulic conductivity, water depletion close to the porous plates occurred according to the model. 
As a result of the acceptance of the model, it was concluded that soil water extraction by the root system of plants depends on the soil's hydraulic properties. During drying of a soil the water potential needed in the roots gets lower and lower, and far more rapidly in soils with a lower hydraulic conductivity. The term limiting potential was introduced as being the smallest water potential a plant can maintain in its roots. When the limiting potential is reached, the mean soil moisture content corresponds to the critical soil moisture content. The time to reach this limiting potential is a function of the initial soil water content, the soil's hydraulic conductivity, the atmospheric transpiration demand and the spatial root distribution.

The limitations of the proposed model are related to the simplifications that were made to develop it, like the disconsideration of the diurnal variations in transpiration rates, the assumption that all roots have the same diameter and that the water at their surfaces has the same total potential, the hypothesis that there is no interaction between roots while extracting soil water and the disconsideration of spatial variability of soil properties. 


\section{INTRODUÇÃO}

As espécies vegetais produzem, através da fotossíntese, carboidratos, fonte energética para o homem e os animais. $O$ carbono necessário na fotossíntese é extraído do $\mathrm{CO}_{2}$ do ar que entra, por difusão, pelos estômatos nas partes verdes da planta. No interior dos estômatos, o ar está quase saturado com água. Como a atmosfera ao redor da planta se encontra normalmente com umidade abaixo da saturação, uma difusão de água ocorre, na forma de vapor, dos estômatos à atmosfera. Chama-se esse processo de perda de água pela planta de transpiração, expressa em volume por unidade de área e tempo.

A planta mantém o equilíbrio hídrico, extraindo água, com nutrientes dissolvidos, do solo através do seu sistema radicular. Quando a quantidade de água presente no solo diminui, a planta encontra dificuldade em absorver uma vazão de água igual àquela que está perdendo e começa a fechar estômatos para diminuir a difusão de água para a atmosfera. Em conseqüência diminui a quantidade de gás carbônico que entra na planta pelas folhas, principalmente, bem como a absorção de água e nutrientes pelas raízes.

Uma outra conseqüência da redução da taxa de transpiração é o aumento da temperatura da planta, afetando a velocidade e eficiência dos processos fotossintéticos, diminuindo ainda mais a produção vegetal. 
Diz-se que a planta, com estômatos parcial ou totalmente fechados, está em estado de "estresse hídrico", do qual resulta a perda da turgescência das células das folhas, fazendo com que a captação de luz solar, fonte energética para o processo de fotossíntese, seja reduzida. A umidade máxima em que ocorre “estresse hídrico" é chamada umidade critica.

Ao manejar o sistema agrícola, o homem tem como prioridade alcançar o rendimento econômico de uma cultura. Portanto, o conhecimento do valor da umidade crítica, também chamado de "ponto de irrigação", é de grande importância para o manejo agrícola, especialmente para o manejo da irrigação. Para poder prever o valor da umidade crítica, deve-se conhecer detalhadamente, dentre outros, os seguintes fenômenos a ela relacionàdos: movimento da água do solo à raiz, absorção da água pela raiz, fluxo de água dentro da própria planta, balanço energético das folhas que influi na evaporação de água dentro dos estômatos, processo de difusão de água dos estômatos à atmosfera, e funcionamento do mecanismo de fechamento e abertura dos estômatos.

Cabe à Ciência do Solo estudar o primeiro desses processos: o movimento da água, dentro do solo, em direção à superficie radicular, relacionando esse processo com os que ocorrem na planta e entre a planta e a atmosfera.

Nesta tese foi desenvolvido e validado um modelo, baseado na contabilização do fluxo de água na zona circundante à raiz e na demanda transpiratória, que descreve quantitativamente o movimento de água em direção à superficie radicular. Em conseqüência do modelo discutir-se-á como e porque as propriedảdes hidráulicas do solo, que variam com a umidade, influenciam na extração de água pelo sistema radicular das espécies vegetais e como a umidade na qual a planta não consegue extrair do solo uma quantidade suficiente de água para suprir a demanda transpiratória depende da condutividade hidráulica do solo, da demanda transpiratória da atmosfera, do potencial 
total da água no solo, e da sensibilidade à seca da planta. Essa sensibilidade é, por sua vez, função do potencial-limite nas raízes e da densidade de enraizamento da cultura. 


\section{REVISÃO DE LITERATURA}

\subsection{Introdução}

O princípio básico do fluxo laminar de água em meios porosos foi descrito pelo francês Henry Darcy, pela primeira vez, no ano de 1856, ao realizar uma experiência sobre infiltração vertical de água em filtros de areia, sob condições de saturação. $\mathbf{O}$ primeiro trabalho que apresenta uma equação quantificando o movimento de água num solo não saturado é o do inglês Buckingham, em 1907. Sua equação, porém, é valida apenas para movimento de água no solo nos casos em que o efeito da gravidade é desprezivel ou inexistente. Foi Richards, em 1928, quem definiu um potencial total igual à soma dos potenciais mátrico e gravitacional. A equação do movimento da solução do solo foi então expressa assim:

$$
\vec{q}=-K(\theta) \cdot \vec{\nabla} \psi_{t}(\theta)
$$

onde $\vec{q}$ é a densidade de fluxo da solução $\left(\mathrm{m} . \mathrm{s}^{-1}\right), K(\theta)$ a função condutividade hidráulica $\left(\mathrm{kPa} \cdot \mathrm{m}^{2} \cdot \mathrm{s}^{-1}\right)$ e $\bar{\nabla} \psi_{t}(\theta)$ o gradiente do potencial total com a distância $\left(\mathrm{kPa} \cdot \mathrm{m}^{-1}\right)$. 
A importância dos aspectos dinâmicos da disponibilidade de água às plantas foi reconhecida há muito tempo. Em 1920, Livingston \& Koketsu', citados por GARDNER (1960) usaram cones de porcelana para medir a "capacidade de fornecer água" do solo. WADLEIGH (1946) relacionou a extração de água do solo pelo sistema radicular com o "estresse total da umidade do solo", sendo esse a soma da "tensão de umidade do solo" (T) e da "pressão osmótica" $(\pi)$. Como T e $\pi$ dependem da umidade do solo, o estresse hídrico aumenta progressivamente com a retirada da água do solo. WADLEIGH (1946) desenvolveu um modelo para avaliar as variações de energia da água do solo que está sendo absorvida pelas raízes, assumindo que essa absorção acontece de tal maneira que o "estresse total da umidade do solo" é constante ao longo do sistema radicular.

Muitos são os trabalhos que estudaram o processo de transpiração em função da quantidade de água disponível no solo às plantas. Pioneiros nessa área foram os trabalhos de VEIHMEÝER \& HENDRICKSON e de THORNTHWAITE \& MATHER, ambos publicados em 1955. Enquanto a conclusão do primeiro trabalho, no qual se trabalhou com plantas perenes, é de que não há variação na evapotranspiração devida à umidade do solo quando esse está mais úmido do que no "ponto de murchamento permanente", no segundo trabalho assumiu-se que a evapotranspiração varia linearmente com a quantidade de água disponível no solo, sendo máxima quando o solo está na "capacidade de campo" e nula quando esse se encontra no "ponto de murchamento permanente". Assim, os primeiros autores igualaram a umidade crítica ao "ponto de murchamento permanente" enquanto os últimos adotaram a hipótese de que a umidade crítica é igual à "capacidade de campo". O método de cálculo do balanço hídrico, baseado na última hipótese, é ainda muito utilizado em nosso meio.

\footnotetext{
${ }^{1}$ LIVINGSTONE, B.E. \& KOKETSU, R. The water supplying power of the soil as related to the wilting of plants. Soil Sci. 9: 469-85. 1920.
} 
Atualmente, porém, reconhece-se que, em muitos casos, a umidade crítica tem um valor menor que a "capacidade de campo". Com o objetivo de definir essa umidade crítica foi definido um "fator de água disponível" (p) (Rijtema \& Aboukhaled² citados por DOORENBOS et al., 1979) tal que:

$$
\theta_{c r}=\theta_{p m p}+(1-p) \cdot\left(\theta_{c c}-\theta_{p m p}\right)
$$

onde $\theta_{c r}$ é a umidade crítica $\left(\mathrm{m}^{3} \cdot \mathrm{m}^{-3}\right), \theta_{c c}$ é a "capacidade de campo" $\left(\mathrm{m}^{3} \cdot \mathrm{m}^{-3}\right)$ e $\theta_{p m p}$ é o "ponto de murchamento permanente" $\left(\mathrm{m}^{3} \cdot \mathrm{m}^{-3}\right)$. Valores para o fator $p$ são tabelados pela FAO (DOORENBOS et al., 1979) em função da demạnda evapotranspiratória e de quatro grupos de cultura quanto à sensibilidade à seca. Assim como THORNTHWATTE \& MATHER (1955), esses autores também assumiram que para umidades menores que a umidade crítica há diminuição linear da evapotranspiração real. DOURADO NETO \& JONG VAN LIER (1993) apresentaram novas hipóteses quanto à diminuição da evapotranspiração em função da armazenagem de água no perfil de solo, e recomendaram o uso de uma equação senoidal para cálculos referentes ao balanço hídrico.

Todos esses métodos para determinar a umidade crítica e a evapotranspiração em função da armazenagem da água no solo partem de uma visão maçoscópica altamente simplificada. Uma análise detalhada de qualquer fenômeno fisico requer o emprego de modelos, baseados em leis ou fatos conhecidos ou, quando não disponíveis, em hipóteses. Os modelos existentes para a descrição analítica do processo de extração de água do solo podem ser subdivididos em dois tipos: os modelos macroscópicos e os modelos microscópicos.

\footnotetext{
${ }^{2}$ RIJTEMA, P.E. \& ABOUKHALED, A. Crop water use. In: Research on crop water use, sált affected soils and drainage in the Arab Republic of Egypt. ABOUKHALED, A.; ARAR, A.; BALBA, A.M.; BISHAY, B.G.; KADRY, L.T.; RUTEMA, P.E. \& TAHER, A. FAO Regional Office for the Near East, 1975. p.5-61.
} 


\subsection{Modelos macroscópicos}

Modelos "macroscópicos" são aqueles que consideram o sistema radicular como um todo, não considerando o fluxo de água às raízes individuais. Esses modelos apresentam um maior grau de empirismo, com a vantagem de que não há necessidade de se conhecer a distribuição espacial das raízes e dos gradientes de potencial total associados. A maior limitação dos modelos macroscópicos é que se baseiam nas médias dos potenciais envolvidos e não levam em consideração a queda do potencial da água na vizinhança imediata das raízes (HILLEL et al., 1975).

GARDNER (1964) desenvolveu um modelo macroscópico que descreve a extração de água por um sistema radicular verticalmente não uniforme quanto à densidade de raízes. Em outros estudos, como os de WHISLER et al. (1968) e de MOLZ \& REMSON (1970), foi proposta a incorporação da extração de água pelo sistema radicular na equação da continuidade como um termo de fonte negativo. Esse tipo de modelo é denominado "extraction-term model". O modelo unidimensional de MOLZ \& REMSON (1970) descreve o uso e extração de água do solo causados pela demanda transpiratória das plantas. Esses autores discutiram a metodologia e as vantagens dos modelos macroscópicos. MOLZ \& REMSON (1971) analisaram a sensibilidade desse modelo quanto à profundidade do sistema radicular e o tipo de solo, calculando umidades, taxas de absorção de água pelas raízes e fluxos de água no solo para diversos sistemas radiculares hipotéticos, num solo arenoso e um outro argiloso dos Estados Unidos. Concluiram que o modelo é capaz de descrever o processo de absorção de água pelo sistema radicular.

NIMAH \& HANKS (1973) desenvolveram um modelo com solução numérica, em função das curvas de retenção e de condutividade hidráulica. Através do modelo, perfis de umidade, evapotranspiração, fluxos de água entre o perfil do solo e o 
lençol freático, extração de água pelas raizes e potencial da água nas raizes podem ser calculados. FEDDES et al. (1974) utilizaram esse modelo, com pequenas modificações, e obtiveram resultados muito bons quanto à evapotranspiração medida e observada, mas os perfis de umidade calculados não estiveram em concordância com os medidos no campo.

SLACK et al. (1977) descreveram um modelo matemático macroscópico que quantifica a extração de água do solo em função dos potenciais totais na folha e no solo. $\mathrm{O}$ modelo foi utilizado para a estimativa da transpiração de uma cultura de milho num solo cada vez mais seco. A comparação dos resultados obtidos pelo modelo e por estimativa através do balanço hídrico mostra que o modelo simula bem a realidade. Os autores ressaltam a dificuldade em se estimar as propriedades hidráulicas em solos muito secos.

Um dos modelos macroscópicos mais completos foi desenvolvido por HILlEL et al. (1976). Esses autores dividiram o sistema radicular em várias "seções", para cada uma das quais podem ser definidos os parâmetros do modelo: propriedades hidráulicas do solo e do sistema radicular, umidade, concentração de sais na solução do solo, a densidade e distribuição do sistema radicular e a evapotranspiração com as suas flutuações diárias. É um dos poucos modelos que leva em consideração que o componente osmótico do potencial total é função da umidade, pois, quando o solo seca, a concentração de sais na água do solo aumenta. Os autores concluem que o esgotamento de água no solo é uma função de fatores do solo, da planta e do clima que podem ser descritos sistematicamente e quantitativamente por simulação dinâmica. Porém, falta muita pesquisa experimental para se obter as informações básicas para modelos desse tipo e para validar os seus resultados. 
A maior limitação do uso de modelos macroscópicos é que esses não consideram a diminuição de umidade e conseqüentemente da condutividade hidráulica, na vizinhança imediata das raízes individuais.

\subsection{Modelos microscópicos}

Os modelos que descrevem, analiticamente, o fluxo de água às raízes individuais, como o modelo desenvolvido nesta tese, são chamados modelos "microscópicos". Uma denominação mais adequada seria "modelos milimétricos" ou talvez "modelos centimétricos", uma vez que muitas das propriedades do solo são resultado de processos que ocorrem numa escala pelo menos milimétrica.

Um dos primeiros estudos quantitativos detalhados sobre a extração de água do solo por raízes de plantas foi publicado por GARDNER em 1960. Ele desenvolveu um modelo microscópico, considerando uma raiz de geometria cilíndrica, com raio uniforme e comprimento infinito, tendo acesso exclusivo a um volume cilíndrico de solo. Seu trabalho baseia-se na "equação da continuidade" para fluxo radial de água:

$$
\frac{\partial \theta}{\partial t}=\frac{1}{r} \cdot \frac{\partial}{\partial \cdot} \cdot\left(r D \cdot \frac{\partial \theta}{\partial r}\right)
$$

onde $\theta$ é a umidade volumétrica $\left(\mathrm{m}^{3} \cdot \mathrm{m}^{-3}\right), t$ é o tempo (s), $r$ é a distância radial do eixo da raiz $(\mathrm{m})$ e $D$ é a difusividade da água no solo $\left(\mathrm{m}^{2} \cdot \mathrm{s}^{-1}\right)$.

Como $D$ é uma função não conhecida de $\theta$, foi impossível apresentar a solução analítica da equação (3). GARDNER (1960) propôs uma solução aproximada, assumindo que $\theta$ é apenas função da distância radial da raiz, e não varia com o tempo (equilíbrio estático, $\partial \theta / \partial=0$ ). Adotou, ainda, a simplificação de que condutividade e difusividade hidráulica têm valores constantes na rizosfera $(\partial K / \partial \theta=0$ e $\partial D / \partial \theta=0)$, 
justificando essa simplificação pelo fato da variação da condutividade hidráulica no intervalo de umidade encontrado nos seus cálculos ser menor do que os erros obtidos em experimentos para a sua determinação. Deduziu que, nessas condições:

$$
\Delta \psi=\frac{q}{4 \cdot \pi \cdot K} \cdot\left(\ln \frac{4 \cdot D \cdot t}{r^{2}}-\gamma\right)
$$

onde $\Delta \psi$ é a diferença entre o potencial mátrico $(\mathrm{kPa})$ no solo e na raiz, $q$ é a extração de água por unidade de tempo e unidade de comprimento da raiz $\left(\mathrm{m}^{3} \cdot \mathrm{m}^{-1} \cdot \mathrm{s}^{-1}\right), K$ é a condutividade $\left(\mathrm{m}^{2} \cdot \mathrm{kPa}^{-1} \cdot \mathrm{s}^{-1}\right)$ hidráulica do solo e $\gamma$ é o número de Euler $(\gamma \approx 0,57722)$.

Ao contrário de GARDNER (1960), ZUR et al. (1982), medindo os fluxos de água num experimento com soja num solo arenoso, atribuíram o decréscimo nas taxas de transpiração para baixas umidades ao fato da umidade e, conseqüentemente, a condutividade hidráulica do solo adjacente à raiz, ser muito menor que a do resto do solo.

COWAN (1965) obteve uma solução parecida com a equação (4) de GARDNER (1960), considerando $\partial \theta / \partial=$ constante, mas diferente de zero (equilíbrio dinâmico). HAINSWORTH \& AYLMORE (1986), conduzindo um experimento em que mediram a umidade do solo na vizinhança de raízes de rabanete, utilizando atenuação de raios-X através de um tomógrafo, concluíram que o modelo de COWAN (1965) não descreve adequadamente o processo de extração de água do solo.

PASSIOURA \& COWAN (1968) avaliaram os modelos de GARDNER (1960) e de COWAN (1965), comparando esses com métodos de soluções exatas, obtidas numericamente, e concluíram que os valores obtidos pelo método do equilíbrio dinâmico são mais concordantes com a realidade que os obtidos pelo método do equilíbrio estático.

Mais recentemente, MOLDRUP et al. (1992) desenvolveram um modelo para simular a resistência do solo contra a extração de água pelas raízes. Consideraram a 
condutividade hidráulica constante na rizosfera por intervalo de simulação, e incluiram no modelo parâmetros que descrevem as curvas de retenção e de condutividade.

Ao invés dos modelos que assumem que $\partial K / \partial \theta=0$ e $\partial D / \partial \theta=0$, existem outros que consideram o fato de que, ao se desenvolver uma zona seca ao redor de uma raiz, o gradiente de $\psi_{t}$ da água no solo, a certa distância não influenciada pela raiz e da água na raiz, deve aumentar para manter a mesma densidade de fluxo $q$, por causa da diminuição conseqüente dos valores de $K$ e $D$. De acordo com LANG \& GARDNER (1970), um fluxo de água máximo pode ser calculado quando se considera que a densidade de fluxo é constante na zona seca. Eles deduziram que, quando

$$
K=a /\left|\psi_{m}\right|^{n}
$$

onde $a\left(\mathrm{~m}^{2} \cdot \mathrm{kPa}^{\mathrm{n}-1} \cdot \mathrm{s}^{-1}\right)$ e $n$ são parâmetros empíricos dessa relação funcional entre $K \mathrm{e}$ $\psi_{m}$, então

$$
Q_{\max }=\frac{2 \cdot \pi \cdot a \cdot \psi_{2}{ }^{1-n}}{(n-1) \cdot \ln \left(r_{2} / r_{1}\right)}
$$

onde $Q_{\max }$ é o fluxo máximo por unidade de comprimento de raiz e por unidade de tempo $\left(\mathrm{m}^{3} \cdot \mathrm{m}^{-1} \cdot \mathrm{s}^{-1}\right), \psi_{2}$ é o potencial mátrico $(\mathrm{kPa})$ na zona não influenciada pela extração de água pela raiz e $r_{1}$ e $r_{2}$ são os raios (m) da raiz e da zona seca, respectivamente.

Propondo um modelo de simulação microscópico dinâmico, utilizando um método de cálculo numérico, HILlEL et al. (1975) alegaram que os possíveis efeitos da convergência de solutos em direção à raiz, e as conseqüências dessa convergência para o potencial osmótico, foram subestimadas em trabalhos anteriores. $\mathrm{O}$ modelo calcula os potenciais mátrico e osmótico em função do tempo e da distância da raiz. 


\subsection{Limitações à extração de água do solo pelas raizes}

\subsubsection{Introdução}

Quando o solo seca, o total da água nele contida e o potencial mátrico, bem como a condutividade hidráulica, ficam cada vez menores, fazendo com que sejam necessários gradientes de potencial cada vez maiores entre solo e raiz para se manter um fluxo de água suficiente. Esse fenômeno foi comprovado experimentalmente por DUNHAM \& NYE (1973), num experimento com um plano de raízes de cebola. Eles mediram a umidade a várias distâncias desse plano, em solos inicialmente secos, úmidos e intermediários e encontraram gradientes de potencial próximo às raízes maiores para o solo mais seco.

Não existe, porém, um consenso entre os pesquisadores da área sobre a causa de o fluxo de água às raízes em certas circunstâncias ser insuficiente para suprir a demanda transpiratória. RENDIG \& TAYLOR (1989) dividem os cientistas em três grupos quanto à sua explicação desse fenômeno. Os do primeiro grupo acreditam que a condutividade hidráulica do solo seja o fator limitante: a ocorrência de uma zona de esgotamento de água próximo às raízes causa uma diminuição na condutividade hidráulica. Entre os trabalhos publicados por esse grupo estão os de GARDNER \& EHLIG (1962), MACKLON \& WEATHERLEY (1965), CARBON (1973), ZUR et al. (1982), Hulugalle \& WillatT (1983), HAINSWORTH \& AYlmORE $(1986,1989)$ e TARDIEU et al. (1992). Pesquisadores do segundo grupo defendem que a água encontra uma maior resistência quanto ao seu movimento dentro do tecido vegetal, a caminho do xilema. Destacam-se aqui os trabalhos de NEWMAN (1969), TAYLOR \& KLEPPER (1975), MOLZ (1976), BELMANS et al. (1979) e BLIzZARD \& BOYER (1980). O terceiro grupo de cientistas é da opinião que existe uma grande resistência ao movimento de água no exato 
limite entre solo e raiz (HUCK et al., 1970; HERKELRATH et al., 1977; FAIZ \& WeATHERLEY, 1982; PASSIOURA, 1988). O modelo desenvolvido nesta tese se limita a estudar a hipótese do primeiro grupo.

\subsubsection{Condutividade hidráulica do solo}

Em 1962, GARDNER \& EHLIG demonstraram, num experimento em casade-vegetação com diversas culturas e três solos de texturas diferentes, que a condutividade hidráulica do solo, e não a do xilema, limita o fluxo de água no sistema solo-planta-atmosfera. Mesmo em solos relativamente úmidos, a resistência ao fluxo de água no solo foi maior que a na planta. Verificaram ainda que uma quantidade considerável de água se move para cima no perfil de solo antes de ser absorvida pelo sistema radicular.

CARBON (1973) mediu transpiração e potencial de água na folha e no solo, oito vezes por dia, em sorgo plantado num solo arenoso na Austrália, sob diferentes regimes de irrigação. Concluiu que existe uma grande variação no potencial da água na folha durante o dia e que, provavelmente, o estresse observado nas horas mais quentes do dia, é conseqüência de uma queda da condutividade hidráulica no solo próximo às raizes. O mesmo foi concluído por ZUR et al. (1982) que, trabalhando com soja, determinaram que as condutividades hidráulicas calculadas utilizando o modelo de GARDNER (1960) são 4 a 6 vezes maiores que as medidas no solo, na vizinhança das raízes.

HULUGALLE \& WILLATT (1983) apresentaram resultados obtidos com soja e pimenta, comparando a densidade de raizes e a função condutividade hidráulica, e concluiram que, principalmente em condições de baixa densidade de raízes, a condutividade hidráulica do solo deve ser considerada o fator limitante. Recomendaram o uso de uma condutividade hidráulica crítica ao invés de uma umidade crítica. 
Os primeiros autores que mediram em detalhe o fluxo de água na vizinhança das raízes foram HAINSWORTH \& AYLMORE (1986), que utilizaram a técnica de tomografia computadorizada ("computer assisted tomography"). $\mathrm{O}$ trabalho deles indicou que a absorção não uniforme de água ao longo do sistema radicular pode causar faixas secas no solo com condutividade hidráulica limitante. Eles ainda concluiram que a distância influenciada pela extração de água pelas raízes pode depender da taxa de extração. Em 1989, os mesmos autores, utilizando novamente a técnica de tomografia computadorizada, demonstraram que a absorção de água ao longo do sistema radicular é muito desuniforme, e que a faixa influenciada pelas raizes quanto à sua umidade é função do tempo. A remoção de água do solo se inicia nas camadas superficiais e progride a camadas mais profundas conforme a resistência ao fluxo nas camadas esgotadas de água aumenta.

TARDIEU et al. (1992) modelaram o fluxo de água às raízes para dois solos com propriedades hidráulicas contrastantes e para três diferentes arranjos espaciais do sistema radicular, variando quanto ao grau de distribuição das raízes. Encontraram uma grande influência da distribuição e concluiram que, a não ser em solos da alta condutividade hidráulica e boa distribuição do sistema radicular, a maior resistência contra o fluxo de água no caminho solo-planta-atmosfera ocorre no solo.

\subsubsection{Condutividade hidráulica do tecido vegetal}

Num experimento com algodão, TAYLOR \& KLEPPER (1975) mediram potenciais da água no solo e na plänta conjuntamente com a densidade de raízes a diversas profundidades. Concluiram que a resistência ao fluxo de água do tecido vegetal é bem maior que a do solo, e que a absorção de água é proporcional à densidade de enraizamento e ao gradiente de potencial entre solo e raiz. 
BELMANS et al. (1979) conduziram um experimento para testar a validade de um modelo para a descrição do processo de extração de água do solo pelo sistema radicular. Mediram o consumo de água pela cultura de centeio e compararam o resultado com os valores calculados pelo modelo. A semelhança entre valores calculados e medidos melhorou muito após a inclusão no modelo de um fator de resistência vegetal.

BLIZZARD \& BOYER (1980) desenvolveram um experimento com soja, medindo potenciais da água no solo, na raiz e na folha e determinaram que tanto a resistência do solo quanto a da planta aumentaram quando o teor de água diminui, mas que a resistencia vegetal é maior que a do solo em toda a faixa medida, de $-0,2$ a -11 bar. Concluiram que trabalhos anteriores que sugeriram que a resistência do solo é a maior ignoraram o aumento da resistência na planta, ou consideraram densidades de raiz muito baixas.

\subsubsection{Condutividade hidráulica da interface solo-raiz}

HERKELRATH et al. (1977), ao compararem o modelo de GARDNER (1960) com dados experimentais, verificaram que a extração de água calculada pelo modelo é em torno de 8 vezes maior que a medida. Propuseram a inclusão de um fator de resistência no contato solo-raiz, devido ao fato da raiz sofrer contração quando o solo seca, criando uma barreira para a passagem de água na interface entre solo e raiz. Esse fato foi também descrito por HUCK et al. (1970) e FAIZ \& WEATHERLEY (1982). Além disso, ao crescerem, as raízes podem formar novos poros no solo, ou crescer em poros já existentes. Segundo TARDIEU \& MANICHON (1986) e WANG et al. (1986), a preferência das raízes é seguir poros grandes e contínuos pre-existentes. Nesses poros, não há um contato íntimo entre as raizes e o material sólido do solo e existe, portanto, um número reduzido de caminhos de fluxo de água para a raiz (PASSIOURA, 1988). Isso faz com que a resistência ao transporte de água do solo à raiz aumente várias vezes. 
Cabe ressaltar que distingüir entre a condutividade hidráulica do solo e da interface solo-raiz nada mais é do que admitir que o solo não é um meio homogêneo, mas que existem variações quanto às suas características e propriedades, variações essas que, no processo de fluxo de água a uma raiz, podem ser de influência decisiva.

\subsection{Distribuição espacial das raízes}

Como foi discutido por MOLZ \& REMSON (1970), o problema dos modelos microscópicos é que, para a sua aplicação a um sistema radicular inteiro, deve-se conhecer a geometria detalhada desse sistema, cuja determinação é praticamente impossivel.

A descrição quantitativa da morfologia de sistemas radiculares pode ser feita de diversas maneiras. Uma é a análise da variação da densidade de enraizamento (expressa, por exemplo, em comprimento de raizes por volume de solo), como fizeram PAGE \& GERWITZ (1974) e TARDIEU \& MANICHON (1986), entre outros. A partir de tais dados, pode-se chegar a valores para a meia-distância média entre duas raízes vizinhas. Uma outra é a quantificação da estrutura do sistema radicular através de modelos dinâmicos que levam em consideração, por exemplo, características de ramificação, velocidade de crescimento e características que determinam a direção do crescimento. Modelos desse tipo foram desenvolvidos recentemente por DIGGLE (1988) e PAGES \& ARIES (1988).

\subsection{Atividade das raízes em função da profundidade}

Além das diferenças que podem existir na distribuição espacial das raizes, outro fator que afeta a extração de água é a atividade das raizes em função da 
profundidade. MAHEY et al. (1984) concluiram que a atividade, e, conseqüentemente a extração de água, diminui com o aumento da profundidade. Existem, porém, vários outros trabalhos que não apoiam essa hipótese (REICOSKY et al., 1972; WILLAT \& TAYLOR, 1978; RASIAH \& KOHL, 1989). HOOGENBOOM et al. (1987) estudaram a influência da disponibilidade de água no desenvolvimento do sistema radicular de soja e concluiram que o crescimento é acelerado em períodos secos, alcançando assim camadas mais profundas e mais úmidas.

BALligAR et al. (1980), analisando o efeito dos potenciais matriciais de $5,-10,-30,-100$ e $-300 \mathrm{kPa}$, e as densidades do solo 1100,1300 e $1500 \mathrm{~kg} \cdot \mathrm{m}^{-3}$ em seis diferentes texturas do solo (arenoso, siltoso, argiloso, e suas combinações) no desenvolvimento radicular da soja, encontraram que o crescimento radicular aumentou em todas as texturas do solo quando o potencial mátrico passou de $-5 \mathrm{kPa}$ para $-30 \mathrm{kPa}$ e, gradualmente, decresceu quando o potencial mátrico passou de $-30 \mathrm{kPa}$ para $-300 \mathrm{kPa}$.

\subsection{Atenuação de radiação $\gamma$}

A técnica de atenuação de radiação $\gamma$ tem sido empregada, como método não destrutivo, na estimativa de vários parâmetros em processos dinâmicos de transferência de massa. Uma ótima revisão do assunto pode ser encontrada em FERRAZ (1974) e em ZUCCHI (1981). No campo da ciência do solo, tem sido utilizada principalmente na determinação da umidade e densidade de solos (DAVIDSON et al., 1963; DEVLIN et al., 1969; MCKINNEY, 1969; CIFTCIOGLU \& TAYLOR, 1972; GARDNER et al., 1972; Reginato, 1974; Herkelrath \& Miller, 1976; FerraZ \& PINTO, 1977; PEDROSA FILHO, 1980; MTYAZAKI et al., 1991) e é um dos mais precisos e sensíveis métodos de determinação da umidade em amostras de solo. 


\section{MATERIAL E MÉTODOS}

\subsection{Modelagem}

\subsubsection{Absorção de água por uma raiz isolada}

A densidade de fluxo de água num meio poroso pode ser determinada pela equação (1), e é diretamente proporcional à condutividade hidráulica do meio e à diferença de potencial total da água por unidade de distância, ambas função da umidade do meio. A planta deve manter, ao longo do seu sistema radicular, um potencial total da água suficientemente baixo para que a densidade de fluxo da água que entra nas raízes, multiplicada pela área total do sistema radicular, seja no mínimo igual ao volume de água transpirada. Se não, entrará em estado de estresse.

Extraindo, inicialmente, água de uma camada pequena, imediatamente circundante à raiz, essa camada fica mais seca, com potenciais mátrico e total conseqüentemente menores. Ela vai, por sua vez, extrair água de uma camada circundante subseqüente. Assim, a camada influenciada pela extração de água pela raiz aumenta, e o solo imediatamente adjacente à raiz fica cada vez mais seco. Como a condutividade hidráulica diminui quando o solo seca, potenciais totais na raiz cada vez menores são necessários para manter o mesmo fluxo. 


\subsubsection{Teoria para um sistema tridimensional}

Considerou-se uma planta, cuja parte aérea ocupa uma área $A\left(\mathrm{~m}^{2}\right)$, e cujo sistema radicular, em um solo homogêneo quanto à sua curva de retenção e de condutividade hidráulica, é composto de raízes com um comprimento total $l(\mathrm{~m})$ de raio uniforme $r(\mathrm{~m})$. A difusão de água do estômato da planta para a atmosfera faz com que a parte aérea dessa planta perca certo volume $V\left(\mathrm{~m}^{3}\right)$ de água num intervalo de tempo $t(\mathrm{~s})$, um processo chamado transpiração $\left(T, \mathrm{~m}^{3} \cdot \mathrm{m}^{-2} \cdot \mathrm{s}^{-1}\right)$ :

$$
V=\text { T.t. } A
$$

Para repor essa água, o mesmo volume $V$ deve entrar no sistema radicular no mesmo intervalo de tempo $t$ :

$$
F=V / t
$$

onde $F\left(\mathrm{~m}^{3} . \mathrm{s}^{-1}\right)$ é o volume de água que entra no sistema radicular por unidade de tempo.

Como a área total do sistema radicular é igual a 2. $\pi$.r.l, a densidade de fluxo na zona muito próxima à raiz $\left(q_{\mathrm{r}}, \mathrm{m}^{3} \cdot \mathrm{m}^{-2} \cdot \mathrm{s}^{-1}\right)$ deve ser

$$
q_{r}=\frac{F}{2 \cdot \pi \cdot r \cdot l}=\frac{V}{2 \cdot \pi \cdot r \cdot l \cdot t}
$$

Considerando a forma cilindrica da raiz, a densidade de fluxo a uma distância $x$ da raiz $\left(q_{x}, \mathrm{~m}^{3} \cdot \mathrm{m}^{-2} \cdot \mathrm{s}^{-1}\right)$ é dada por

$$
q_{x}=\frac{q_{r} \cdot r}{r+x}
$$


Substituindo (9) em (10) tem-se que:

$$
q_{x}=\frac{V}{(r+x) \cdot 2 \cdot \pi \cdot l \cdot t}
$$

Substituição de (7) em (11) resulta em

$$
q_{x}=\frac{T \cdot A}{(r+x) \cdot 2 \cdot \pi \cdot l}
$$

Reescrevendo a equação de Darcy-Buckingham (equação (1)) deduz-se que:

$$
\frac{d \psi}{d x}=\frac{q}{K}
$$

onde $d \psi / d x\left(\mathrm{kPa} \cdot \mathrm{m}^{-1}\right)$ é o gradiente do potencial total e $K\left(\mathrm{~m}^{2} \cdot \mathrm{kPa}^{-1} \cdot \mathrm{s}^{-1}\right)$ é a condutividade hidráulica. No caso específico, a equação (13) pode ser escrita como:

$$
\left(\frac{d \psi}{d x}\right)_{x}=\frac{q_{x}}{K_{x}}
$$

onde $(d \psi / d x)_{x}\left(\mathrm{kPa}^{-1}\right)$ é o gradiente do potencial total num ponto a distância $x(\mathrm{~m})$ da raiz, e $K_{x}\left(\mathrm{~m}^{2} \cdot \mathrm{kPa}^{-1} \cdot \mathrm{s}^{-1}\right)$ a condutividade hidráulica no mesmo ponto.

Substituindo (12) em (14) tem-se que:

$$
\left(\frac{d \psi}{d x}\right)_{x}=\frac{T \cdot A}{K_{x} \cdot 2 \cdot \pi \cdot l \cdot(r+x)}
$$


Da matemática sabe-se que, quando $f(x)$ é uma função contínua de $x$ no intervalo de $x$ a $x+p$ :

$$
f(x+p)=f(x)+\int_{x}^{x+p} f^{\prime}(y) \cdot d y
$$

onde $x$ e $p$ pertencem à família dos números reais

Como o potencial mátrico no ponto $x\left(\psi_{x}, \mathrm{kPa}\right)$ é função da distância da raiz, deduz-se que, analogamente:

$$
\psi_{x}=\psi_{s}+\int_{R_{t}}^{x} \frac{\partial \psi}{\partial x} d x
$$

onde $\psi_{s}(\mathrm{kPa})$ é o potencial mátrico do solo na zona não influenciada pela extração de água pela raiz e $R_{\mathrm{t}}$ (m) é a distância limite da área influenciada pela extração de água no instante $t$, conforme representado graficamente na Figura 1. 


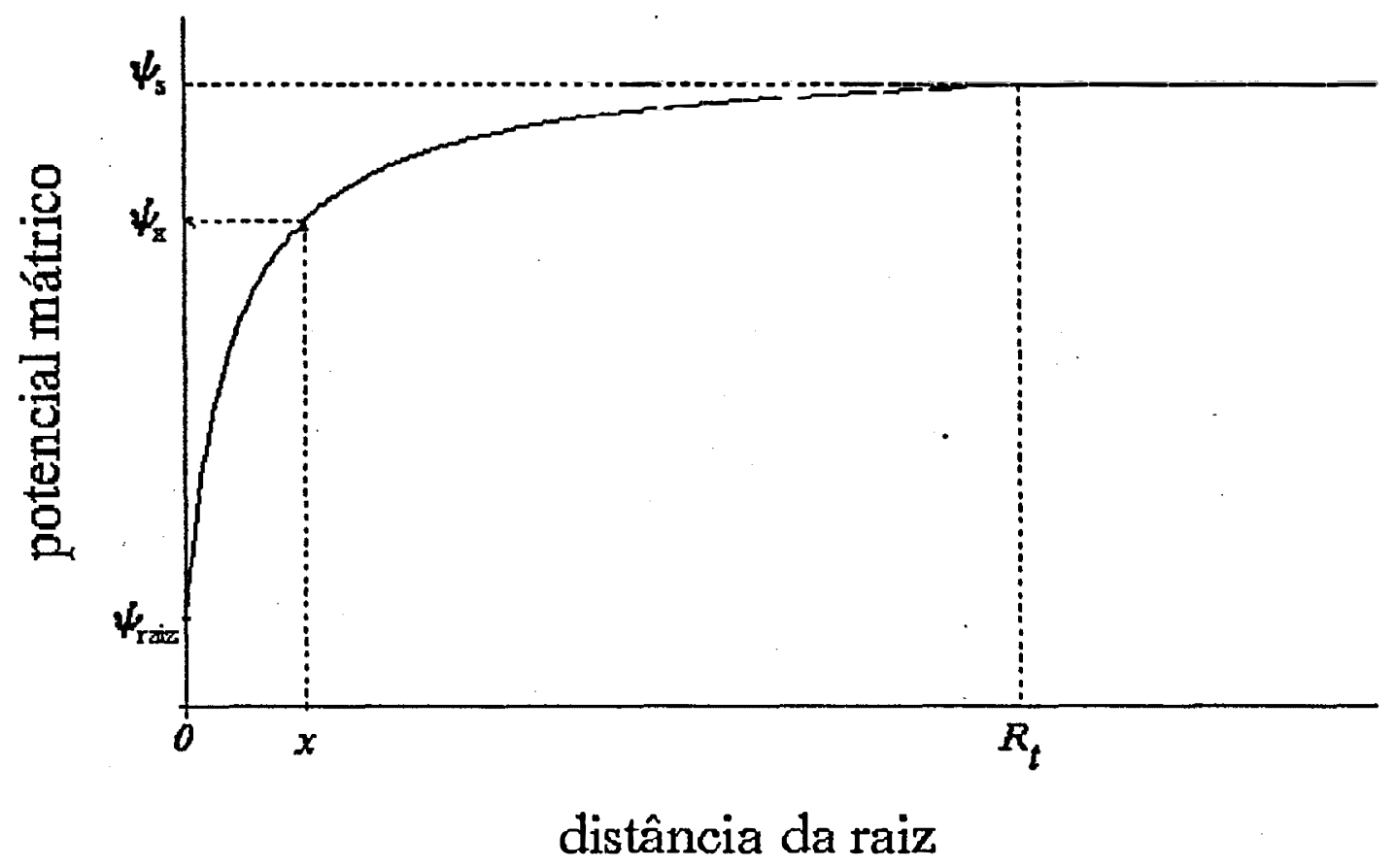

Figura 1 - Representação gráfica do potencial mátrico em função da distância da raiz.

Substituindo (15) em (17) tem-se que

$$
\psi_{x}=\psi_{s}+\int_{R_{t}}^{x} \frac{T \cdot A}{K_{x} \cdot 2 \cdot \pi \cdot l \cdot(r+x)} d x
$$

Reescrevendo a equação (18), colocando os parâmetros independentes de $x$ fora do sinal de integração, obtém-se a seguinte equação geral:

$$
\psi_{x}=\psi_{s}+\frac{T \cdot A}{2 \cdot \pi \cdot l} \int_{R_{t}}^{x} \frac{1}{K_{x} \cdot(r+x)} d x
$$


Através da equação (19) pode-se calcular o valor do potencial mátrico em qualquer ponto dentro da zona influenciada pela raiz, conhecendo-se os parâmetros referentes à planta $(A, l$ e $r)$ e à atmosfera $(T)$, e a relação $K-\theta$ ou $K-\psi$.

\subsection{Condutividade hidráulica}

A condutividade hidráulica $\left(K, \mathrm{~m}^{2} \cdot \mathrm{kPa}^{-1} \cdot \mathrm{s}^{-1}\right)$ em função da umidade foi determinada através do método proposto por REICHARDT \& LIBARDI (1974). Esses autores acharam que a difusividade hidráulica $\left(D, \mathrm{~m}^{2} \cdot \mathrm{s}^{-1}\right)$ é relacionada com a umidade pela seguinte equação:

$$
D(\theta)=8,770 \cdot 10^{-4} \cdot f^{2} \cdot e^{8,087 \cdot \theta-\theta_{0} / \theta_{1}-\theta_{0}}
$$

onde $\theta_{0}, \theta_{1}$ e $f$ são determinados num experimento de infiltração horizontal (difusão). $\theta_{0}$ é a umidade volumétrica da terra antes da infiltração, $\theta_{1}$ é a umidade após a infiltração e $f\left(\mathrm{~m} . \mathrm{s}^{-0,5)}\right.$ é a tangente da reta que descreve o avanço da frente de molhamento em função da raiz do tempo. Para determinar o valor do parâmetro $f$ o material do solo foi compactado com a densidade encontrada na seção inferior dos aneis (vide próximo item), num cilindro de acrílico com diâmetro interno de 0,055 m e um comprimento de 0,50 m. A coluna foi colocada horizontalmente e água foi aplicada em uma extremidade com uma ligeira sucção (pressão atmosférica atuando a $0,03 \mathrm{~m}$ abaixo do centro do cilindro) através de uma placa porosa. Após o início da infiltração, o avanço da frente de molhamento $(x, \mathrm{~m})$ foi medido em função do tempo $(t, \mathrm{~s})$. O parâmetro $f$ foi determinado através de regressão linear de $x$ versus $\sqrt{ } t$.

Da difusividade calcula-se a condutividade pela expressão

$$
K=D \cdot \frac{d \theta}{d \psi_{m}}
$$


onde $d \theta / d \psi_{m}$ é a derivada da curva de retenção da água no solo, curva que descreve a relação entre a umidade volumétrica do solo e o potencial mátrico da água no solo.

\subsection{Curva de retenção}

Seis anéis de PVC de $0,05 \mathrm{~m}$ de diâmetro, com uma tela colada na sua extremidade inferior para segurar o material do solo, foram preenchidos com terra da mesma maneira que as unidades experimentais de acrílico e juntos com elas deixados na mesma bacia com solução nutritiva até a retirada da solução (procedimentos a serem descritos detalhadamente nos itens 3.2.3. e 3.2.4.). Cada um dos anéis era composto de três seções horizontais separáveis, a inferior e a superior de 0,045 $\mathrm{m}$ de altura, e a do meio de 0,010 m de altura. Após terminar o experimento, as três seções foram separadas. A seção superior foi descartada, a inferior foi utilizada para determinar a densidade da terra (vide item 3.1.1.1.1.) e a do meio para determinar a curva de retenção. Essas seções de $0,010 \mathrm{~m}$ de altura foram submetidas a sucções de 0,$49 ; 0,98 ; 1,96 ; 3,92 ; 5,89 ; 7,85$ e $9,81 \mathrm{kPa}$ através de um funil de Haynes. Em seguida, numa câmara de pressão de Richards ("panela de pressão") aplicaram-se pressões de 10, 18, 36, 90, 230, 595 e $1490 \mathrm{kPa}$. Após cada equilíbrio a amostra foi pesada. No final, a amostra foi seca numa estufa a uma temperatura de aproximadamente $380 \mathrm{~K}$, e a umidade referente a cada sucção foi calculada por diferença.

Com as umidades determinadas em função do potencial mátrico obtiveram-se, através de regressão não linear simultânea, os 5 parâmetros empíricos da equação proposta por VAN GENUCHTEN (1980): 


$$
\theta=\theta_{r}+\frac{\theta_{s}-\theta_{r}}{\left[1+\left(\alpha \cdot\left|\psi_{m}\right|\right)^{n}\right]^{m}}
$$

onde $\psi_{m}$ é o potencial mátrico $(\mathrm{kPa}), \theta$ é a umidade volumétrica $\left(\mathrm{m}^{3} \cdot \mathrm{m}^{-3}\right)$ e $\theta_{r}$ (umidade residual, $\left.\mathrm{m}^{3} \cdot \mathrm{m}^{-3}\right), \theta_{s}$ (umidade de saturação, $\left.\mathrm{m}^{3} \cdot \mathrm{m}^{-3}\right), \alpha\left(\mathrm{kPa}^{-1}\right), m$ e $n$ são os parâmetros empíricos da equação. $O$ ajuste foi feito utilizando um programa desenvolvido para esse fim (DOURADO NETO et al., 1990) que emprega o método iterativo de Newton-Raphson, minimizando a soma dos quadrados dos desvios em relação à umidade. Para estimar os valores das umidades de saturação e residual aplicouse o método de extrapolação, proposto por JONG VAN LIER \& DOURADO NETO (1993). Para cada regressão foram calculados o coeficiente de ajuste (c.a.) e o valor $F$, segundo as seguintes equações:

$$
\begin{gathered}
c . a .=1-\frac{\sum_{i=1}^{n}\left(\hat{\theta}_{i}-\theta_{i}\right)^{2}}{\sum_{i=1}^{n}\left(\theta_{i}-\bar{\theta}\right)^{2}} \\
F=\frac{\sum_{i=1}^{n}\left(\theta_{i}-\bar{\theta}\right)^{2}-\sum_{i=1}^{n}\left(\hat{\theta}_{i}-\theta_{i}\right)^{2}}{v-1} \\
\frac{\sum_{i=1}^{n}\left(\hat{\theta}_{i}-\theta_{i}\right)^{2}}{n-v}
\end{gathered}
$$

onde $\boldsymbol{n}$ é o número de pares de dados, $\boldsymbol{v}$ é o número de parâmetros empíricos do modelo, $\theta$ é a umidade medida $\left(\mathrm{m}^{3} \cdot \mathrm{m}^{-3}\right), \hat{\theta}$ é a umidade estimada pelo modelo $\left(\mathrm{m}^{3} \cdot \mathrm{m}^{-3}\right)$ e $\bar{\theta}$ é a umidade média $\left(\mathrm{m}^{3} \cdot \mathrm{m}^{-3}\right)$.

Derivando a equação de VAN GENUCHTEN (1980) tem-se que: 


$$
\frac{d \theta}{d \psi_{m}}=\frac{\left(\theta_{s}-\theta_{r}\right) \cdot m \cdot n \cdot \alpha^{n} \cdot\left|\psi_{m}\right|^{n-1}}{\left[1+\left(\alpha \cdot\left|\psi_{m}\right|\right)^{n}\right]^{m+1}}
$$

Substituindo (20) e (25) em (21) obtém-se a seguinte expressão que permite calcular a condutividade em função dos parâmetros do experimento de difusividade, dos parâmetros da curva de retenção e do potencial mátrico:

$$
K=8,770 \cdot 10^{-4} \cdot f^{2} \cdot e^{8,087 \cdot \theta-\theta_{0} / \theta_{1}-\theta_{0}} \cdot \frac{\left(\theta_{s}-\theta_{r}\right) \cdot m \cdot n \cdot \alpha^{n} \cdot\left|\psi_{m}\right|^{n-1}}{\left[1+\left(\alpha \cdot\left|\psi_{m}\right|\right)^{n}\right]^{m+1}}
$$

Observe que o valor de $K$ na equação (26) é explicitado em função de $\theta$ e $\psi_{m}$, cuja relação é descrita pela equação (22) A explicitação em só $\theta$ ou $\psi_{m}$ não foi representada pois aumenta muito o tamanho da equação e dificulta a sua interpretação.

Substituindo (26) em (19) e desconsiderando-se outros potenciais que o mátrico tem-se que:

$$
\psi_{x}=\psi_{s}+\frac{T \cdot A}{8,77.10^{-4} f^{2}\left(\theta_{s}-\theta_{r}\right) m n \alpha^{n} \cdot 2 \pi l} \cdot \int_{R_{t}}^{x} \frac{e^{-8,087 \cdot\left(\frac{\theta_{x}-\theta_{0}}{\theta_{1}-\theta_{0}}\right)} \cdot\left|\psi_{x}\right|^{1-n} \cdot\left[1+\left(\alpha \cdot\left|\psi_{x}\right|\right)^{n}\right]^{m-1}}{r+x} d x(27)
$$

Observa-se que a variável dependente $\psi_{x}$ depende, entre outros, de si mesmo. A solução analítica geral da equação (27) torna-se assim impossível. Utilizando um método numérico pode-se, com a ajuda de recursos computacionais, chegar a soluções particulares e, conhecendo-se os valores dos parâmetros referentes ao solo $(\alpha$, $\left.m, n, \theta_{r}, \theta_{s}, \psi_{s}, f, \theta_{0}, \theta_{1}\right)$, à planta $(A, l, r)$ e à atmosfera $(T)$ obtém-se, em função da extensão da zona influenciada pela extração de água $\left(R_{\mathfrak{t}}\right)$ um valor de $\psi_{x}$ para cada $x$. Calcula-se o valor da umidade volumétrica no ponto $x\left(\theta_{x}\right)$, correspondente ao potencial 
mátrico nesse ponto $\psi_{x}$ através da equação (22), e verifica-se que o volume total de água retirada do solo entre o instante 0 e um instante $t\left(Q_{\mathfrak{t}}\right)$ é igual a

$$
Q_{t}=2 . \pi \cdot l \cdot \int_{r}^{R_{t}}\left(\theta_{R}-\theta_{x}\right) \cdot x \cdot d x
$$

Sendo assim, a extensão da zona influenciada pela extração de água $\left(R_{t}\right)$ será atingida após a perda de um volume $Q_{\mathrm{t}}$ de água.

\subsubsection{Teoria para um sistema bidimensional}

Como as unidades experimentais descritas no item 3.2.3. não apresentam forma cilíndrica, o fluxo de água em direção às placas porosas terá características bidimensionais. Num sistema bidimensional, as dimensões de algumas grandezas mudam em relação ao sistema tridimensional.

A área total do sistema radicular é igual a $l$ e a densidade de fluxo em direção à raiz $\left(q, \mathrm{~m}^{2} \cdot \mathrm{m}^{-1} \cdot \mathrm{s}^{-1}\right)$ deve ser

$$
q=\frac{F}{l}=\frac{V}{l . t}=\frac{T \cdot A}{l}
$$

Substituindo (29) em (14) tem-se que

$$
\left(\frac{d \psi}{d x}\right)_{x}=\frac{T \cdot A}{K\left(\psi_{x}\right) \cdot l}
$$

A combinação das equações (17) e (30) resulta em

$$
\psi_{x}=\psi_{s}+\int_{R_{t}}^{x} \frac{T \cdot A}{K\left(\psi_{x}\right) \cdot l} d x
$$


Substituindo (26) em (31), desconsiderando-se outros potenciais que o mátrico e reescrevendo a equação colocando os parâmetros independentes de $\boldsymbol{x}$ fora do sinal de integração tem-se que:

$$
\psi_{x}=\psi_{s}+\frac{T . A}{8,77.10^{-4} f^{2}\left(\theta_{s}-\theta_{r}\right) m n \alpha^{n} . l} \cdot \int_{R_{t}}^{x} e^{-8,087 \cdot\left(\frac{\theta_{x}-\theta_{0}}{\theta_{1}-\theta_{0}}\right)} \cdot\left|\psi_{x}\right|^{1-n} \cdot\left[1+\left(\alpha .\left|\psi_{x}\right|\right)^{n}\right]^{m-1} d x(32)
$$

Analogamente à equação (28), pode-se calcular a quantidade de água retirada do solo entre o instante 0 e um instante $t$ através da equação

$$
Q_{t}=l \cdot \int_{0}^{R_{t}}\left(\theta_{R}-\theta_{x}\right) \cdot d x
$$

\subsubsection{Ajuste das umidades medidas à teoria}

As umidades medidas nas unidades experimentais foram comparadas com as esperadas pela equação (32). Conhecendo-se os valores de $A, f, \theta_{s}, \theta_{r}, \alpha, m, n, l, \theta_{0}$ e $\theta_{1}$, encontrou-se os valores de $T, R_{t}$ e $\theta$ através de uma regressão não-linear iterativa. Essa regressão foi feita utilizando um programa computacional desenvolvido para esse fim. Utlilizou-se como incremento, na integração numérica, $0,0001 \mathrm{~m}$

\subsubsection{Absorção de água por um sistema radicular completo}

Um sistema radicular é composto de uma grande quantidade e variedade de raízes, cada uma delas participando na extração de água. A distribuição geométrica dessas raízes é complexa e, na aplicação da equação (27), deve-se levar em consideração que há interação entre as faixas influenciadas pelas raízes quanto às suas umidades. Essa interação depende da geometria do sistema radicular, o que faz com que a sua análise seja 
dificil. Para simular a absorção de água por um sistema radicular foram adotadas as seguintes simplificações:

- A umidade do solo é igual em toda parte, e a absorção de água ocorre com a mesma intensidade em todas as camadas do solo e em todas as raízes.

- As raízes estão distribuídas regularmente no solo. Em outras palavras, a distância entre duas raizes vizinhas é considerada ser a média.

Nessas condições, pode-se aplicar a equação (27), considerando que o valor de $R_{t}$ pode no máximo atingir o raio médio entre duas raízes. Esse raio médio $(\bar{r}$, m) é calculado em função da profundidade efetiva do sistema radicular $\left(Z_{e}, \underline{\mathrm{m}}\right)$, da área da parte aérea da planta $\left(A, \mathrm{~m}^{2}\right)$ e do comprimento total das raízes $(C, \mathrm{~m})$. A razão $C / Z_{e}$ indica quantas raízes com comprimento $Z_{e}$ a planta possui. Se essas raízes são distribuídas regularmente sobre a área $A$ ocupada pela planta, verifica-se que o raio médio entre as raízes é dado pela seguinte equação:

$$
\bar{r}=\frac{\sqrt{\frac{Z_{e} \cdot A}{C}}}{2}
$$

Em função da umidade inicial, da demanda transpiratória e da área total do sistema radicular pode-se, através de uma regressão não-linear iterativa calcular qual deve ser o potencial nas raízes para manter um fluxo de água ao sistema radicular igual à transpiração. Foi elaborado um programa para microcomputador que faz essa regressão. 


\subsection{Delineamento experimental}

\subsubsection{Terra: coleta e pretratamento}

Foi coletado material do horizonte superficial de dois solos do município de Piracicaba. O primeiro, de textura média, foi classificado como Latossolo Vermelho Amarelo álico A moderado por VIDAL-TORRADO \& SPAROVEK (1993) e será abreviado nesse texto pela sigla LV. O segundo, de textura muito argilosa, foi classificado como Latossolo Vermelho Escuro álico A moderado, unidade "Limeira" por OLIVEIRA \& PRADO (1989) e será abreviado pela sigla LE.

O material foi peneirado, calado e incubado. Antes da calagem foi feita uma análise física e química e depois da calagem uma outra análise química, pelo laboratório do Departamento de Ciência do Solo da ESALQ/USP. Os resultados dessas análises estão nas Tabelas 1 a 3.

Tabela 1 - Resultados da análise química do material dos solos LE e LV antes da calagem

\begin{tabular}{|c|c|c|c|c|c|c|c|c|c|c|c|c|c|c|}
\hline \multirow[t]{2}{*}{ Solo } & \multicolumn{3}{|c|}{ pH } & \multirow{2}{*}{$\begin{array}{c}\text { m.o. } \\
\text { g/kg }\end{array}$} & \multirow{2}{*}{$\begin{array}{c}P \\
\mu g / g\end{array}$} & $\mathbf{K}$ & $\mathrm{Ca}$ & $\mathrm{Mg}$ & Al & $\mathrm{H}+\mathrm{Al}$ & SB & $T$ & $\mathbf{v}$ & Al \\
\hline & $\mathrm{H}_{3} \mathrm{O}$ & $\mathrm{KCl}$ & $\mathrm{CaCl}_{2}$ & & & \multicolumn{7}{|c|}{$\mathrm{mol}_{r} / \mathrm{kg}$} & \multicolumn{2}{|c|}{$\mathrm{mol}_{2} / \mathrm{mol}_{\Omega}$} \\
\hline LE1 $^{*}$ & 6,1 & 4,5 & 4,5 & 32 & 51 & 15,1 & 21 & 5 & 2 & 58 & 41 & 99 & 0,41 & 0,05 \\
\hline LE2 & 5,7 & 4,5 & 4,4 & 32 & 41 & 14,7 & 13 & 5 & 2 & 58 & 33 & 91 & 0,36 & 0,06 \\
\hline LE3 & 6,1 & 4,5 & 4,5 & 38 & 57 & 17,8 & 24 & 6 & 2 & 58 & 48 & 106 & 0,45 & 0,04 \\
\hline LE-média & 6,0 & 4,5 & 4,5 & 34 & 50 & 15,9 & 19 & 5 & 2 & 58 & 41 & 99 & 0,41 & 0,05 \\
\hline LV1 & 5,1 & 3,9 & 4,2 & 23 & 5 & 0,7 & 13 & 4 & 5 & 47 & 18 & 65 & 0,28 & 0,22 \\
\hline LV2 & 5,5 & 4,2 & 4,0 & 28 & 3 & 0,6 & 13 & 4 & 5 & 42 & 18 & 60 & 0,30 & 0,22 \\
\hline LV3 & 5,0 & 3,9 & 4,2 & 20 & 3 & 0,5 & 11 & 4 & 4 & 47 & 16 & 63 & 0,25 & 0,20 \\
\hline LV-média & 5,2 & 4,0 & 4,1 & 24 & 4 & 0,6 & 12 & 4 & 5 & 45 & 17 & 63 & 0,28 & 0,21 \\
\hline
\end{tabular}

" O número após a sigla do solo indica uma repetiçáo da análise. 
Tabela 2 - Resultados da análise química do material dos solos LE e LV depois da calagem

\begin{tabular}{|c|c|c|c|c|c|c|c|c|c|c|c|c|c|c|}
\hline \multirow[t]{2}{*}{ Solo. } & \multicolumn{3}{|c|}{ pH } & \multirow{2}{*}{$\begin{array}{l}\text { m.o. } \\
\text { g/kg }\end{array}$} & \multirow{2}{*}{$\begin{array}{c}P \\
\mu g / g\end{array}$} & $K$ & \multirow[t]{2}{*}{$\mathrm{Ca}$} & \multirow[t]{2}{*}{$\mathrm{Mg}$} & \multirow{2}{*}{$\frac{\text { Al }}{101 / / \mathrm{kg}}$} & \multirow[t]{2}{*}{$\mathrm{H}+\mathrm{Al}$} & \multirow[t]{2}{*}{ SB } & \multirow[t]{2}{*}{$\mathbf{T}$} & \multirow{2}{*}{\multicolumn{2}{|c|}{$\frac{\mathbf{A} \quad \text { A }}{\mathrm{mol} / \mathrm{mol}_{-}}$}} \\
\hline & $\mathrm{H}_{2} \mathrm{O}$ & $\mathrm{KCl}$ & $\mathrm{CaCl}_{2}$ & & & & & & & & & & & \\
\hline LE1 $^{\circ}$ & 6,0 & 4,9 & 5,1 & 33 & 108 & 13,0 & 50 & 12 & 0 & 52 & 75 & 127 & 0,59 & 0,00 \\
\hline LE2 & 5,8 & 4,4 & 4,8 & 35 & 103 & 13,0 & 49 & 12 & 2 & 58 & 74 & 132 & 0,56 & 0,03 \\
\hline LE3 & 5,9 & 4,9 & 5,1 & 33 & 76 & 12,2 & 46 & 9 & 0 & 38 & 67 & 105 & 0,64 & 0,00 \\
\hline LE-média & 5,9 & 4,7 & 4,9 & 34 & 96 & 12,7 & 48 & 11 & 1 & 49 & 72 & 121 & 0,60 & 0,01 \\
\hline LV1 & 5,7 & 4,5 & 4,6 & 26 & 6 & 1,3 & 31 & 8 & 2 & 38 & 40 & 78 & 0,51 & 0,05 \\
\hline LV2 & 5,6 & 4,8 & 4,8 & 27 & 5 & 0,7 & 34 & 11 & 2 & 31 & 46 & 77 & 0,60 & 0,04 \\
\hline LV3 & 5,7 & 4,6 & 4,5 & 28 & 5 & 1,0 & 34 & 10 & 2 & 38 & 45 & 83 & 0,54 & 0,04 \\
\hline LV-média & 5,7 & 4,6 & 4,6 & 27 & 5 & 1,0 & 33 & 10 & 2 & 36 & 44 & 79 & 0,55 & 0,04 \\
\hline
\end{tabular}

"O número após a sigla do solo indica uma repetiçăo da análise.

Tabela 3 - Resultados da análise fisica do material dos solos LE e LV.

\begin{tabular}{c|ccccc}
\hline \multirow{2}{*}{ Solo } & areia grossa & areia fina & areia total & silte & argila \\
\cline { 2 - 6 } & \multicolumn{5}{c}{$\mathrm{kg} / \mathrm{kg}$} \\
\hline LE1 & 0,05 & 0,10 & 0,15 & 0,12 & \\
LE2 & 0,05 & 0,10 & 0,15 & 0,12 & 0,73 \\
LE3 & 0,05 & 0,14 & 0,19 & 0,10 & 0,71 \\
LE-média & 0,05 & 0,11 & 0,16 & 0,11 & 0,72 \\
& & & & 0,69 & 0,27 \\
\hline LV1 & 0,18 & 0,51 & 0,69 & 0,04 & 0,27 \\
LV2 & 0,19 & 0,48 & 0,67 & 0,06 & 0,27 \\
LV3 & 0,17 & 0,52 & 0,69 & 0,04 & 0,27 \\
LV-média & 0,18 & 0,50 & 0,68 & 0,05 & \\
\hline \hline
\end{tabular}

"O número após a sigla do solo indica uma repetiçåo da análise.

"areia grossa: >0,25 mm; areia fina: 0,25 a 0,05 mm; silte: 0,05 a 0,002 mm; argila: $<0,002 \mathrm{~mm}$.

\subsubsection{Planta}

A planta utilizada foi o arroz (Oryza sativa L.), cultivar IAC-165, proveniente da estação experimental de Pindamonhangaba (SP). 


\subsubsection{Unidades experimentais}

Para poder medir o movimento de água à raiz de uma planta, foi necessário criar um ambiente artificial, uma vez que o sistema radicular, por natureza, possui uma geometria complexa, não sendo possível a determinação suficientemente detalhada de fluxos de água dentro dele por métodos disponíveis: a resolução de uma fonte colimada de radiação $\gamma$ é da ordem de grandeza de $1 \mathrm{~mm}$, maior do que o menor detalhe no sistema radicular.

Foram confeccionadas 8 unidades experimentais de acrílico, com uma altura de 0,1 m e uma área retangular de 0,123 $\mathrm{m} \mathrm{x} \mathrm{0,018} \mathrm{m}$ (Figura 2). Na parte central das unidades experimentais, uma área de $0,018 \mathrm{~m} \times 0,020 \mathrm{~m}$ foi delimitada por duas placas porosas de cerâmica, de $0,0015 \mathrm{~m}$ de espessura, permitindo o fluxo de água e nutrientes da parte externa das placas à parte interna, mas impedindo a passagem das raízes. Essa parte das unidades experimentais, onde cresceram as raízes e não foram feitas medidas de umidade, será chamada de "parte interna". A parte das unidades experimentais não compreendida entre as placas porosas, onde não cresceram raízes e foram feitas medições de umidade, será chamada de "parte externa". Cada unidade experimental consiste de uma parte interna e duas externas. $\mathrm{Na}$ base das unidades experimentais, na parte externa de cada lado, foi feita uma abertura, permitindo a entrada da solução nutritiva. Para segurar a terra dentro das unidades experimentais, essas aberturas foram cobertas por um tela de náilon. Acrílico, placas e tela foram colados com borracha de silicone. Após secagem da cola, procedeu-se a saturação das placas porosas, gradativamente submergendo-se as unidades experimentais em água, e deixando-as aproximadamente 24 horas. Em seguida, as unidades experimentais foram preenchidas, até aproximadamente $0,01 \mathrm{~m}$ da borda, com a terra coletada nos dois solos (item 3.2.1.), passada por uma peneira de $1 \mathrm{~mm}$. A terra foi colocada numa bacia, com a unidade 
experimental, de cabeça para baixo, por cima da terra. $O$ conjunto bacia-unidade experimental foi virada em um movimento só, preenchendo a unidade experimental com terra, evitando a estratificação. Em quatro unidades experimentais utilizou-se a terra do LV, nas outras quatro a do LE.

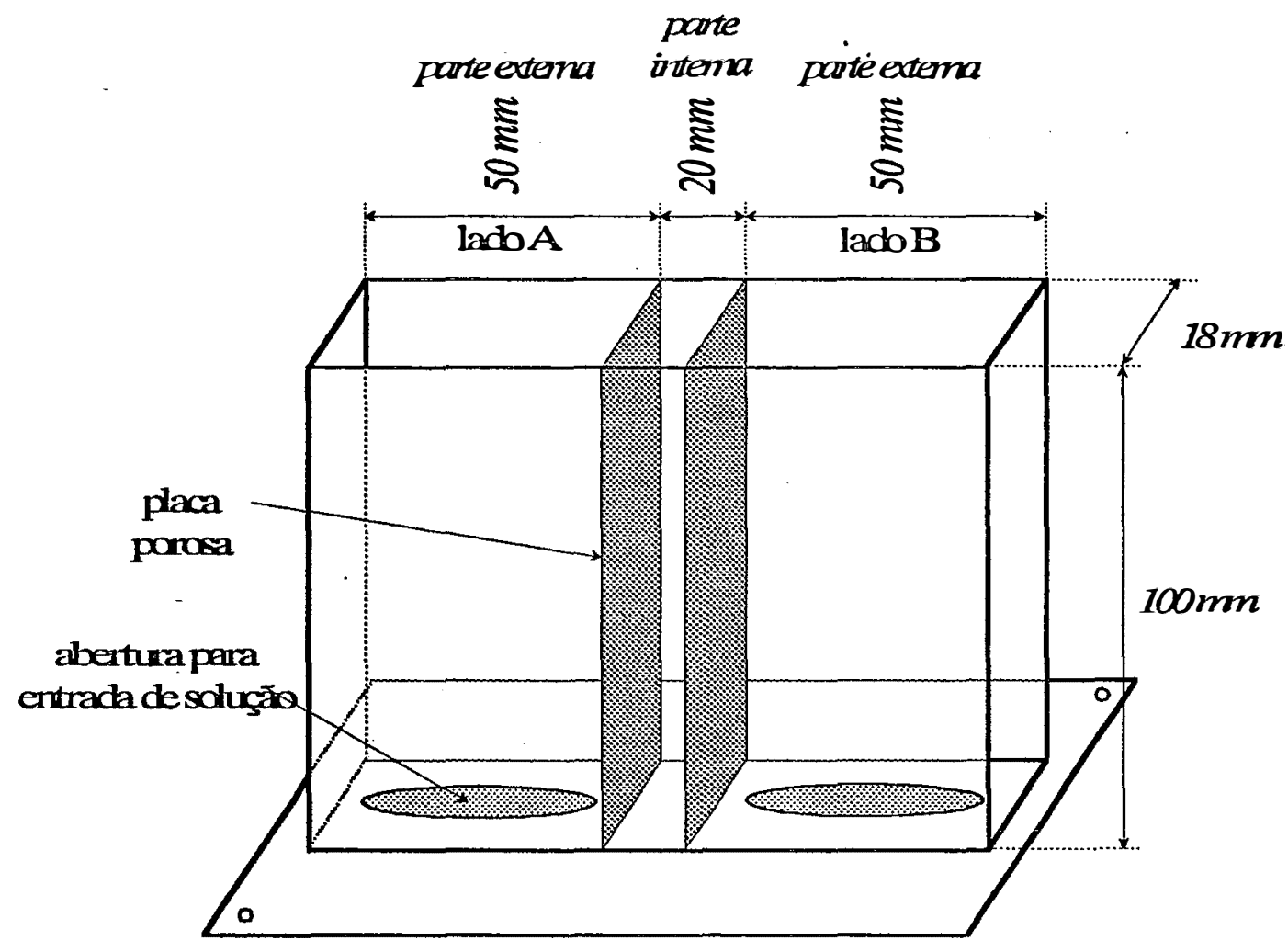

Figura 2 - Desenho esquemático, com dimensões aproximadas, da unidade experimental de acrílico com placas porosas, utilizada para medir o fluxo de água ao sistema radicular.

\subsubsection{Crescimento da cultura}

Imediatamente após preenchidas com terra, em 30/08/1993, as unidades experimentais foram colocadas numa bacia com uma lâmina de aproximadamente $0,03 \mathrm{~m}$ 
de solução nutritiva completa, conforme proposta de SARRUGE (1975), e cuja composição está especificada na Tabela 4. 0 lado de fora das unidades experimentais foi coberto com isopor para evitar o aquecimento excessivo da terra e o crescimento indesejado de algas. No dia seguinte foram semeadas 5 sementes de arroz, na parte interior de cada unidade. As primeiras emergências foram observadas quatro dias depois, em 04/09/93. Alguns dias após completadas as emergências a terra foi coberta por uma camada de aproximadamente $0,01 \mathrm{~m}$ de areia muito grossa, reduzindo assim as perdas de água por evaporação. A solução nutritiva foi trocada e a bacia limpada semanalmente. Em 20/09/93, 16 dias após a emergência, foi feito um desbaste, deixando as três maiores plantas em cada unidade. Ao decorrer do experimento, em quatro das oito unidades experimentais, dois com material do LV e dois com material do LE, observou-se que algumas raízes tinham penetrado na cola e passado para o outro lado da placa porosa, inviabilizando o uso dessas unidades experimentais para o experimento. Assim, sobraram duas repetições para cada material. No dia 17/10/93, 43 dias após a emergência, retirouse a solução nutritiva, deixando drenar o excesso de água, e iniciando as medições com radiação $\gamma$ no dia seguinte. No dia 19/10/93 fecharam-se, com fita adesiva, as aberturas de entrada de solução para evitar a evaporação de água através delas. 
Tabela 4 - Composição da solução nutritiva completa, conforme SARRUGE (1975).

\begin{tabular}{r|r}
\hline COMPONENTE & CONCENTRAÇẢO \\
\hline $\mathrm{KH}_{2} \mathrm{PO}_{4}$ & $0,001 \mathrm{M}$ \\
$\mathrm{KNO}_{3}$ & $0,005 \mathrm{M}$ \\
$\mathrm{Ca}\left(\mathrm{NO}_{3}\right)_{2}$ & $0,005 \mathrm{M}$ \\
$\mathrm{MgSO}_{4}$ & $0,002 \mathrm{M}$ \\
$\mathrm{FeEDTA}$ & $0,001 \mathrm{~m}^{3} \mathrm{solução} / \mathrm{m}^{3}$ \\
$\mathrm{H}_{3} \mathrm{BO}_{3}$ & $2,86.10^{-3} \mathrm{~kg} / \mathrm{m}^{3}$ \\
$\mathrm{MnCl}_{2} .4 \mathrm{H}_{2} \mathrm{O}$ & $1,81.10^{-3} \mathrm{~kg} / \mathrm{m}^{3}$ \\
$\mathrm{ZnCl}_{2}$ & $0,10.10^{-3} \mathrm{~kg} / \mathrm{m}^{3}$ \\
$\mathrm{CuCl}_{3}$ & $0,04.10^{-3} \mathrm{~kg} / \mathrm{m}^{3}$ \\
$\mathrm{H}_{2} \mathrm{MoO}_{4} \cdot \mathrm{H}_{2} \mathrm{O}$ & $0,02.10^{-3} \mathrm{~kg} / \mathrm{m}^{3}$ \\
\hline \hline
\end{tabular}

* FeEDTA-solução: $24,9 \mathrm{~g}$ de FeSO $4.7 \mathrm{H}_{2} \mathrm{O}+26,1 \mathrm{~g}$ EDTA + $286 \mathrm{ml}$ iN $\mathrm{NaOH}$, completar com $\mathrm{H}_{3} \mathrm{O}$ até 1 litro.

\subsubsection{Medições com radiação $\gamma$}

Anteriormente à semeadura do arroz tinha sido feita uma avaliação do equipamento de radiação $\gamma$ do laboratório de radioisótopos do Centro de Energia Nuclear na Agricultura (CENA), em Piracicaba (SP). A fonte radioativa foi o ${ }^{241} \mathrm{Am}$, que tem uma meia-vida de 432 anos e uma energia de radiação $\gamma$ de 59,6 keV. A sua atividade, em 1974 , era de $3,7.10^{9} \mathrm{~Bq}$. Mediu-se a contagem do equipamento para várias voltagens. Os resultados dessas contagens estão representados graficamente na Figura 3. Com base nesses resultados decidiu-se usar a faixa de 2,0 a 4,2 V para as medições posteriores. 


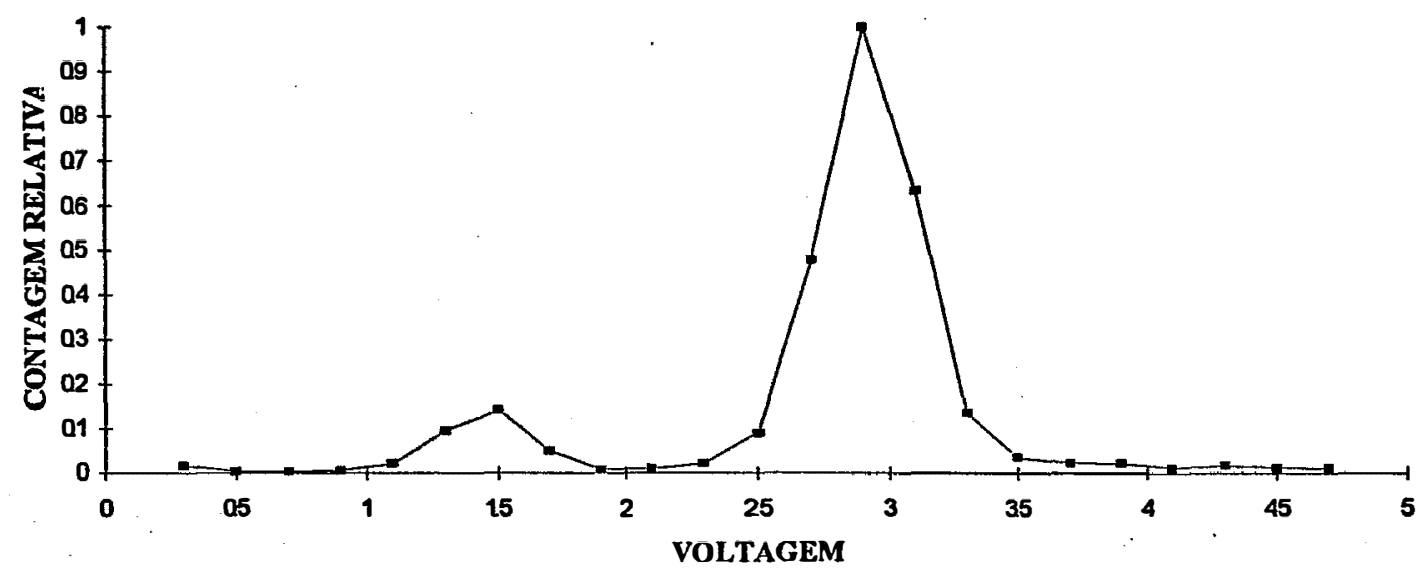

Figura 3 - Espectro do ${ }^{241}$ Am obtido com o equipamento utilizado.

As leituras de atenuação de radiação $\gamma$ foram feitas em 9 datas (nos dias $18,19,20,21,22,24,26,28$ e 30 de outubro de 1993), sempre de manhã, até a morte das plantas. A Figura 4 esquematiza a configuração fonte $\gamma$ - unidade experimental de acrílico - detector $\gamma$. Os colimadores são de secção reta-circular, em blocos de chumbo. $\mathbf{O}$ colimador do feixe de Amerício tem um diâmetro igual a 3,97.10-3 m. No lado da fonte, a distância de colimação é de $0,030 \mathrm{~m}$ e no lado do detector a distância é de $0,020 \mathrm{~m}$. A divergência máxima de colimação é de 0,05 rad (FERRAZ, 1974).

As unidades experimentais foram colocadas num trilho, construído para possibilitar o posicionamento preciso entre a fonte e o detector de radiação. Leituras foram feitas em 3 profundidades $(0,04,0,05$ e $0,06 \mathrm{~m})$ em toda a parte externa (parte não compreendida entre as placas porosas), com distâncias de 0,0014 m entre leituras subseqüentes, resultando em aproximadamente 36 leituras a cada profundidade e a cada lado das unidades experimentais. O tempo de contagem utilizado foi 6 segundos. Determinara-se, previamente, que o coeficiente de variação da contagem de fótons para esse tempo de leitura era $0,78 \%$. As 6 leituras mais próximas à placa porosa (de cada 
lado) foram feitas com uma repetição, utilizando o valor medido médio para fins de cálculo, diminuindo o coeficiente de variação dessas leituras a $0,62 \%$.

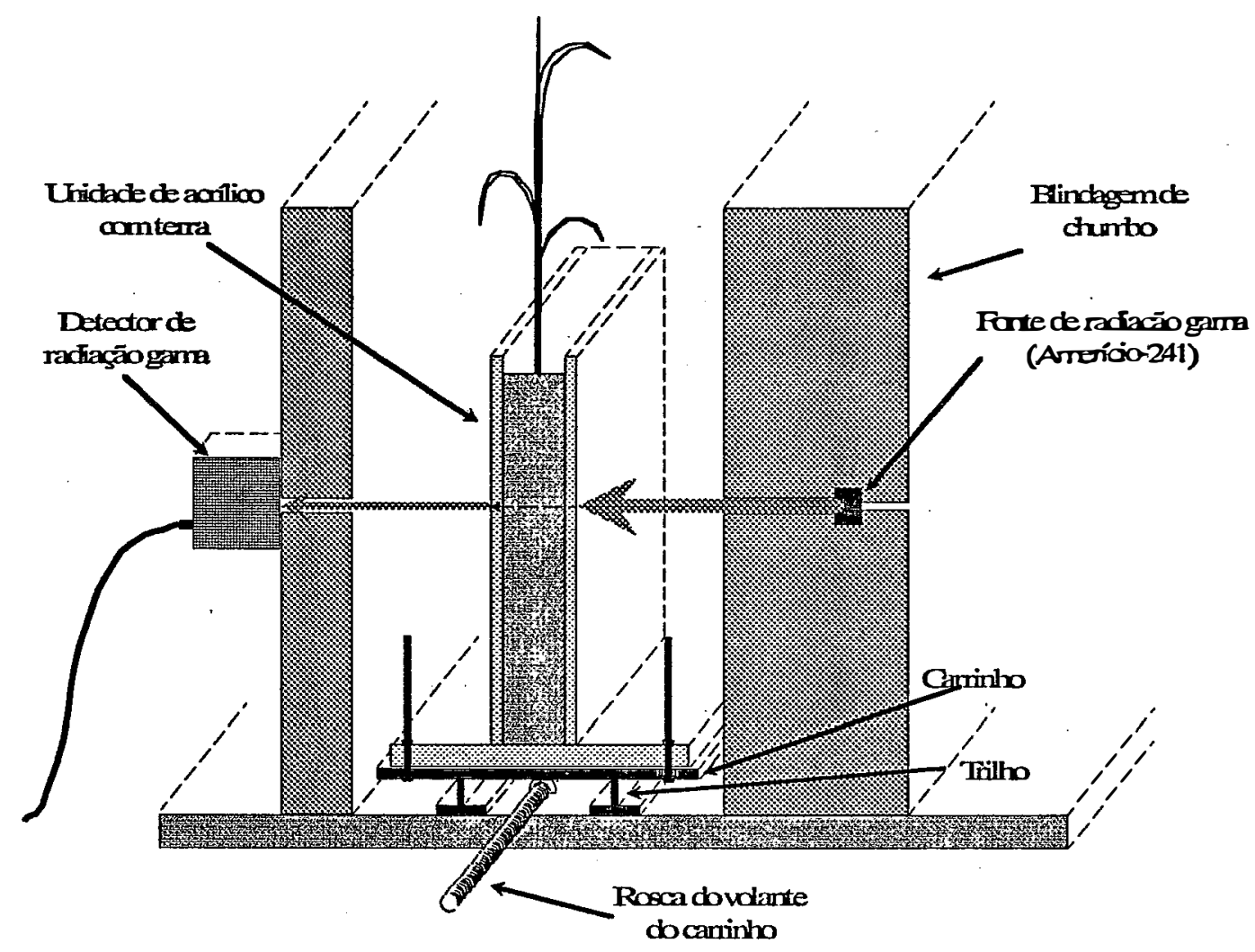

Figura 4 - Corte transversal, mostrando esquematicamente o posicionamento da unidade experimental de acrílico entre a fonte e o detector de radiação $\gamma$.

A equação da atenuação da radiação $\gamma$, de acordo com a equação de Lambert-Beer, tem a seguinte forma:

$$
I=I_{00} \cdot e^{-\mu \cdot \rho \cdot x}
$$

onde $I$ e $I_{00}$ são as intensidades dos feixes incidente e emergente (fótons. $\mathrm{m}^{-2} \cdot \mathrm{s}^{-1}$ ), respectivamente, $\mu$ é o coeficiente de atenuação de massa do meio absorvedor para a 
energia da radiação $\gamma$ considerada $\left(\mathrm{m}^{2} \cdot \mathrm{kg}^{-1}\right), \rho$ é a densidade do meio absorvedor $\left(\right.$ kg. $\left.\mathrm{m}^{-3}\right)$ e $x$ é a espessura do meio absorvedor (m).

Aplicando a equação (35) ao caso específico tem-se que:

$$
I=I_{00} \cdot e^{-\mu_{p} \cdot \rho_{p} \cdot x \cdot(1-\alpha)-\mu_{w} \cdot \rho_{w} \cdot x \cdot \theta-\mu_{a} \cdot \rho_{a} \cdot x_{a}}
$$

onde $I_{00}$ (fótons. $\mathrm{m}^{-2} . \mathrm{s}^{-1}$ ) é a intensidade do feixe através do ar, $I$ (fótons. $\mathrm{m}^{-2} \cdot \mathrm{s}^{-1}$ ) é à intensidade do feixe através da unidade experimental com terra, $\mu_{p}, \mu_{w}$ e $\mu_{a}\left(\mathrm{~m}^{2} . \mathrm{kg}^{-1}\right)$ são os coeficientes de atenuação de massa para a energia da radiação $\gamma$ considerada da fração sólida do solo, da água e do acrílico, respectivamente, $\rho_{p}$, $\rho_{w}$ e $\rho_{a}\left(\mathrm{~kg} \cdot \mathrm{m}^{-3}\right)$ são as densidades da fração sólida do solo, da água e do acrílico, respectivamente, $x(\mathrm{~m})$ é a espessura de solo, $x_{\mathbf{a}}(\mathrm{m})$ é a espessura do acrílico, $\alpha\left(\mathrm{m}^{3} \cdot \mathrm{m}^{-3}\right)$ é a porosidade do solo e $\theta$ $\left(\mathrm{m}^{3} \cdot \mathrm{m}^{-3}\right)$ é a umịdade volumétrica do solo. Se $\theta=0$ (no solo seco em estufa), a equação (36) reduz para:

$$
I_{0}=I_{00} \cdot e^{-\mu_{p} \cdot \rho_{p} \cdot x \cdot(1-\alpha)-\mu_{a} \cdot \rho_{a} \cdot x_{a}}
$$

onde $I_{0}$ (fótons. $\mathrm{m}^{-2} \cdot \mathrm{s}^{-1}$ ) é a intensidade do feixe através da unidade experimental com terra seca. Dividindo (36) por (37) tem-se que:

$$
I=I_{0} \cdot e^{-\mu_{w} \cdot \rho_{w} \cdot x \cdot \theta}
$$

donde se deduz que

$$
\theta=\frac{\ln \left(I_{0} / I\right)}{\mu_{w} \cdot \rho_{w} \cdot x}
$$


Para determinar os valores de $I_{0}$, as unidades experimentais com terra foram secas em estufa após a morte das plantas, e a intensidade de radiação foi medida em cada ponto de leitura. $\mathbf{O}$ valor de $\mu_{w}$ foi determinado medindo a atenuação de radiação $\gamma$ atravessando recipientes de dimensões conhecidas com água pura. Nesse caso, aplicando a equação (35), tem-se que

$$
\ln \frac{I_{00}}{I}=\mu_{w} \cdot x \cdot \rho_{w}
$$

donde se deduz que $\mu_{w}$ é o coeficiente angular da reta obtida por regressão linear passando pela origem, dos valores de $\ln \left(I_{00} / I\right)$ como parâmetro dependente contra $x . \rho_{w}$ como variável dependente.

\subsubsection{Estimativa da evapotranspiração}

Com base nas umidades determinadas utilizando a radiação $\gamma$, estimou-se a taxa de evapotranspiração. Supondo que o componente evaporação foi desprezível, verifica-se que a variação do armazenamento de água entre dois instantes equivale ao volume de água transpirada pela planta nesse mesmo período. Dividindo esse volume pela área da planta e pela duração do intervalo, tem-se a taxa de evapotranspiração, conforme equação (41):

$$
T_{i-1, i}=\frac{h \cdot X \cdot\left(\bar{\theta}_{i-1}-\bar{\theta}_{i}\right)}{x \cdot n_{i-1, i}}
$$

onde $T_{i-1, i}$ é a taxa de evapotranspiração entre os instantes $i$ e $i$-1, expressa em $\mathrm{m}^{3} \cdot \mathrm{m}^{-2} \cdot \mathrm{s}^{-1}, h$ é a altura de terra na unidade experimental $(\mathrm{m}), X$ é a largura total das partes externas (m), $x$ é a largura da parte interna $(\mathrm{m}), \bar{\theta}_{i-1}$ é a umidade volumétrica 
média medida no instante $i-1\left(\mathrm{~m}^{3} \cdot \mathrm{m}^{-3}\right), \bar{\theta}_{i}$ é a umidade volumétrica média medida no instante $i\left(\mathrm{~m}^{3} \cdot \mathrm{m}^{-3}\right)$ e $n_{i-1, i}$ é o tempo corrido entre o instante $i-1$ e $i(\mathrm{~s})$. 


\section{RESULTADOS E DISCUSSÃO}

\subsection{Curvas de retenção}

As umidades obtidas no material dos dois solos para as 14 tensões aplicadas estão na Tabela 5.

Tabela 5 - Umidades volumétricas obtidas no material dos solos LV e LE para as 14 tensões aplicadas.

\begin{tabular}{|c|c|c|c|}
\hline \multicolumn{2}{|c|}{$\begin{array}{r}\text { pressão/sucção } \\
(\mathrm{kPa})\end{array}$} & \multicolumn{2}{|c|}{ umidade $\left(\theta, \mathrm{m}^{3} \cdot \mathrm{m}^{-3}\right.$} \\
\hline & & LV & LE \\
\hline $\begin{array}{c}\text { funil } \\
\text { de } \\
\text { Haynes }\end{array}$ & $\begin{array}{l}0,49 \\
0,98 \\
1,96 \\
3,92 \\
5,89 \\
7,85 \\
9,81\end{array}$ & $\begin{array}{l}0,390 \\
0,381 \\
0,366 \\
0,323 \\
0,295 \\
0,191 \\
0,163\end{array}$ & $\begin{array}{l}0,508 \\
0,497 \\
0,479 \\
0,422 \\
0,368 \\
0,335 \\
0,313\end{array}$ \\
\hline $\begin{array}{c}\text { câmara } \\
\text { de } \\
\text { Richards }\end{array}$ & $\begin{array}{r}10 \\
18 \\
36 \\
90 \\
230 \\
595 \\
1490\end{array}$ & $\begin{array}{l}0,167 \\
0,108 \\
0,070 \\
0,045 \\
0,029 \\
0,016 \\
0,008\end{array}$ & $\begin{array}{l}0,303 \\
0,262 \\
0,225 \\
0,193 \\
0,169 \\
0,150 \\
0,134\end{array}$ \\
\hline
\end{tabular}


O ajuste à equação (22), a equação de VAN GENUCHTEN (1980) resultou nos parâmetros apresentados na Tabela 6. As curvas e as umidades determinadas estão representadas nas Figuras 5 e 6 para o material dos solos LV e LE respectivamente. Observa-se que o ajuste da equação de VAN GENUCHTEN (1980) aos dados obtidos foi muito bom, sendo que o coeficiente de ajuste foi maior do que 0,99 e o nível de significância pelo teste $\mathrm{F}$ menor do que 0,00005 \% para as duas curvas.

Tabela 6 - Parâmetros da equação de VAN GENUCHTEN (1980) (equação (22)) e parâmetros estatísticos da regressão para o material dos solos LV e LE.

\begin{tabular}{|c|c|c|}
\hline \multirow[t]{2}{*}{ parâmetro } & \multicolumn{2}{|c|}{ solo } \\
\hline & LV & LE \\
\hline $\begin{array}{r}\theta_{\mathrm{r}}\left(\mathrm{m}^{3} \cdot \mathrm{m}^{-3}\right) \\
\theta_{\mathrm{s}}\left(\mathrm{m}^{3} \cdot \mathrm{m}^{-3}\right) \\
\alpha\left(\mathrm{kPa}^{-1}\right) \\
m \\
n \\
\text { coeficiente de ajuste } \\
\text { valor } \mathrm{F} \\
\text { nivel de significância pelo teste } \mathrm{F}(\%)\end{array}$ & $\begin{array}{r}0,004 \\
0,390 \\
0,3170 \\
0,2148 \\
3,4779 \\
0,99.7 \\
1867 \\
<0,00005 \\
\end{array}$ & $\begin{array}{r}0,115 \\
0,509 \\
0,4302 \\
0,1632 \\
2,8748 \\
0,998 \\
2995 \\
<0,00005\end{array}$ \\
\hline
\end{tabular}




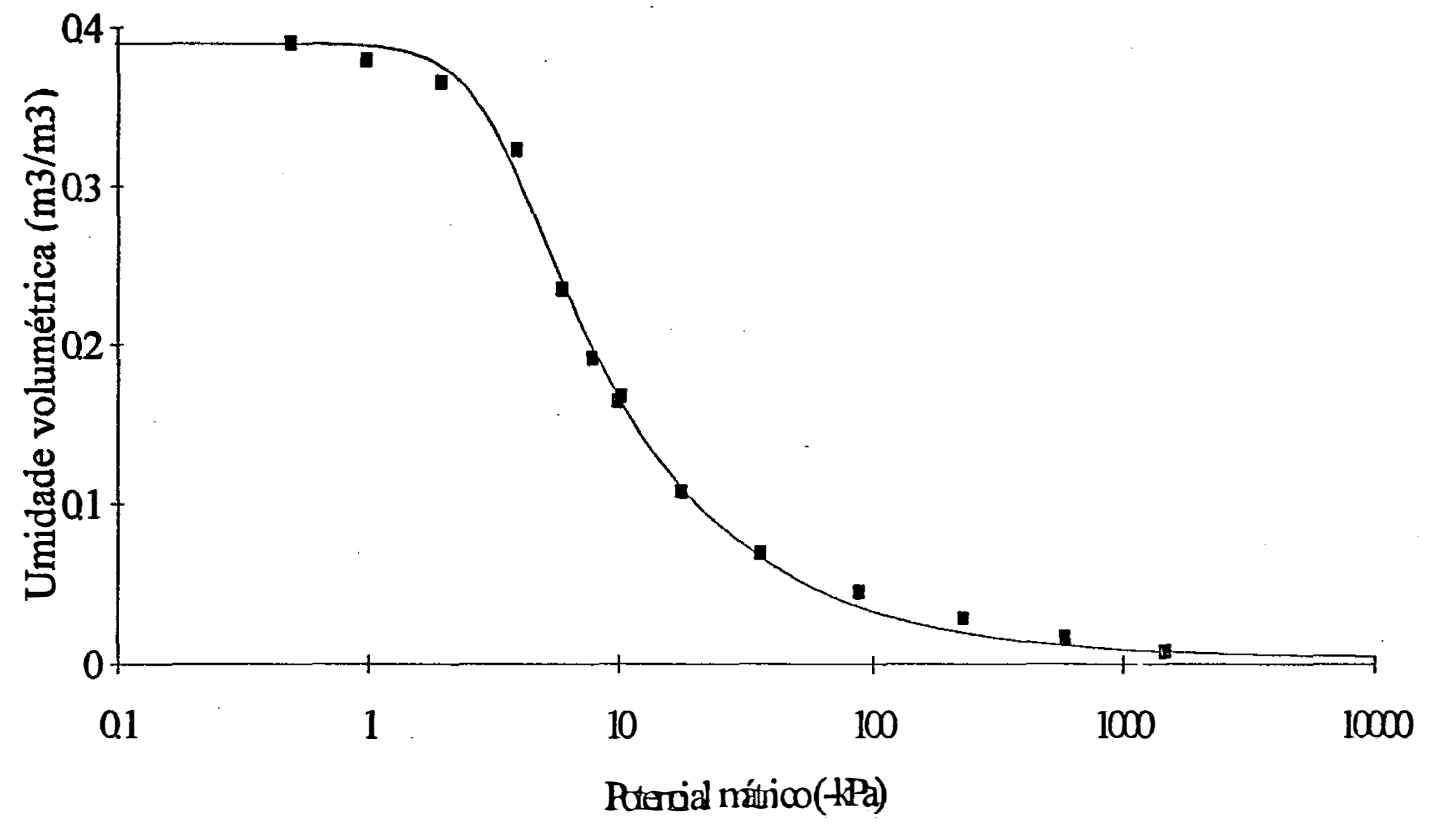

Figura 5 - Curva de retenção do material do solo LV. A linha é resultado do ajuste da equação (22) às umidades medidas (pontos). 


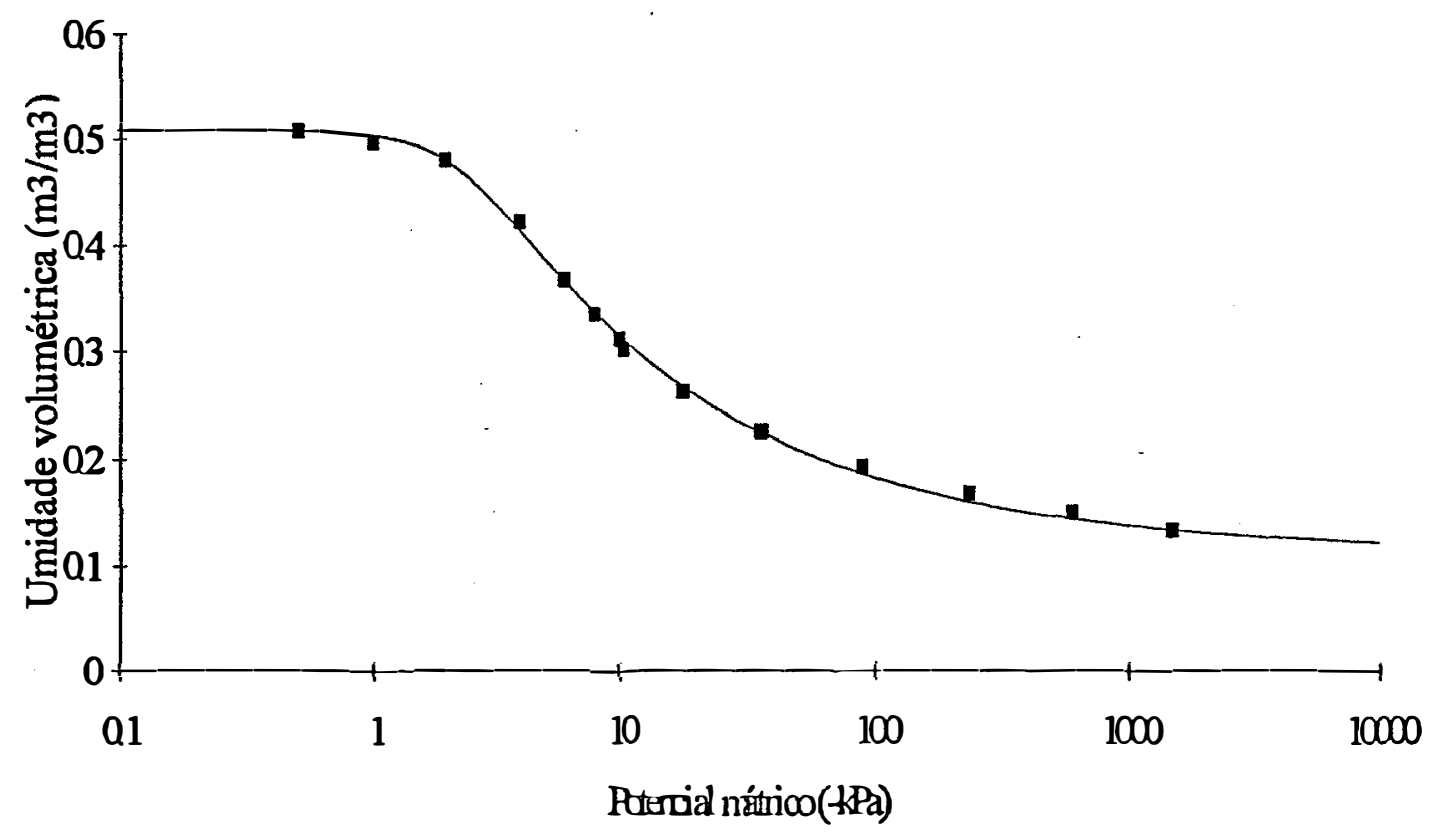

Figura 6 - Curva de retenção do material do solo LE. A linha é resultado do ajuste da equação (22) às umidades medidas (pontos).

\subsection{Condutividade hidráulica}

Conforme descrito no item 3.1.1.1.1., para determinar o valor do parâmetro $f$ o material do solo foi compactado com a densidade encontrada na seção inferior dos aneis (item 3.1.1.1.2.), que foi de $1341 \mathrm{~kg} \cdot \mathrm{m}^{-3}$ para o LV e $1168 \mathrm{~kg} \cdot \mathrm{m}^{-3}$ para o LE, num cilindro de acrílico. Os resultados dos ensaios de difusividade para o material dos dois solos estão representados na Tabela 7. 
Tabela 7 - Avanço da frente de molhamento em função do tempo para o material dos solos LV e LE no experimento de infiltração horizontal.

\begin{tabular}{r|cr}
\hline \hline tempo (min) & \multicolumn{2}{|c}{ avanço (m) } \\
\cline { 2 - 3 } & \multicolumn{2}{c}{ LV } \\
\hline 0 & 0,042 & 0,006 \\
1 & 0,060 & 0,009 \\
2 & 0,072 & 0,011 \\
3 & 0,090 & 0,013 \\
5 & 0,109 & 0,015 \\
7 & 0,123 & 0,017 \\
9 & 0,141 & 0,019 \\
12 & 0,160 & 0,022 \\
16 & 0,178 & 0,025 \\
20 & 0,196 & 0,028 \\
25 & 0,214 & 0,031 \\
30 & 0,234 & 0,034 \\
36 & 0,255 & 0,036 \\
42 & 0,275 & 0,039 \\
49 & 0,308 & 0,045 \\
64 & 0,335 & 0,051 \\
81 & 0,365 & 0,056 \\
100 & 0,408 & 0,062 \\
121 & 0,436 & 0,068 \\
144 & n.d. & 0,074 \\
169 & n.d. & 0,165 \\
1010 & & \\
\hline * não determinado & &
\end{tabular}

Os resultados da regressão linear de $x$ versus $\ell^{0,5}$ bem como as umidades determinadas $\theta_{0}$ e $\theta_{1}$ estão apresentados na Tabela 8 . Os valores quase máximos de $\mathrm{r}^{2}$ confirmam a relação linear entre o avanço da frente de molhamento e a raiz quadrada do tempo. Na Figura 7 encontram-se as representações gráficas da condutividade hidráulica $\left(K, \mathrm{~m}^{2} \cdot \mathrm{kPa}^{-1} \cdot \mathrm{s}^{-1}\right)$ em função da umidade volumétrica, calculada através da equação (26) $\mathrm{e}$ com base nos resultados apresentados na Tabela 8 para o material dos solos LV e LE. As condutividades calculadas por essa equação não são confiáveis para umidades muito 
próximas à saturação, uma vez que $d \theta / d \psi_{m}$, e conseqüentemente $K$, tendem para zero quando a umidade tende para saturação. Esses valores errôneos não foram representados na Figura 7. Fica evidenciado o fato que a relação entre umidade e condutividade hidráulica é logarítmica num grande intervalo de umidades, no caso até aproximadamente $0,05 \mathrm{~m}^{3} \cdot \mathrm{m}^{-3}$, correspondendo ao potencial mátrico de $-54 \mathrm{kPa}$, para o material do LV e até aproximadamente $0,2 \mathrm{~m}^{3} \cdot \mathrm{m}^{-3}$, correspondendo ao potencial mátrico de $-61 \mathrm{kPa}$, para o material do LE. Para umidades menores, o decréscimo da condutividade hidráulica é mais rápido. $\mathrm{O}$ valor da condutividade quase-saturada para o material do $\mathrm{LV}$ é da ordem de grandeza de $10^{-6} \mathrm{~m}^{2} \cdot \mathrm{kPa}^{-1} \cdot \mathrm{s}^{-1}$, o do material do LE aproximadamente 100 vezes menor: $10^{-8} \mathrm{~m}^{2} \cdot \mathrm{kPa}^{-1} \cdot \mathrm{s}^{-1}$. Observa-se ainda que a tangente da reta $\log (K)$ - $\theta$ é maior para o material do LE, ou seja, com o decréscimo da umidade a sua condutividade hidráulica diminui ainda mais rapidamente que a do material do LV.

Tabela 8 - Resultados da regressão linear de $x$ versus $t^{0,5}$ e umidades determinadas $\theta_{0} \mathrm{e}$ $\theta_{1}$ no experimento de infiltração horizontal para o material dos $\operatorname{solos}_{a} \mathrm{LV}$ e LE.

\begin{tabular}{c|rrrr}
\hline \hline Solo & $f\left(\mathrm{~m}^{-0} \mathrm{~s}^{-5}\right)$ & $\mathrm{r}^{2}$ & $\theta_{1}\left(\mathrm{~m}^{3} \cdot \mathrm{m}^{-3}\right)$ & $\theta_{0}\left(\mathrm{~m}^{3} \cdot \mathrm{m}^{-3}\right)$ \\
\hline LV & 0,004884 & 0,995 & 0,3602 & 0,0153 \\
LE & 0,000698 & 0,996 & 0,4863 & 0,0308 \\
\hline \hline
\end{tabular}




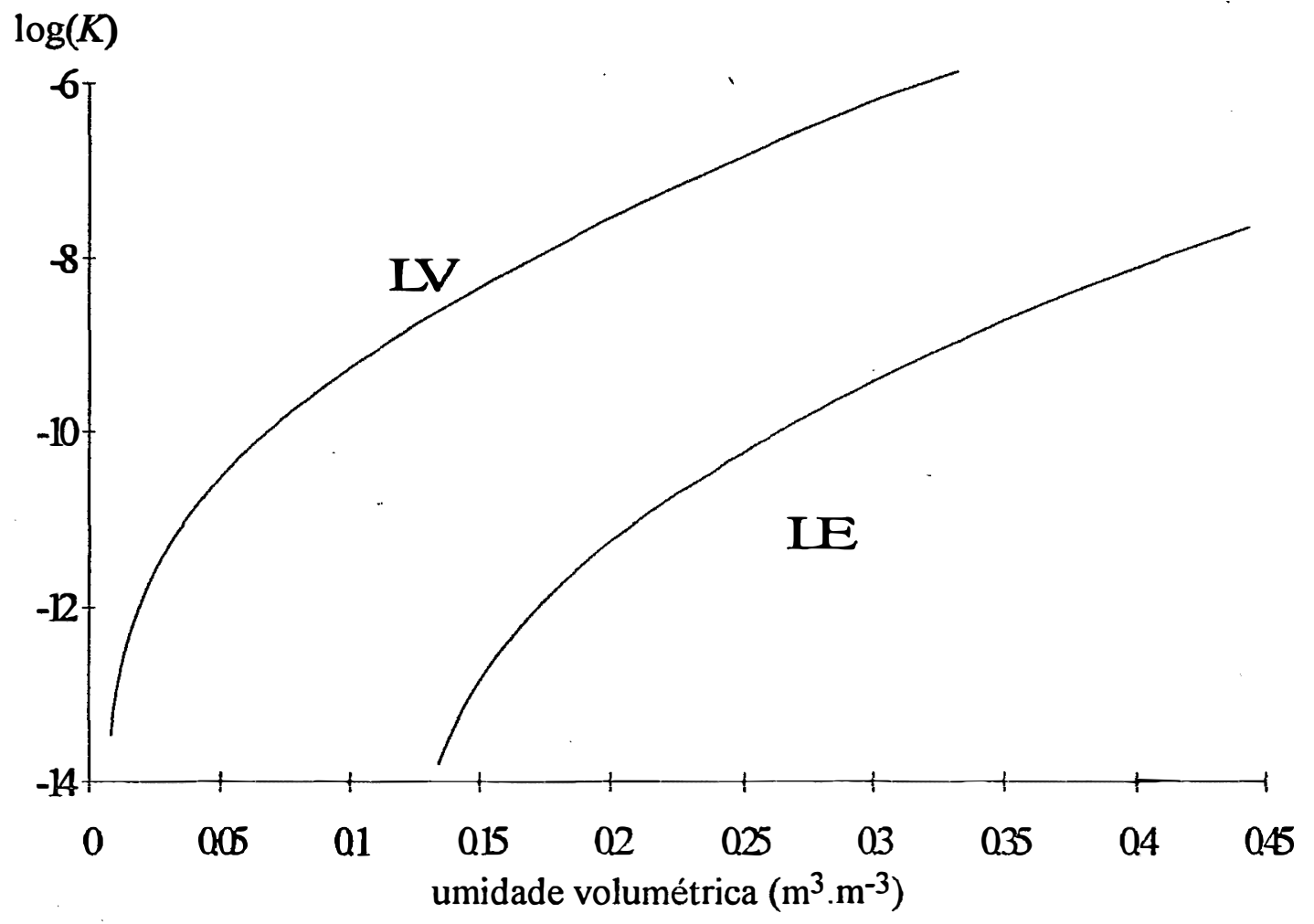

Figura 7 - Condutividade hidráulica $\left(\log (K), \log \left(\mathrm{m}^{2} \cdot \mathrm{kPa}^{-1} \cdot \mathrm{s}^{-1}\right)\right)$ em função da umidade volumétrica, calculada através da equação (26) e com base nos resultados apresentados na Tabela 8 para o material dos solos LV e LE.

\subsection{Coeficiente de atenuação da radiação $\gamma$ pela água}

A atenuação da radiação $\gamma$ por água pura foi medida em três recipientes retangulares de acrílico, cujos diâmetros foram determinados: 0,0158 $\mathrm{m}, 0,0307 \mathrm{~m}$ e $0,0545 \mathrm{~m}$. Foram feitas leituras de $60 \mathrm{~s}$ cada. Os valores obtidos para o termo $\ln \left(I_{00} / I\right)$ da equação (40) foram $0,30125,0,59307$ e 1,06051 respectivamente. Regressão linear, conforme descrito no item 3.2.5. e considerando que a densidade da água é $1000 \mathrm{~kg} \cdot \mathrm{m}^{-3}$ resultou num coeficiente angular, equivalente a $\mu_{w}$, de $0,0194 \mathrm{~m}^{2} \cdot \mathrm{kg}^{-1}$. 


\subsection{Medições da umidade através da atenuação de radiação $\gamma$}

Os resultados das medições da umidade através da atenuação de radiação $\gamma$ estão compilados no apêndice, e representados graficamente nas Figuras 8 a 19.

\subsubsection{Estimativa da evapotranspiração}

As taxas de evapotranspiração, estimadas através da equação (41) estão representadas na Tabela 9. Utilizaram-se os valores de $0,10 \mathrm{~m}, 0,02 \mathrm{~m} \mathrm{e} 0,08 \mathrm{~m}$ para $X, x$ e $h$, respectivamente. As taxas são as médias calculadas com base nas umidades determinadas a $0,04,0,05$ e $0,06 \mathrm{~m}$ de profundidade e dos dois lados das unidades experimentais.

Tabela 9 - Taxas de evapotranspiração $\left(10^{-8} \cdot \mathrm{m}^{3} \cdot \mathrm{m}^{-2} \cdot \mathrm{s}^{-1}\right)$ estimadas com base nas umidades medidas nas 9 datas para as duas repetições dos materiais dos solos LV e LE.

\begin{tabular}{|c|c|c|c|c|}
\hline \multirow[b]{2}{*}{ data } & \multicolumn{2}{|c|}{ LV } & \multicolumn{2}{|c|}{ LE } \\
\hline & repetição 1 & repetição 2 & repetição 1 & repetição 2 \\
\hline $18-19 / 10 / 93$ & 10,31 & 9,60 & 11,86 & 13,45 \\
\hline 19-20/10/93 & 8,93 & 7,48 & 1,05 & 3,25 \\
\hline $20-21 / 10 / 93$ & 10,52 & 7,60 & 3,74 & 3,49 \\
\hline $21-22 / 10 / 93$ & 11,78 & 12,51 & 3,18 & 2,51 \\
\hline $22-24 / 10 / 93$ & 10,74 & 11,22 & 2,56 & 2,68 \\
\hline $24-26 / 10 / 93$ & 6,32 & 5,86 & 2,16 & 2,88 \\
\hline $26-28 / 10 / 93$ & 1,42 & 0,83 & $-0,19$ & $-0,09$ \\
\hline $28-30 / 10 / 93$ & 0,63 & $-0,12$ & 0,20 & 0,14 \\
\hline
\end{tabular}

Pode-se observar que as taxas de evapotranspiração assim estimadas são muito maiores para o material do LV do que para o do LE. No LV, os valores variam em torno de $10.10^{-8} \mathrm{~m}^{3} / \mathrm{m}^{-2} / \mathrm{s}^{-1}$, enquanto que no LE os valores comuns estão em torno de $3.10^{-8} \mathrm{~m}^{3} \cdot \mathrm{m}^{-2} \cdot \mathrm{s}^{-1}$. Esse fenômeno não tem explicação fácil. A transpiração de uma planta é regida primeiramente pela demanda atmosférica transpiratória, que não depende do 
solo. Um desenvolvimento diferente das plantas nos dois materiais poderia explicar a discrepância, porém, não foi observada diferença significativa no desenvolvimento entre as plantas. A diferença pode ter origem em variações da umidade do material no sentido vertical, causando um conseqüente movimento de água nesse sentido. A diferença ainda pode ser causada por erros de determinação: pelo método empregado, qualquer perda de água é atribuída a evapotranspiração. Pode ter havido evaporação e/ou drenagem, o que explica os valores altos da taxa de evapotranspiração para esse material nesse período. Um outro fator que poderia ter causado a diferença é a má disponibilidade de água no LE, que estaria, desde o início do experimento, abaixo da umidade crítica. A diminuição com o tempo dos valores do potencial mátrico medidos nesse solo (Tabelas 16 a 21) comprovam, porém, o contrário.

Fica evidente que, no final do período de medições, houve uma queda nas taxas de evapotranspiração nos dois materiais, no LV entre 24 e 26/10/93 e no LE, mais abruptamente, em 26/10/93. Valores praticamente nulos são atingidos logo em seguida, indicando a morte das plantas.

De 18 para 19/10/93, as aberturas para entrada de solução não tinham sido ainda cobertas com fita adesiva. É provável que tenha havido drenagem nesse período, principalmente no material do LE, incluída no cálculo como se fosse evapotranspiração.

\subsubsection{Ajuste do modelo proposto às umidades medidas}

Conforme procedimento descrito no item 3.1.2., os valores da transpiração $\left(T, 10^{-8} \mathrm{~m}^{3} \cdot \mathrm{m}^{-2} \cdot \mathrm{s}^{-1}\right)$, zona influenciada $\left(R_{t}, \mathrm{~m}\right)$, umidade do solo na zona não influenciada $\left(\theta_{\text {solo }}, \mathrm{m}^{3} \cdot \mathrm{m}^{-3}\right)$, potencial na raiz $\left(\psi_{\text {raiz }}, \mathrm{kPa}\right)$ e coeficientes de ajuste (c.a.) calculados através da equação (23) foram determinados através de ajuste à equação (32) para os dois materiais, duas repetições e três profundidades. Os resultados estão nas Tabelas $10 \mathrm{a}$ 21. Os valores de umidade estimados através da equação (32) ajustada e medidos através 
da radiação $\gamma$, estão representados graficamente nas Figuras 8 a 19. Desconsiderando-se eventuais diferenças ocorridas em função da profundidade nas unidades, pode-se considerar que as três profundidades de determinação de umidade, os dois lados das unidades experimentais e as duas unidades experimentais preenchidas com o mesmo material são repetições idênticas. Assim tem-se doze $(3 \times 2 \times 2)$ repetições para cada material. As médias para a transpiraçào, zona influenciada, umidade do solo na zona não influenciada e potencial na raiz, bem como os seus coeficientes de variação estão nas Tabelas 22 (LV) e 23 (LE).

Os valores da transpiração são da mesma ordem de grandeza para os dois materiais, em torno de $6.10^{-8} \mathrm{~m}^{3} \cdot \mathrm{m}^{-2} \cdot \mathrm{s}^{-1}$, mas não se mostram coerentes com as taxas estimadas com base nas umidades medidas, representadas na Tabela 9. Possivelmente, os valores da Tabela 9 não são muito confiáveis, como foi discutido anteriormente.

Os outros resultados se mostram bem distintos para o LV e o LE. Os valores de umidade no apêndice e as Figuras 8 a 19 mostram que não ocorreu uma variação de umidade com a distância no LV, enquanto nas unidades experimentais com o material do LE houve um decréscimo da umidade aproximando-se da placa porosa. Ao mesmo tempo, a zona influenciada foi muito maior no LV (valores comuns entre 5 e $10 \mathrm{~m}$ ) do que no LE (valores comuns entre 0 e 0,3 m). Explicam-se esses dois fatos pela grande diferença no valor da condutividade hidráulica entre os dois materiais, que pode ser conferida na Figura 7. No dia 19/10/93, por exemplo, após a drenagem do excesso de água, as umidades do LV e do LE estavam praticamente iguais, aproximadamente $0,25 \mathrm{~m}^{3} \cdot \mathrm{m}^{-3}$. Essa umidade corresponde a uma condutividade hidráulica da ordem de $10^{-7} \mathrm{~m}^{2} \cdot \mathrm{kPa}^{-1} \cdot \mathrm{s}^{-1}$ para o LV e $10^{-10} \mathrm{~m}^{2} \cdot \mathrm{kPa}^{-1} \cdot \mathrm{s}^{-1}, 1000$ vezes menor, para o LE. Conseqüentemente, para manter uma mesma densidade de fluxo de água, no LE precisava-se de um gradiente de potencial 1000 vezes maior que no LV. Como resultado, 
no LV variações mínimas de umidade causam densidades de fluxo de água consideráveis e o progresso de uma frente de secamento é muito mais rápido que no LE.

Os coeficientes de ajuste, em torno de zero para todas as regressões feitas com os valores de umidade obtidos no $\mathrm{LV}$, indicam que a umidade estimada através do modelo é, para esses casos, mais ou menos igual ao valor médio dessas umidades (confira equação (23)). Nesse caso, porém, os baixíssimos valores dos coeficientes de ajuste não indicam a rejeição do modelo. Como foi visto, a unidade experimental teve uma extensão muito pequena para esse material de condutividade hidráulica altíssima. Estava-se medindo apenas até $0,05 \mathrm{~m}$, menos do que $1 \%$ da zona influenciada estimada. Sendo assim, não se pode julgar a validade do modelo com base em apenas esse experimento com esse material. Como existe uma clara correlação entre a velocidade de avanço da zona de influência $\left(R_{t}\right)$ e a velocidade do avanço da frente de molhamento no experimento de infiltração horizontal (item 4.2.), poder-se-ia utilizar os resultados desse experimento como indicação sobre o tamanho necessário das unidades experimentais para um certo material de solo. Os resultados com o material do LE mostram coeficientes de ajuste bem maiores, principalmente no final do experimento, quando a variação de umidade com a distância ficou cada vez mais pronunciada.

As regressões mostraram apenas para alguns casos do LE o esperado decréscimo na taxa de evapotranspiração no final do experimento, registrado pela estimativa com base nas umidades medidas (Tabela 9).

Ao contrário do esperado, o potencial na raiz no final do experimento é muito menor no LE que no LV. Isto, mais provavelmente, deve-se a erros de determinação. Devido à forma da sua curva de retenção, um pequeno erro na determinação da umidade no $\mathrm{LV}$ resulta numa grande diferença em potencial mátrico. 
Tabela 10 - Transpiração $\left(T, 10^{-8} \mathrm{~m}^{3} \cdot \mathrm{m}^{-2} \cdot \mathrm{s}^{-1}\right)$, zona influenciada $\left(R_{t}, \mathrm{~m}\right)$, umidade do solo na zona não influenciada $\left(\theta_{\text {solo }}, \mathrm{m}^{3} \cdot \mathrm{m}^{-3}\right)$, potencial na raiz $\left(\psi_{\text {raiz }}, \mathrm{kPa}\right) \mathrm{e}$ coeficientes de ajuste (c.a.), para o material do solo $L V, 1^{\text {a }}$ repetição, a $0,04 \mathrm{~m}$ de profundidade, para as 9 datas de leitura.

\begin{tabular}{|c|c|c|c|c|c|c|c|c|c|c|}
\hline \multirow[b]{2}{*}{ data } & \multicolumn{5}{|c|}{ Iado A } & \multicolumn{5}{|c|}{ lado B } \\
\hline & $\bar{T}$ & $\overline{R_{t}}$ & $\bar{\theta}_{\text {solo }}$ & $\psi_{\text {raiz }}$ & c.a. & $T$ & $R_{t}$ & $\theta_{\text {solo }}$ & $\psi_{\text {raiz }}$ & c.a \\
\hline $18 / 10 / 93$ & 5,96 & 2,790 & 0,283 & $-4,6$ & 0,000 & 5,76 & 6,418 & 0,287 & $-4,5$ & - \\
\hline $19 /$ & 5,93 & 5,429 & 0,270 & $-5,1$ & 0,0 & 5,98 & 886 & 263 & $-5,2$ & 0,0 \\
\hline $20 / 10 / 93$ & 6,00 & 4,981 & 0,250 & $-5,9$ & 0,000 & 6,00 & 5,399 & 0,245 & $-6,1$ & 0,000 \\
\hline $21 / 1$ & 6,04 & 6,509 & 0,234 & $-6,9$ & 0,0 & 6,02 & 6,300 & 0,236 & $-6,7$ & 0,00 \\
\hline $22 / 1$ & 5,85 & 7,154 & 0,219 & $-8,3$ & -0, & 4,63 & 1,767 & 0,204 & $-7,9$ & $-0,0$ \\
\hline $24 /$ & 4,88 & 7,424 & 0,199 & $-11,7$ & & 05 & 8,808 & 0,209 & $-12,4$ & 0 \\
\hline $26 /$ & 6,05 & 9,030 & 0,205 & 0 & & 6,05 & 9,071 & 0,206 & 5,9 & 0,005 \\
\hline & 6,0 & 31 & 0,206 & $-18,0$ & & 6,51 & 11,098 & 0,215 & $-19,3$ & 0,01 \\
\hline $30 / 1$ & 6,05 & 19 & 0,206 & $-17,1$ & 0,012 & 6,05 & 9,143 & 0,205 & $-19,0$ & 0,00 \\
\hline
\end{tabular}

Tabela 11 - Transpiração $\left(T, 10^{-8} \mathrm{~m}^{3} \cdot \mathrm{m}^{-2} \cdot \mathrm{s}^{-1}\right)$, zona influenciada $\left(R_{t}, \mathrm{~m}\right)$, umidade do solo na zona não influenciada $\left(\theta_{\text {solo }}, \mathrm{m}^{3} \cdot \mathrm{m}^{-3}\right)$, potencial na raiz $\left(\psi_{\text {raiz }}, \mathrm{kPa}\right) \mathrm{e}$ coeficientes de ajuste (c.a.), para o material do solo $L V, 1^{\text {a }}$ repetição, a $0,05 \mathrm{~m}$ de profundidade, para as 9 datas de leitura.

\begin{tabular}{|c|c|c|c|c|c|c|c|c|c|c|}
\hline \multirow[b]{2}{*}{ dafa } & \multicolumn{5}{|c|}{ Iado A } & \multicolumn{5}{|c|}{ lado B } \\
\hline & $T$ & $R_{t}$ & $\boldsymbol{\theta}_{\text {solo }}$ & $\psi_{\text {raiz }}$ & c.a. & $T$ & $R_{t}$ & $\theta_{\text {solo }}$ & $\psi_{\text {raiz }}$ & c.a. \\
\hline $18 / 10 / 93$ & 5,91 & 3,724 & 0,277 & $-4,8$ & 0,000 & 5,75 & 6,694 & 0,289 & $-4,5$ & 0,000 \\
\hline 19/10/93 & 5,98 & 3,278 & 0,266 & $-5,2$ & 0,000 & 5,92 & 4,124 & 0,260 & $-5,4$ & 0,000 \\
\hline $20 / 10 / 93$ & 6,00 & 5,266 & 0,246 & $-6,0$ & 0,0 & 6,01 & 4,644 & 0,244 & $-6,1$ & 0,000 \\
\hline $21 / 1$ & 6,03 & 6,816 & 0,230 & $-7,2$ & 0,000 & 6,03 & 6,722 & 0,231 & $-7,1$ & 0,000 \\
\hline $22 / 10 / 93$ & 6,34 & 6,822 & 0,221 & $-8,1$ & 0,000 & 6,01 & 7,827 & 0,217 & $-8,5$ & $-0,002$ \\
\hline $24 / 10 / 93$ & 5,92 & 8,830 & 0,209 & $-12,2$ & 0,000 & 6,05 & 8,951 & 0,208 & $-13,6$ & 0,001 \\
\hline $26 / 10 / 93$ & 6,05 & 9,067 & 0,206 & $-16,5$ & 0,003 & 6,05 & 8,981 & 0,206 & $-15,8$ & $-0,001$ \\
\hline $28 / 10 / 93$ & 6,05 & 9,113 & 0,206 & $-16,3$ & 0,011 & 6,37 & 9,903 & 0,211 & $-17,5$ & 0,005 \\
\hline $30 / 10 / 93$ & 6,05 & 9,047 & 0,205 & $-18,5$ & $-0,016$ & 6,05 & 8,966 & 0,205 & $-18,4$ & $-0,002$ \\
\hline
\end{tabular}


Tabela 12 - Transpiração $\left(T, 10^{-8} \mathrm{~m}^{3} \cdot \mathrm{m}^{-2} \cdot \mathrm{s}^{-1}\right)$, zona influenciada $\left(R_{t}, \mathrm{~m}\right)$, umidade do solo na zona não influenciada $\left(\theta_{\text {solo }}, \mathrm{m}^{3} \cdot \mathrm{m}^{-3}\right)$, potencial na raiz $\left(\psi_{\text {raiz }}, \mathrm{kPa}\right) \mathrm{e}$ coeficientes de ajuste (c.a.), para o material do solo $\mathrm{LV}, 1^{\mathbf{a}}$ repetição, a $0,06 \mathrm{~m}$ de profundidade, para as 9 datas de leitura.

\begin{tabular}{|c|c|c|c|c|c|c|c|c|c|c|}
\hline \multirow[b]{2}{*}{ data } & \multicolumn{5}{|c|}{ lado A } & \multicolumn{5}{|c|}{ lado B } \\
\hline & $T$ & $\boldsymbol{R}_{t}$ & $\theta_{\text {solo }}$ & $\psi_{\text {raiz }}$ & $\overline{c . a}$ & $\bar{T}$ & $R R_{t}$ & $\theta_{\text {solo }}$ & $\psi_{\text {raiz }}$ & c.a. \\
\hline $18 / 10 / 93$ & 5,97 & 1,890 & 0,283 & $-4,6$ & 0,000 & 6,45 & 3,735 & 0,283 & $-4,6$ & 0,000 \\
\hline 19/10/93 & 5,79 & 5,125 & 0,262 & $-5,4$ & 0,000 & 6,44 & 7,364 & 0,263 & $-5,4$ & 0,001 \\
\hline $20 / 10 / 93$ & 5,98 & 4,945 & 0,253 & $-5,7$ & 0,000 & 6,01 & 4,342 & 0,247 & $-5,9$ & 0,000 \\
\hline 21/10/93 & 6,02 & 6,503 & 0,234 & $-6,8$ & $-0,001$ & 6,02 & 6,323 & 0,236 & $-6,7$ & 0,000 \\
\hline 22/10/93 & 6,06 & 7,710 & 0,223 & $-8,1$ & 0,003 & 5,31 & 2,811 & 0,204 & $-8,2$ & $-0,001$ \\
\hline $24 / 10 / 93$ & 6,04 & 8,689 & 0,210 & $-11,8$ & 0,003 & 6,40 & 9,122 & 0,213 & $-11,8$ & 0,002 \\
\hline $26 / 10 / 93$ & 6,05 & 9,037 & 0,205 & $-17,7$ & $-0,002$ & 6,05 & 9,050 & 0,206 & $-15,7$ & 0,002 \\
\hline 28 & 6,07 & 9,129 & 0,206 & $-17,9$ & 0,002 & 6,05 & 9,067 & 0,205 & $-17,6$ & 0,001 \\
\hline $30 / 10 / 93$ & 6,05 & 9,083 & 0,204 & $-20,0$ & $-0,001$ & 6,05 & 9,097 & 0,206 & $-17,3$ & 0,004 \\
\hline
\end{tabular}

Tabela 13 - Transpiração $\left(T, 10^{-8} \mathrm{~m}^{3} \cdot \mathrm{m}^{-2} \cdot \mathrm{s}^{-1}\right)$, zona influenciada $\left(R_{t}, \mathrm{~m}\right)$, umidade do solo na zona não influenciada $\left(\theta_{\text {solo }}, \mathrm{m}^{3} \cdot \mathrm{m}^{-3}\right)$, potencial na raiz $\left(\psi_{\text {raiz, }} \mathrm{kPa}\right) \mathrm{e}$ coeficientes de ajuste (c.a.), para o material do solo LV, $2^{\mathbf{a}}$ repetição, a $0,04 \mathrm{~m}$ de profundidade, para as 9 datas de leitura.

\begin{tabular}{|c|c|c|c|c|c|c|c|c|c|c|}
\hline \multirow[b]{2}{*}{ data } & \multicolumn{5}{|c|}{ lado A } & \multicolumn{5}{|c|}{ lado B } \\
\hline & 7 & $\boldsymbol{R}_{t}$ & $\bar{\theta}_{\text {solo }}$ & $\psi_{\text {raiz }}$ & c.a. & $T$ & $R_{t}$ & $\bar{\theta}_{\text {solo }}$ & $\psi_{\text {raiz }}$ & c.a. \\
\hline $18 / 10 / 93$ & 5,85 & 5,383 & 0,275 & $-4,9$ & 0,000 & 10,02 & 1,597 & 0,276 & $-4,8$ & 0,000 \\
\hline 19/10/9 & 6,06 & 3,479 & 0,253 & $-5,6$ & 0,000 & 6,07 & 4,325 & 0,256 & $-5,6$ & 0,000 \\
\hline $20 / 10 / 93$ & 6,01 & 5,934 & 0,240 & $-6,4$ & 0,000 & 6,02 & 5,254 & 0,245 & $-6,1$ & 0,001 \\
\hline $21 / 10 / 93$ & 6,02 & 6,574 & 0,233 & $-7,0$ & 0,000 & 6,09 & 6,046 & 0,232 & $-6,9$ & 0,001 \\
\hline $22 / 10 / 93$ & 6,46 & 6,608 & 0,222 & $-8,1$ & 0,001 & 6,04 & 7,486 & 0,222 & $-8,1$ & 0,001 \\
\hline $24 / 10 / 93$ & 6,05 & 8,830 & 0,209 & $-12,5$ & 0,003 & 6,17 & 8,621 & 0,209 & $-12,7$ & 0,002 \\
\hline $26 / 10 / 93$ & 6,05 & 9,066 & 0,206 & $-16,7$ & 0,003 & 6,05 & 9,059 & 0,206 & $-16,5$ & 0,003 \\
\hline $28 / 10 / 93$ & 6,05 & 9,182 & 0,206 & $-17,4$ & 0,008 & 6,05 & 9,059 & 0,205 & $-17,5$ & 0,001 \\
\hline $30 / 10 / 93$ & $6,8 \mathrm{~s}$ & 12,423 & 0,222 & $-18,0$ & 0,009 & 6,05 & 9,088 & 0,206 & $-16,8$ & 0,003 \\
\hline
\end{tabular}


Tabela 14 - Transpiração $\left(T, 10^{-8} \mathrm{~m}^{3} \cdot \mathrm{m}^{-2} \cdot \mathrm{s}^{-1}\right)$, zona influenciada $\left(R_{t}, \mathrm{~m}\right)$, umidade do solo na zona não influenciada $\left(\theta_{\text {solo }}, \mathrm{m}^{3} \cdot \mathrm{m}^{-3}\right)$, potencial na raiz $\left(\psi_{\text {raiz }}, \mathrm{kPa}\right) \mathrm{e}$ coeficientes de ajuste (c.a.), para o material do solo $L V, 2^{\mathbf{a}}$ repetição, a $0,05 \mathrm{~m}$ de profundidade, para as 9 datas de leitura.

\begin{tabular}{|c|c|c|c|c|c|c|c|c|c|c|}
\hline \multirow[b]{2}{*}{ data } & \multicolumn{5}{|c|}{ lado A } & \multicolumn{5}{|c|}{ lado B } \\
\hline & $T$ & $R_{t}$ & $\boldsymbol{\theta}_{\text {solo }}$ & $\psi_{\text {raiz }}$ & c.a. & $T$ & $R_{t}$ & $\boldsymbol{\theta}_{\text {solo }}$ & $\psi_{\text {raiz }}$ & c.a. \\
\hline $18 / 10 / 93$ & 5,98 & 2,695 & 0,275 & $-4,8$ & 0,000 & 5,97 & 2,668 & 0,275 & $-4,8$ & 0,000 \\
\hline 19/10/93 & 5,38 & 5,228 & 0,264 & $-5,3$ & 0,0 & 5,99 & 4,503 & 0,260 & $-5,4$ & 0,000 \\
\hline $20 / 10 / 93$ & 6,00 & 5,285 & 0,248 & $-6,0$ & 0,000 & 6,01 & 4,139 & 0,253 & $-5,7$ & 0,000 \\
\hline $21 / 10 / 93$ & 5,99 & 6,474 & 0,236 & $-6,7$ & 0,001 & 9,64 & 7,173 & 0,245 & $-6,7$ & 0,003 \\
\hline $22 / 10 / 93$ & 6,11 & 7,203 & 0,225 & $-7,7$ & 0,002 & 6,35 & 6,609 & 0,220 & $-8,2$ & 0,001 \\
\hline $24 / 10 / 93$ & 6,30 & 8,178 & 0,209 & $-11,8$ & 0,007 & 6,04 & 8,718 & 0,209 & $-12,1$ & 0,000 \\
\hline $26 / 10 / 93$ & 6,05 & 9,059 & 0,206 & $-15,8$ & 0,005 & 6,05 & 9,089 & 0,207 & $-15,0$ & 0,008 \\
\hline $28 / 10 / 93$ & 6,05 & 9,049 & 0,206 & $-16,4$ & 0,003 & 6,05 & 9,170 & 0,206 & $-16,6$ & 0,010 \\
\hline $30 / 10 / 93$ & 6,05 & 9,046 & 0,207 & $-15,5$ & 0,016 & 6,05 & 9,038 & 0,206 & $-16,1$ & 0,002 \\
\hline
\end{tabular}

Tabela 15 - Transpiração $\left(T, 10^{-8} \mathrm{~m}^{3} \cdot \mathrm{m}^{-2} \cdot \mathrm{s}^{-1}\right)$, zona influenciada $\left(R_{t}, \mathrm{~m}\right)$, umidade do solo na zona não influenciada $\left(\theta_{\text {solo }}, \mathrm{m}^{3} \cdot \mathrm{m}^{-3}\right)$, potencial na raiz $\left(\psi_{\text {raiz }}, \mathrm{kPa}\right) \mathrm{e}$ coeficientes de ajuste (c.a.), para o material do solo $\mathrm{LV}, 2^{\mathrm{a}}$ repetição, a $0,06 \mathrm{~m}$ de profundidade, para as 9 datas de leitura.

\begin{tabular}{|c|c|c|c|c|c|c|c|c|c|c|}
\hline \multirow[b]{2}{*}{ data } & \multicolumn{5}{|c|}{ lado A } & \multicolumn{5}{|c|}{ lado B } \\
\hline & $T$ & $R_{t}$ & $\bar{\theta}_{\text {solo }}$ & $\psi_{\text {raiz }}$ & c.a. & $\bar{T}$ & $R_{t}$ & $\theta_{\text {solo }}$ & $\psi_{\text {raiz }}$ & c.a. \\
\hline $18 / 10 / 93$ & 5,56 & 5,504 & 0,286 & $-4,6$ & 0,000 & 6,01 & 2,564 & 0,271 & $-5,0$ & 0,000 \\
\hline 19/10/93 & 5,90 & 4,793 & 0,259 & $-5,5$ & 0,000 & 5,93 & 3,995 & 0,258 & 5,4 & 0,000 \\
\hline $20 / 10 / 93$ & 6,00 & 5,280 & 0,247 & $-6,0$ & 0,000 & 6,01 & 5,163 & 0,244 & $-6,2$ & 0,001 \\
\hline $21 / 10 / 93$ & 7,90 & 7,029 & 0,244 & $-6,5$ & 0,001 & 6,25 & 6,823 & 0,240 & $-6,5$ & 0,000 \\
\hline $22 / 10 / 93$ & 6,33 & 7,295 & 0,222 & $-8,2$ & 0,001 & 4,26 & 7,679 & 0,213 & $-8,4$ & 0,000 \\
\hline $24 / 10 / 93$ & 6,04 & 8,647 & 0,210 & $-11,8$ & $-0,003$ & 6,20 & 8,825 & 0,210 & $-12,2$ & 0,002 \\
\hline $26 / 10 / 93$ & 6,05 & 9,105 & 0,207 & $-15,8$ & 0,011 & 6,05 & 8,994 & 0,206 & $-16,2$ & $-0,003$ \\
\hline $28 / 10 / 93$ & 6,05 & 9,040 & 0,206 & $-16,7$ & 0,004 & 6,05 & 9,008 & 0,206 & $-15,6$ & 0,002 \\
\hline $30 / 10 / 93$ & 6,05 & 9,059 & 0,206 & $-16,7$ & 0,004 & 6,05 & 9,028 & 0,206 & $-16,5$ & 0,002 \\
\hline
\end{tabular}


Tabela 16 - Transpiração $\left(T, 10^{-8} \mathrm{~m}^{3} \cdot \mathrm{m}^{-2} \cdot \mathrm{s}^{-1}\right)$, zona influenciada $\left(R_{t}, \mathrm{~m}\right)$, umidade do solo na zona não influenciada $\left(\theta_{\text {solo }}, \mathrm{m}^{3} \cdot \mathrm{m}^{-3}\right)$, potencial na raiz $\left(\psi_{\text {raiz }}, \mathrm{kPa}\right)$ e coeficientes de ajuste (c.a.), para o material do solo LE, $1^{\text {a }}$ repetição, a $0,04 \mathrm{~m}$ de profundidade, para as 9 datas de leitura.

\begin{tabular}{|c|c|c|c|c|c|c|c|c|c|c|}
\hline \multirow[b]{2}{*}{ data } & \multicolumn{5}{|c|}{ lado A } & \multicolumn{5}{|c|}{ lado B } \\
\hline & $T$ & $R_{t}$ & $\boldsymbol{\theta}_{\text {solo }}$ & $\psi_{\text {raiz }}$ & c.a. & $T$ & $R_{t}$ & $\theta_{\text {solo }}$ & $\psi_{\text {raiz }}$ & c.a. \\
\hline $18 / 10 / 93$ & 5,91 & 0,009 & 0,244 & $-26,6$ & 0,004 & 2,55 & 0,027 & 0,242 & $-28,3$ & $-0,006$ \\
\hline 19/10/93 & 5,30 & 0,024 & 0,216 & $-60,3$ & 0,2 & 4,80 & 0,027 & 0,217 & $-58,5$ & 0,113 \\
\hline $20 / 10 / 93$ & 5,98 & 0,090 & 0,248 & $-63,9$ & 0,2 & 6,06 & 0,100 & 0,248 & $-86,7$ & 31 \\
\hline $21 /$ & 4,04 & 0,081 & 0,230 & $-75,9$ & 0,2 & 6,00 & 14 & 250 & 112,5 & 04 \\
\hline 22 & 5,11 & 0,118 & 0,245 & $-110,1$ & 0,365 & 5,18 & 0,123 & 0,245 & $-148,0$ & 0,392 \\
\hline $24 /$ & 5,16 & 0,134 & 0,247 & $-214,6$ & 0,430 & 4,32 & 0,148 & 0,243 & $-235,7$ & 0,406 \\
\hline $1 / 93$ & 4,80 & 0,146 & 0,245 & $-358,7$ & 0,500 & 5,76 & 0,155 & 0,253 & -4516 & 0,666 \\
\hline 28 & 6,00 & 0,145 & 0,254 & $-555,3$ & 0,598 & 5,61 & 0,156 & 0,253 & -1225 & 0,602 \\
\hline $30 / 10 / 93$ & 4,83 & 0,140 & 0,242 & $-522,3$ & 0,600 & 4,07 & 0,141 & 0,233 & $-940,5$ & 0,560 \\
\hline
\end{tabular}

Tabela 17 - Transpiração $\left(T, 10^{-8} \mathrm{~m}^{3} \cdot \mathrm{m}^{-2} \cdot \mathrm{s}^{-1}\right)$, zona influenciada $\left(R_{t}, \mathrm{~m}\right)$, umidade do solo na zona não influenciada $\left(\theta_{\text {solo }}, \mathrm{m}^{3} \cdot \mathrm{m}^{-3}\right)$, potencial na raiz $\left(\psi_{\text {raiz }}, \mathrm{kPa}\right) \mathrm{e}$ coeficientes de ajuste (c.a.), para o material do solo $L E, 1^{\underline{a}}$ repetição, a $0,05 \mathrm{~m}$ de profundidade, para as 9 datas de leitura.

\begin{tabular}{|c|c|c|c|c|c|c|c|c|c|c|}
\hline \multirow[b]{2}{*}{ data } & \multicolumn{5}{|c|}{ lado A } & \multicolumn{5}{|c|}{ lado B } \\
\hline & $T$ & $\overline{R_{t}}$ & $\boldsymbol{\theta}_{\text {solo }}$ & $\psi_{\text {raiz }}$ & c.a. & $\bar{T}$ & $\overline{R_{t}}$ & $\theta_{\text {solo }}$ & $\psi_{\text {raiz }}$ & c.a. \\
\hline $18 / 10 / 93$ & 5,97 & 0,039 & 0,248 & $-30,7$ & $-0,086$ & 3,94 & 0,022 & 0,240 & $-30,0$ & 0,016 \\
\hline$/ 10 / 93$ & 5,47 & 0,033 & 0,226 & $-51,7$ & 0,1 & 79 & 0,091 & 0,248 & $-60,1$ & 0,235 \\
\hline 20 & 7,05 & 0,155 & 0,275 & $-60,2$ & 0,3 & 4,28 & 0,049 & 0,225 & $-58,7$ & 0,166 \\
\hline 21/10/93 & 5,37 & 0,041 & 0,217 & $-86,1$ & 0,342 & 6,30 & 0,089 & 0,244 & $-91,7$ & 0,381 \\
\hline $22 / 10 / 93$ & 5,56 & 0,047 & 0,215 & $-125,5$ & 0,392 & 4,36 & 0,126 & 0,245 & $-87,1$ & 0,212 \\
\hline $24 / 10 / 93$ & 3,85 & 0,133 & 0,236 & $-167,8$ & 0,323 & 5,32 & 0,134 & 0,248 & $-230,1$ & 0,515 \\
\hline $26 / 10 / 93$ & 6,16 & 0,146 & 0,255 & $-843,9$ & 0,710 & 5,97 & 0,154 & 0,256 & $-629,3$ & 0,603 \\
\hline $28 /$ & 5,57 & 0,153 & 0,25 & -387 & 0,544 & 6,17 & 0,150 & 0,256 & $-800,7$ & 0,650 \\
\hline 30/10/93 & 7,21 & 0,167 & 0,269 & $-859,3$ & 0,649 & 6,26 & 0,142 & 0,254 & $-797,3$ & 0,589 \\
\hline
\end{tabular}


Tabela 18 - Transpiração $\left(T, 10^{-8} \mathrm{~m}^{3} \cdot \mathrm{m}^{-2} \cdot \mathrm{s}^{-1}\right)$, zona influenciada $\left(R_{t}, \mathrm{~m}\right)$, umidade do solo na zona não influenciada $\left(\theta_{\text {solo }}, \mathrm{m}^{3} \cdot \mathrm{m}^{-3}\right)$, potencial na raiz $\left(\psi_{\text {raiz }}, \mathrm{kPa}\right) \mathrm{e}$ coeficientes de ajuste (c.a.), para o material do solo $L E, 1 \underline{\underline{a}}$ repetição, a $0,06 \mathrm{~m}$ de profundidade, para as 9 datas de leitura.

\begin{tabular}{|c|c|c|c|c|c|c|c|c|c|c|}
\hline \multirow[b]{2}{*}{ data } & \multicolumn{5}{|c|}{ Iado A } & \multicolumn{5}{|c|}{ lado B } \\
\hline & $\bar{T}$ & $R_{t}$ & $\bar{\theta}_{\text {solo }}$ & $\psi_{\text {raiz }}$ & c.a. & $T$ & $R_{t}$ & $\theta_{\text {solo }}$ & $\psi_{\text {raiz }}$ & - \\
\hline $18 / 10 / 93$ & 4,79 & 0,022 & 0,248 & $-26,0$ & 0,003 & 13 &, 009 & 0,245 & $-26,1$ & 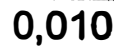 \\
\hline & 5,32 & 029 &, 2 & $-49,0$ & & & & 24 & 1,2 & \\
\hline & 8,17 & 1 & 3 & & & & & & & \\
\hline & 6 , & & 0,250 & -6 & & & & 28 & $-74,1$ & \\
\hline & 7, & 5 & 0,256 & $-132,3$ & & 0 & & 0,250 & 3,4 & \\
\hline 24 & 8,0 & 0,144 & 0,269 & $-388,7$ & 0 , & 5,26 & 0,120 & 0,250 & 7,7 & 0,53 \\
\hline & 5,61 & 5 & 0,2 & -41 & & 36 & 39 & 0,252 & 4,7 & 0,57 \\
\hline $28 /$ & 5 & 12 & 0,253 & -41 & 0,5 & 6,28 & 0,155 & 0,259 & $-900,2$ & 0,63 \\
\hline $30 / 10 / 93$ & 6,02 & 0,130 & 0,251 & $-317,2$ & 0,590 & 5,48 & 0,138 & 0,248 & $-449,7$ & 0,5 \\
\hline
\end{tabular}

Tabela 19 - Transpiração $\left(T, 10^{-8} \mathrm{~m}^{3} \cdot \mathrm{m}^{-2} \cdot \mathrm{s}^{-1}\right)$, zona influenciada $\left(R_{t}, \mathrm{~m}\right)$, umidade do solo na zona -não influenciada $\left(\theta_{\text {solo }}, \mathrm{m}^{3} \cdot \mathrm{m}^{-3}\right)$, potencial na raiz $\left(\psi_{\text {raiz }}, \mathrm{kPa}\right) \mathrm{e}$ coeficientes de ajuste (c.a.), para o material do solo LE, $2^{-\mathbf{a}}$ repetição, a $0,04 \mathrm{~m}$ de profundidade, para as 9 datas de leitura.

\begin{tabular}{|c|c|c|c|c|c|c|c|c|c|c|}
\hline \multirow[b]{2}{*}{ data } & \multicolumn{5}{|c|}{ Iado A } & \multicolumn{5}{|c|}{ lado B } \\
\hline & $\bar{T}$ & $\overline{R_{t}}$ & $\overline{\theta_{\text {solo }}}$ & $\psi_{\text {raiz }}$ & c.a. & $T$ & $R_{t}$ & $\boldsymbol{\theta}_{\text {solo }}$ & $\psi_{\text {raiz }}$ & c.a. \\
\hline $18 / 10 / 93$ & 5,19 & $-0,002$ & 0,258 & $-20,3$ & $-0,005$ & 6,84 & $-0,018$ & 0,259 & $-19,8$ & $-0,137$ \\
\hline 19/10/93 & 8,51 & 0,256 & 0,308 & $-50,0$ & 0,387 & 6,00 & 0,065 & 0,250 & $-38,7$ & 0,184 \\
\hline $20 / 10 / 93$ & 8,55 & 0,262 & 0,308 & $-59,9$ & 0,427 & 8,30 & 0,528 & 0,341 & $-65,2$ & 0,518 \\
\hline $21 / 10 / 93$ & 8,65 & 0,197 & 0,292 & $-91,9$ & 0,580 & 6,82 & 0,190 & 0,281 & $-69,1$ & 0,385 \\
\hline $22 / 10 / 93$ & 7,18 & 0,116 & 0,259 & $-109,3$ & 0,421 & 6,05 & 0,110 & 0,253 & $-76,5$ & 0,396 \\
\hline 24/10/93 & 8,49 & 0,325 & 0,314 & $-257,8$ & 0,664 & 8,88 & 0,372 & 0,324 & $-295,0$ & 0,744 \\
\hline 26/10/93 & 6,18 & 0,142 & 0,255 & $-495,4$ & 0,570 & 5,96 & 0,147 & 0,255 & $-424,6$ & 0,547 \\
\hline $28 / 10 / 93$ & 8,96 & 0,107 & 0,257 & -1049 & 0,790 & 6,67 & 0,158 & 0,264 & $-413,4$ & 0,581 \\
\hline $30 / 10 / 93$ & 6,05 & 0,137 & 0,251 & $-584,2$ & 0,671 & 5,76 & 0,112 & 0,241 & $-377,1$ & 0,606 \\
\hline
\end{tabular}


Tabela 20 - Transpiração $\left(T, 10^{-8} \mathrm{~m}^{3} \cdot \mathrm{m}^{-2} \cdot \mathrm{s}^{-1}\right)$, zona influenciada $\left(R_{t}, \mathrm{~m}\right)$, umidade do solo na zona não influenciada $\left(\theta_{\text {solo }}, \mathrm{m}^{3} \cdot \mathrm{m}^{-3}\right)$, potencial na raiz $\left(\psi_{\text {raiz }}, \mathrm{kPa}\right) \mathrm{e}$ coeficientes de ajuste (c.a.), para o material do solo LE, $2^{\mathbf{a}}$ repetição, a $0,05 \mathrm{~m}$ de profundidade, para as 9 datas de leitura.

\begin{tabular}{|c|c|c|c|c|c|c|c|c|c|c|}
\hline \multirow[b]{2}{*}{ data } & \multicolumn{5}{|c|}{ lado A } & \multicolumn{5}{|c|}{ lado B } \\
\hline & $T$ & $R_{t}$ & $\boldsymbol{\theta}_{\text {solo }}$ & $\psi_{\text {raiz }}$ & c.a. & $T$ & $R_{t}$ & $\theta_{\text {solo }}$ & $\psi_{\text {raiz }}$ & c.a. \\
\hline $18 / 10 / 93$ & 5,99 & 0,002 & 0,260 & $-19,7$ & 0,002 & 6,69 & $-0,002$ & 0,258 & $-20,2$ & $-0,067$ \\
\hline /93 & 6,00 & 0,070 & 0,250 & $-40,2$ & 0,2 & 6,99 & 0,139 & 0,275 & $-43,6$ & 0,284 \\
\hline $20 /$ & 7,76 & 0,140 & 0,276 & $-56,6$ & 0,3 & 7,38 & 0,198 & 0,290 & $-50,7$ & 0,330 \\
\hline $21 / 10 / 93$ & 7,01 & 0,198 & 0,284 & $-69,8$ & 0,431 & 5,82 & 0,103 & 0,250 & $-71,3$ & 0,224 \\
\hline $22 / 10 / 93$ & 8,03 & 0,174 & 0,282 & $-106,1$ & 0,488 & 10,18 & 0,305 & 0,322 & $-112,3$ & 0,584 \\
\hline $24 / 10 / 93$ & 6,35 & 0,125 & 0,253 & $-185,8$ & 0,567 & 8,22 & 0,142 & 0,271 & $-203,5$ & 0,576 \\
\hline $26 / 10 / 93$ & 6,93 & 0,145 & 0,261 & $-606,8$ & 0,668 & 7,75 & 0,242 & 0,293 & $-372,7$ & 0,662 \\
\hline $28 / 10 / 93$ & 6,94 & 0,170 & 0,268 & $-793,9$ & 0,664 & 6,31 & 0,135 & 0,255 & $-303,3$ & 0,573 \\
\hline $30 / 10 / 93$ & 6,83 & 0,144 & 0,260 & $-468,4$ & 0,656 & 6,93 & 0,122 & 0,253 & $-496,1$ & 0,679 \\
\hline
\end{tabular}

Tabela 21 - Transpiração $\left(T, 10^{-8} \mathrm{~m}^{3} \cdot \mathrm{m}^{-2} \cdot \mathrm{s}^{-1}\right)$, zona influenciada $\left(R_{t}, \mathrm{~m}\right)$, umidade do solo na zona não influenciada $\left(\theta_{\text {solo }}, \mathrm{m}^{3} \cdot \mathrm{m}^{-3}\right)$, potencial na raiz $\left(\psi_{\text {raiz }}, \mathrm{kPa}\right)$ e coeficientes de ajuste (c.a.), para o material do solo LE, $2^{\underline{\mathbf{a}}}$ repetição, a $0,06 \mathrm{~m}$ de profundidade, para as 9 datas de leitura.

\begin{tabular}{|c|c|c|c|c|c|c|c|c|c|c|}
\hline \multirow[b]{2}{*}{ data } & \multicolumn{5}{|c|}{ Iado A } & \multicolumn{5}{|c|}{ lado B } \\
\hline & $\bar{T}$ & $R_{t}$ & $\overline{\theta_{\text {solo }}}$ & $\psi_{\text {raiz }}$ & c.a. & $T$ & $R_{t}$ & $\boldsymbol{\theta}_{\text {solo }}$ & $\psi_{\text {raiz }}$ & c.a. \\
\hline $18 / 10 / 93$ & 6,01 & 0,007 & 0,264 & $-18,9$ & 0,007 & 5,88 & 0,040 & 0,259 & $-24,3$ & 0,081 \\
\hline 19/10/93 & 5,43 & 0,100 & 0,255 & $-45,5$ & 0,189 & 6,00 & 0,075 & 0,250 & $-43,8$ & 0,205 \\
\hline $20 / 10 / 93$ & 7,14 & 0,149 & 0,274 & $-62,1$ & 0,353 & 6,01 & 0,087 & 0,251 & $-52,0$ & 0,311 \\
\hline $21 / 10 / 93$ & 8,48 & 0,253 & 0,304 & $-83,0$ & 0,410 & 6,09 & 0,102 & 0,254 & $-61,4$ & 0,306 \\
\hline $22 /$ & 6,00 & 0,106 & 0,250 & $-86,5$ & 0,4 & 8,22 & 0,131 & 0,270 & $-105,3$ & 0,563 \\
\hline $24 / 1$ & 6,72 & 0,104 & 0,249 & $-153,9$ & 0,550 & 6,25 & 0,117 & 0,252 & $-129,2$ & 0,497 \\
\hline $26 / 10 / 93$ & 6,28 & 0,136 & 0,253 & $-481,1$ & 0,611 & 7,32 & 0,161 & 0,269 & $-534,3$ & 0,699 \\
\hline $28 / 10 / 93$ & 7,41 & 0,145 & 0,264 & $-566,5$ & 0,640 & 5,54 & 0,136 & 0,248 & $-401,7$ & 0,538 \\
\hline $30 / 10 / 93$ & 6,00 & 0,138 & 0,253 & $-339,3$ & 0,535 & 6,69 & 0,131 & 0,256 & $-330,3$ & 0,559 \\
\hline
\end{tabular}


Tabela 22 - Médias da transpiração $\left(T, 10^{-8} \mathrm{~m}^{3} \cdot \mathrm{m}^{-2} \cdot \mathrm{s}^{-1}\right)$, da zona influenciada $\left(R_{t}, \mathrm{~m}\right)$, da umidade do solo na zona não influenciada $\left(\theta_{\text {solo }}, \mathrm{m}^{3} \cdot \mathrm{m}^{-3}\right)$ e do potencial na raiz $\left(\psi_{\text {raiz }}, \mathrm{kPa}\right)$, bem como os respectivos coeficientes de variação (c.v., $\%$ ), para o material do solo LV para as 9 datas de leitura.

\begin{tabular}{|c|c|c|c|c|c|c|c|c|}
\hline \multirow[b]{2}{*}{ data } & \multicolumn{2}{|c|}{$T$} & \multicolumn{2}{|l|}{$R_{t}$} & \multicolumn{2}{|c|}{$\theta_{\text {solo }}$} & \multicolumn{2}{|c|}{$\psi_{\text {raiz }}$} \\
\hline & média & c.v. & média & c.v. & média & C.v. & média & c.v. \\
\hline $18 / 10 / 93$ & 6,27 & 19,2 & 3,805 & 46,3 & 0,280 & 2,1 & $-4,7$ & $\overline{3,4}$ \\
\hline 19/10/93 & 5,95 & 4 & 4,544 & 26 & 261 & & -5 & 2,9 \\
\hline $20 /$ & 6,00 & 0 & $-5,053$ & 9,7 & 247 & 1, & $-6,0$ & 3,3 \\
\hline $21 / 1$ & 6,50 & 17,3 & 6,608 & 4,9 & 0,236 & 2 & $-6,8$ & 3,2 \\
\hline $22 / 1$ & 5,81 & 12,2 & 6,414 & 30,9 & 0,218 & 3,3 & $-8,2$ & 3,5 \\
\hline $24 / 10 / 93$ & 6,01 & 6 & 8,637 & 5,1 & 0,209 & 1,6 & $-12,2$ & 4,4 \\
\hline $26 / 10 / 93$ & 6,05 & 0,0 & 9,051 & 0,4 & 0,206 & 0,3 & $-16,2$ & 4,4 \\
\hline $28 / 10 / 93$ & 6,12 & 2,5 & 9,337 & 6,5 & 0,207 & 1,4 & $-17,2$ & 5,7 \\
\hline $30 / 10 / 93$ & 6,12 & 4,0 & 9,353 & 10,4 & 0,207 & 2,3 & $-17,5$ & 7,5 \\
\hline
\end{tabular}

Tabela 23 - Médias da transpiração $\left(T, 10^{-8} \mathrm{~m}^{3} \cdot \mathrm{m}^{-2} \cdot \mathrm{s}^{-1}\right)$, da zona influenciada $\left(R_{t}, \mathrm{~m}\right)$, da umidade do solo na zona não influenciada $\left(\theta_{\text {solo }}, \mathrm{m}^{3} \cdot \mathrm{m}^{-3}\right)$ e do potencial na raiz $\left(\psi_{\text {raiz }}, \mathrm{kPa}\right)$, bem como os respectivos coeficientes de variação (c.v., \%), para o material do solo LE para as 9 datas de leitura.

\begin{tabular}{|c|c|c|c|c|c|c|c|c|}
\hline \multirow[b]{2}{*}{ data } & \multicolumn{2}{|l|}{$I$} & \multicolumn{2}{|c|}{$R_{t}$} & \multicolumn{2}{|c|}{$\theta_{\text {solo }}$} & \multicolumn{2}{|c|}{$\psi_{\text {raiz }}$} \\
\hline & média & c.v. & média & c.v. & média & c.v. & Tédia & c.v. \\
\hline $18 / 10 / 93$ & 5,49 & 22,2 & 0,013 & 135,4 & 0,252 & 3 , & $-24,2$ & 17,8 \\
\hline 19/10/93 & 1 & 16,7 & 0,078 & & 0,245 & 10 & $-49,4$ & 15,0 \\
\hline & & 21 & & & 272 & & $-62,3$ & 14,9 \\
\hline 21 & 6,18 & 24 & 9 & 49 & 257 & 10 & $-79,6$ & 17,8 \\
\hline 22 & 6,57 & 24 & 32 & 46 & 0,258 & 10,0 & $-109,8$ & 18,4 \\
\hline 24/ & 6,49 & 25,5 & 0,167 & 51,9 & 0,263 & 10,6 & $-221,7$ & 31,4 \\
\hline $26 / 10 / 93$ & 6,22 & 12 , & 0,156 & 18,1 & 0,259 & 4,7 & $-838,5$ & 139,1 \\
\hline $28 / 10 / \mathrm{s}$ & 6,45 & 15, & 0,146 & 10,8 & 0,257 & 2,2 & $-651,2$ & 45,7 \\
\hline $30 / 10 / 93$ & 6,01 & 15,0 & 0,137 & 9,7 & 0,251 & 3,7 & $-540,1$ & 39,7 \\
\hline
\end{tabular}




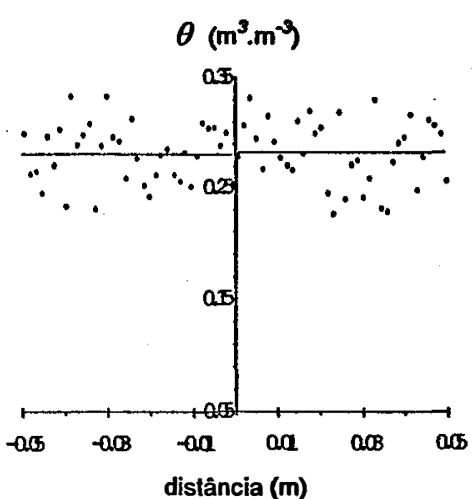

$18 / 10 / 93$

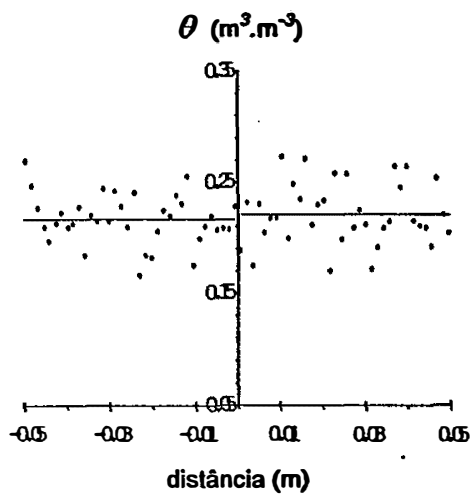

$21 / 10 / 93$

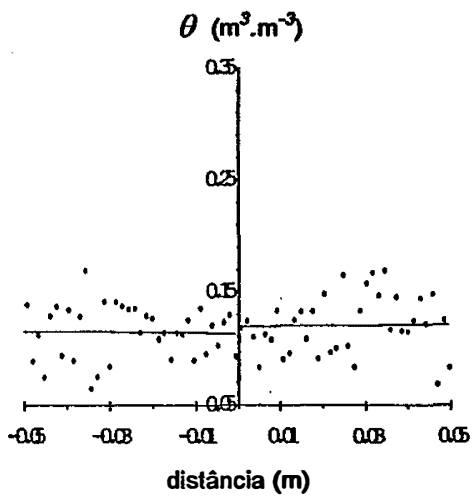

26/10/93

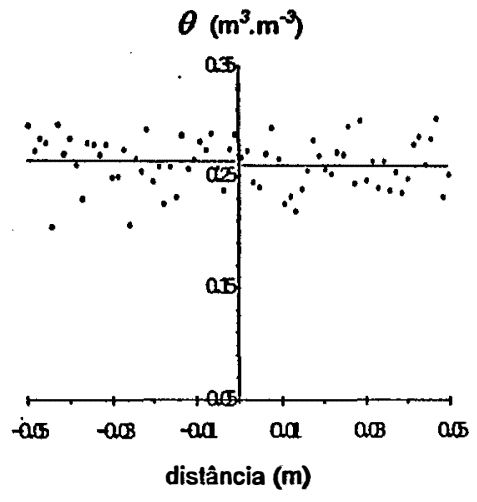

19/10/93

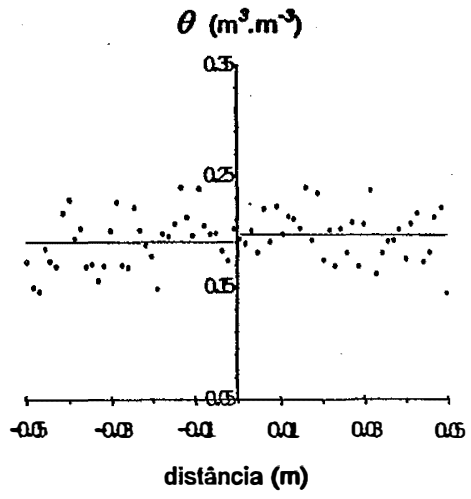

$22 / 10 / 93$

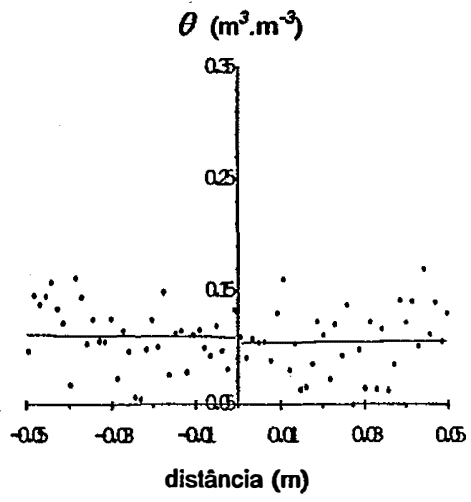

28/10/93

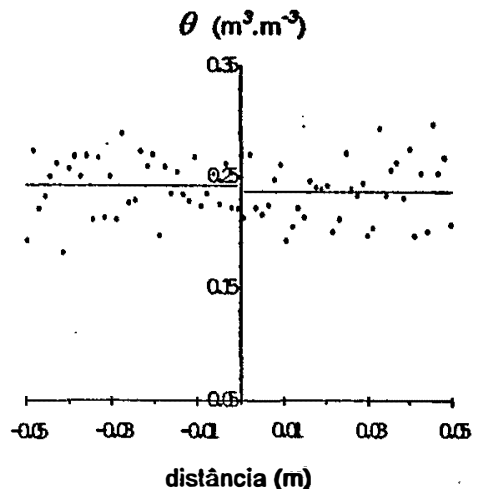

$20 / 10 / 93$

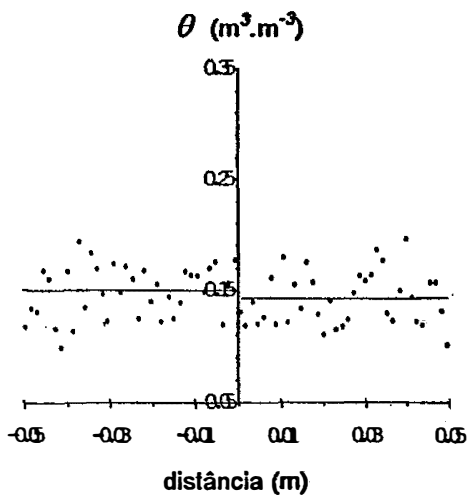

$24 / 10 / 93$

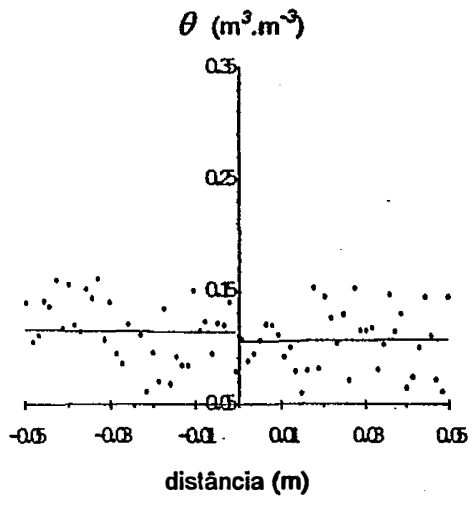

$30 / 10 / 93$

Figura 8 - Umidades volumétricas $\left(\mathrm{m}^{3} \cdot \mathrm{m}^{-3}\right)$ em função da distância (m) da placa porosa, medidas (pontos) e calculadas através de regressão (linhas) para o material do solo $\mathrm{LV}, 1^{\underline{a}}$ repetição, a $0,04 \mathrm{~m}$ de profundidade, para as 9 datas de leitura. Valores negativos para a distância indicam o lado A, valores positivos o lado B. 


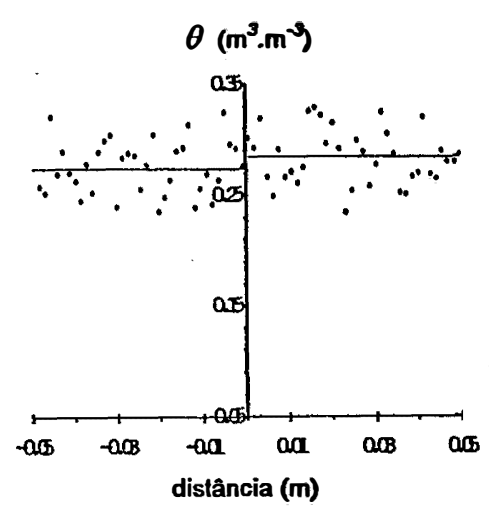

18/10/93

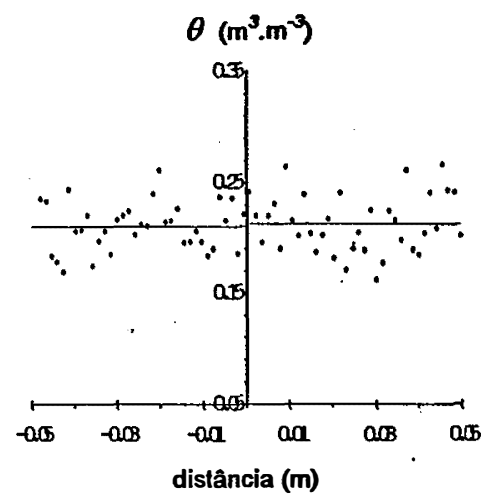

$21 / 10 / 93$

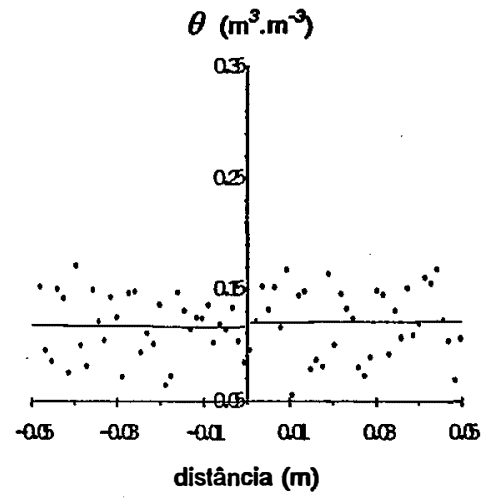

26/10/93
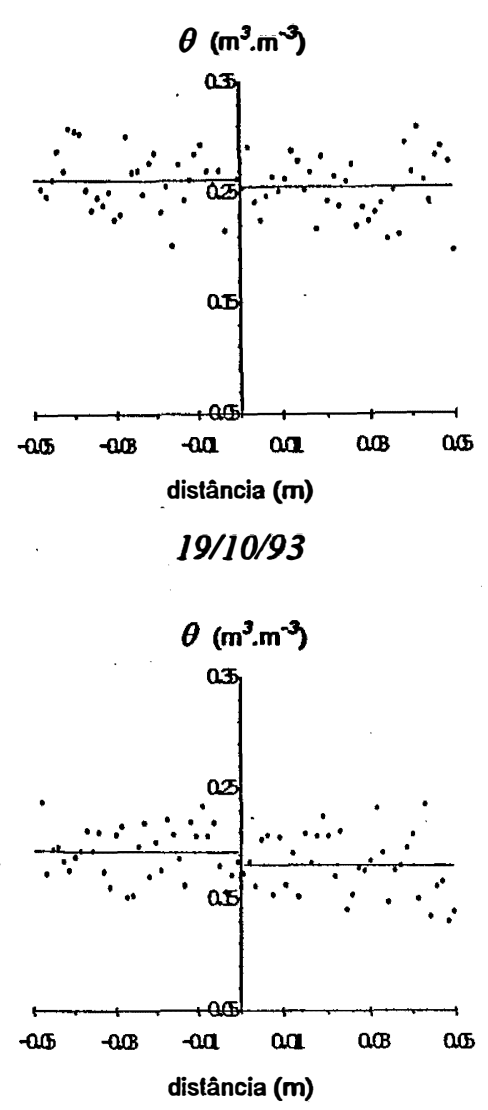

$22 / 10 / 93$

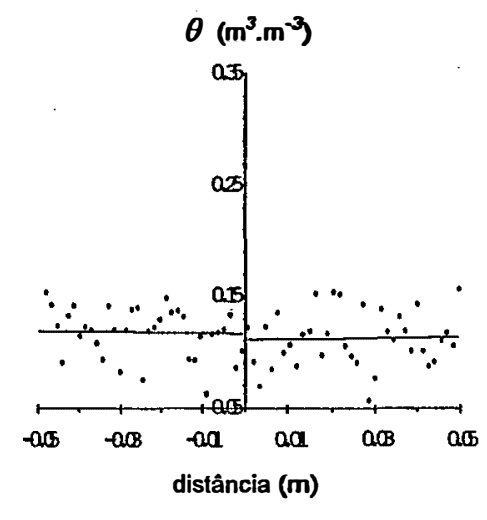

28/10/93
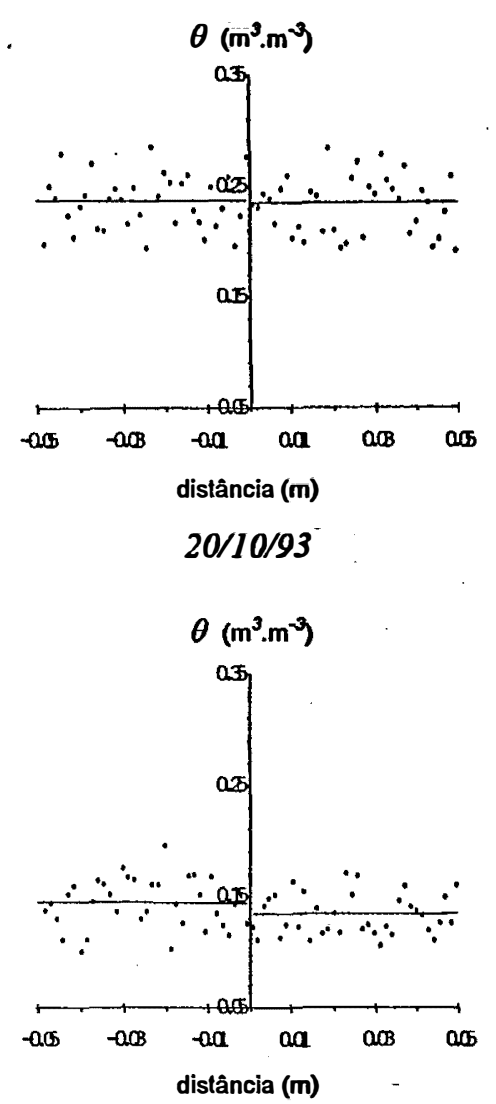

$24 / 10 / 93$

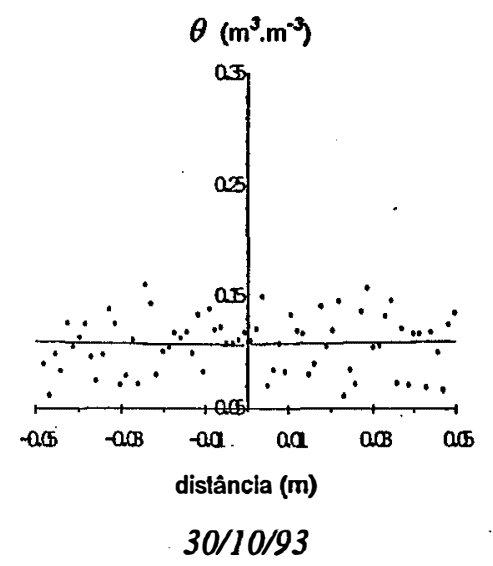

Figura 9 - Umidades volumétricas $\left(\mathrm{m}^{3} \cdot \mathrm{m}^{-3}\right)$ em função da distância (m) da placa porosa, medidas (pontos) e calculadas através de regressão (linhas) para o material do solo $\mathrm{LV}, 1^{\underline{a}}$ repetição, a $0,05 \mathrm{~m}$ de profundidade, para as 9 datas de leitura. Valores negativos para a distância indicam o lado $\mathrm{A}$, valores positivos $\mathrm{o}$ lado B. 


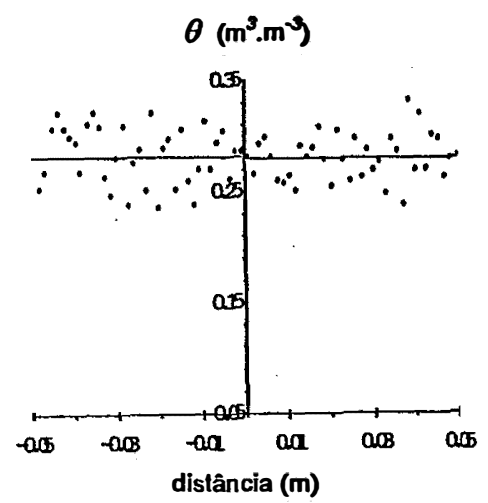

$18 / 10 / 93$

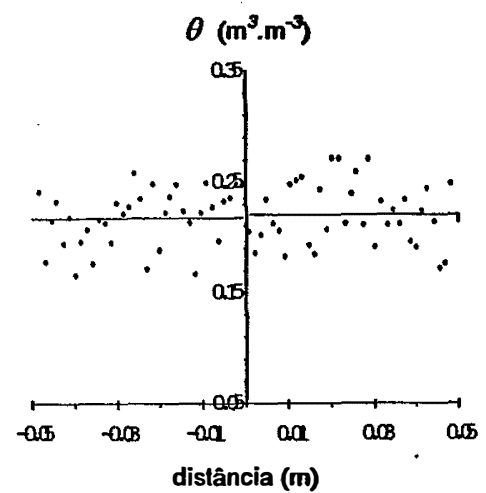

21/10/93

$\theta\left(m^{3} \cdot m^{-3}\right)$

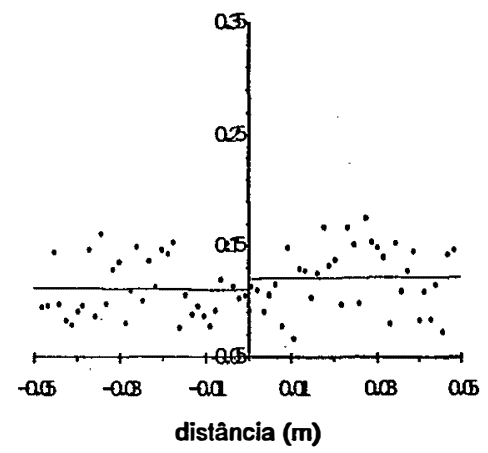

26/10/93

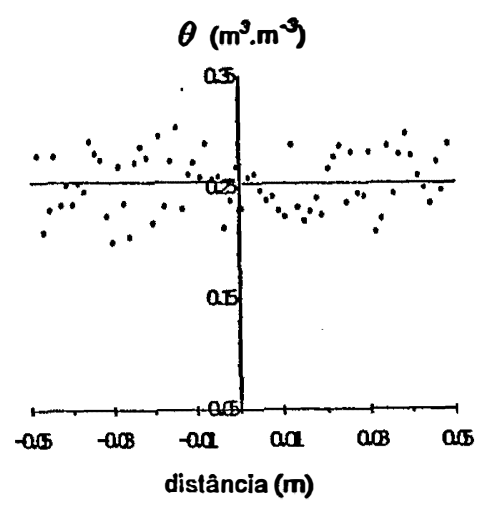

$19 / 10 / 93$

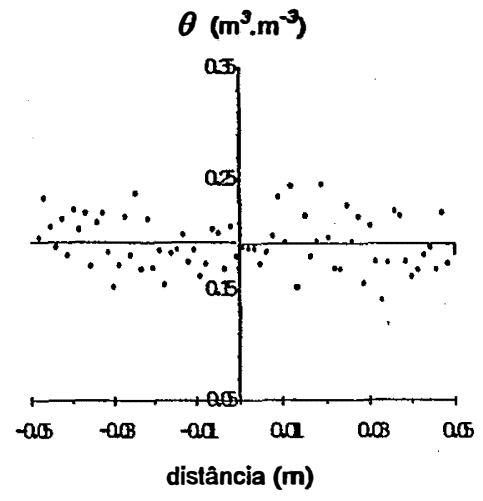

22/10/93.

$\theta\left(m^{3} \cdot m^{-3}\right)$

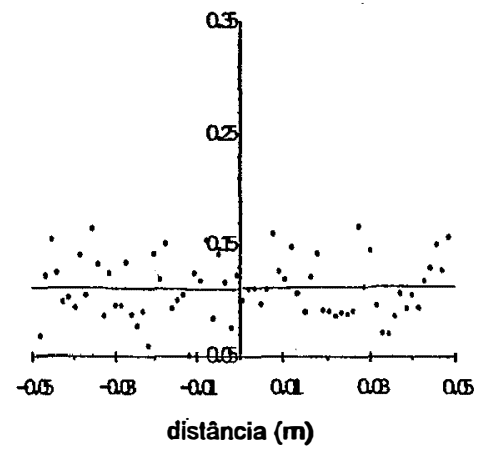

28/10/93

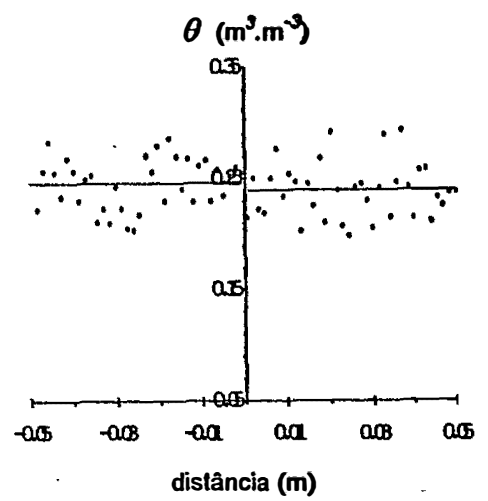

$20 / 10 / 93$
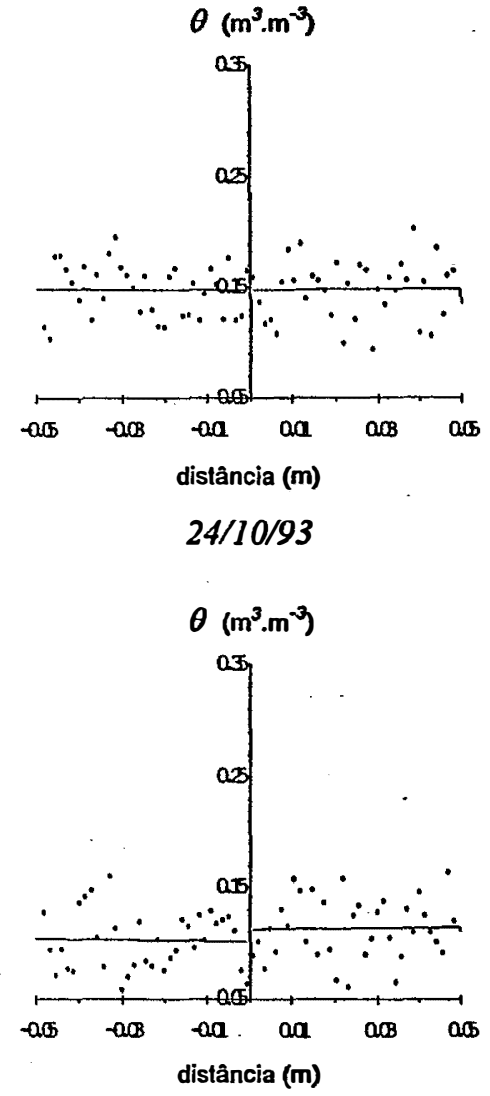

30/10/93

Figura 10 - Umidades volumétricas $\left(\mathrm{m}^{3} \cdot \mathrm{m}^{-3}\right)$ em função da distância (m) da placa porosa, medidas (pontos) e calculadas através de regressão (linhas) para o material do solo LV, $1^{\underline{a}}$ repetição, a $0,06 \mathrm{~m}$ de profundidade, para as 9 datas de leitura. Valores negativos para a distância indicam o lado A, valores positivos o lado B. 


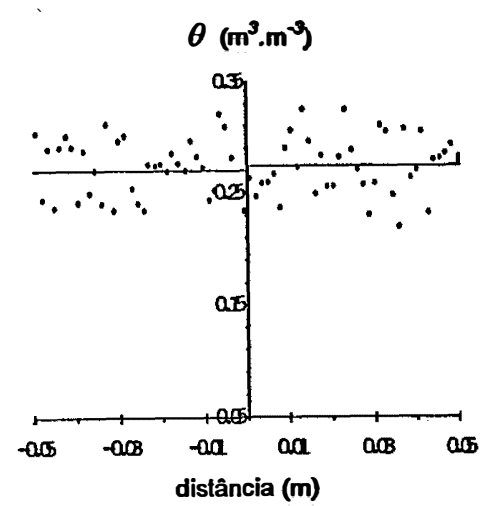

18/10/93

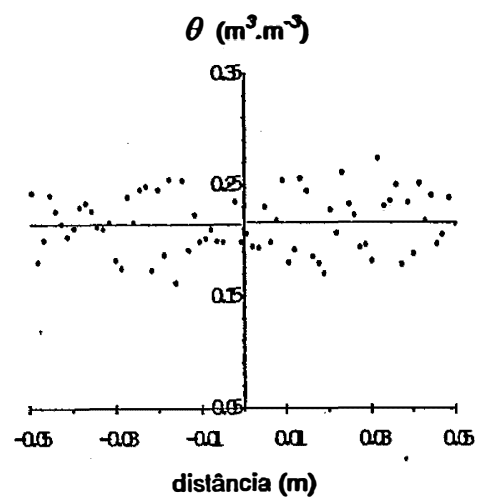

$21 / 10 / 93$

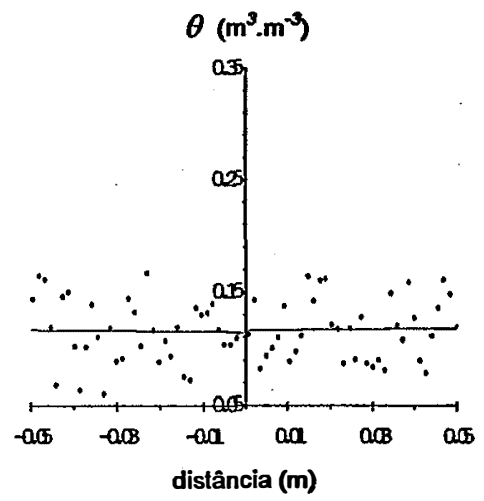

26/10/93

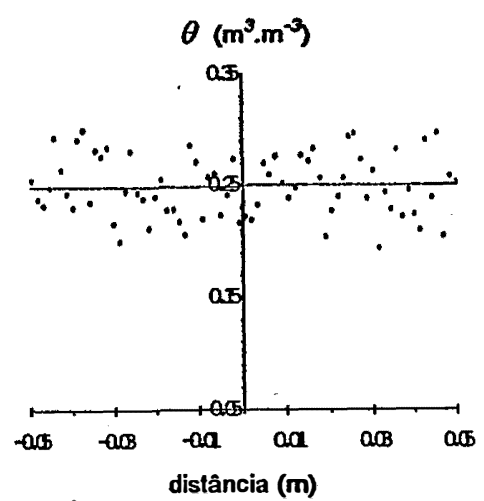

19/10/93

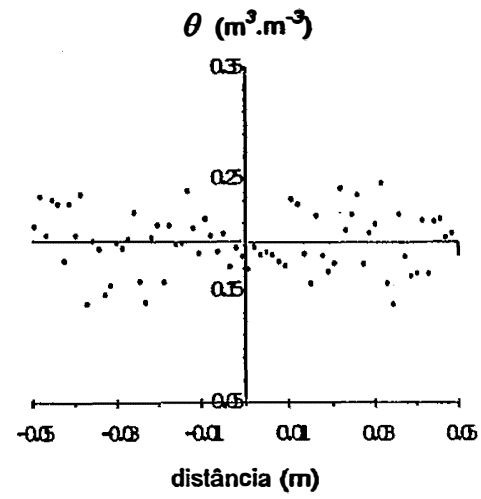

22/10/93

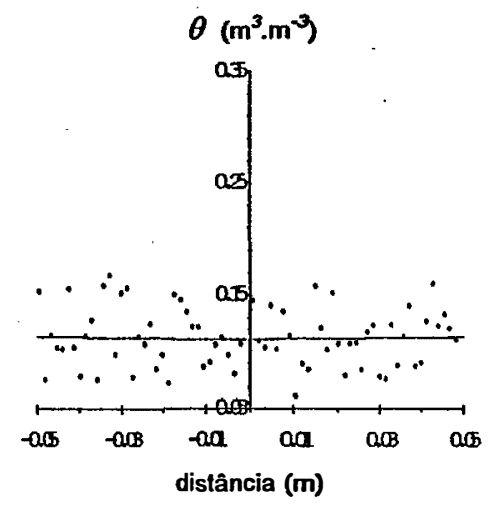

28/10/93

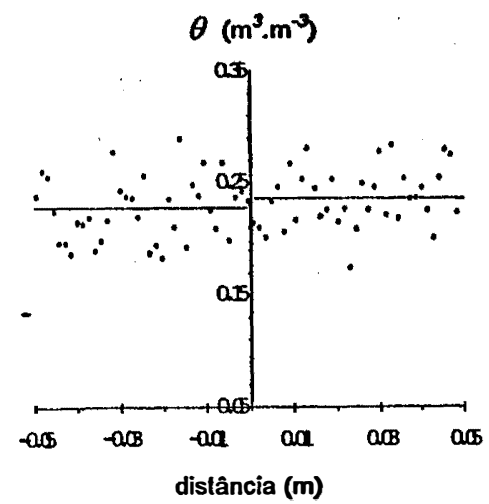

20/10/93

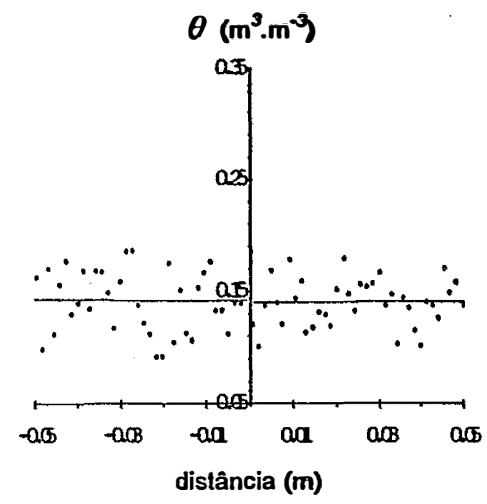

24/10/93

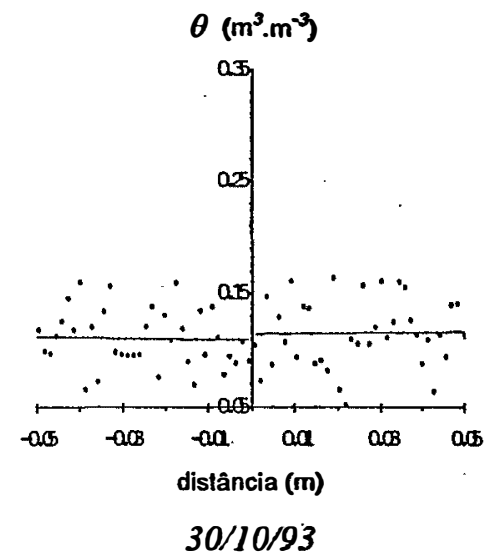

30/10/93

Figura 11 - Umidades volumétricas $\left(\mathrm{m}^{3} \cdot \mathrm{m}^{-3}\right)$ em função da distância $(\mathrm{m})$ da placa porosa, medidas (pontos) e calculadas através de regressão (linhas) para o material do solo $\mathrm{LV}, 2^{\mathrm{a}}$ repetição, a $0,04 \mathrm{~m}$ de profundidade, para as 9 datas de leitura. Valores negativos para a distância indicam o lado $\mathrm{A}$, valores positivos o lado B. 


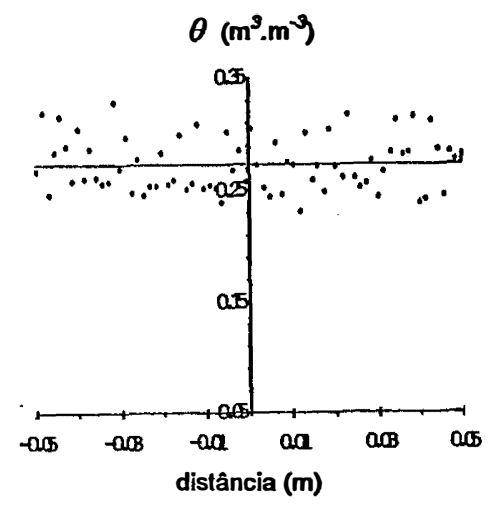

18/10/93

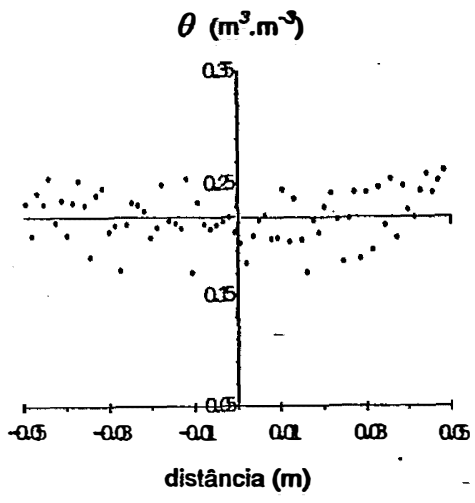

$21 / 10 / 93$

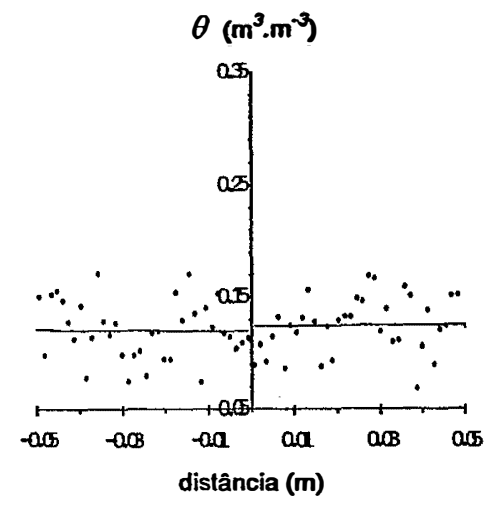

26/10/93

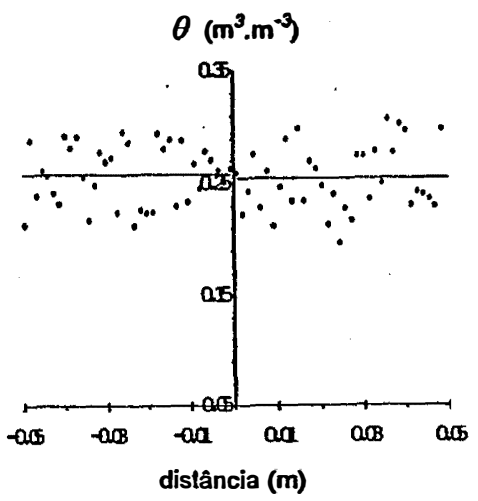

19/10/93

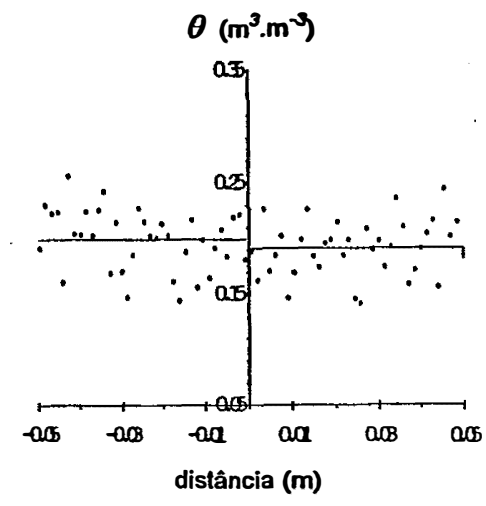

$22 / 10 / 93$

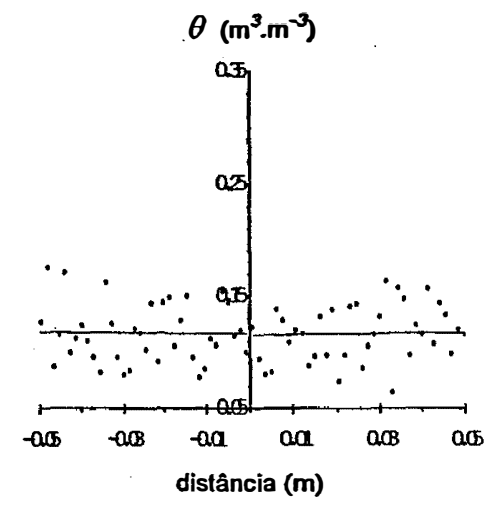

28/10/93

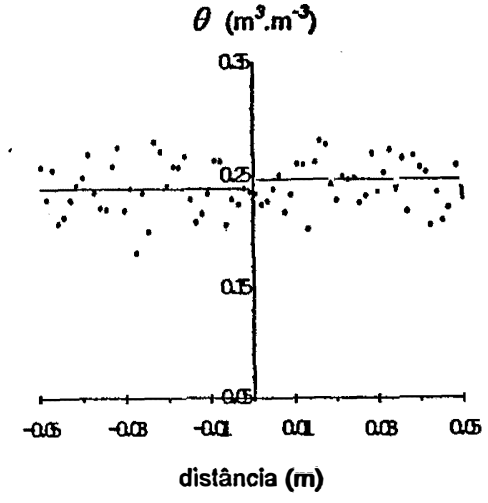

20/10/93
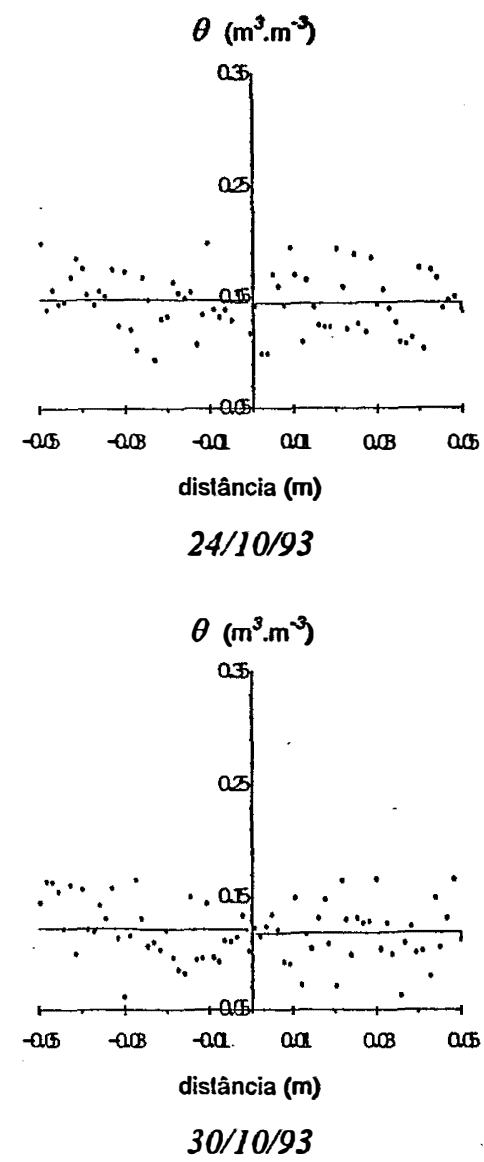

Figura 12 - Umidades volumétricas $\left(\mathrm{m}^{3} \cdot \mathrm{m}^{-3}\right)$ em função da distância $(\mathrm{m})$ da placa porosa, medidas (pontos) e calculadas através de regressão (linhas) para o material do solo LV, $2^{\mathbf{a}}$ repetição, a $0,05 \mathrm{~m}$ de profundidade, para as 9 datas de leitura. Valores negativos para a distância indicam o lado $\mathrm{A}$, valores positivos $\mathrm{o}$ lado B. 


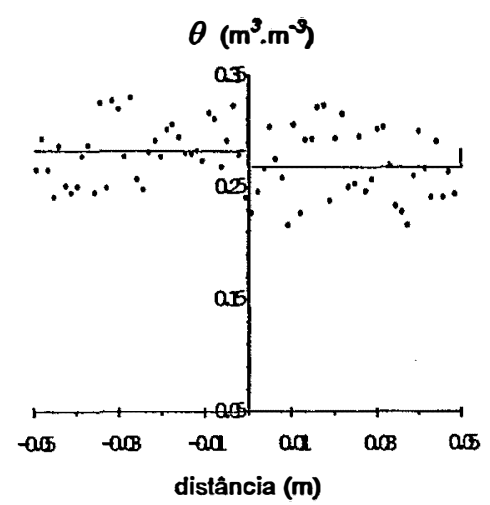

18/10/93

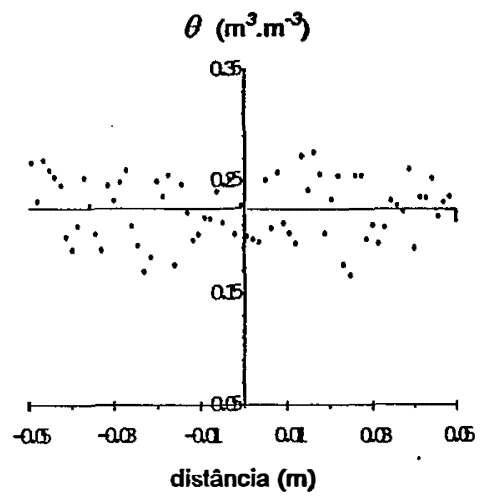

$21 / 10 / 93$

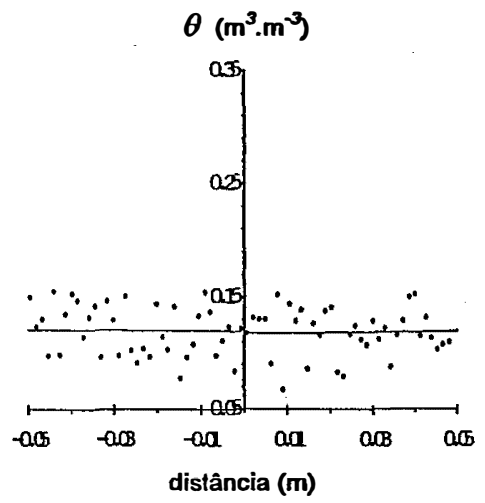

$26 / 10 / 93$

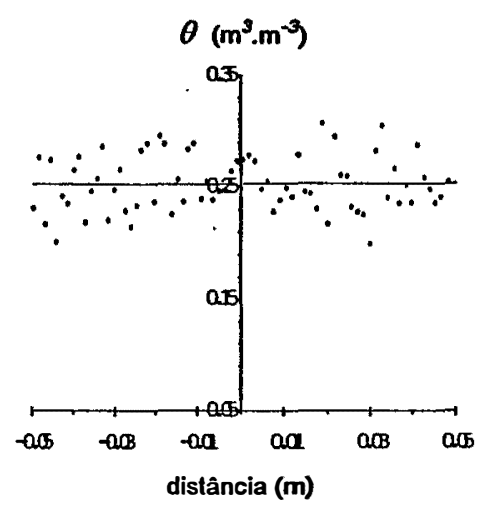

$19 / 10 / 93$

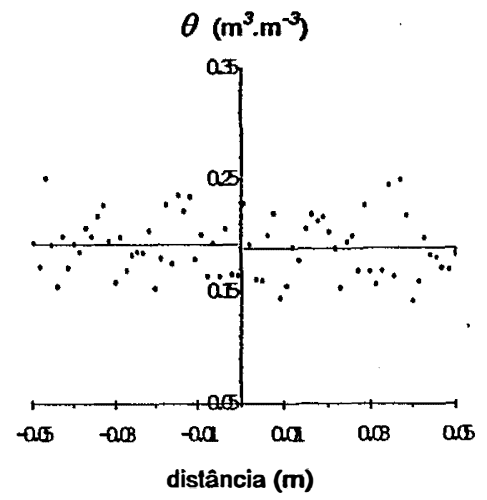

$22 / 10 / 93$

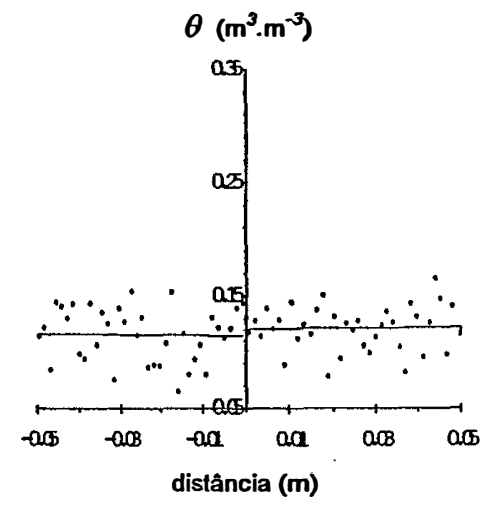

$28 / 10 / 93$

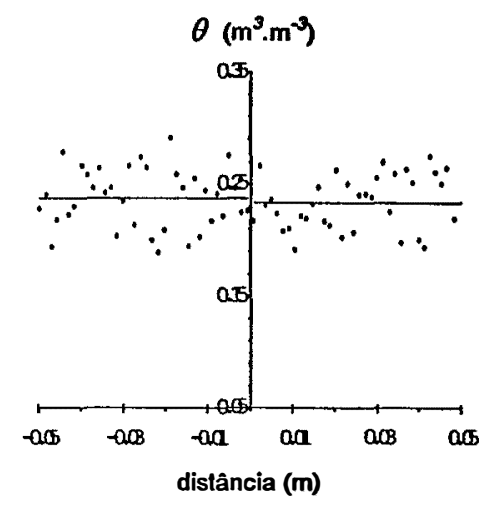

20/10/93

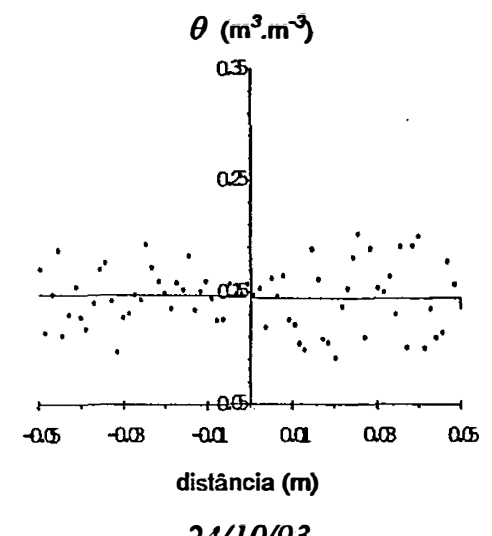

$24 / 10 / 93$

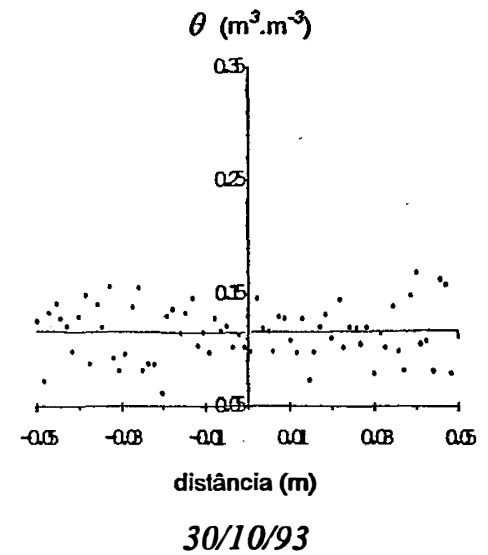

Figura 13 - Umidades volumétricas $\left(\mathrm{m}^{3} \cdot \mathrm{m}^{-3}\right)$ em função da distância $(\mathrm{m})$ da placa porosa, medidas (pontos) e calculadas através de regressão (linhas) para o material do solo $\mathrm{LV}, 2$ a repetição, a $0,06 \mathrm{~m}$ de profundidade, para as 9 datas de leitura. Valores negativos para a distância indicam o lado $\mathrm{A}$, valores positivos o lado B. 


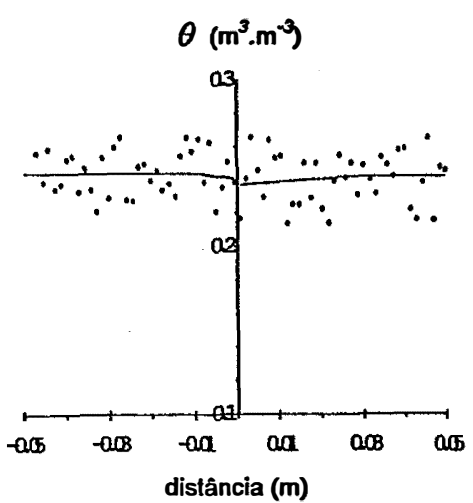

$18 / 10 / 93$

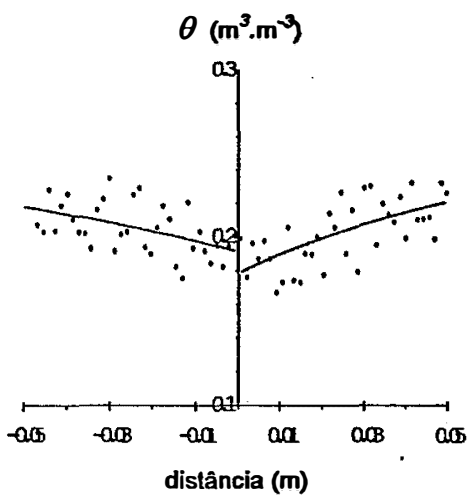

$21 / 10 / 93$

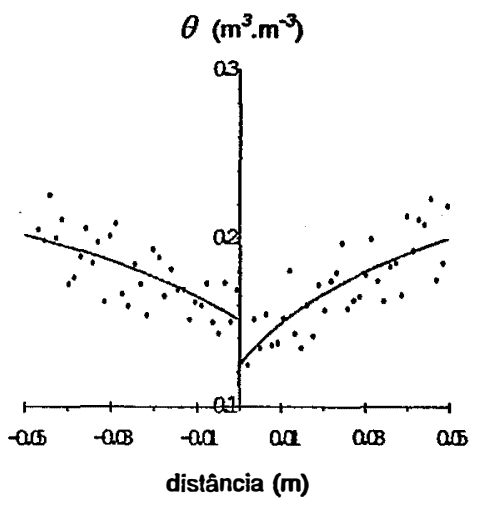

26/10/93

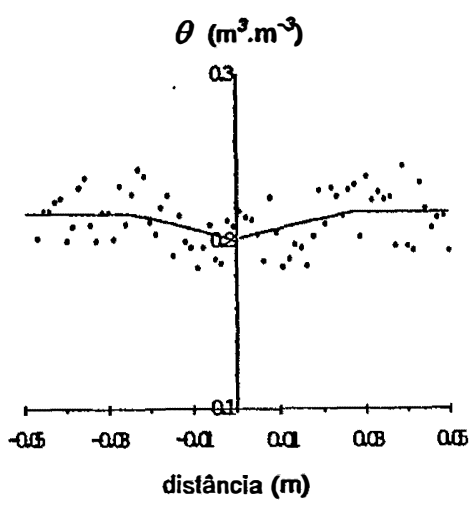

$19 / 10 / 93$

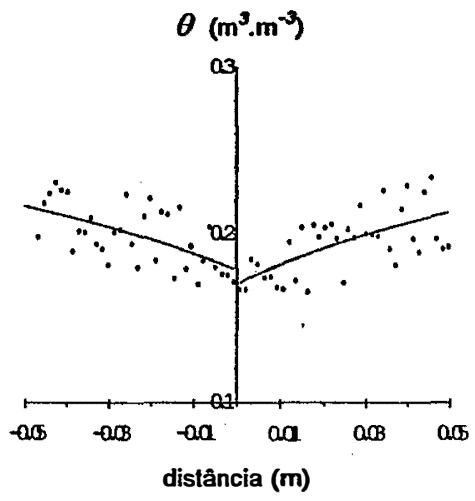

$22 / 10 / 93$

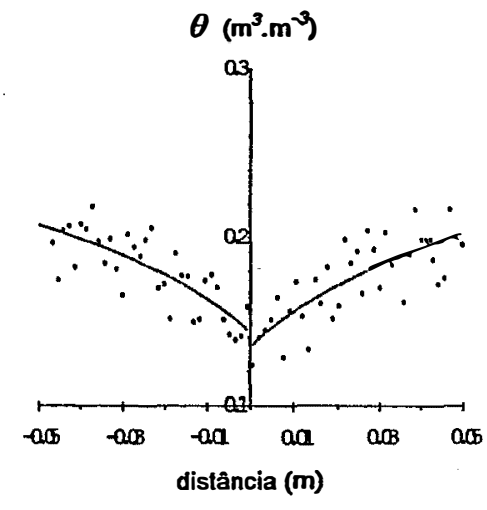

$28 / 10 / 93$

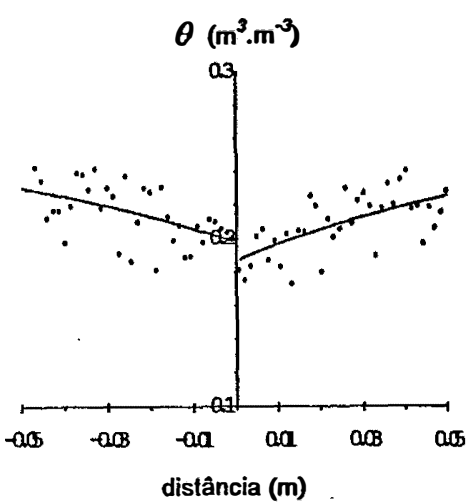

20/10/93

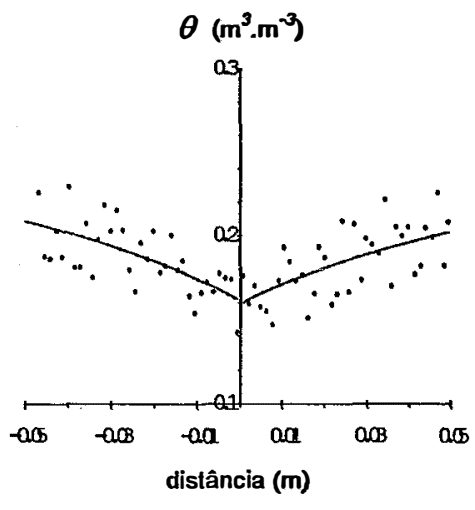

$24 / 10 / 93$

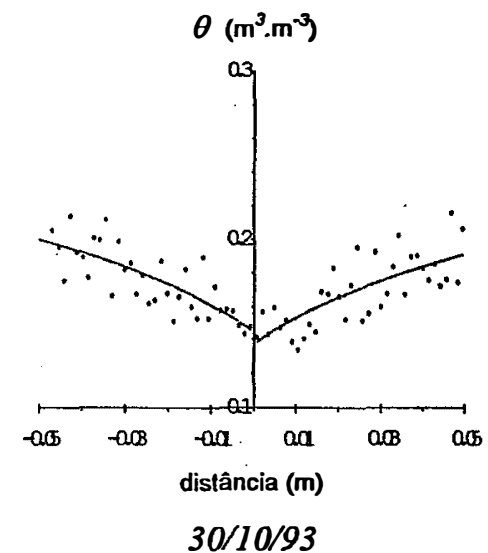

Figura 14 - Umidades volumétricas $\left(\mathrm{m}^{3} \cdot \mathrm{m}^{-3}\right)$ em função da distância $(\mathrm{m})$ da placa porosa, medidas (pontos) e calculadas através de regressão (linhas) para o material do solo LE, $1 \underline{a}$ repetição, a $0,04 \mathrm{~m}$ de profundidade, para as 9 datas de leitura. Valores negativos para a distância indicam o lado $\mathrm{A}$, valores positivos 0 lado B. 


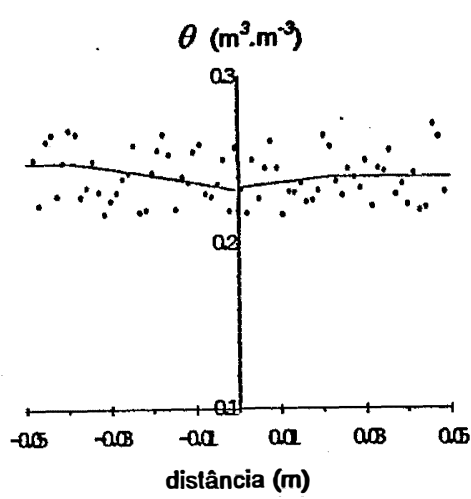

$18 / 10 / 93$

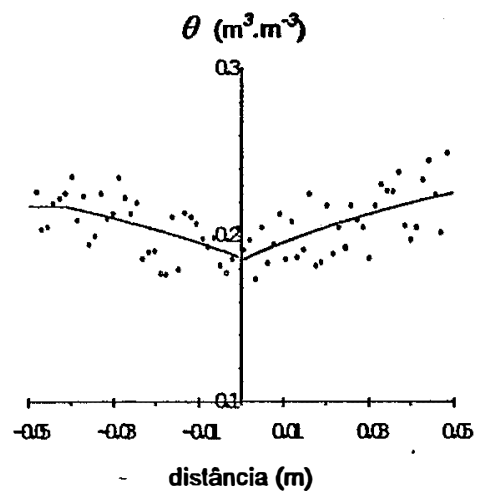

$21 / 10 / 93$

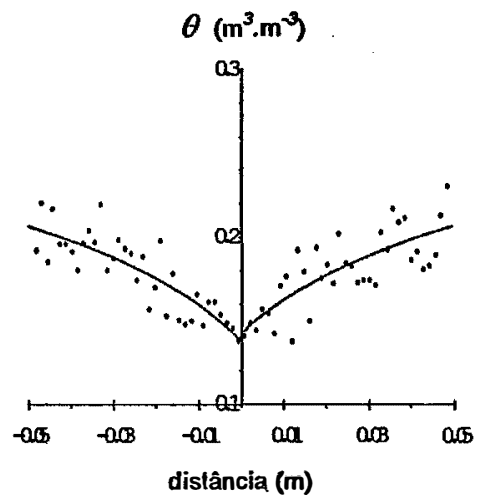

26/10/93

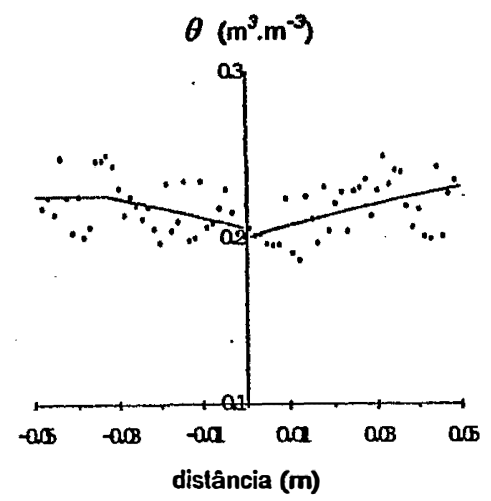

$19 / 10 / 93$

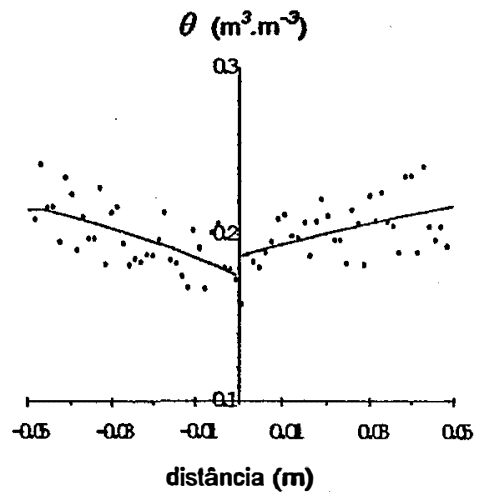

22/10/93

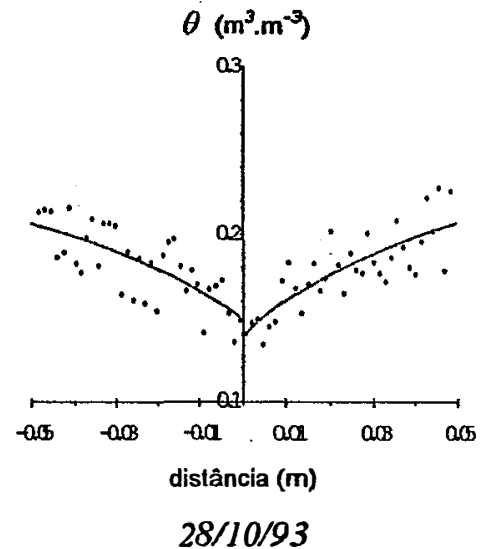

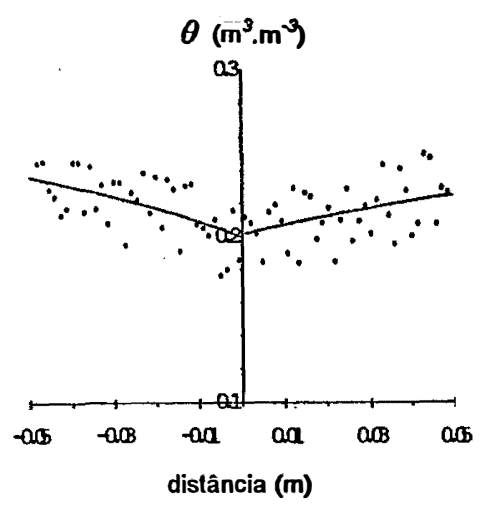

20/10/93

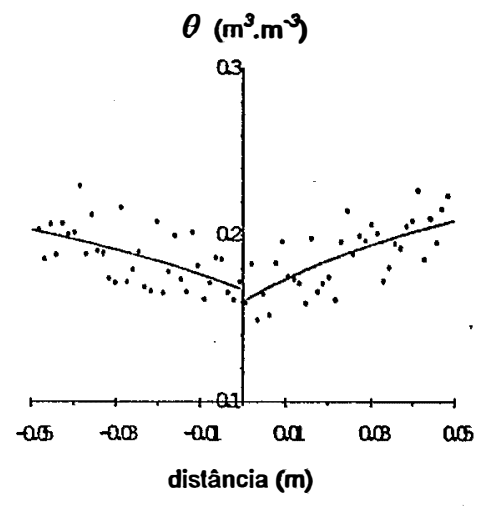

24/10/93

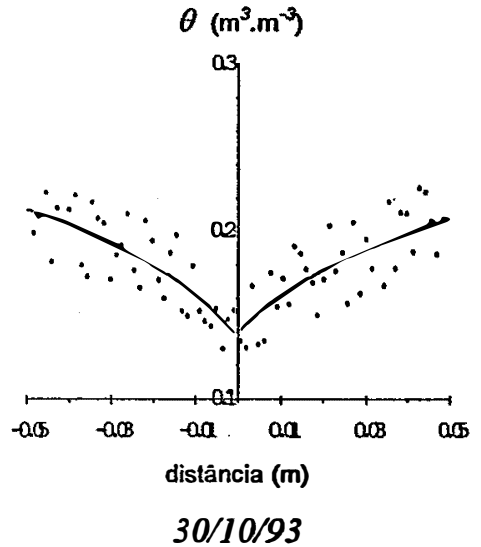

Figura 15 - Umidades volumétricas $\left(\mathrm{m}^{3} \cdot \mathrm{m}^{-3}\right)$ em função da distância $(\mathrm{m})$ da placa porosa, medidas (pontos) e calculadas através de regressão (linhas) para o material do solo $\mathrm{LE}, \mathrm{I}^{\mathrm{a}}$ repetição, a $0,05 \mathrm{~m}$ de profundidade, para as 9 datas de leitura. Valores negativos para a distância indicam o lado $\mathrm{A}$, valores positivos $\mathrm{o}$ lado B. 


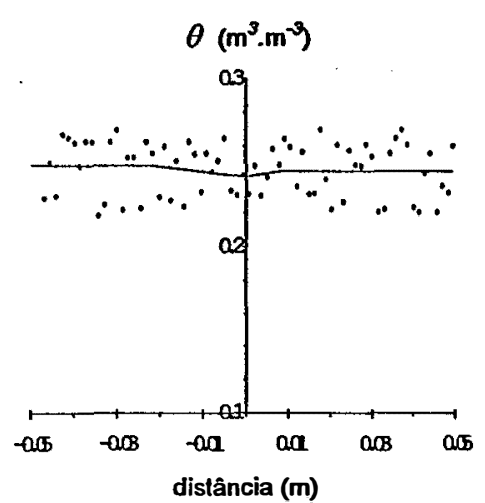

18/10/93

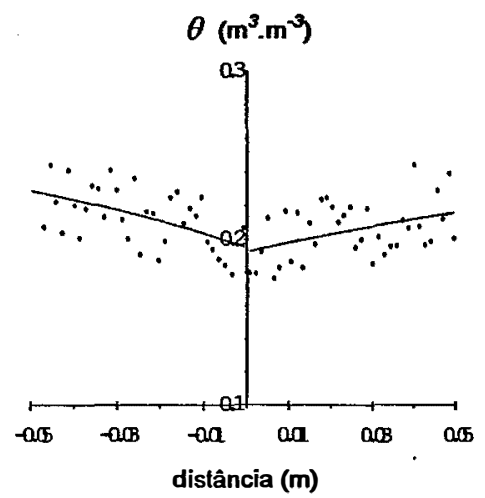

21/10/93

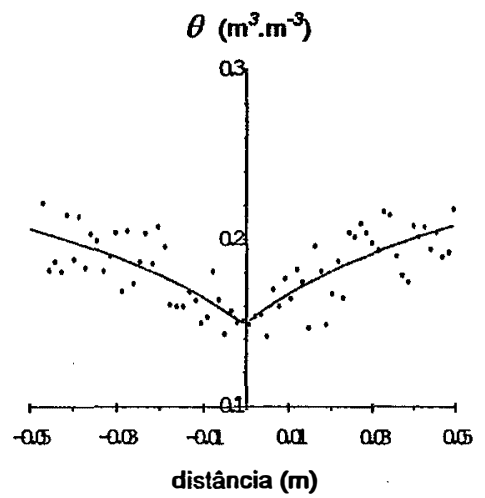

26/10/93

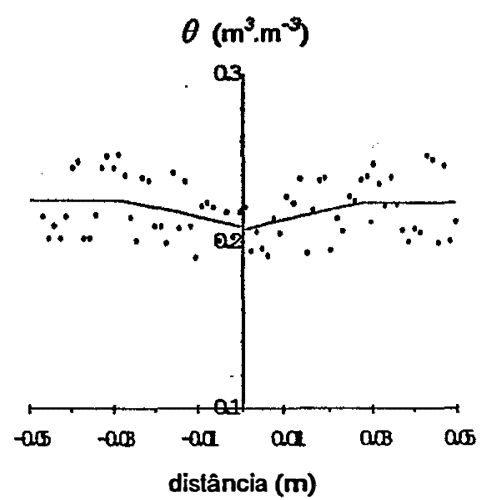

19/10/93

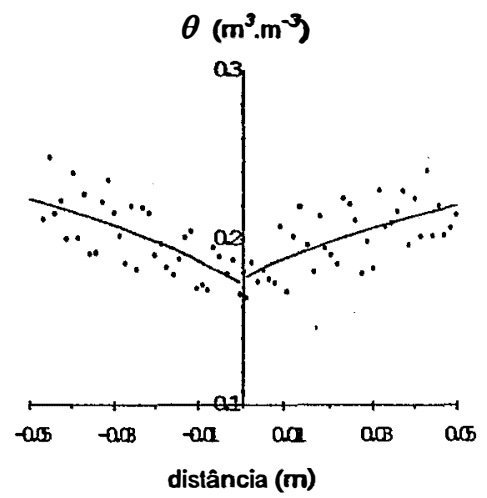

22/10/93

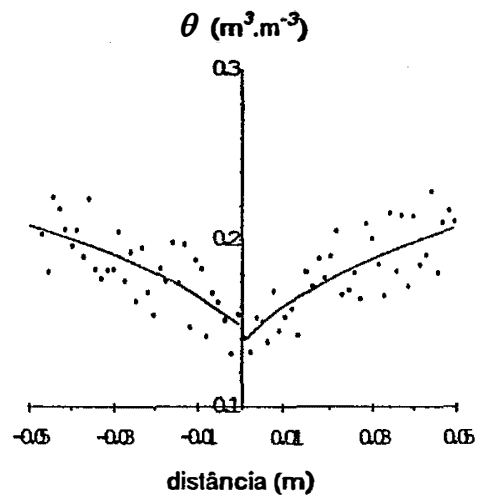

28/10/93

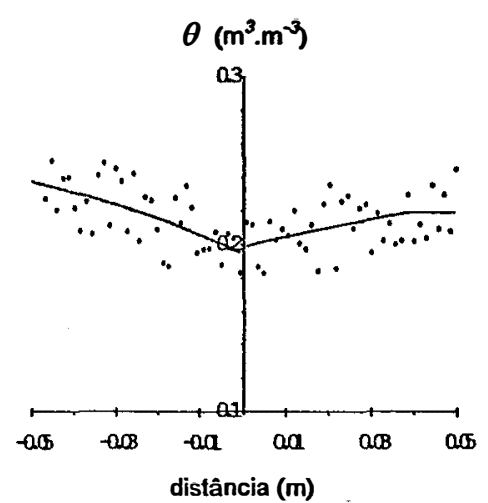

20/10/93

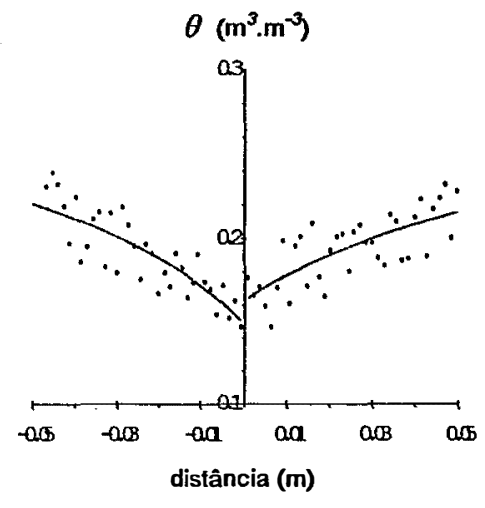

24/10/93

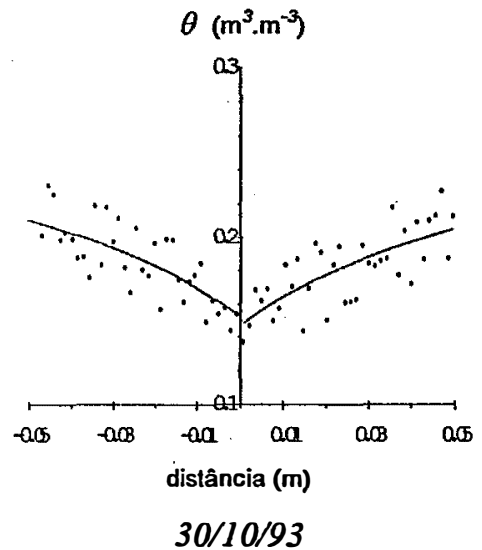

Figura 16 - Umidades volumétricas $\left(\mathrm{m}^{3} \cdot \mathrm{m}^{-3}\right)$ em função da distância $(\mathrm{m})$ da placa porosa, medidas (pontos) e calculadas através de regressão (linhas) para o material do solo LE, $1 \stackrel{a}{a}$ repetição, a $0,06 \mathrm{~m}$ de profundidade, para as 9 datas de leitura. Valores negativos para a distância indicam o lado A, valores positivos o lado B. 


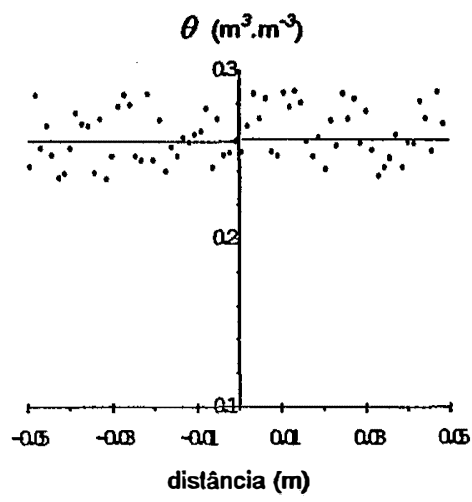

18/10/93

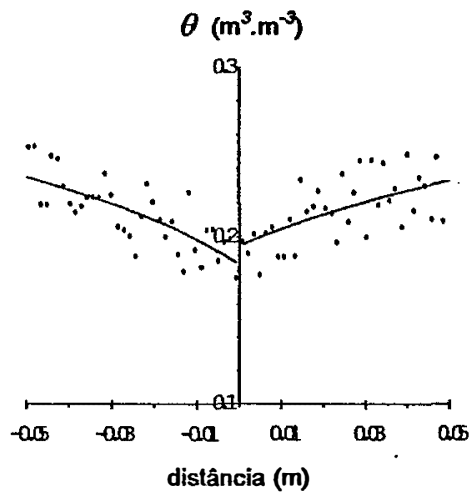

21/10/93

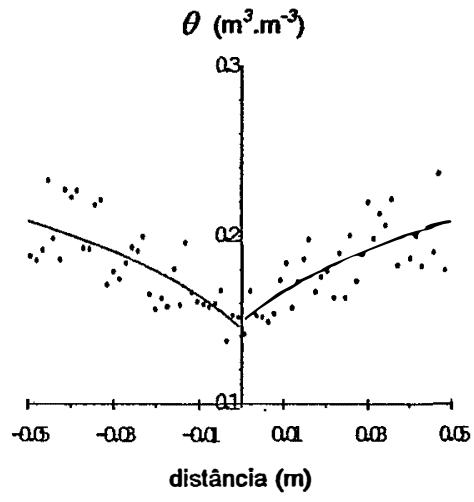

26/10/93

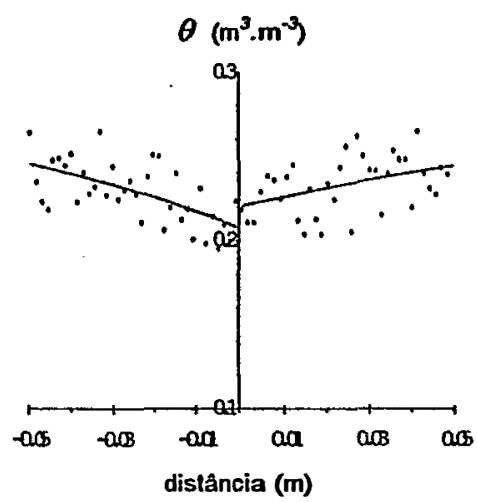

19/10/93
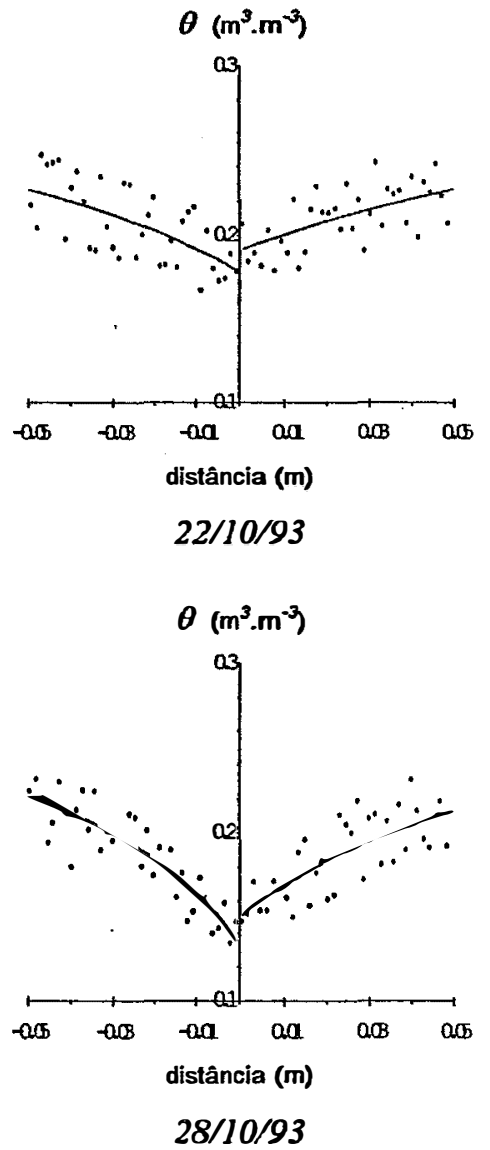
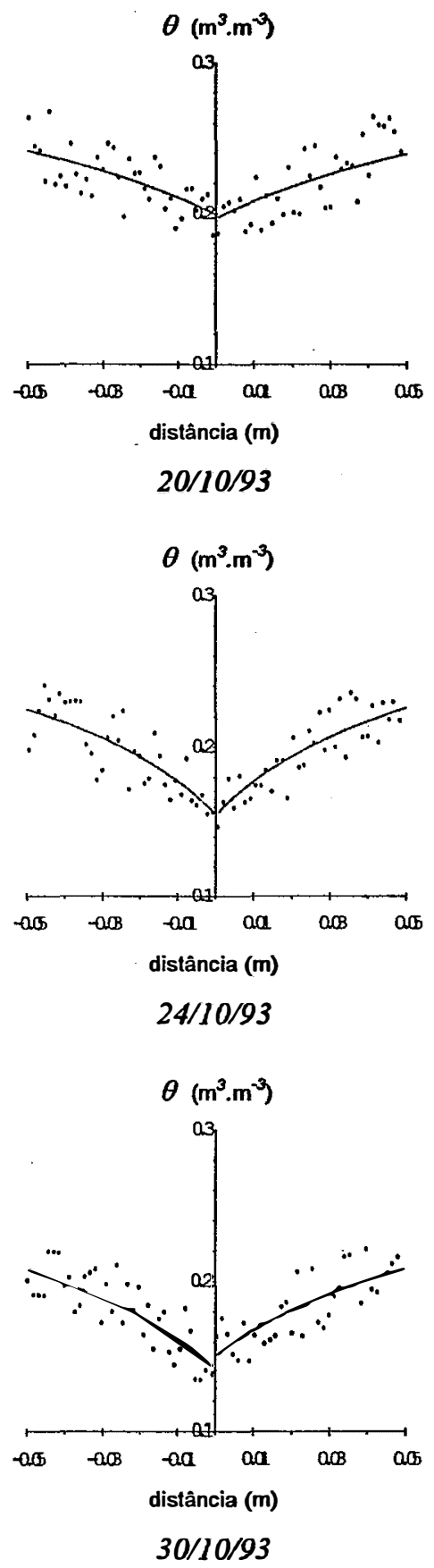

Figura 17 - Umidades volumétricas $\left(\mathrm{m}^{3} \cdot \mathrm{m}^{-3}\right)$ em função da distância $(\mathrm{m})$ da placa porosa, medidas (pontos) e calculadas através de regressão (linhas) para o material do solo LE, 2 ${ }^{\text {a }}$ repetição, a $0,04 \mathrm{~m}$ de profundidade, para as 9 datas de leitura. Valores negativos para a distância indicam o lado $\mathrm{A}$, valores positivos $\mathrm{o}$ lado B. 


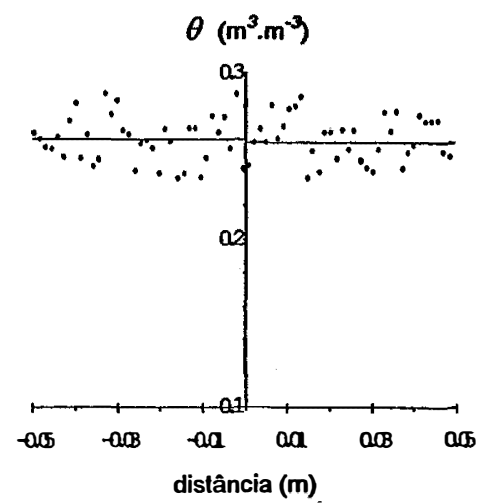

18/10/93

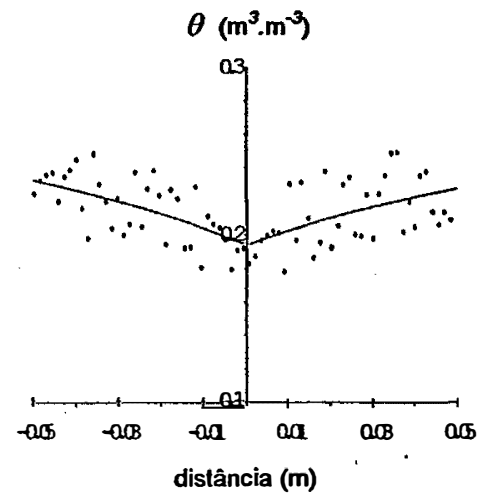

$21 / 10 / 93$

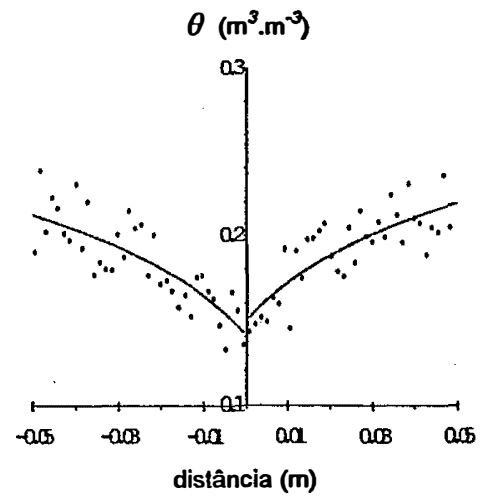

26/10/93

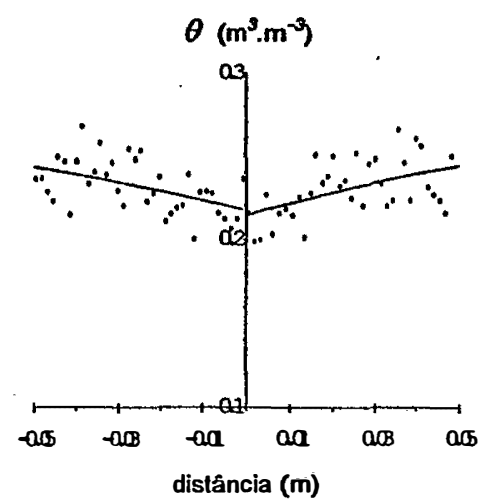

19/10/93

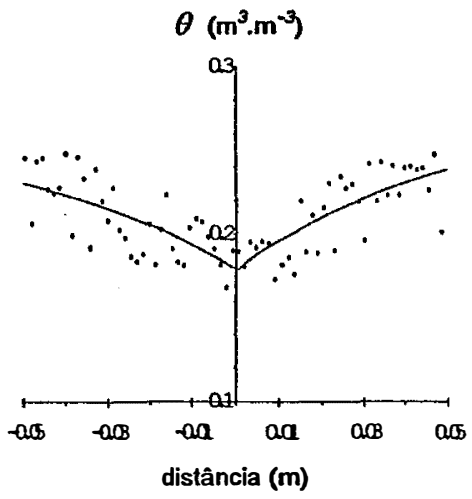

$22 / 10 / 93$

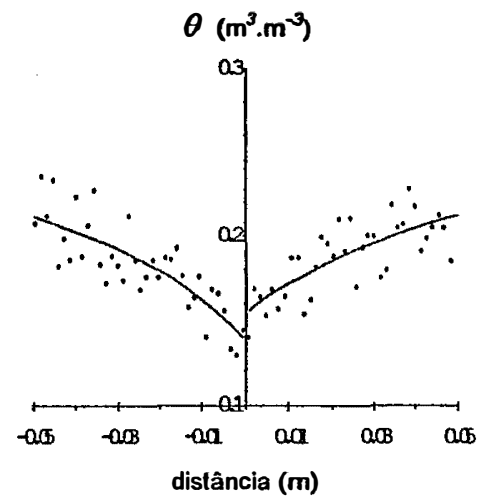

$28 / 10 / 93$

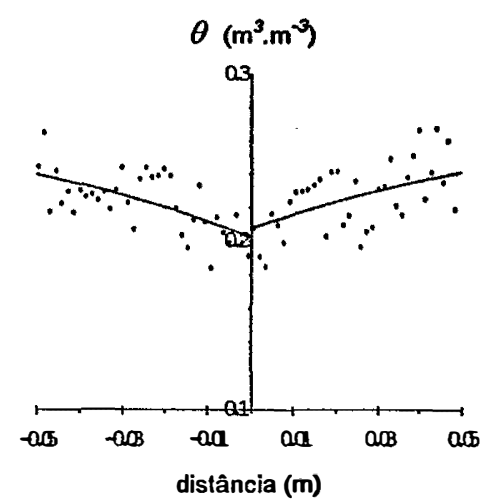

20/10/93

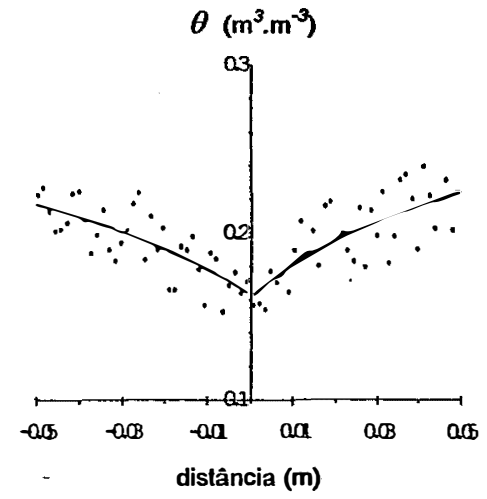

24/10/93

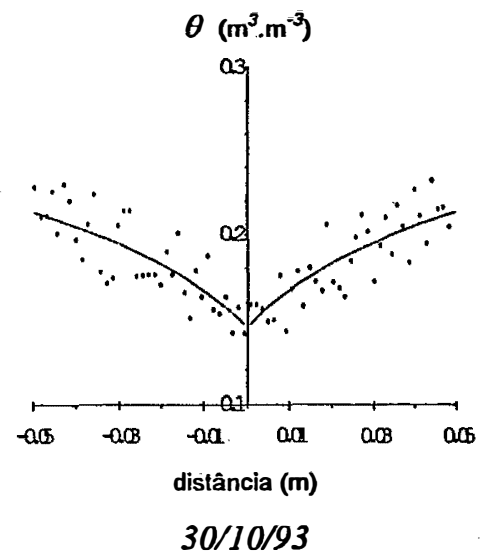

Figura 18 - Umidades volumétricas $\left(\mathrm{m}^{3} \cdot \mathrm{m}^{-3}\right)$ em função da distância $(\mathrm{m})$ da placa porosa, medidas (pontos) e calculadas através de regressão (linhas) para o material do solo LE, $2^{\underline{a}}$ repetição, a $0,05 \mathrm{~m}$ de profundidade, para as 9 datas de leitura. Valores negativos para a distância indicam o lado $\mathrm{A}$, valores positivos o lado B. 


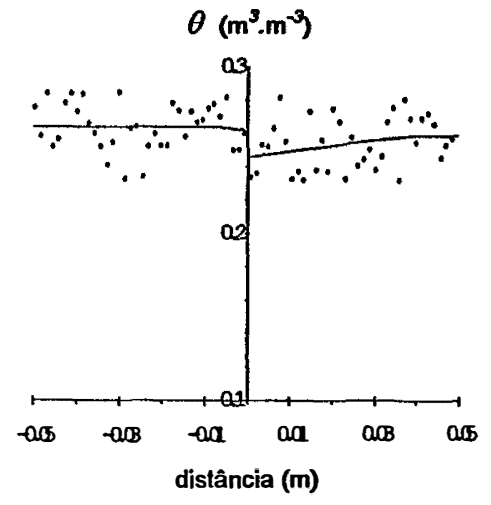

$18 / 10 / 93$

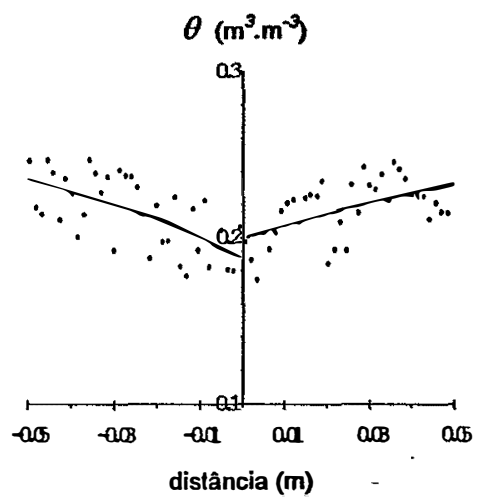

$21 / 10 / 93$

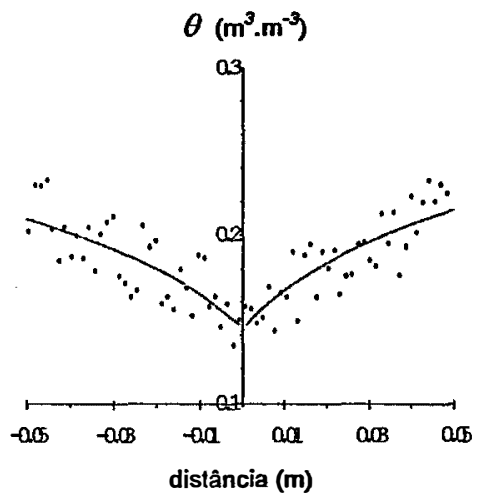

$26 / 10 / 93$

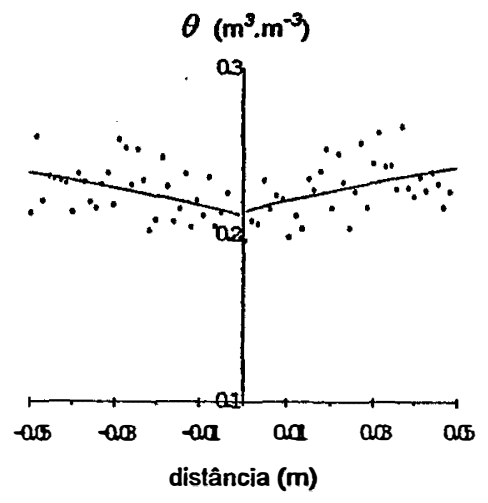

19/10/93

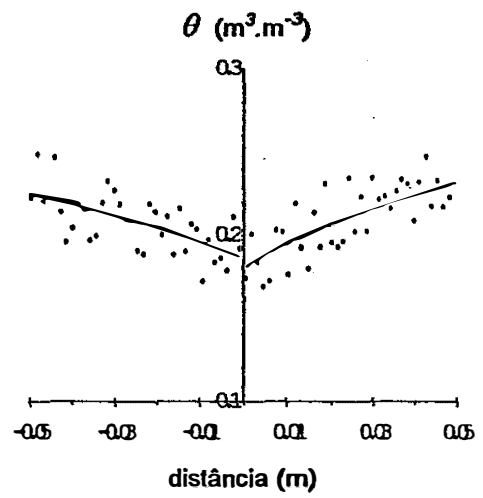

$22 / 10 / 93$

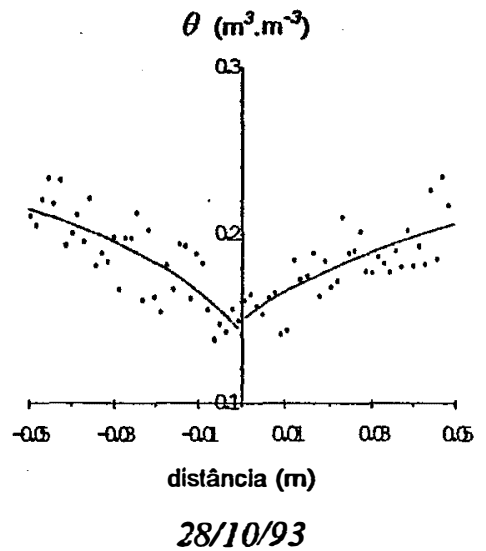

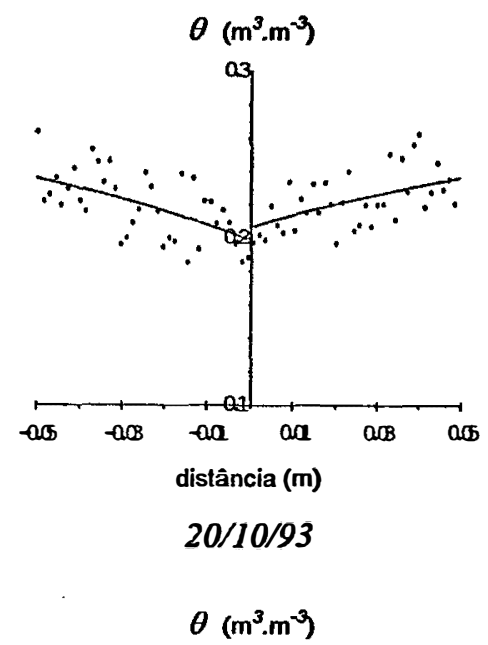

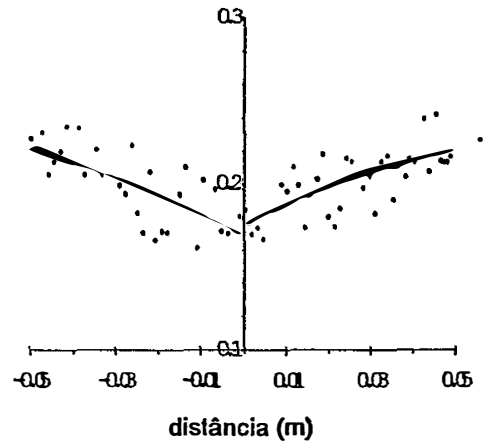

$24 / 10 / 93$

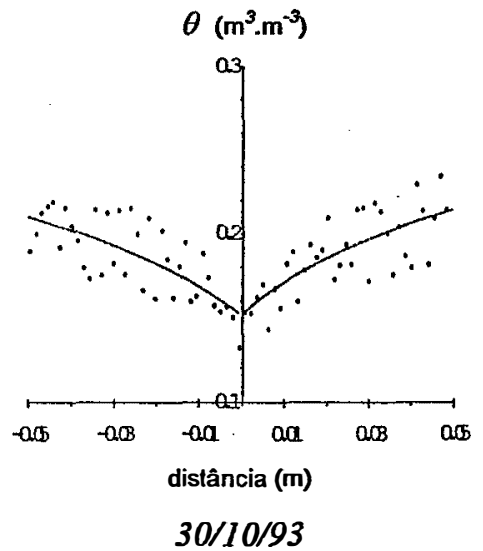

Figura 19 - Umidades volumétricas $\left(\mathrm{m}^{3} \cdot \mathrm{m}^{-3}\right)$ em função da distância $(\mathrm{m})$ da placa porosa, medidas (pontos) e calculadas através de regressão (linhas) para o material do solo LE, 2 a repetição, a $0,06 \mathrm{~m}$ de profundidade, para as 9 datas de leitura. Valores negativos para a distância indicam o lado $\mathrm{A}$, valores positivos $\mathrm{o}$ lado B. 


\subsection{Extrapolação do modelo a um sistema radicular}

Com o objetivo de utilizar o exposto para o manejo de irrigação, especificamente na determinação do valor da umidade crítica, deve-se levar em consideração que, num sistema radicular, existem raízes de diversos tamanhos e idades, cada uma com as suas características próprias quanto à extração de água, e num arranjo geométrico complicado. Pelo que foi visto, o avanço da frente de secagem ao redor de uma raiz é função da condutividade hidráulica do solo. Porém, observou-se que, mesmo num solo com uma condutividade hidráulica relativamente baixa, como o LE, o avanço da frente está na ordem de centímetros por dia. Considerando que, num sistema radicular comum, a distância entre duas raízes vizinhas dificilmente ultrapassará $0,01 \mathrm{~m}$, pode-se concluir que, já dentro de um dia, haverá interferência quanto às faixas explotadas pelas raízes individuais. Situações que favorecem o esgotamento quase que total de água ao redor das raízes, enquanto o solo entre as raízes ainda contém água, como defendem GARDNER \& EHLIG (1962), MACKLON \& WEATHERLEY (1965), CARBON (1973), ZUR et al. (1982), Hulugalle \& Willatt (1983), HAINSWORTH \& AYLMORE (1986, 1989) e TARDIEU et al. (1992), entre outros, são uma condutividade hidráulica baixa, um mau desenvolvimento radicular ou uma má distribuição espacial das raízes, e alta demanda transpiratória.

Utilizando o programa descrito no item 3.1.3. pode-se calcular o potencial mátrico necessário na raiz para manter uma certa taxa de transpiração. Exemplos gráficos, baseados em regressões feitas por esse programa, são dados nas Figuras 20 a 21 para uma planta com uma parte aérea de área $0,01 \mathrm{~m}^{2}$, uma profundidade efetiva do sistema radicular de $0,3 \mathrm{~m}$, variando as taxas de transpiração e o comprimento total do 
sistema radicular. Como umidade inicial adotou-se aquela correspondente ao potencial mátrico de $-10 \mathrm{kPa}$. Na Figura 20 usou-se um comprimento total do sistema radicular de $7,0 \mathrm{~m}$, nesse caso correspondendo a um raio médio entre as raízes de $0,010 \mathrm{~m}$. Compararam-se as taxas de transpiração de $3.10^{-8}, 6.10^{-8}$ e $12.10^{-8} \mathrm{~m}^{3} \cdot \mathrm{m}^{-2} . \mathrm{s}^{-1}$ para o material dos solos LV e LE, respectivamente. É claro que, quanto menor a taxa de transpiração, maior o potencial necessário na raiz. Com o tempo o solo vai secando, aumentando a necessidade de potenciais totais na raiz menores para manter o fluxo suficiente de água. Observa-se que, para o LE a altas taxas transpiratórias, ocorre uma descontinuidade na derivada da curva, indicando que, após certo tempo, há necessidade de potenciais totais extremamente baixos para manter o fluxo necessário. Certamente, as raízes não conseguirão esses potenciais, fazendo com que o fluxo às raízes seja insuficiente e a planta entre em estresse. Para o LV, tendo uma condutividade hidráulica bem maior, essa descontinuidade não ocorre para as taxas de transpiração avaliadas.

Na Figura 21 demostra-se a influência da densidade do sistema radicular no potencial necessário. A mesma planta que na Figura 20 foi avaliada, com a taxa de transpiração igual a $6.10^{-8} \mathrm{~m}^{3} \cdot \mathrm{m}^{-2} \cdot \mathrm{s}^{-1}$, para dois comprimentos totais do sistema radicular: $0,7 \mathrm{~m}$ e $7,0 \mathrm{~m}$, correspondendo a um raio médio entre as raízes de $0,033 \mathrm{~m}$ e $0,010 \mathrm{~m}$, respectivamente. Observa-se que, para ambos os solos os potenciais necessários são, inicialmente, praticamente iguais. Porém, em certo instante, a planta com um sistema radicular menos desenvolvido ou distribuído precisa de potenciais totais nas raízes muito maiores. 


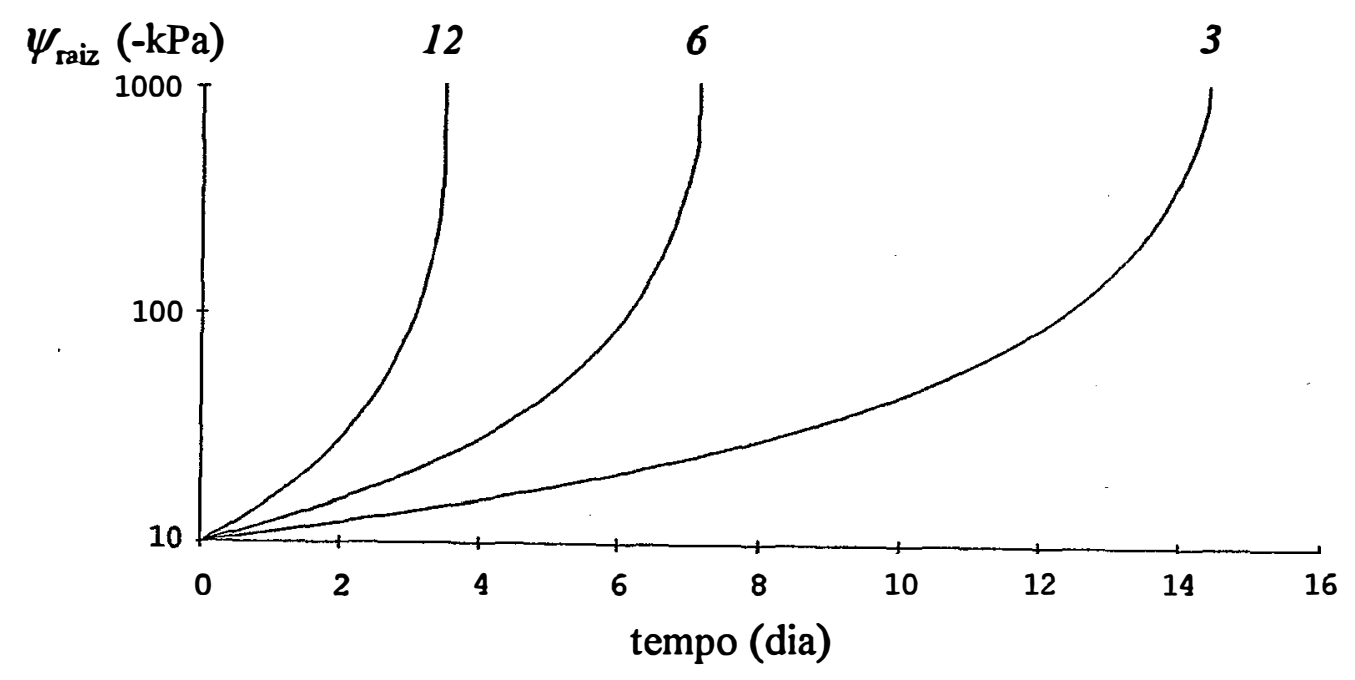

$\boldsymbol{a}$

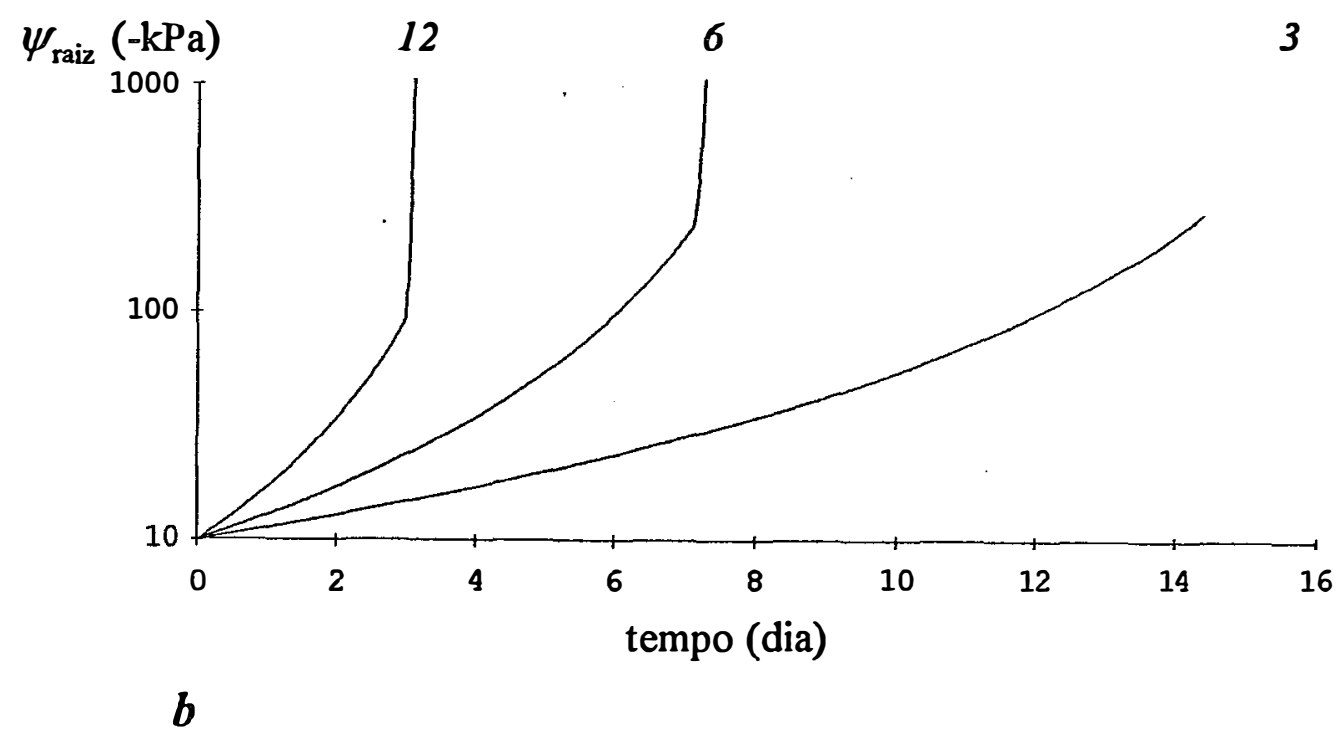

Figura 20 - Potencial total necessário nas raizes de uma planta de $0,01 \mathrm{~m}^{2} \mathrm{com}$ profundidade efetiva do sistema radicular de $0,3 \mathrm{~m}$ e comprimento total do sistema radicular de 7,0 m no material do solo LV (a) e LE (b) com umidade inicial correspondente ao potencial mátrico de $-10 \mathrm{kPa}$, para manter um fluxo de água de acordo com a taxa de transpiração de $3 \cdot 10^{-8} \mathrm{~m}^{3} \cdot \mathrm{m}^{-2} \cdot \mathrm{s}^{-1}$ (3), $6.10^{-8} \mathrm{~m}^{3} \cdot \mathrm{m}^{-2} \cdot \mathrm{s}^{-1}(6)$, e $12 \cdot 10^{-8} \mathrm{~m}^{3} \cdot \mathrm{m}^{-2} \cdot \mathrm{s}^{-1}(12)$. 

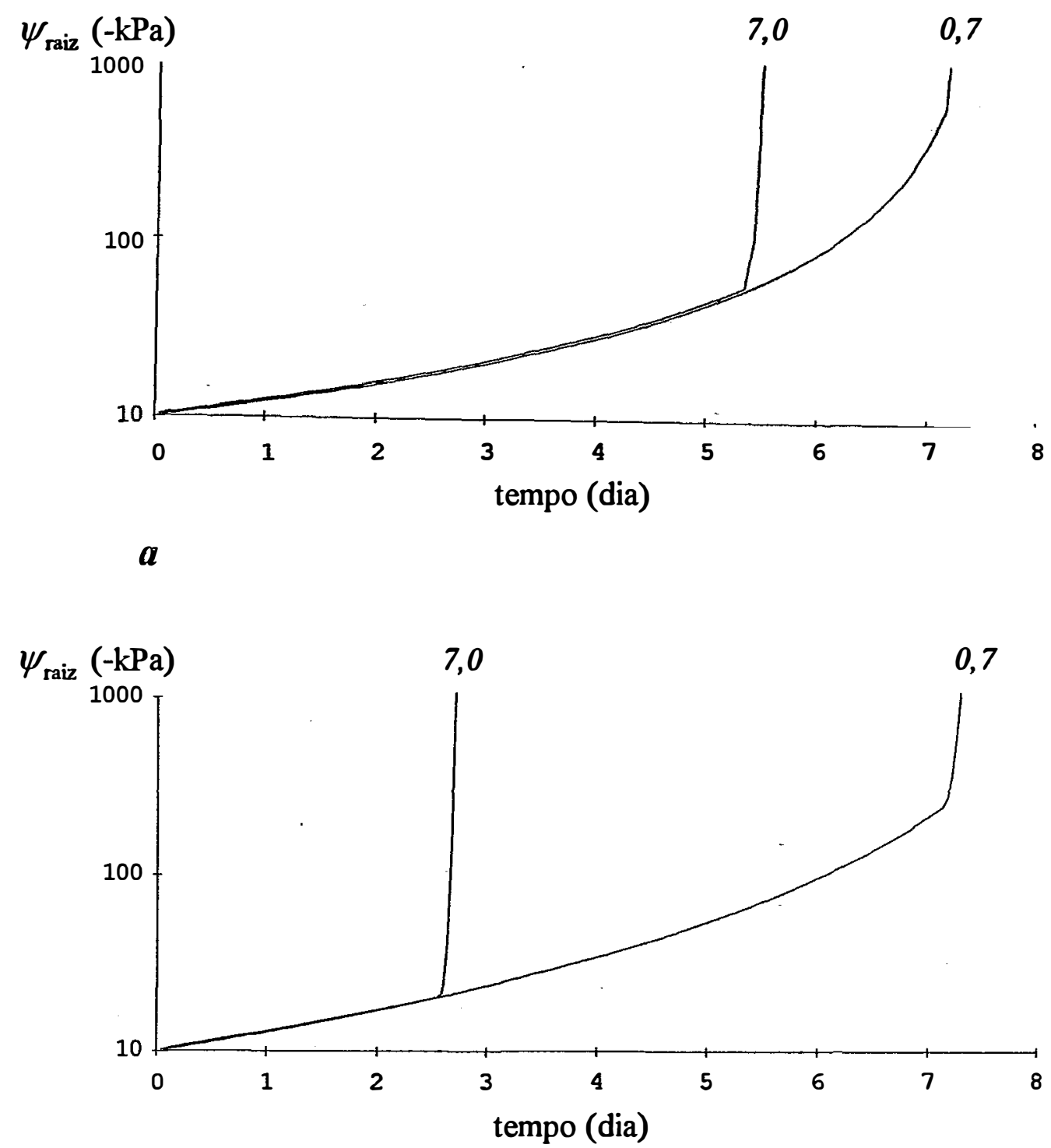

b

Figura 21 - Potencial total necessário nas raizes de uma planta de $0,01 \mathrm{~m}^{2}$ com profundidade efetiva do sistema radicular de $0,3 \mathrm{~m}$ e comprimento total do sistema radicular de $0,7 \mathrm{~m}(0,7)$ e $7,0 \mathrm{~m}(7,0)$ no material do solo $\mathrm{LV}(\boldsymbol{a})$ e LE (b) com umidade inicial correspondente ao potencial mátrico de $-10 \mathrm{kPa}$, para manter um fluxo de água de acordo com a taxa de transpiração de $6.10^{-8} \mathrm{~m}^{3} \cdot \mathrm{m}^{-2} \cdot \mathrm{s}^{-1}$. 
O início do estresse de água na planta está relacionado a um certo potencial total nas raízes, que é chamado de potencial-limite. $\mathrm{O}$ valor desse potencial depende de características da espécie e das condições da planta em particular. A relação entre a umidade crítica e o potencial-limite é que a umidade crítica é a umidade média no solo quando o potencial na raiz equivale o potencial-limite. Para poder calcular a umidade crítica com base no potencial-limite deve-se conhecer a umidade em função da distância das raízes, que pode ser determinada através da metodologia apresentada nesta tese, e a distribuição (média) do sistema radicular. Essa pode ser aproximada através de modelos de simulação do crescimento do sistema radicular, como os propostos por DIGGLE (1988) e PAGES \& ARIES (1988). 


\section{CONCLUSÕES}

Em função dos resultados obtidos no experimento conduzido com o material do solo LE, considera-se validado o modelo desenvolvido. Em conseqüência da aceitação do modelo conclui-se que:

- A extração da água do solo pelo sistema radicular de plantas depende das propriedades hidráulicas do solo: a curva característica de retenção de água e a relação condutividade hidráulica - umidade.

- Durante a secagem do solo, devida ao consumo de água por uma planta, o potencial para manter o fluxo necessário de água em direção às raízes diminui, e muito mais rapidamente em solos com condutividade hidráulica baixa.

- Quando o potencial-limite das raízes é atingido, a umidade média do solo corresponde à crítica.

- $\quad$ tempo para se chegar ao potencial-limite é função da umidade inicial do solo, da condutividade hidráulica do solo, da demanda transpiratória e da distribuição espacial das raízes.

- Levando em consideração esses fatos, na prática da irrigação é preferivel trabalhar com um "potencial mátrico crítico" do que com uma umidade crítica, uma vez que o potencial-limite das plantas é relacionado mais diretamente com o potencial da água no solo do que com a sua umidade. 
As limitações do modelo proposto dizem respeito às simplificações feitas para desenvolvê-lo, como:

- A desconsideração das variações na taxa de transpiração durante um dia.

- A suposição que todas as raízes têm o mesmo raio e que a água nas suas superficies possui o mesmo potencial total.

- A hipótese de que, ao extrair água do solo, não há interação entre raízes.

- A desconsideração da variabilidade espacial, tanto na direção horizontal como na vertical, das características do solo.

Para poder aplicar o modelo proposto em sistemas radiculares, essas limitações devem ser estudadas. Em conseqüência desses estudos, modelos mais completos podem ser desenvolvidos. 


\section{REFERÊNCIAS BIBLIOGRÁFICAS}

ADEOYE, K.B. \& RAWLINS, S.L. A split-root technique for measuring root water potential. Plant Physiology, Rockville (EUA), 68: 44-7, 1981

BALLIGAR, V.C.; WHISLER, F.D.; NASH, V.E. Soybean seedling root growth as influenced by soil texture, matric suction and bulkdensity. Communications in Soil Science and Plant Analysis, 11:903-15, 1980

BELMANS, C.; FEYEN, J.; HILLEL, D. An attempt at experimental validation of macroscopic-scale models of soil moisture extraction by roots. Soil Science, Baltimore (EUAA), 127: 174-86, 1979

BLIZZARD, W.E \& BOYER, J.S. Comparative resistance of the soil and the plant to water transport. Plant Physiology, Rockville (EUA), 66: 809-14, 1980

BRUCKLER, L.; LAFOLIE, F.; TARDIEU, F. Modeling root water potential and soil-root water transport: II. Field comparisons. Soil Science Society of America Journal, Madison (EUA), 55: 1213-20, 1991

CARBON, B.A. Diumal water stress in plants grown on a course soil. Australian Journal of Soil Research, Melbourne (Austrália), 11: 33-42, 1973

CIFTCIOGLU, O. \& TAYLOR, D. Moving gamma-source soil density gauges. Soil Science, Baltimore (EUA), 113: 13-7, 1972

COWAN, I.R. Transport of water in the soil-plant-atmosphere system. The Journal of Applied Ecology, Oxford (Grã-Bretanha), 2: 221-39, 1965

DAVIDSON, J.M.; BIGGAR, J.W.; NIELSEN, D.R. Gamma-radiation attenuation for measuring bulk density and transient water flow in porous materials. Journal of Geophysical Research, Cleveland (EUA), 68(16):4777-83, 1963

DEVLIN, G.; HENDERSON, I.A.; TAYLOR, D. Design and performance of a moving gamma-source soil density gauge. Nuclear instruments and methods, Haarlem (Holanda), 76:150-6, 1969 
DIGGLE, A.J. ROOTMAP - a model in three-dimensional coordinates of the growth and structure of fibrous root systems. Plant and Soil, Haia (Holanda), 105: 169-78, 1988

DIRKSEN, C. \& RAATS, P.A.C. Water uptake and release by alfalfa roots. Agronomy Journal, Madison (EUA), 77: 621-6, 1985

DOORENBOS, J.; KASSAN, A.H.; BENTVELSEN, C.L.M.; BRANSCHED, V.; PLUSJÉ, J.M.G.A.; SMTH, M.; UIMENBOGAARD, G.O.; VAN DER WAL, H.K. Yield response to water. Rome, FAO, 1979, 193p. (Irrigation and Drainage paper 33).

DOURADO NETO, D. \& JONG VAN LIER, Q. DE Estimativa do armazenamento de água no solo para realização de balanço hídrico. Revista Brasileira de Ciência do Solo, Campinas (SP), 17(1):915,1993

DOURADO NETO, D.; JONG VAN LIER, Q. DE; BOTREL, T.A.; LIBARDI, P.L. Programa para confecção da curva de retenção da água no solo utilizando o modelo de Genuchten. Engenharia Rural, Piracicaba (SP), 1:92-102, 1990

DUNHAM, R.J. \& NYE, P.H. The influence of soil water content on the uptake of ions by roots. I. Soil water content gradients near a plane of onion roots. The Journal of Applied Ecology, Oxford (Grã-Bretanha), 10: 58̈5-98, 1973

FAIZ, S.M.A. \& WEATHERLEY, P.E. Root contraction in transpiring plants. New Phytologist, Cambridge (Grã-Bretanha), 92:333-43, 1982

FEDDES, R.A.; BRESLER, E.; NEUMAN, S.P. Field test of a modified numerical model for water uptake by root systems. Water Resources Research, Washington (EUA), 10(6): 1199-206, 1974

FERRAZ, E.S.B. Determinação simultânea de densidade e umidade de solos por atenuação de raios gama do ${ }^{137} \mathrm{Cs}$ e ${ }^{241} \mathrm{Am}$. Piracicaba, 120p. (Tese de Livre-Docência, USP/ESALQ). 1974

FERRAZ, E.S.B. \& PINTO, F.A. Determinação de variação de umidade do solo "in situ" por atenuação gama. Cientifica, Botucatu, ( $\mathrm{n}^{\circ}$ especial):49-52, 1977

GARDNER, W.R. Dynamic aspects of water availability to plants. Soil Science, Baltimore (EUA), 89: 63-7, fev. 1960

GARDNER, W.R Relation of root distribution to water uptake and availability. Agronomy Journal, Madison (EUA), 56: 41-5, 1964

GARDNER, W.R \& EHLIG, C.F. Some observations on the movement of water to plant roots. Agronomy Journal, Madison (EUA), 54: 453-6, 1962 
GARDNER, W.H.; CAMPBELL, G.S.; CALISSENDORFF, C. Systematic and random errors in dual gamma energy soil bulk density and water content measurements. Soil Science Society of America Proceedings, Madison (EUA), 36: 393-8, 1972

HAINSWORTH, J.M. \& AYLMORE, L.A.G. Water extraction by single plant roots. Soil Science Society of America Journal, Madison (EUA), 50: 841-8, 1986

HAINSWORTH, J.M. \& AYLMORE, L.A.G. Non-uniform soil water extraction by plant roots. Plant and Soil, Haia (Holanda), 113: 121-4, 1989

HERKELRATH, W.N. \& MILLER, E.E. High performance gamma system for soil columns. Soil Science Society of America Journal, Madison (EUA), 40: 331-2, 1976

HERKELRATH, W.N.; MILLER, E.E.; GARDNER, W.R Water uptake by plants: II. The root contact model. Soil Science Society of America Journal, Madison (EUA), 41: 1039-43, 1977

HILLEL, D.; BEEK, C.G.E.M. VAN; TALPAZ, H. A microscopic-scale model of soil water uptake and salt movement to plant roots. Soil Science, Baltimore (ËUA), 120: 385-99, 1975

HILLEL, D.; TALPAZ, H.; KEULEN, H VAN. A macroscopic model of water uptake by a nonuniform root system and of water and salt movement in the soil profile. Soil Science, Baltimore (EUA), 121: 242-55, 1976.

HOOGENBOOM, G.; HUCK, M.G.; PETERSON, C.M. Root growth rate of soybean as affected by drought stress. Agronomy Journal, Madison (EUA), 79: 607-14, 1987

HUCK, M.G.; KLEPPER, B.; TAYLOR, H.M. Diurnal variations in root diameter. Plant Physiology, Rockville (EUA), 45:529-30, 1970

HULUGALLE, N.R \& WILLATT, S.T. The role of soil resistance in determining water uptake by plant root systems. Australian Journal of Soil Research, Melbourne (Austrália), 21:571-4, 1983

JONG VAN LIER, Q. DE \& DOURADO NETO, D. Valores extremos de umidade do solo referentes ao modelo de Van Genuchten. Revista Brasileira de Ciência do Solo, Campinas (SP), 17(3):325-9, 1993

LAFOLIE, F.; BRUCKLER, L.; TARDIEU, F. Modeling root water potential and soil-root water transport: I. Model presentation. Soil Science Society of America Journal, Madison (EUA), 55: 1203-12, 1991

LANG, A.R.G. \& GARDNER, W.R Limitation to water flux from soils to plants. Agronomy Journal, Madison (EUA), 62: 693-5, 1970 
LIBARDI, P.L.; REICHARDT, K.; NIELSEN, D.R.; BIGGAR, J.W. Simplified field methods for estimating the unsaturated hydraulic conductivity. Soil Science Society of America Journal, Madison (EUA), 44: 3-6, 1980

MACKLON, A.E.S. \& WEATHERLEY, P.E. Controlled environment studies of the nature and origins of water deficits in plants. New Phytologist, Cambridge (Grã-Bretanha), 64: 414-27, 1965

MAHEY, R.K.; FEYEN, J.; WYSEURE, G. A numerical analysis of irrigation treatments of barley with respect to drainage losses and crop response. Transactions of the ASAE, St. Joseph (EUA), 27: 1805-16, 1984

MCCOY, E.L.; BOERSMA, L.; UNGS, M.L.; AKRATANAKUL, S. Toward understanding soil water uptake by plant roots. Soil Science, Baltimore (EUA), 137: 69-77, 1984

MCKINNEY, F.E. Measuring moisture with gamma radiation. Isotopes and Radiation Technology, Viena (Áustria), 7:29-35, 1969

MIYAZAKI, T.; KASUBUCHI, T.; HASEGAWA, S. A statistical approach for predicting accuracies of soil properties measured by single, double and dual gamma beams. Journal of Soil Science, Oxford (Grã-Bretanha), 42:127-37, 1991

MOLDRUP, P.; ROLSTON, D.E.; HANSEN, J.A.; YAMAGUCH, T. A simple, mechanistic model for soil resistance to plant water uptake. Soil Science, Baltimore (EUA), 153: 87-93, 1992

MOLZ, F.J. Water transport in the soil-root system: transient analysis. Water Resources Research, Washington (EUA), 12(4): 805-8, 1976

MOLZ, F.J. \& REMSON, I. Extraction term models of soil moisture use by transpiring plants. Water Resources Research, Washington (EUA), 6(5): 1346-56, 1970

MOLZ, F.J. \& REMSON, I. Application of an extraction-term model to the study of moisture flow to plant roots. Agronomy Journal, Madison (EUA), 63: 72-7, 1971

NEWMAN, E.I. Resistance to water flow in soil and plant, 2, A review of experimental evidence of the rhizosphere resistance. The Journal of Applied Ecology, Oxford (Grã-Bretanha), 6: 261-72, 1969

NIMAH, M.N. \& HANKS, R.J. Model for estimating soil water, plant and atmospheric interrelations: I. description and sensitivity. Soil Science Society of America Proceedings, Madison (EUA), 37: $522-7,1973$ 
OLIVEIRA, J.B. de \& PRADO, H. Carta pedológica semi-detalhada do Estado de São Paulo. Folha de Piracicaba, Campinas, Instituto Agronômico e São Paulo Instituto Geográfico e Cartográfico. 1989 (escala 1:100.000)

PAGE, E.R \& GERWITZ, A. Mathematical models, based on diffusion equations, to describe root systems of isolated plants, row crops, and swards. Plant and Soil, Haia (Holanda), 41:243-54, 1974

PAGES, L. \& ARIES, F. SARAH: modèle de simulation de la croissance, du développement et de l'architecture des systèmes racinaires. Agronomie, Paris (França), 8: 889-96, 1988

PASSIOURA, J.B. Water transport in and to roots. Annual review of plant physiology and plant molecular biology, 39: 245-65, 1988

PASSIOURA, J.B. \& COWAN, I.R On solving the non-linear diffusion equation for the radial flow of water to roots. Agricultural Meteorology, Amsterdam (Holanda), 5: 129-34, 1968

PEDROSA FILHO, L. de A. Montagem de um sistema para medição de umidade por atenuação de raios gama e seu uso no estudo da infiltração uni e bidimensional. São Carlos, 1980. 127p. (MestradoEscola de Engenharia de São Carlos)

RASIAH, V. \& KOHL, RA. Soybean root water uptake in two soils. Journal of Agricultural Water Management, Amsterdam (Holanda), 15:387-93, 1989

REGINATO, RJ. Gamma radiation measurements of bulk density changes in a soil pedon following irrigation. Soil Science Society of America Proceedings, Madison (EUA), 38:24-9, 1974

REICHAROT, K. \& LIBARDI, P.L. A new equation to estimate soil-water diffusivity. Isotope and Radiation Techniques in Soil Physics and Irrigation Studies 1973, Viena, Áustria (International Atomic Energy Agency), 45-51, 1974

REICOSKY, D.C.; MIILINGTON, RJ.; KLUTE, A.; PEIERS, D.B. Pattern of water uptake and root distribution of soybean in the presence of water table. Agronomy Journal, Madison (EUA), 64: 292-7, 1972

REICOSKY, D.C. \& RITCHIE, J.T. Relative importance of soil resistance and plant resistance in root water absorption: Soil Science Society of America Journal, Madison (EUA), 40: 293-7, 1976

RENDIG, V.V. \& TAYLOR, H.M. Principles of soil-plant interrelationships. (capitulo 4, p.117-39). New York, McGraw-Hill publishing company, 1989.

SARRUGE, J.R Soluções nutritivas. Summa Phytopathologica, Piracicaba (SP), 1: 231-3, 1975 
SLACK, D.C.; HAAN, C.T.; WELLS, L.G. Modeling soil water movement into plant roots. Transactions of the ASAE, St. Joseph (EUA), 20: 919-27, 1977

STEPHENS, D.B. \& REHFELDT, K.R. Evaluation of closed-form analytical models to calculate conductivity in a fine sand. Science Society of America Journal, Madison (EUA), 49: 12-9, 1985

TARDIEU, F.; BRUCKLER, L.; LAFOLIE, F. Root clumping may affect the root water potential and the resistance to soil-root water transport. Plant and Soil, Haia (Holanda), 140: 291-301, 1992

TARDIEU, F. \& MANICHON, H. Caractérisation en tant que capteur d'eau de l'enracinement du maĩs en parcelle cultivée. 2. Une méthode d'étude de la répartition verticale et horizontale des racines. Agronomie, Paris (França), 6:415-25, 1986

TAYLOR, H.M. \& KLEPPER, B. Water uptake by roots. Soil Science, Baltimore (EUA), 120: 57-67, 1975

THORNIHWAITE, C.W. \& MATHER, J.R. The water balance. Drexel Institute of Technology, 8(1):1-14, 1955

VAN GENUCHTEN, M.T. A closed-form equation for predicting the hydraulic conductivity of unsaturated soils. Soil Science Society of America Journal, Madison (EUA), 44: 892-7, 1980

VIDAL-TORRADO, P. \& SPAROVEK, G. Mapa pedológico detalhado do campus "Luiz de Queiroz", Piracicaba, Depto. de Ciência do Solo da ESALQ/USP. 1993 (escala 1:10.000)

WADLEIGH, C.H. The integrated soil moisture stress upon a root system in a large container of saline soil. Soil Science, Baltimore (EUA), 61: 225-38, 1946

WANG, J.; HESKETH, J.D.; WOOLLEY, J.T. Preexisting channels and soy-bean rooting patterns. Soil Science, Baltimore (EUA), 141: 432-7, 1986

WHISLER, F.D.; KLUTE, A.; MILLINGTON, R.J. Analysis of steady-state evapotranspiration from a soil column. Soil Science Society of America Proceedings, Madison (EUA), 32: 167-74, 1968

WILLAT, S.T. \& TAYLOR, H.M. Water uptake by soybean roots as affected by their depth and soil water content. Journal of Agricultural Science, Cambridge (Grã-Bretanha), 90:205-13, 1978

ZUCCHI, O.L.A.D. Equipamentos nucleares na determinação dos coeficientes de atenuação de massa de solos e da água. Piracicaba (SP), 82p. 1981 (Tese de Mestrado. USP/ESALQ).

ZUR, B.; JONES, J.W.; BOOTE, K.J.; HAMMOND, L.C. Total resistance to water flow in field soybeans: II. Limiting soil moisture. Agronomy Journal; Madison (EUA), 74: 99-105, 1982 


\section{APÊNDICE}

Umidades volumétricas $\left(\mathrm{m}^{3} \cdot \mathrm{m}^{-3}\right)$ medidas em função da distância $(\mathrm{m})$ da placa porosa. 
Solo LV, profundidade $0,04 \mathrm{~m}, 1$ a repetição, lado $\mathrm{A}$.

\begin{tabular}{|c|c|c|c|c|c|c|c|c|c|}
\hline \multirow{2}{*}{$\begin{array}{l}\text { distăncia } \\
\text { (m) }\end{array}$} & \multicolumn{9}{|c|}{ umidade $\left(\mathrm{m}^{3} \cdot \mathrm{m}^{3}\right)$} \\
\hline & $18 / 10793$ & $19 / 10 / 93$ & $20 / 10793$ & $1 / 10 / 93$ & $22710 / 93$ & $24 / 10 / 93$ & $26 / 10793$ & $28 / 10 / 93$ & $30710 / 93$ \\
\hline $\begin{array}{l}0,0007 \\
0,0021 \\
0,0035 \\
0,0049 \\
0,0063 \\
0,0077 \\
0,0091 \\
0,0105 \\
0,0119 \\
0,0133 \\
0,0147 \\
0,0161 \\
0,0175 \\
0,0189 \\
0,0203 \\
0,0217 \\
0,0231 \\
0,0245 \\
0,00259 \\
0,0273 \\
0,0287 \\
0,0301 \\
0,0315 \\
0,0329 \\
0,0343 \\
0,0357 \\
0,0371 \\
0,0385 \\
0,0399 \\
0,0413 \\
0,0427 \\
0,0441 \\
0,0455 \\
0,0469 \\
0,0483 \\
0,0497\end{array}$ & $\begin{array}{l}0,25422 \\
0,30035 \\
0,28813 \\
0,30593 \\
0,30516 \\
0,30945 \\
0,27929 \\
0,25175 \\
0,28242 \\
0,25669 \\
0,26259 \\
0,28534 \\
0,27958 \\
0,26271 \\
0,24293 \\
0,25281 \\
0,27666 \\
0,31291 \\
0,25948 \\
0,29269 \\
0,29693 \\
0,33358 \\
0,28799 \\
0,23149 \\
0,30863 \\
0,29879 \\
0,28945 \\
0,33366 \\
0,23366 \\
0,30366 \\
0,27043 \\
0,29696 \\
0,24565 \\
0,26527 \\
0,26328 \\
0,29930\end{array}$ & $\begin{array}{l}0,28834 \\
0,27469 \\
0,23760 \\
0,25820 \\
0,28874 \\
0,274112 \\
0,28121 \\
0,26614 \\
0,25729 \\
0,28764 \\
0,23116 \\
0,25958 \\
0,22504 \\
0,25973 \\
0,24589 \\
0,29293 \\
0,25546 \\
0,26733 \\
0,20645 \\
0,27492 \\
0,25015 \\
0,24929 \\
0,27947 \\
0,26984 \\
0,27906 \\
0,28041 \\
0,22986 \\
0,26123 \\
0,28410 \\
0,27108 \\
0,29708 \\
0,20425 \\
0,28082 \\
0,28448 \\
0,27294 \\
0,29624\end{array}$ & $\begin{array}{l}0,22114 \\
0,22190 \\
0,26227 \\
0,22519 \\
0,25367 \\
0,23523 \\
0,22357 \\
0,26865 \\
0,22858 \\
0,23418 \\
0,25454 \\
0,23531 \\
0,25929 \\
0,19734 \\
0,27153 \\
0,26055 \\
0,27370 \\
0,22888 \\
0,22708 \\
0,28962 \\
0,21148 \\
0,25175 \\
0,21349 \\
0,26923 \\
0,21171 \\
0,27095 \\
0,25182 \\
0,27033 \\
0,25845 \\
0,18286 \\
0,26397 \\
0,25176 \\
0,23298 \\
0,22161 \\
0,27354 \\
0,19244\end{array}$ & $\begin{array}{l}0,22808 \\
0,20754 \\
0,20884 \\
0,20822 \\
0,21968 \\
0,21125 \\
0,19986 \\
0,17608 \\
0,25665 \\
0,23107 \\
0,23914 \\
0,21987 \\
0,22504 \\
0,20608 \\
0,18256 \\
0,18473 \\
0,16663 \\
0,23989 \\
0,20988 \\
0,22890 \\
0,24089 \\
0,21569 \\
0,24388 \\
0,21522 \\
0,22088 \\
0,18487 \\
0,22804 \\
0,21321 \\
0,20723 \\
0,22294 \\
0,21159 \\
0,19753 \\
0,20781 \\
0,22726 \\
0,24825 \\
0,27006\end{array}$ & $\begin{array}{l}0,20220 \\
0,17412 \\
0,18343 \\
0,19840 \\
0,19788 \\
0,20574 \\
0,23928 \\
0,19617 \\
0,21340 \\
0,24042 \\
0,20676 \\
0,19596 \\
0,19818 \\
0,14834 \\
0,17851 \\
0,18821 \\
0,20204 \\
0,22252 \\
0,16736 \\
0,17011 \\
0,22676 \\
0,20116 \\
0,16941 \\
0,15640 \\
0,17053 \\
0,16846 \\
0,20326 \\
0,19365 \\
0,22924 \\
0,21682 \\
0,16829 \\
0,17263 \\
0,18536 \\
0,14609 \\
0,14999 \\
0,17251\end{array}$ & $\begin{array}{l}0,17834 \\
0,15665 \\
0,12019 \\
0,17825 \\
0,17256 \\
0,14982 \\
0,16529 \\
0,16579 \\
0,16897 \\
0,13937 \\
0,12661 \\
0,14516 \\
0,12369 \\
0,15635 \\
0,14002 \\
0,16970 \\
0,12497 \\
0,16091 \\
0,17355 \\
0,14847 \\
0,17636 \\
0,12380 \\
0,14735 \\
0,16995 \\
0,18439 \\
0,13535 \\
0,19425 \\
0,11393 \\
0,16745 \\
0,09979 \\
0,11589 \\
0,16117 \\
0,16864 \\
0,13088 \\
0,13444 \\
0,11815\end{array}$ & $\begin{array}{l}158 \\
60 \\
16 \\
28 \\
52 \\
33 \\
01 \\
53 \\
26 \\
45 \\
68 \\
61 \\
54 \\
65 \\
37 \\
10 \\
82 \\
97 \\
26 \\
84 \\
50 \\
05 \\
42 \\
35 \\
49 \\
67 \\
76 \\
25 \\
11 \\
79 \\
50 \\
09 \\
64 \\
53 \\
18 \\
11\end{array}$ & $\begin{array}{l}0,13387 \\
0,08045 \\
0,09619 \\
0,11840 \\
0,09145 \\
0,09943 \\
0,11487 \\
0,11076 \\
0,07745 \\
0,11364 \\
0,11192 \\
0,07539 \\
0,14924 \\
0,10022 \\
0,12353 \\
0,09806 \\
0,05440 \\
0,05691 \\
0,09631 \\
0,11431 \\
0,07251 \\
0,12498 \\
0,10434 \\
0,10632 \\
0,12466 \\
0,10323 \\
0,14377 \\
0,16252 \\
0,06692 \\
0,12032 \\
0,13366 \\
0,15817 \\
0,14407 \\
0,13695 \\
0,14537 \\
0,09705\end{array}$ & $\begin{array}{l}0,07895 \\
0,14051 \\
0,11959 \\
0,12138 \\
0,09503 \\
0,12303 \\
0,11487 \\
0,15132 \\
0,08406 \\
0,08404 \\
0,09148 \\
0,06781 \\
0,13445 \\
0,07009 \\
0,09533 \\
0,06128 \\
0,11049 \\
0,04932 \\
0,12052 \\
0,08570 \\
0,09518 \\
0,14028 \\
0,10661 \\
0,16169 \\
0,14422 \\
0,15276 \\
0,11393 \\
0,12024 \\
0,15636 \\
0,11620 \\
0,16083 \\
0,13661 \\
0,14223 \\
0,11093 \\
0,10530 \\
0,14057\end{array}$ \\
\hline
\end{tabular}

Solo $\mathrm{LV}$, profundidade $0,04 \mathrm{~m}, 1$ a repetição, lado B.

\begin{tabular}{|c|c|c|c|c|c|c|c|c|c|}
\hline \multirow{2}{*}{$\begin{array}{c}\text { distância } \\
\text { (m) }\end{array}$} & \multicolumn{9}{|c|}{ umidade $\left(\mathrm{m}^{\mathrm{s}} \cdot \mathrm{m}\right)$} \\
\hline & $18710 / 93$ & $19 / 10 / 93$ & 20710793 & 80 & $22 / 10 / 93$ & $\frac{1}{24 / 10 / 93}$ & $26 / 10 / 93$ & $28 / 10 / 93$ & $30 / 10 / 93$ \\
\hline $\begin{array}{l}0,0007 \\
0,0021 \\
0,0035 \\
0,0049 \\
0,0063 \\
0,0077 \\
0,0091 \\
0,0105 \\
0,0119 \\
0,0133 \\
0,0147 \\
0,0161 \\
0,0175 \\
0,0189 \\
0,0203 \\
0,0017 \\
0,0231 \\
0,0245 \\
0,0259 \\
0,0273 \\
0,0287 \\
0,0301 \\
0,0315 \\
0,0329 \\
0,00343 \\
0,0357 \\
0,0371 \\
0,00385 \\
0,0399 \\
0,0413 \\
0,0427 \\
0,0441 \\
0,0455 \\
0,0469 \\
0,0483 \\
0,0497\end{array}$ & $\begin{array}{l}0,27936 \\
0,30704 \\
0,33247 \\
0,29513 \\
0,26746 \\
0,31558 \\
0,29193 \\
0,27780 \\
0,27111 \\
0,26704 \\
0,31137 \\
0,28178 \\
0,32018 \\
0,, 29950 \\
0,30491 \\
0,24542 \\
0,22679 \\
0,31966 \\
0,24082 \\
0,27156 \\
0,27509 \\
0,24225 \\
0,25974 \\
0,33087 \\
0,23196 \\
0,22920 \\
0,27397 \\
0,29123 \\
0,29690 \\
0,31700 \\
0,24868 \\
0,27833 \\
0,31221 \\
0,30691 \\
0,29981 \\
0,25698\end{array}$ & $\begin{array}{l}0,26746 \\
0,27285 \\
0,24487 \\
0,24009 \\
0,27058 \\
0,29467 \\
0,26588 \\
0,22516 \\
0,23207 \\
0,21881 \\
0,23919 \\
0,25567 \\
0,28294 \\
0,26952 \\
0,25700 \\
0,25297 \\
0,27266 \\
0,27003 \\
0,29609 \\
0,24419 \\
0,30053 \\
0,24636 \\
0,26496 \\
0,23951 \\
0,26437 \\
0,23763 \\
0,25422 \\
0,23520 \\
0,24837 \\
0,27821 \\
0,28570 \\
0,26198 \\
0,28405 \\
0,30295 \\
0,23121 \\
0,25199\end{array}$ & $\begin{array}{l}0,21293 \\
0,27069 \\
0,22194 \\
0,21619 \\
0,22437 \\
0,24829 \\
0,26082 \\
0,19225 \\
0,20453 \\
0,22188 \\
0,21298 \\
0,24662 \\
0,24065 \\
0,23862 \\
0,24182 \\
0,20117 \\
0,21147 \\
0,27125 \\
0,23862 \\
0,23310 \\
0,24406 \\
0,19744 \\
0,20403 \\
0,29383 \\
0,23320 \\
0,25699 \\
0,26376 \\
0,23089 \\
0,27439 \\
0,19686 \\
0,25439 \\
0,20002 \\
0,2971 \\
0,25401 \\
0,26847 \\
0,20631\end{array}$ & $\begin{array}{l}0,18888 \\
0,23026 \\
0,17515 \\
0,22934 \\
0,20476 \\
0,21792 \\
0,21824 \\
0,27281 \\
0,19966 \\
0,24901 \\
0,23500 \\
0,27142 \\
0,21180 \\
0,22798 \\
0,23215 \\
0,17045 \\
0,25832 \\
0,19875 \\
0,25801 \\
0,20721 \\
0,22493 \\
0,21017 \\
0,17183 \\
0,19107 \\
0,20729 \\
0,21481 \\
0,26440 \\
0,24570 \\
0,26445 \\
0,21378 \\
0,20903 \\
0,20799 \\
0,19186 \\
0,25401 \\
0,22119 \\
0,20386\end{array}$ & $\begin{array}{l}0,19331 \\
0,18954 \\
0,20104 \\
0,18194 \\
0,22099 \\
0,19127 \\
0,22322 \\
0,19771 \\
0,21368 \\
0,21147 \\
0,20352 \\
0,24061 \\
0,19294 \\
0,23486 \\
0,17545 \\
0,20179 \\
0,16962 \\
0,20349 \\
0,18180 \\
0,20940 \\
0,16945 \\
0,20727 \\
0,23778 \\
0,16242 \\
0,18162 \\
0,19100 \\
0,19209 \\
0,20275 \\
0,17597 \\
0,20772 \\
0,21717 \\
0,17259 \\
0,18181 \\
0,21294 \\
0,22119 \\
0,14463\end{array}$ & $\begin{array}{l}0,13156 \\
0,12068 \\
0,13991 \\
0,12178 \\
0,12832 \\
0,16214 \\
0,12185 \\
0,18077 \\
0,12355 \\
0,15522 \\
0,13414 \\
0,17591 \\
0,15741 \\
0,12867 \\
0,11068 \\
0,14128 \\
0,11542 \\
0,11840 \\
0,12458 \\
0,14812 \\
0,16379 \\
0,15962 \\
0,16454 \\
0,18747 \\
0,17737 \\
0,13237 \\
0,12410 \\
0,15031 \\
0,19646 \\
0,14376 \\
0,12479 \\
0,12154 \\
0,15746 \\
0,15748 \\
0,13209 \\
0,10256\end{array}$ & $\begin{array}{l}0,11828 \\
0,124118 \\
0,10927 \\
0,08376 \\
0,11117 \\
0,10690 \\
0,13326 \\
0,08944 \\
0,09476 \\
0,12546 \\
0,13242 \\
0,10759 \\
0,13300 \\
0,09043 \\
0,14842 \\
0,09573 \\
0,09955 \\
0,16469 \\
0,10140 \\
0,08244 \\
0,13346 \\
0,15677 \\
0,16678 \\
0,14643 \\
0,16949 \\
0,11676 \\
0,14474 \\
0,11532 \\
0,11426 \\
0,12434 \\
0,14301 \\
0,12154 \\
0,14692 \\
0,06791 \\
0,12484 \\
0,08323\end{array}$ & $\begin{array}{l}0,10908 \\
0,09079 \\
0,10809 \\
0,10504 \\
0,10557 \\
0,08873 \\
0,13085 \\
0,16093 \\
0,08018 \\
0,10365 \\
0,06315 \\
0,06505 \\
0,08540 \\
0,12326 \\
0,11068 \\
0,07206 \\
0,12073 \\
0,09327 \\
0,13784 \\
0,04968 \\
0,09795 \\
0,06348 \\
0,12176 \\
0,06333 \\
0,11614 \\
0,06254 \\
0,08507 \\
0,14196 \\
0,12249 \\
0,14140 \\
0,10128 \\
0,16956 \\
0,11126 \\
0,14069 \\
0,10622 \\
0,13033\end{array}$ & $\begin{array}{l}0,10707 \\
0,08790 \\
0,09481 \\
0,10592 \\
0,12091 \\
0,12008 \\
0,11108 \\
0,09178 \\
0,10002 \\
0,07911 \\
0,05979 \\
0,07972 \\
0,15323 \\
0,08095 \\
0,14491 \\
0,12561 \\
0,10365 \\
0,12932 \\
0,07063 \\
0,15241 \\
0,11454 \\
0,11447 \\
0,11681 \\
0,08056 \\
0,10312 \\
0,14691 \\
0,11384 \\
0,13009 \\
0,06486 \\
0,07379 \\
0,10008 \\
0,14485 \\
0,11004 \\
0,07154 \\
0,06170 \\
0,14463\end{array}$ \\
\hline
\end{tabular}




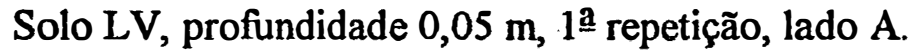

\begin{tabular}{|c|c|c|c|c|c|c|c|c|c|}
\hline $\begin{array}{l}\text { distancia } \\
\text { (m) }\end{array}$ & $18 / 10 / 93$ & $19 / 10 / 93$ & 20710793 & 21710793 & $\frac{10 \mathrm{de}(\mathrm{m})}{22 / 10 / 93}$ & $24710 / 93$ & $26 / 10793$ & $28 / 10 / 93$ & $30710 / 93$ \\
\hline $\begin{array}{l}0,0007 \\
0,0021 \\
0,0035 \\
0,0049 \\
0,0063 \\
0,0077 \\
0,0091 \\
0,0105 \\
0,0119 \\
0,0133 \\
0,0147 \\
0,0161 \\
0,0175 \\
0,0189 \\
0,0203 \\
0,0217 \\
0,0231 \\
0,0245 \\
0,0259 \\
0,0273 \\
0,0287 \\
0,0301 \\
0,0315 \\
0,0329 \\
0,0343 \\
0,0357 \\
0,0371 \\
0,0385 \\
0,0399 \\
0,0413 \\
0,0427 \\
0,0441 \\
0,0455 \\
0,0469 \\
0,0483 \\
\end{array}$ & $\begin{array}{l}0,27603 \\
0,29270 \\
0,29647 \\
0,32532 \\
0,26445 \\
0,24299 \\
0,27002 \\
0,25704 \\
0,23947 \\
0,31379 \\
0,28937 \\
0,28599 \\
0,26493 \\
0,24873 \\
0,23586 \\
0,30068 \\
0,27773 \\
0,25665 \\
0,28131 \\
0,28353 \\
0,27916 \\
0,24024 \\
0,30061 \\
0,29527 \\
0,28454 \\
0,25326 \\
0,27845 \\
0,24607 \\
0,25852 \\
0,26625 \\
0,28995 \\
0,26450 \\
0,32141 \\
0,25243 \\
0,25879 \\
\end{array}$ & $\begin{array}{l}0,26324 \\
0,25224 \\
0,21607 \\
0,27091 \\
0,25892 \\
0,27103 \\
0,29424 \\
0,28595 \\
0,26343 \\
0,24479 \\
0,27708 \\
0,20344 \\
0,25811 \\
0,23384 \\
0,28749 \\
0,27874 \\
0,25040 \\
0,27121 \\
0,27037 \\
0,30157 \\
0,23152 \\
0,22699 \\
0,25163 \\
0,24002 \\
0,24621 \\
0,23480 \\
0,25323 \\
0,30317 \\
0,30580 \\
0,30800 \\
0,27052 \\
0,28862 \\
0,26347 \\
0,24827 \\
0,25465 \\
\end{array}$ & $\begin{array}{l}0,27693 \\
0,22383 \\
0,19649 \\
0,25963 \\
0,23090 \\
0,21465 \\
0,25010 \\
0,20238 \\
0,21854 \\
0,22925 \\
0,26485 \\
0,25324 \\
0,21808 \\
0,25793 \\
0,26707 \\
0,24198 \\
0,28610 \\
0,19479 \\
0,22535 \\
0,25314 \\
0,2133 \\
0,24198 \\
0,25163 \\
0,24237 \\
0,21067 \\
0,21248 \\
0,27139 \\
0,24665 \\
0,23260 \\
0,20482 \\
0,22455 \\
0,28015 \\
0,24282 \\
0,25421 \\
0,19851 \\
\end{array}$ & $\begin{array}{l}0,22172 \\
0,18699 \\
0,23698 \\
0,21584 \\
0,23781 \\
0,19035 \\
0,18436 \\
0,19675 \\
0,20617 \\
0,19674 \\
0,19544 \\
0,22709 \\
0,21528 \\
0,21450 \\
0,26184 \\
0,24018 \\
0,21109 \\
0,21232 \\
0,20172 \\
0,22485 \\
0,21960 \\
0,21551 \\
0,18620 \\
0,20497 \\
0,19558 \\
0,17513 \\
0,22075 \\
0,20545 \\
0,20637 \\
0,24444 \\
0,17030 \\
0,17883 \\
0,18417 \\
0,23346 \\
0,23581 \\
\end{array}$ & $\begin{array}{l}0,18458 \\
0,17194 \\
0,15717 \\
0,18051 \\
0,21943 \\
0,20740 \\
0,23438 \\
0,20689 \\
0,21966 \\
0,16293 \\
0,18753 \\
0,20849 \\
0,22200 \\
0,17680 \\
0,20216 \\
0,17167 \\
0,21925 \\
0,19806 \\
0,15398 \\
0,15254 \\
0,21620 \\
0,20865 \\
0,16179 \\
0,17553 \\
0,21123 \\
0,19374 \\
0,21211 \\
0,19355 \\
0,18827 \\
0,17663 \\
0,18447 \\
0,19750 \\
0,19484 \\
0,17389 \\
0,23816 \\
\end{array}$ & $\begin{array}{l}0,12558 \\
0,15209 \\
0,14314 \\
0,11514 \\
0,12468 \\
0,13478 \\
0,16845 \\
0,11861 \\
0,15175 \\
0,16966 \\
0,16896 \\
0,12608 \\
0,14304 \\
0,10293 \\
0,19536 \\
0,16235 \\
0,16260 \\
0,13645 \\
0,12987 \\
0,16685 \\
0,16910 \\
0,17574 \\
0,13651 \\
0,15324 \\
0,16289 \\
0,16616 \\
0,14569 \\
0,11170 \\
0,10120 \\
0,16065 \\
0,15340 \\
0,11107 \\
0,12967 \\
0,14402 \\
0,13729\end{array}$ & $\begin{array}{l}0,08473 \\
0,10493 \\
0,13431 \\
0,11430 \\
0,11889 \\
0,10309 \\
0,13637 \\
0,12407 \\
0,12549 \\
0,11465 \\
0,13110 \\
0,14796 \\
0,07269 \\
0,06461 \\
0,13658 \\
0,10202 \\
0,11103 \\
0,09405 \\
0,14848 \\
0,14741 \\
0,07194 \\
0,12490 \\
0,14363 \\
0,10472 \\
0,12137 \\
0,15052 \\
0,08087 \\
0,10021 \\
0,17198 \\
0,07499 \\
0,14274 \\
0,15106 \\
0,08593 \\
0,09533 \\
0,15317\end{array}$ & $\begin{array}{l}0,10200 \\
0,08641 \\
0,13317 \\
0,12161 \\
0,11834 \\
0,11650 \\
0,06296 \\
0,11479 \\
0,09356 \\
0,09438 \\
0,13220 \\
0,13755 \\
0,13597 \\
0,14844 \\
0,12994 \\
0,12313 \\
0,11890 \\
0,07623 \\
0,14025 \\
0,13888 \\
0,11953 \\
0,08261 \\
0,12069 \\
0,14187 \\
0,09440 \\
0,10852 \\
0,12002 \\
0,12269 \\
0,11488 \\
0,14195 \\
0,13269 \\
0,09130 \\
0,12329 \\
0,14287 \\
0,15374\end{array}$ & $\begin{array}{l}0,11854 \\
0,11142 \\
0,10826 \\
0,10841 \\
0,12303 \\
0,12099 \\
0,13973 \\
0,08333 \\
0,13421 \\
0,09984 \\
0,11841 \\
0,11304 \\
0,11758 \\
0,10511 \\
0,10191 \\
0,08051 \\
0,14435 \\
0,16168 \\
0,07215 \\
0,11119 \\
0,07945 \\
0,07120 \\
0,12613 \\
0,13904 \\
0,09869 \\
0,07474 \\
0,09624 \\
0,12600 \\
0,11378 \\
0,10547 \\
0,12656 \\
0,08455 \\
0,09909 \\
0,06244 \\
0,09018\end{array}$ \\
\hline
\end{tabular}

Solo LV, profundidade $0,05 \mathrm{~m}, 1^{\mathrm{a}}$ repetição, lado $\mathrm{B}$.

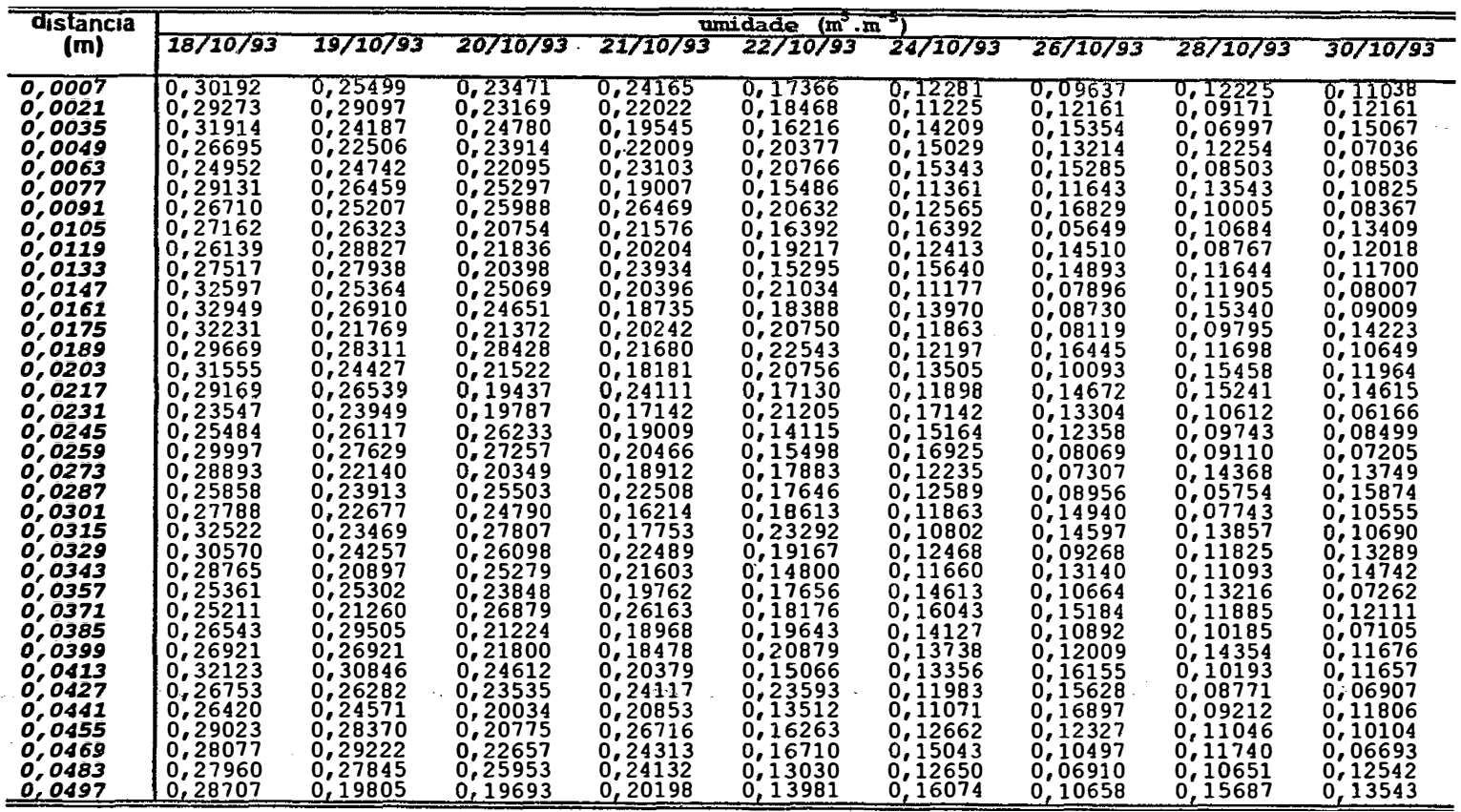


Solo $\mathrm{LV}$, profundidade $0,06 \mathrm{~m}, 1 \mathrm{a}$ repetição, lado $\mathrm{A}$.

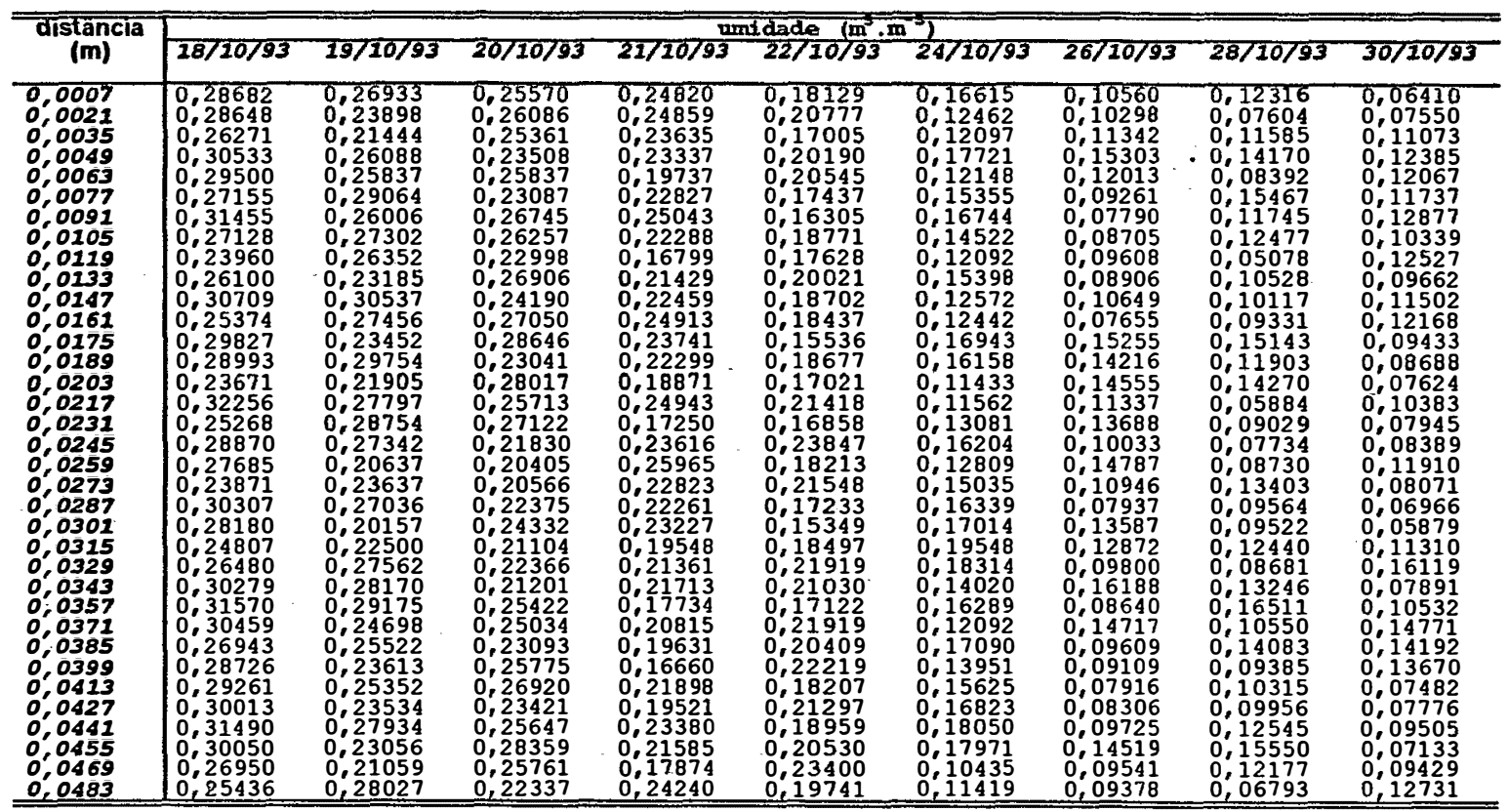

Solo $\mathrm{LV}$, profundidade $0,06 \mathrm{~m}, 1^{\mathrm{a}}$ repetição, lado B.

\begin{tabular}{|c|c|c|c|c|c|c|c|c|c|}
\hline $\begin{array}{l}\text { distān } \\
\text { (m) }\end{array}$ & $8 / 10 / 93$ & $19 / 10 / 93$ & $20 / 10793$ & $21 / 10 / 93$ & $\frac{1 \text { dade }\left(\mathrm{m}^{3}\right.}{22 / 10 / 93}$ & $\frac{1}{24 / 10 / 93}$ & 26710793 & 28710793 & $30 / 10 / 93$ \\
\hline $\begin{array}{l}0,0007 \\
0,0021 \\
0,0035 \\
0,0049 \\
0,0063 \\
0,0077 \\
0,0091 \\
0,0105 \\
0,019 \\
0,0133 \\
0,0147 \\
0,0161 \\
0,0175 \\
0,0189 \\
0,0203 \\
0,0217 \\
0,0231 \\
0,0245 \\
0,0259 \\
0,0273 \\
0,0287 \\
0,0301 \\
0,0315 \\
0,00329 \\
0,00343 \\
0,0357 \\
0,00371 \\
0,0385 \\
0,0399 \\
0,0413 \\
0,0427 \\
0,0441 \\
0,0455 \\
0,0469 \\
0,0483\end{array}$ & $\begin{array}{l}0,28255 \\
0,26708 \\
0,29360 \\
0,29975 \\
0,28107 \\
0,26079 \\
0,25859 \\
0,26555 \\
0,25207 \\
0,29212 \\
0,28160 \\
0,29005 \\
0,30870 \\
0,27892 \\
0,25589 \\
0,30545 \\
0,27818 \\
0,25999 \\
0,29849 \\
0,26392 \\
0,28805 \\
0,27003 \\
0,27717 \\
0,24911 \\
0,29849 \\
0,28680 \\
0,23914 \\
0,33283 \\
0,26990 \\
0,32050 \\
0,27047 \\
0,30087 \\
0,29837 \\
0,26409 \\
0,27985 \\
\end{array}$ & $\begin{array}{l}0,23140 \\
0,25924 \\
0,26281 \\
0,24784 \\
0,23915 \\
0,24256 \\
0,23019 \\
0,22447 \\
0,28907 \\
0,23263 \\
0,21981 \\
0,22904 \\
0,24129 \\
0,22600 \\
0,26812 \\
0,27741 \\
0,28781 \\
0,23664 \\
0,28141 \\
0,24486 \\
0,24312 \\
0,28170 \\
0,20987 \\
0,22208 \\
0,28758 \\
0,24489 \\
0,27988 \\
0,29878 \\
0,27826 \\
0,26126 \\
0,25051 \\
0,23605 \\
0,27338 \\
0,24782 \\
0,28914\end{array}$ & $\begin{array}{l}0,21551 \\
0,25083 \\
0,22268 \\
0,21911 \\
0,25052 \\
0,27711 \\
0,23423 \\
0,25492 \\
0,24740 \\
0,20279 \\
0,24595 \\
0,22572 \\
0,26902 \\
0,21690 \\
0,29216 \\
0,24008 \\
0,21409 \\
0,20464 \\
0,24278 \\
0,24605 \\
0,23025 \\
0,21244 \\
0,24215 \\
0,28958 \\
0,22247 \\
0,24720 \\
0,29340 \\
0,24257 \\
0,21499 \\
0,25828 \\
0,25930 \\
0,21149 \\
0,23400 \\
0,22588 \\
0,23731 \\
\end{array}$ & $\begin{array}{l}0,20590 \\
0,18681 \\
0,20255 \\
0,23488 \\
0,21310 \\
0,20617 \\
0,18334 \\
0,24845 \\
0,25265 \\
0,25567 \\
0,19336 \\
0,18621 \\
0,24429 \\
0,20558 \\
0,27221 \\
0,27196 \\
0,21057 \\
0,23783 \\
0,26022 \\
0,20949 \\
0,27141 \\
0,19201 \\
0,23173 \\
0,20983 \\
0,22542 \\
0,21103 \\
0,23279 \\
0,, 19680 \\
0,19113 \\
0,22445 \\
0,24525 \\
0,21266 \\
0,17284 \\
0,17747 \\
0,24989\end{array}$ & $\begin{array}{l}0,18960 \\
0,18822 \\
0,18791 \\
0,17434 \\
0,18531 \\
0,19906 \\
0,23423 \\
0,19263 \\
0,24449 \\
0,15263 \\
0,21698 \\
0,18022 \\
0,19315 \\
0,24544 \\
0,19726 \\
0,16985 \\
0,16930 \\
0,2652 \\
0,19350 \\
0,21652 \\
0,15658 \\
0,20789 \\
0,17571 \\
0,14145 \\
0,17566 \\
0,22132 \\
0,21728 \\
0,17594 \\
0,16233 \\
0,16843 \\
0,18181 \\
0,18888 \\
0,16885 \\
0,22014 \\
0,17418\end{array}$ & $\begin{array}{l}0,15978 \\
0,13728 \\
0,11750 \\
0,12175 \\
0,10831 \\
0,15515 \\
0,18504 \\
0,15718 \\
0,19036 \\
0,140110 \\
0,16107 \\
0,15696 \\
0,14760 \\
0,12539 \\
0,17292 \\
0,10027 \\
0,15435 \\
0,12113 \\
0,17123 \\
0,16707 \\
0,09484 \\
0,14882 \\
0,13473 \\
0,16253 \\
0,14797 \\
0,17422 \\
0,15946 \\
0,20321 \\
0,10955 \\
0,15806 \\
0,10705 \\
0,18658 \\
0,12591 \\
0,16395 \\
0,16861\end{array}$ & 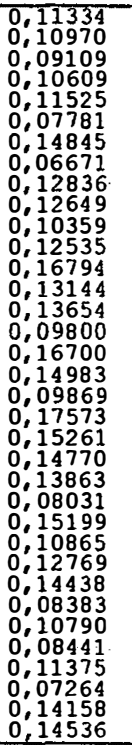 & $\begin{array}{l}0,10057 \\
0,11025 \\
0,11094 \\
0,09816 \\
0,10970 \\
0,16102 \\
0,12674 \\
0,11883 \\
0,14849 \\
0,10733 \\
0,09062 \\
0,12110 \\
0,14297 \\
0,092114 \\
0,09080 \\
0,08612 \\
0,08919 \\
0,08822 \\
0,09132 \\
0,16764 \\
0,11210 \\
0,14548 \\
0,09601 \\
0,07145 \\
0,07045 \\
0,08679 \\
0,10726 \\
0,09352 \\
0,10562 \\
0,09383 \\
0,11760 \\
0,12951 \\
0,15069 \\
0,12769 \\
0,15751\end{array}$ & $\begin{array}{l}75 \\
38 \\
31 \\
57 \\
17 \\
1 \\
1 \\
38 \\
37 \\
72 \\
32 \\
39 \\
4 \\
31 \\
36 \\
30 \\
99 \\
2 \\
2 \\
3 \\
35 \\
0 \\
5 \\
39 \\
4 \\
37 \\
71 \\
36 \\
33 \\
16 \\
32 \\
9 \\
94 \\
1 \\
58\end{array}$ \\
\hline
\end{tabular}


Solo LV, profundidade $0,04 \mathrm{~m}, 2^{\mathrm{a}}$ repetição, lado $\mathrm{A}$.

\begin{tabular}{|c|c|c|c|c|c|c|c|c|c|}
\hline $\begin{array}{c}\text { distancia } \\
\text { (m) }\end{array}$ & $18710 / 93$ & $19 / 10 / 93$ & $20 / 10 / 93$ & $21 / 10 / 93$ & $\frac{d \text { dade }(\mathrm{m})}{22 / 10 / 93}$ & $\frac{1}{24 / 10 / 93}$ & $26 / 10 / 93$ & $28 / 10 / 93$ & $30710 / 93$ \\
\hline 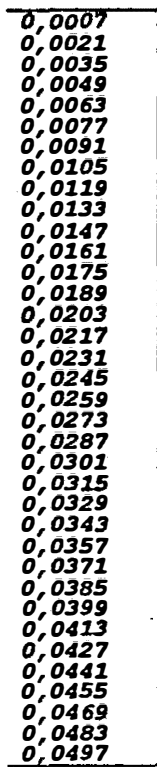 & 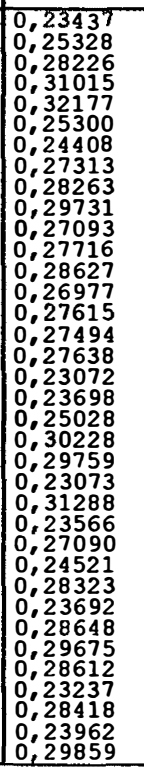 & $\begin{array}{l}0,21697 \\
0,27418 \\
0,24199 \\
0,22384 \\
0,26078 \\
0,25810 \\
0,21986 \\
0,27134 \\
0,28632 \\
0,20619 \\
0,21797 \\
0,22874 \\
0,22839 \\
0,25534 \\
0,24035 \\
0,21245 \\
0,23883 \\
0,24401 \\
0,28081 \\
0,24545 \\
0,20021 \\
0,21645 \\
0,28448 \\
0,27639 \\
0,28199 \\
0,23565 \\
0,30029 \\
0,29162 \\
0,23090 \\
0,24338 \\
0,26451 \\
0,29337 \\
0,24848 \\
0,23315 \\
0,23783 \\
0,25531\end{array}$ & 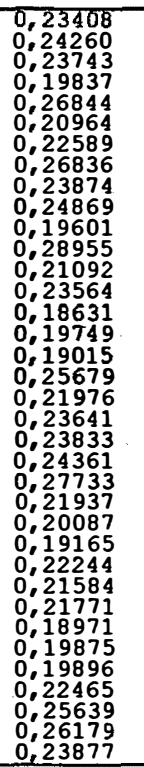 & 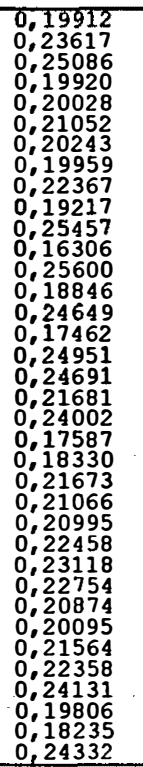 & 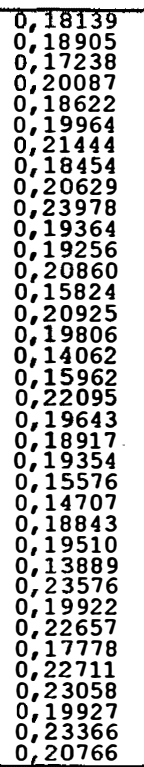 & 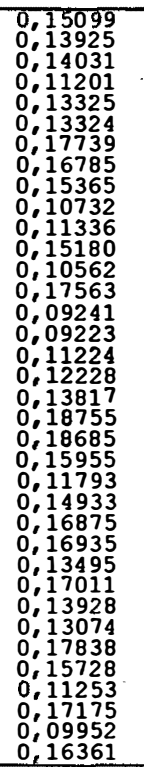 & 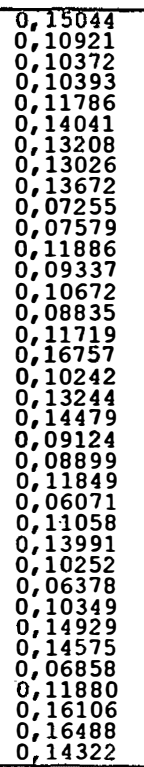 & 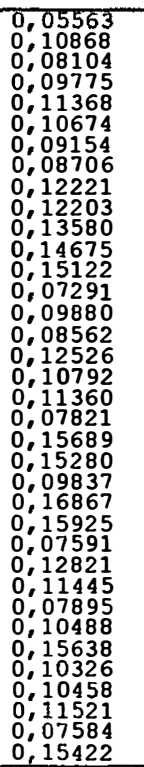 & 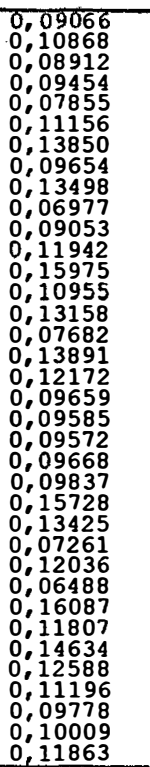 \\
\hline
\end{tabular}

Solo LV, profundidade $0,04 \mathrm{~m}, 2^{\mathrm{a}}$ repetição, lado B.

\begin{tabular}{|c|c|c|c|c|c|c|c|c|c|}
\hline $\begin{array}{l}\text { distancla } \\
\text { (m) }\end{array}$ & $18 / 10 / 93$ & $19 / 10793$ & $20710 / 93$ & $21 / 10 / 93$ & $\frac{\text { indade }(\mathrm{m} \text {. }}{22 / 10 / 93}$ & $24 / 10 / 93$ & $26 / 10 / 93$ & $28 / 10 / 93$ & $30 / 10793$ \\
\hline 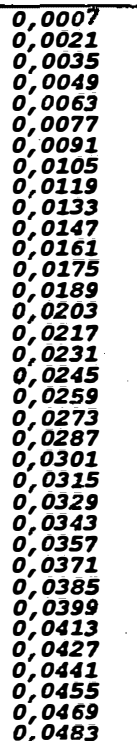 & 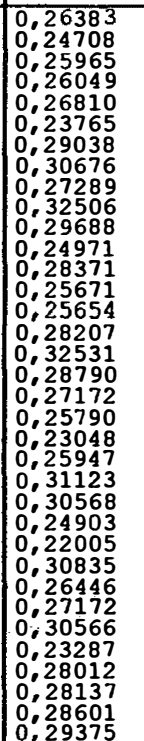 & 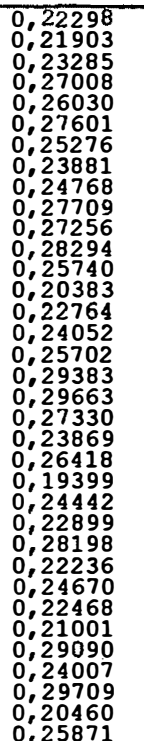 & $\begin{array}{l}0,21392 \\
0,20994 \\
0,20138 \\
0,23346 \\
0,24685 \\
0,20658 \\
0,26762 \\
0,21730 \\
0,25339 \\
0,28070 \\
0,24487 \\
0,21992 \\
0,22605 \\
0,25371 \\
0,21535 \\
0,22661 \\
0,17431 \\
0,20852 \\
0,24990 \\
0,22624 \\
0,24634 \\
0,27777 \\
0,22126 \\
0,28390 \\
0,21874 \\
0,25434 \\
0,23610 \\
0,23669 \\
0,24568 \\
0,22622 \\
0,20109 \\
0,25462 \\
0,27949 \\
0,27450 \\
0,22413\end{array}$ & 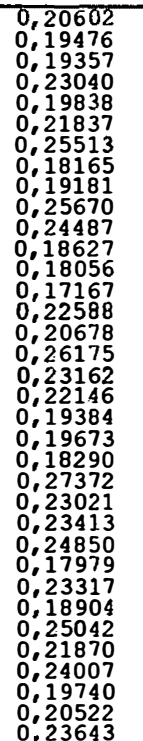 & 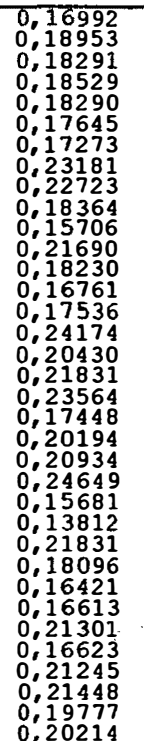 & 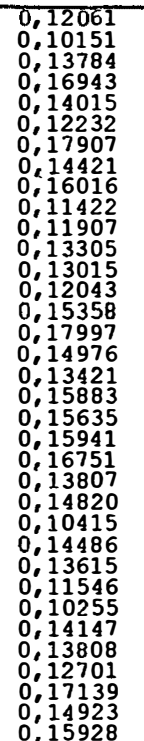 & 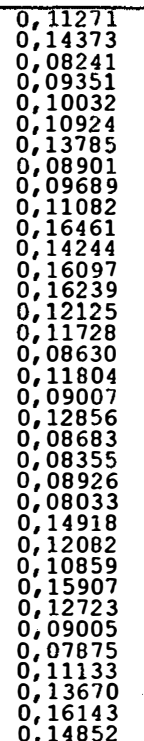 & 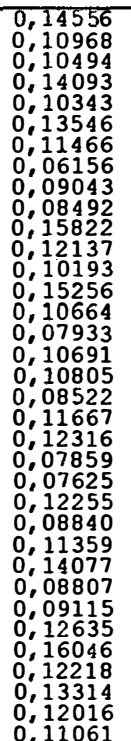 & 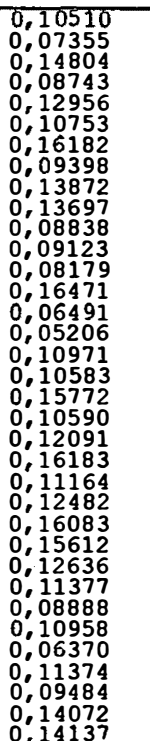 \\
\hline
\end{tabular}


Solo $\mathrm{LV}$, profundidade $0,05 \mathrm{~m}, 2^{\underline{a}}$ repetição, lado $\mathrm{A}$.

\begin{tabular}{|c|c|c|c|c|c|c|c|c|c|}
\hline \multirow{2}{*}{$\begin{array}{l}\text { distancia } \\
\text { (m) }\end{array}$} & \multirow[b]{2}{*}{$18 / 10 / 93$} & \multirow[b]{2}{*}{$19 / 10 / 93$} & \multirow{2}{*}{20710793} & \multicolumn{2}{|c|}{ unidade $\left(\mathrm{m}^{5} \cdot \mathrm{m}\right.$} & \multirow{2}{*}{ रो $24 / 10 / 93$} & \multirow[b]{2}{*}{$26 / 10793$} & \multirow[b]{2}{*}{$28 / 10 / 93$} & \multirow[b]{2}{*}{$30 / 10 / 93$} \\
\hline & & & & $21 / 10 / 93$ & $22 / 10 / 93$ & & & & \\
\hline $\begin{array}{l}0,0007 \\
0,0021 \\
0,0035 \\
0,0049 \\
0,0063 \\
0,0077 \\
0,0091 \\
0,0105 \\
0,0119 \\
0,0133 \\
0,0147 \\
0,0161 \\
0,0175 \\
0,0189 \\
0,0203 \\
0,0217 \\
0,0231 \\
0,0245 \\
0,0259 \\
0,0273 \\
0,0287 \\
0,0301 \\
0,0315 \\
0,0329 \\
0,0343 \\
0,0357 \\
0,0371 \\
0,0385 \\
0,0399 \\
0,0413 \\
0,0427 \\
0,0441 \\
0,0455 \\
0,0469 \\
0,0483 \\
0,0497\end{array}$ & $\begin{array}{l}0,25892 \\
0,28576 \\
0,26966 \\
0,30258 \\
0,24045 \\
0,25368 \\
0,25567 \\
0,25283 \\
0,30941 \\
0,25732 \\
0,25188 \\
0,30046 \\
0,26021 \\
0,25648 \\
0,28403 \\
0,25481 \\
0,25509 \\
0,24660 \\
0,27840 \\
0,24853 \\
0,29787 \\
0,27033 \\
0,32914 \\
0,25882 \\
0,25710 \\
0,26224 \\
0,28745 \\
0,26146 \\
0,30562 \\
0,25924 \\
0,28966 \\
0,31651 \\
0,28410 \\
0,24752 \\
0,31994 \\
0,26838 \\
\end{array}$ & $\begin{array}{l}0,26377 \\
0,25181 \\
0,26214 \\
0,27165 \\
0,27941 \\
0,24671 \\
0,26879 \\
0,23463 \\
0,28906 \\
0,23062 \\
0,28970 \\
0,28153 \\
0,29534 \\
0,22459 \\
0,22358 \\
0,22658 \\
0,21277 \\
0,28699 \\
0,29669 \\
0,22439 \\
0,27311 \\
0,26972 \\
0,27838 \\
0,24928 \\
0,21696 \\
0,25750 \\
0,29221 \\
0,28239 \\
0,29316 \\
0,23113 \\
0,24137 \\
0,25802 \\
0,26265 \\
0,23847 \\
0,28917 \\
0,21417 \\
\end{array}$ & $\begin{array}{l}0,23659 \\
0,23976 \\
0,22547 \\
0,22962 \\
0,20686 \\
0,26402 \\
0,26461 \\
0,23522 \\
0,21673 \\
0,20934 \\
0,22991 \\
0,26758 \\
0,25900 \\
0,25945 \\
0,24217 \\
0,27261 \\
0,28092 \\
0,20117 \\
0,23582 \\
0,18294 \\
0,23988 \\
0,21976 \\
0,27539 \\
0,25942 \\
0,22053 \\
0,22225 \\
0,23618 \\
0,27041 \\
0,24968 \\
0,24270 \\
0,22880 \\
0,21406 \\
0,20886 \\
0,25661 \\
0,22987 \\
0,25880 \\
\end{array}$ & $\begin{array}{l}0,20730 \\
0,22073 \\
0,21684 \\
0,21391 \\
0,21017 \\
0,21453 \\
0,23435 \\
0,17159 \\
0,25589 \\
0,21106 \\
0,21517 \\
0,21782 \\
0,25060 \\
0,21171 \\
0,20273 \\
0,22658 \\
0,23240 \\
0,23460 \\
0,21450 \\
0,17338 \\
0,21335 \\
0,20786 \\
0,24743 \\
0,24096 \\
0,18562 \\
0,22751 \\
0,25434 \\
0,23007 \\
0,20461 \\
0,23113 \\
0,21629 \\
0,25617 \\
0,22748 \\
0,24269 \\
0,20425 \\
0,22804 \\
\end{array}$ & $\begin{array}{l}0,18215 \\
0,22195 \\
0,21992 \\
0,18489 \\
0,20897 \\
0,19161 \\
0,16560 \\
0,19917 \\
0,15705 \\
0,21795 \\
0,18884 \\
0,14458 \\
0,16212 \\
0,20296 \\
0,21224 \\
0,20095 \\
0,20301 \\
0,21529 \\
0,22831 \\
0,18632 \\
0,14816 \\
0,17130 \\
0,21566 \\
0,16955 \\
0,24385 \\
0,22517 \\
0,20312 \\
0,22360 \\
0,20403 \\
0,20511 \\
0,25716 \\
0,16130 \\
0,22326 \\
0,22166 \\
0,23166 \\
0,19213 \\
\end{array}$ & $\begin{array}{l}0,11756 \\
0,15127 \\
0,15389 \\
0,12986 \\
0,13944 \\
0,13297 \\
0,13928 \\
0,19975 \\
0,13501 \\
0,10869 \\
0,15585 \\
0,14979 \\
0,15458 \\
0,16479 \\
0,13363 \\
0,13115 \\
0,09518 \\
0,14876 \\
0,16896 \\
0,10410 \\
0,12142 \\
0,17481 \\
0,12482 \\
0,17649 \\
0,15407 \\
0,15880 \\
0,14382 \\
0,155118 \\
0,17724 \\
0,18651 \\
0,16929 \\
0,14650 \\
0,14501 \\
0,15777 \\
0,13924 \\
0,19928 \\
\end{array}$ & $\begin{array}{l}0,11353 \\
0,10898 \\
0,10476 \\
0,11531 \\
0,11870 \\
0,15364 \\
0,12338 \\
0,14090 \\
0,07490 \\
0,13587 \\
0,17143 \\
0,12960 \\
0,15458 \\
0,09284 \\
0,09290 \\
0,11988 \\
0,11840 \\
0,08061 \\
0,10318 \\
0,09645 \\
0,07524 \\
0,09735 \\
0,12765 \\
0,11693 \\
0,12921 \\
0,17195 \\
0,11466 \\
0,07897 \\
0,13950 \\
0,11337 \\
0,12852 \\
0,14473 \\
0,15613 \\
0,15019 \\
0,09961 \\
0,14805 \\
\end{array}$ & $\begin{array}{l}0,10093 \\
0,11986 \\
0,11510 \\
0,14478 \\
0,15444 \\
0,10728 \\
0,11264 \\
0,08609 \\
0,07820 \\
0,09603 \\
0,15068 \\
0,12902 \\
0,10585 \\
0,14933 \\
0,14464 \\
0,09247 \\
0,14407 \\
0,10331 \\
0,11754 \\
0,12111 \\
0,08452 \\
0,08032 \\
0,09670 \\
0,12601 \\
0,16338 \\
0,08293 \\
0,09631 \\
0,11088 \\
0,12444 \\
0,11279 \\
0,10088 \\
0,17201 \\
0,11711 \\
0,08796\end{array}$ & $\begin{array}{l}0,10293 \\
0,13463 \\
0,11422 \\
0,11058 \\
0,11172 \\
0,09295 \\
0,09746 \\
0,14486 \\
0,09645 \\
0,09493 \\
0,15068 \\
0,08174 \\
0,08603 \\
0,09732 \\
0,12037 \\
0,10362 \\
0,11008 \\
0,10712 \\
0,13086 \\
0,16609 \\
0,11643 \\
0,06170 \\
0,11354 \\
0,15860 \\
0,13094 \\
0,14346 \\
0,11968 \\
0,12217 \\
0,15746 \\
0,10060 \\
0,16133 \\
0,12181 \\
0,15554 \\
0,16363 \\
0,16424 \\
0,14590 \\
\end{array}$ \\
\hline
\end{tabular}

Solo $\mathrm{LV}$, profundidade $0,05 \mathrm{~m}, 2^{\mathrm{a}}$ repetição, lado $\mathrm{B}$.

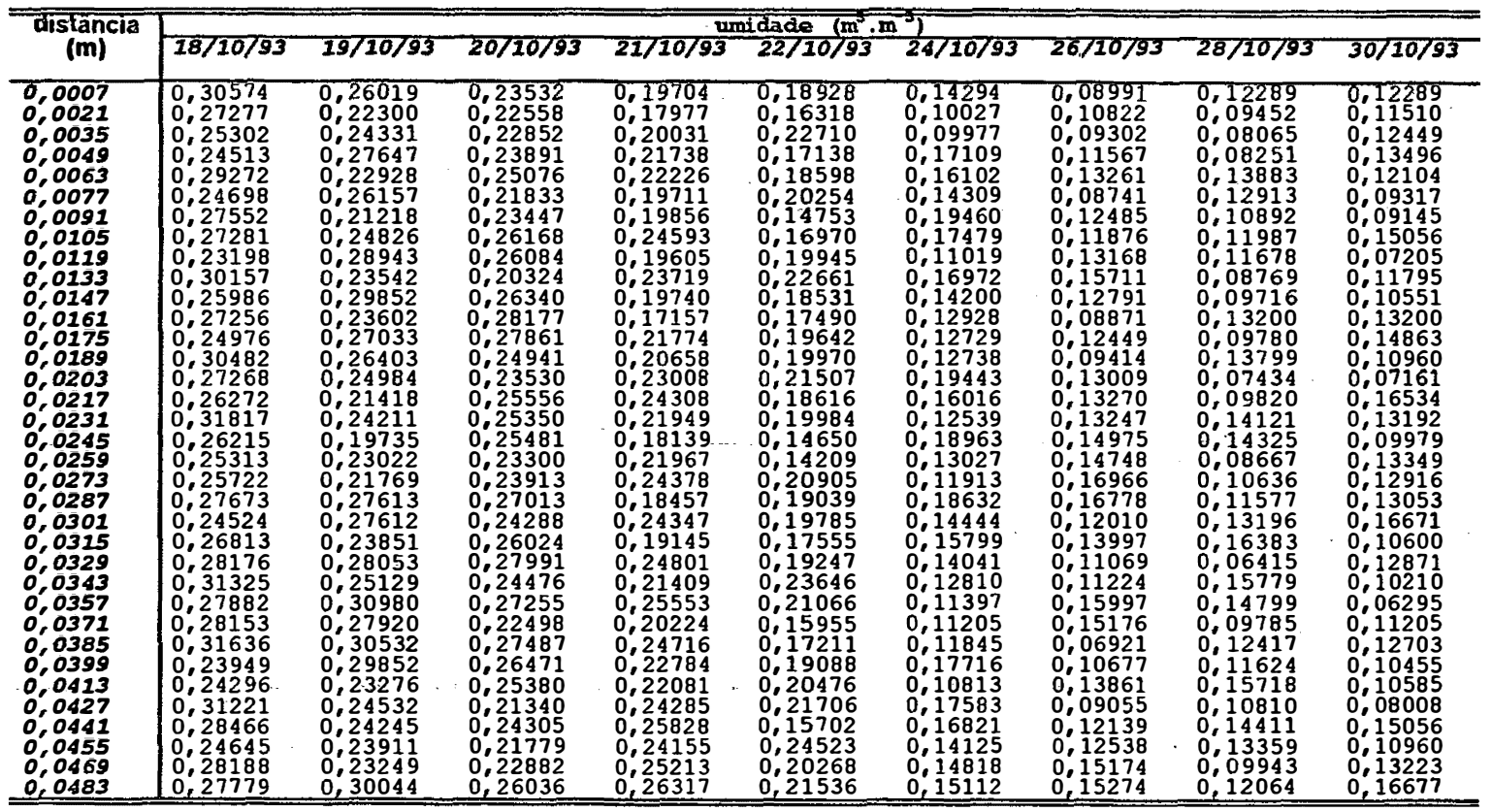


Solo $\mathrm{LV}$, profundidade $0,06 \mathrm{~m}, 2^{\mathrm{a}}$ repetição, lado $\mathrm{A}$.

\begin{tabular}{c|cccccccc}
\hline distancia \\
(m)
\end{tabular}

Solo LV, profundidade $0,06 \mathrm{~m}, 2$ a repetição, lado B.

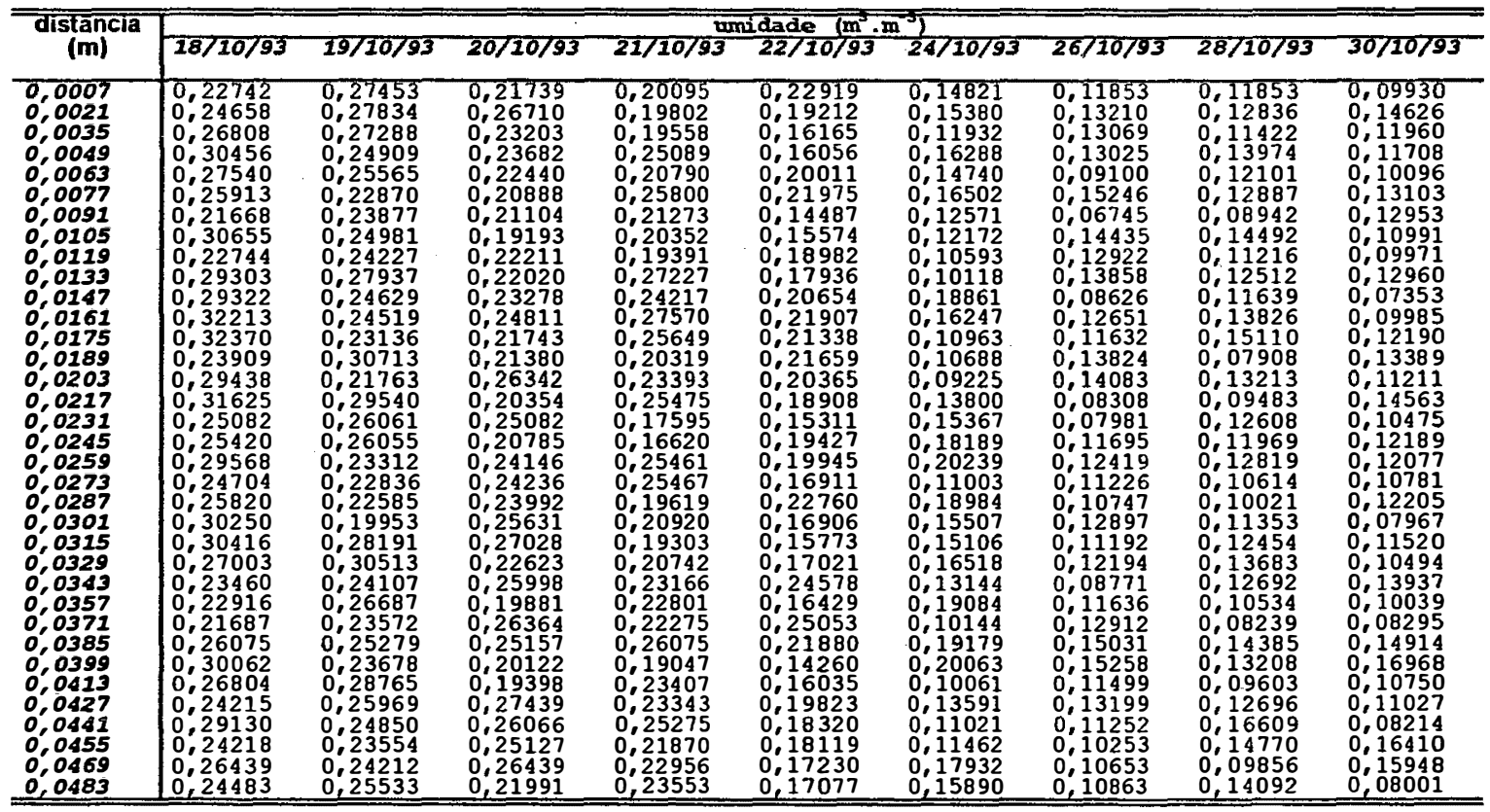


Solo $\mathrm{LE}$, profundidade $0,04 \mathrm{~m}, \mathrm{l}^{\mathrm{a}}$ repetição, lado $\mathrm{A}$.

\begin{tabular}{|c|c|c|c|c|c|c|c|c|c|}
\hline $\begin{array}{l}\text { distancia } \\
\text { (m) }\end{array}$ & \multicolumn{9}{|c|}{ 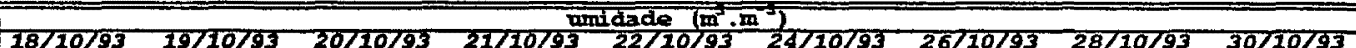 } \\
\hline $\begin{array}{l}0,0007 \\
0,0021 \\
0,0035 \\
0,0049 \\
0,0063 \\
0,0077 \\
0,0091 \\
0,0105 \\
0,0119 \\
0,0133 \\
0,0147 \\
0,0161 \\
0,0175 \\
0,0189 \\
0,0203 \\
0,0217 \\
0,0231 \\
0,0245 \\
0,0259 \\
0,0273 \\
0,0287 \\
0,0301 \\
0,0315 \\
0,0329 \\
0,0343 \\
0,0357 \\
0,0371 \\
0,0385 \\
0,0399 \\
0,0413 \\
0,0427 \\
0,0441 \\
0,0455 \\
0,0469\end{array}$ & $\begin{array}{l}0,23863 \\
0,25075 \\
0,23570 \\
0,22160 \\
0,26312 \\
0,23935 \\
0,26486 \\
0,25726 \\
0,26591 \\
0,25416 \\
0,23073 \\
0,23805 \\
0,23461 \\
0,24621 \\
0,24014 \\
0,24969 \\
0,24816 \\
0,22789 \\
0,22874 \\
0,26571 \\
0,25990 \\
0,22957 \\
0,25395 \\
0,22118 \\
0,23454 \\
0,24715 \\
0,23316 \\
0,25437 \\
0,25229 \\
0,23779 \\
0,23437 \\
0,25906 \\
0,23931 \\
0,25610\end{array}$ & $\begin{array}{l}0,20890 \\
0,21228 \\
0,18710 \\
0,18945 \\
0,20964 \\
0,19608 \\
0,18426 \\
0,19596 \\
0,19965 \\
0,21522 \\
0,19152 \\
0,22744 \\
0,22057 \\
0,20410 \\
0,21134 \\
0,23909 \\
0,24348 \\
0,22866 \\
0,21032 \\
0,23356 \\
0,201118 \\
0,21727 \\
0,21751 \\
0,20009 \\
0,20963 \\
0,23837 \\
0,23237 \\
0,20902 \\
0,20023 \\
0,22577 \\
0,22378 \\
0,21837 \\
0,21820 \\
0,20159\end{array}$ & $\begin{array}{l}0,19981 \\
0,20363 \\
0,20560 \\
0,21007 \\
0,21158 \\
0,19840 \\
0,20772 \\
0,18983 \\
0,18954 \\
0,20813 \\
0,19931 \\
0,21312 \\
0,23165 \\
0,18212 \\
0,22842 \\
0,23080 \\
0,21017 \\
0,18727 \\
0,23800 \\
0,19179 \\
0,22619 \\
0,23112 \\
0,21909 \\
0,24244 \\
0,23013 \\
0,23910 \\
0,24029 \\
0,21987 \\
0,19774 \\
0,21722 \\
0,21729 \\
0,21295 \\
0,23539 \\
0,24365\end{array}$ & $\begin{array}{l}0,20057 \\
0,19462 \\
0,18259 \\
0,19516 \\
0,18483 \\
0,19221 \\
0,20301 \\
0,19366 \\
0,22077 \\
0,17605 \\
0,18297 \\
0,21086 \\
0,21910 \\
0,20568 \\
0,19051 \\
0,19414 \\
0,22949 \\
0,22557 \\
0,20344 \\
0,20178 \\
0,19215 \\
0,23575 \\
0,22303 \\
0,21648 \\
0,19364 \\
0,20206 \\
0,20249 \\
0,21068 \\
0,22613 \\
0,21892 \\
0,20353 \\
0,22849 \\
0,20345 \\
0,20736\end{array}$ & $\begin{array}{l}0,17162 \\
0,17591 \\
0,17658 \\
0,18034 \\
0,20419 \\
0,18450 \\
0,17028 \\
0,19290 \\
0,17946 \\
0,21601 \\
0,17367 \\
0,21161 \\
0,21321 \\
0,18446 \\
0,22142 \\
0,21054 \\
0,18032 \\
0,19413 \\
0,22412 \\
0,20255 \\
0,20118 \\
0,18221 \\
0,19168 \\
0,19387 \\
0,20963 \\
0,20134 \\
0,20171 \\
0,18993 \\
0,22529 \\
0,22662 \\
0,23111 \\
0,22459 \\
0,21820 \\
0,19800\end{array}$ & $\begin{array}{l}0,14262 \\
0,17435 \\
0,17471 \\
0,17806 \\
0,16676 \\
0,17221 \\
0,16641 \\
0,15410 \\
0,16404 \\
0,18540 \\
0,17987 \\
0,20037 \\
0,18253 \\
0,17821 \\
0,20283 \\
0,18672 \\
0,19558 \\
0,16681 \\
0,17989 \\
0,20332 \\
0,21555 \\
0,20274 \\
0,21830 \\
0,19776 \\
0,17558 \\
0,20712 \\
0,18147 \\
0,18167 \\
0,22949 \\
0,18750 \\
0,20272 \\
0,18673 \\
0,18801 \\
0,22617\end{array}$ & $\begin{array}{l}0,16938 \\
0,15000 \\
0,17359 \\
0,14344 \\
0,15034 \\
0,17336 \\
0,16023 \\
0,16242 \\
0,15177 \\
0,16984 \\
0,16981 \\
0,18172 \\
0,16587 \\
0,18916 \\
0,19359 \\
0,15432 \\
0,17271 \\
0,18499 \\
0,15955 \\
0,16657 \\
0,20874 \\
0,20121 \\
0,16223 \\
0,19776 \\
0,18567 \\
0,20567 \\
0,18924 \\
0,17673 \\
0,17293 \\
0,21125 \\
0,20030 \\
0,22615 \\
0,19881 \\
0,20519\end{array}$ & $\begin{array}{l}0,15894 \\
0,14117 \\
0,13899 \\
0,14194 \\
0,15110 \\
0,17029 \\
0,17804 \\
0,17457 \\
0,15100 \\
0,14974 \\
0,17677 \\
0,17727 \\
0,19126 \\
0,15179 \\
0,17214 \\
0,16974 \\
0,20556 \\
0,19870 \\
0,18898 \\
0,19409 \\
0,20194 \\
0,16561 \\
0,18157 \\
0,19931 \\
0,18495 \\
0,19774 \\
0,21818 \\
0,20486 \\
0,20772 \\
0,18244 \\
0,20676 \\
0,20443 \\
0,17496 \\
0,19656\end{array}$ & $\begin{array}{l}0,14817 \\
0,14347 \\
0,14862 \\
0,15731 \\
0,15796 \\
0,15768 \\
0,17183 \\
0,15259 \\
0,18954 \\
0,15283 \\
0,15979 \\
0,18247 \\
0,16587 \\
0,15102 \\
0,16757 \\
0,18746 \\
0,16362 \\
0,16153 \\
0,17914 \\
0,16734 \\
0,18614 \\
0,18221 \\
0,19870 \\
0,16607 \\
0,21182 \\
0,19990 \\
0,20093 \\
0,17755 \\
0,18944 \\
0,19257 \\
0,21404 \\
0,17524 \\
0,19495 \\
0,20519\end{array}$ \\
\hline
\end{tabular}

Solo LE, profundidade $0,04 \mathrm{~m}, 1^{\mathrm{a}}$ repetição, lado $\mathrm{B}$.

\begin{tabular}{|c|c|c|c|c|c|c|c|c|c|}
\hline $\begin{array}{c}\text { distancia } \\
\text { (m) }\end{array}$ & $18 / 10 / 93$ & $19 / 10 / 93$ & 20710793 & $21 / 10 / 93$ & $\frac{1 d a d e(\mathrm{~m}}{22 / 10 / 93}$ & $\frac{1}{24 / 10 / 93}$ & $26 / 10793$ & $28710 / 93$ & $30 / 10793$ \\
\hline $\begin{array}{l}0,0007 \\
0,0021 \\
0,0035 \\
0,0049 \\
0,0063 \\
0,0077 \\
0,0091 \\
0,0105 \\
0,0119 \\
0,0133 \\
0,0147 \\
0,0161 \\
0,0175 \\
0,0189 \\
0,0203 \\
0,0217 \\
0,0231 \\
0,0245 \\
0,0259 \\
0,0273 \\
0,0287 \\
0,0301 \\
0,0315 \\
0,0329 \\
0,, 0343 \\
0,0357 \\
0,0371 \\
0,0385 \\
0,0399 \\
0,0413 \\
0,0427 \\
0,0441 \\
0,0455 \\
0,0469 \\
0,0483 \\
0,0497\end{array}$ & $\begin{array}{l}0,21702 \\
0,24109 \\
0,26592 \\
0,24595 \\
0,23025 \\
0,26451 \\
0,25335 \\
0,25430 \\
0,21386 \\
0,22546 \\
0,22536 \\
0,25002 \\
0,22932 \\
0,25013 \\
0,22274 \\
0,21414 \\
0,23950 \\
0,25489 \\
0,24161 \\
0,25024 \\
0,23146 \\
0,24895 \\
0,24059 \\
0,23198 \\
0,25356 \\
0,24944 \\
0,24249 \\
0,25803 \\
0,25869 \\
0,22238 \\
0,21616 \\
0,23933 \\
0,26541 \\
0,21588 \\
0,24746 \\
0,24607\end{array}$ & $\begin{array}{l}0,21826 \\
0,21441 \\
0,21257 \\
0,20423 \\
0,18843 \\
0,22622 \\
0,20548 \\
0,18509 \\
0,18977 \\
0,19764 \\
0,19574 \\
0,18530 \\
0,20285 \\
0,23033 \\
0,21013 \\
0,23200 \\
0,22684 \\
0,21528 \\
0,23113 \\
0,23413 \\
0,20258 \\
0,23930 \\
0,22490 \\
0,23025 \\
0,22522 \\
0,22719 \\
0,19732 \\
0,24556 \\
0,19730 \\
0,19440 \\
0,23566 \\
0,21995 \\
0,20762 \\
0,21431 \\
0,21525 \\
0,19389\end{array}$ & $\begin{array}{l}0,18124 \\
0,17528 \\
0,18424 \\
0,20142 \\
0,20587 \\
0,18769 \\
0,19860 \\
0,18352 \\
0,20259 \\
0,17334 \\
0,20451 \\
0,20408 \\
0,22610 \\
0,21973 \\
0,18042 \\
0,21182 \\
0,20093 \\
0,20586 \\
0,23038 \\
0,20902 \\
0,22285 \\
0,22730 \\
0,21915 \\
0,19006 \\
0,21839 \\
0,23294 \\
0,22062 \\
0,23562 \\
0,24136 \\
0,21812 \\
0,21940 \\
0,19654 \\
0,21874 \\
0,20649 \\
0,216000 \\
0,22835\end{array}$ & $\begin{array}{l}0,19928 \\
0,17651 \\
0,19611 \\
0,18740 \\
0,19753 \\
0,18769 \\
0,16748 \\
0,17333 \\
0,20581 \\
0,17414 \\
0,17353 \\
0,19076 \\
0,19011 \\
0,20016 \\
0,17809 \\
0,21414 \\
0,20562 \\
0,22710 \\
0,19034 \\
0,21661 \\
0,18016 \\
0,22969 \\
0,23067 \\
0,19515 \\
0,22010 \\
0,21328 \\
0,20854 \\
0,22408 \\
0,19892 \\
0,23263 \\
0,21050 \\
0,21073 \\
0,21189 \\
0,19870 \\
0,23243 \\
0,22646\end{array}$ & $\begin{array}{l}0,16739 \\
0,16711 \\
0,18547 \\
0,18261 \\
0,17424 \\
0,17484 \\
0,16899 \\
0,16787 \\
0,19537 \\
0,17253 \\
0,20371 \\
0,16587 \\
0,20525 \\
0,19791 \\
0,20385 \\
0,20564 \\
0,19703 \\
0,17159 \\
0,20288 \\
0,19768 \\
0,21737 \\
0,20028 \\
0,19951 \\
0,19856 \\
0,22607 \\
0,19134 \\
0,18217 \\
0,21504 \\
0 ; 22905 \\
0,19693 \\
0,18957 \\
0,22499 \\
0,23420 \\
0,19714 \\
0,19153 \\
0,19265\end{array}$ & $\begin{array}{l}0,17634 \\
0,15979 \\
0,17039 \\
0,15761 \\
0,15505 \\
0,14701 \\
0,17352 \\
0,19295 \\
0,18498 \\
0,17334 \\
0,17669 \\
0,15120 \\
0,16560 \\
0,19341 \\
0,18743 \\
0,15898 \\
0,16522 \\
0,20899 \\
0,16689 \\
0,20675 \\
0,17400 \\
0,19791 \\
0,19462 \\
0,19006 \\
0,22180 \\
0,17037 \\
0,20533 \\
0,19951 \\
0,20541 \\
0,17758 \\
0,18237 \\
0,20488 \\
0,19911 \\
0,22608 \\
0,18269 \\
0,20825\end{array}$ & $\begin{array}{l}0,12665 \\
0,12465 \\
0,15177 \\
0,13480 \\
0,15466 \\
0,13665 \\
0,13746 \\
0,15231 \\
0,18099 \\
0,14286 \\
0,13511 \\
0,16046 \\
0,14131 \\
0,17254 \\
0,15719 \\
0,17495 \\
0,17992 \\
0,19725 \\
0,15815 \\
0,16321 \\
0,16557 \\
0,17823 \\
0,19951 \\
0,17482 \\
0,16273 \\
0,18326 \\
0,18535 \\
0,16628 \\
0,21354 \\
0,19271 \\
0,21131 \\
0,20822 \\
0,22388 \\
0,17545 \\
0,18563 \\
0,21954\end{array}$ & $\begin{array}{l}0,12425 \\
0,13994 \\
0,14451 \\
0,15051 \\
0,16404 \\
0,12900 \\
0,15618 \\
0,17412 \\
0,15246 \\
0,13331 \\
0,17511 \\
0,16046 \\
0,18218 \\
0,15109 \\
0,15873 \\
0,19793 \\
0,18457 \\
0,19179 \\
0,16689 \\
0,20372 \\
0,19251 \\
0,17040 \\
0,20277 \\
0,18327 \\
0,18873 \\
0,16155 \\
0,18934 \\
0,21668 \\
0,19811 \\
0,19778 \\
0,18637 \\
0,17169 \\
0,17540 \\
0,21666 \\
0,19892 \\
0,19514\end{array}$ & $\begin{array}{l}0,14150 \\
0,15694 \\
0,14291 \\
0,15919 \\
0,14687 \\
0,15163 \\
0,13895 \\
0,13452 \\
0,14066 \\
0,14925 \\
0,14447 \\
0,16897 \\
0,16717 \\
0,18296 \\
0,16569 \\
0,15217 \\
0,17295 \\
0,19491 \\
0,15161 \\
0,15578 \\
0,19251 \\
0,15948 \\
0,16789 \\
0,18412 \\
0,20225 \\
0,16716 \\
0,19013 \\
0,19055 \\
0,18278 \\
0,17591 \\
0,18557 \\
0,17251 \\
0,17624 \\
0,21588 \\
0,17461 \\
0,20637\end{array}$ \\
\hline
\end{tabular}


Solo LE, profundidade $0,05 \mathrm{~m}, 1^{\mathrm{a}}$ repetição, lado $\mathrm{A}$.

\begin{tabular}{|c|c|c|c|c|c|c|c|c|c|}
\hline $\begin{array}{l}\text { oistancia } \\
\text { (m) }\end{array}$ & $18 / 10 / 93$ & $19 / 10793$ & 20710793 & $21710 / 93$ & $\frac{\text { dade }(\mathrm{m}}{22 / 10 / 9}$ & $\frac{7}{24 / 10 / 93}$ & 26710793 & $28 / 10 / 93$ & 30710793 \\
\hline $\begin{array}{l}0,0007 \\
0,0021 \\
0,0035 \\
0,0049 \\
0,0063 \\
0,0077 \\
0,0091 \\
0,0105 \\
0,0119 \\
0,0133 \\
0,0147 \\
0,0161 \\
0,0175 \\
0,0189 \\
0,0203 \\
0,0217 \\
0,0231 \\
0,0245 \\
0,0259 \\
0,0273 \\
0,0287 \\
0,0301 \\
0,0315 \\
0,0329 \\
0,0343 \\
0,0357 \\
0,0371 \\
0,0385 \\
0,0399 \\
0,0413 \\
0,0427 \\
0,041 \\
0,0455 \\
0,0469 \\
0,0483\end{array}$ & \begin{tabular}{|l}
0,25790 \\
0,21986 \\
0,25057 \\
0,23620 \\
0,22861 \\
0,23065 \\
0,26005 \\
0,25548 \\
0,23723 \\
0,24069 \\
0,22112 \\
0,25364 \\
0,26574 \\
0,25618 \\
0,24332 \\
0,22027 \\
0,21880 \\
0,25955 \\
0,24267 \\
0,23940 \\
0,23107 \\
0,22574 \\
0,21776 \\
0,23150 \\
0,24957 \\
0,23428 \\
0,22847 \\
0,26221 \\
0,26849 \\
0,24858 \\
0,22890 \\
0,26185 \\
0,25761 \\
0,22368 \\
0,25067
\end{tabular} & $\begin{array}{l}0,20161 \\
0,20267 \\
0,21594 \\
0,22995 \\
0,21828 \\
0,20999 \\
0,20680 \\
0,23512 \\
0,20039 \\
0,19856 \\
0,23527 \\
0,21030 \\
0,20455 \\
0,23400 \\
0,19768 \\
0,20606 \\
0,21958 \\
0,21232 \\
0,22024 \\
0,22617 \\
0,21461 \\
0,23126 \\
0,24412 \\
0,25005 \\
0,24714 \\
0,24686 \\
0,20723 \\
0,20143 \\
0,22583 \\
0,20377 \\
0,22562 \\
0,24847 \\
0,21460 \\
0,22534 \\
0,21911\end{array}$ & $\begin{array}{l}0,18591 \\
0,21603 \\
0,18020 \\
0,17661 \\
0,21028 \\
0,20062 \\
0,20505 \\
0,20795 \\
0,23182 \\
0,23102 \\
0,19149 \\
0,22879 \\
0,23497 \\
0,20597 \\
0,23643 \\
0,21473 \\
0,23911 \\
0,22258 \\
0,22718 \\
0,19530 \\
0,23343 \\
0,23362 \\
0,20852 \\
0,23227 \\
0,21738 \\
0,24292 \\
0,21555 \\
0,24550 \\
0,24587 \\
0,21754 \\
0,21335 \\
0,22438 \\
0,22886 \\
0,24611 \\
0,24527\end{array}$ & $\begin{array}{l}0,20469 \\
0,18673 \\
0,17788 \\
0,18235 \\
0,19890 \\
0,19343 \\
0,19793 \\
0,20718 \\
0,21108 \\
0,21400 \\
0,17989 \\
0,21107 \\
0,17683 \\
0,17747 \\
0,19090 \\
0,19035 \\
0,18632 \\
0,21965 \\
0,21332 \\
0,22307 \\
0,23500 \\
0,21316 \\
0,21006 \\
0,22535 \\
0,19983 \\
0,19456 \\
0,22391 \\
0,20925 \\
0,23543 \\
0,22567 \\
0,22234 \\
0,21942 \\
0,20541 \\
0,20390 \\
0,22646\end{array}$ & $\begin{array}{l}0,17333 \\
0,17955 \\
0,18058 \\
0,20662 \\
0,20117 \\
0,16772 \\
0,19209 \\
0,20255 \\
0,16857 \\
0,17519 \\
0,18298 \\
0,18509 \\
0,21332 \\
0,19694 \\
0,18790 \\
0,18879 \\
0,18401 \\
0,18611 \\
0,18200 \\
0,19454 \\
0,21696 \\
0,21316 \\
0,18250 \\
0,22843 \\
0,19745 \\
0,19765 \\
0,21101 \\
0,19130 \\
0,22423 \\
0,23465 \\
0,19545 \\
0,21695 \\
0,21627 \\
0,24278 \\
0,20912\end{array}$ & $\begin{array}{l}0,17219 \\
0,16112 \\
0,16557 \\
0,18581 \\
0,18718 \\
0,17199 \\
0,16163 \\
0,18183 \\
0,20192 \\
0,16648 \\
0,17372 \\
0,19958 \\
0,17840 \\
0,16557 \\
0,20826 \\
0,16697 \\
0,16946 \\
0,19046 \\
0,17972 \\
0,17238 \\
0,21696 \\
0,17193 \\
0,17414 \\
0,19024 \\
0,19110 \\
0,21240 \\
0,18914 \\
0,23047 \\
0,20197 \\
0,20054\end{array}$ & $\begin{array}{l}0,13858 \\
0,14580 \\
0,14836 \\
0,15374 \\
0,16128 \\
0,16133 \\
0,14724 \\
0,16581 \\
0,14981 \\
0,14770 \\
0,14995 \\
0,17826 \\
0,15252 \\
0,19769 \\
0,16992 \\
0,15690 \\
0,18863 \\
0,17454 \\
0,19037 \\
0,19300 \\
0,19826 \\
0,18742 \\
0,18022 \\
0,21921 \\
0,19665 \\
0,20385 \\
0,19591 \\
0,18044 \\
0,19170 \\
0,19570 \\
0,19545 \\
0,21695 \\
0,18547 \\
0,22038 \\
0,19188\end{array}$ & $\begin{array}{l}0,14873 \\
0,13575 \\
0,15256 \\
0,17278 \\
0,16951 \\
0,16737 \\
0,14079 \\
0,17038 \\
0,17914 \\
0,16648 \\
0,18143 \\
0,19729 \\
0,19501 \\
0,18794 \\
0,15429 \\
0,18332 \\
0,15879 \\
0,18611 \\
0,16082 \\
0,18994 \\
0,16431 \\
0,20534 \\
0,20698 \\
0,20698 \\
0,18161 \\
0,20929 \\
0,19742 \\
0,17734 \\
0,18304 \\
0,21591 \\
0,18977 \\
0,18661 \\
0,21376 \\
0,21460 \\
0,21311\end{array}$ & $\begin{array}{l}0,15286 \\
0,14729 \\
0,13012 \\
0,15374 \\
0,14304 \\
0,14613 \\
0,15227 \\
0,17953 \\
0,14906 \\
0,15202 \\
0,19692 \\
0,18737 \\
0,15955 \\
0,17077 \\
0,19392 \\
0,20606 \\
0,16641 \\
0,17671 \\
0,21025 \\
0,19224 \\
0,18586 \\
0,17116 \\
0,20468 \\
0,20774 \\
0,21738 \\
0,17300 \\
0,18015 \\
0,22259 \\
0,21308 \\
0,20538 \\
0,21416 \\
0,18253 \\
0,22382 \\
0,20883 \\
0,19916\end{array}$ \\
\hline
\end{tabular}

Solo LE, profundidade $0,05 \mathrm{~m}, 1^{\underline{a}}$ repetição, lado B.

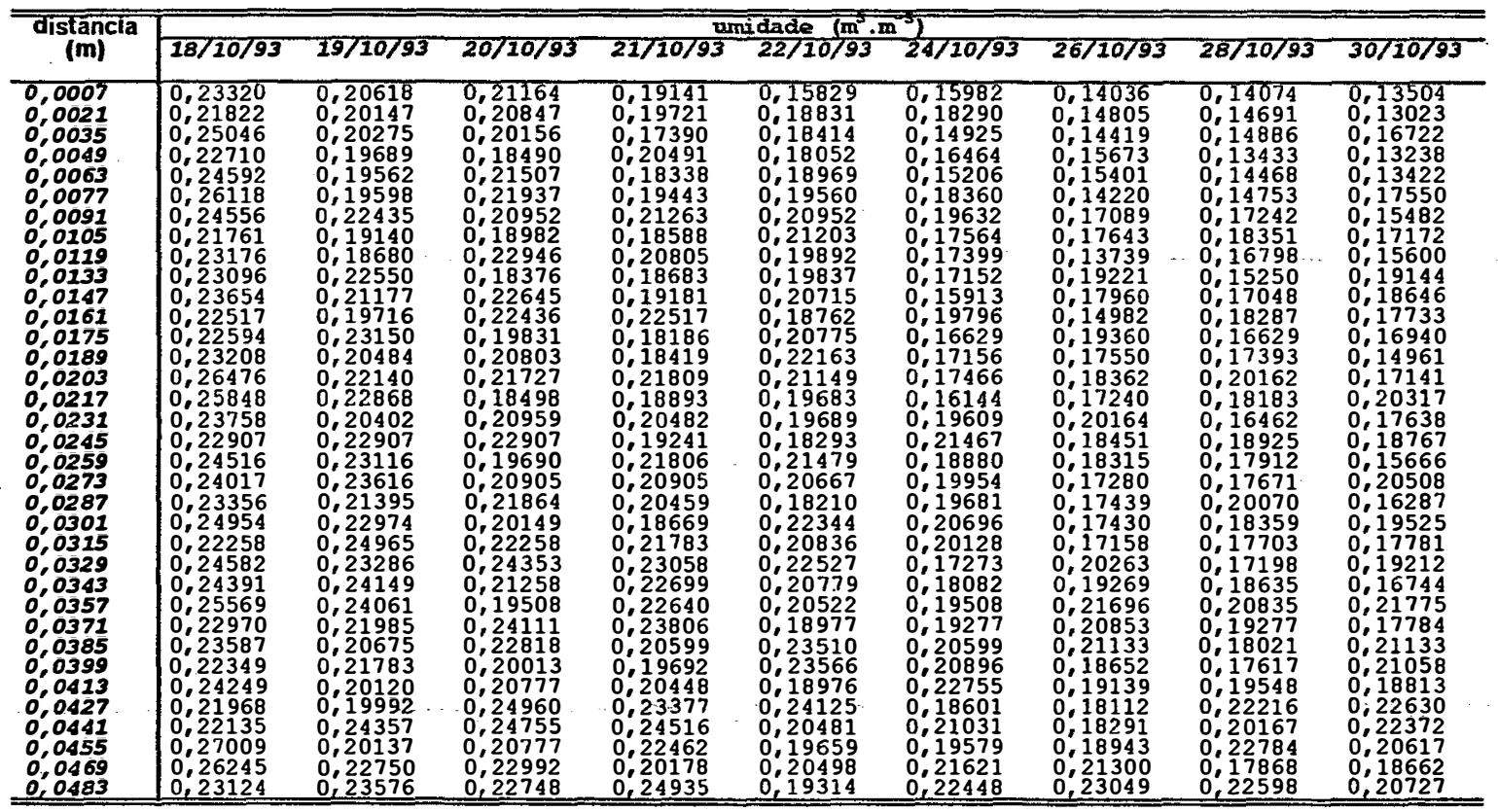


Solo $\mathrm{LE}$, profundidade $0,06 \mathrm{~m}, 1^{\mathrm{a}}$ repetição, lado $\mathrm{A}$.

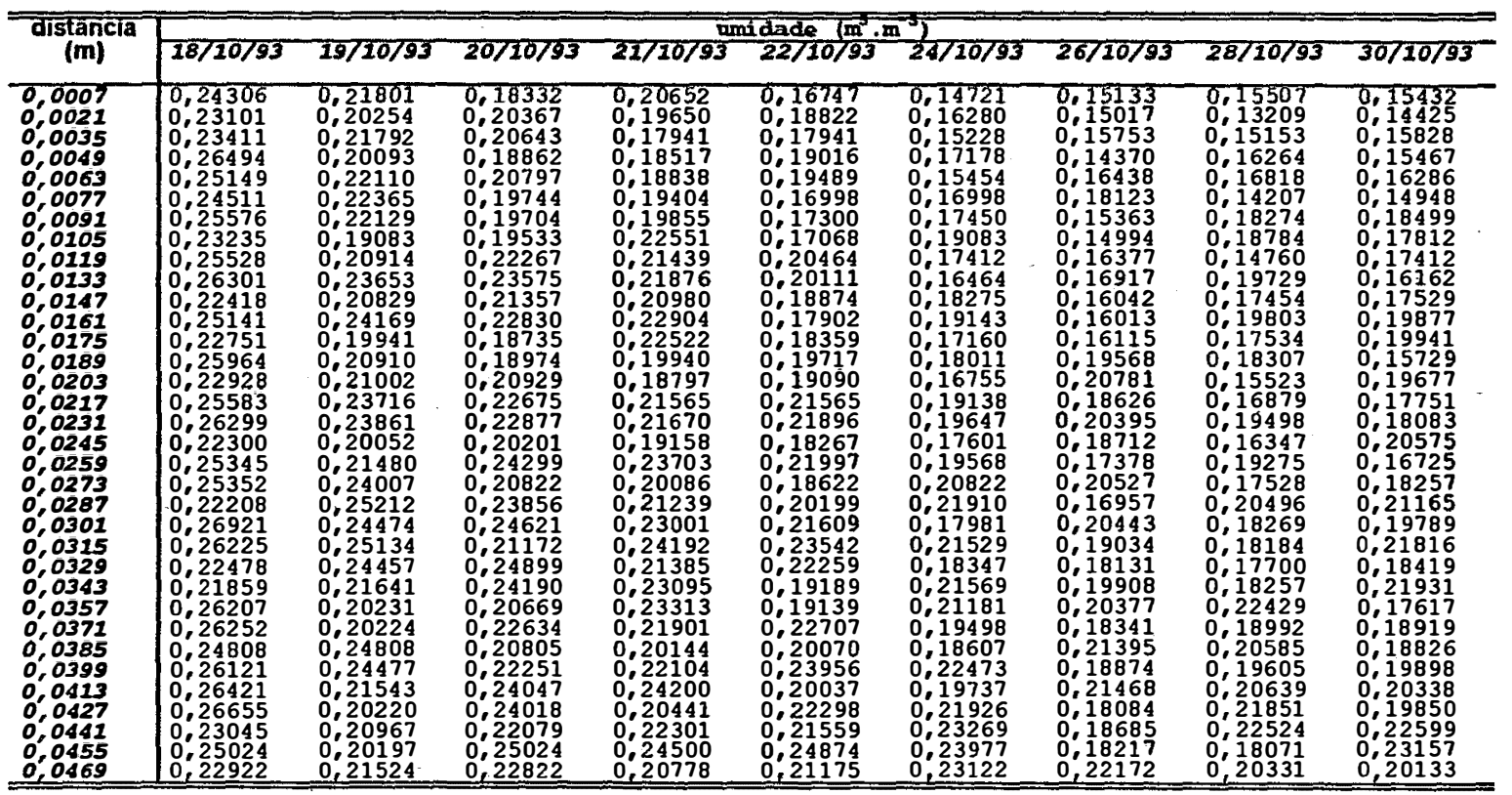

Solo LE, profundidade $0,06 \mathrm{~m}, 1$ a repetição, lado $B$.

\begin{tabular}{|c|c|c|c|c|c|c|c|c|c|}
\hline \multirow{2}{*}{$\begin{array}{l}\text { distancia } \\
\text { (m) }\end{array}$} & \multicolumn{9}{|c|}{ umidade $(\mathrm{m} \cdot \mathrm{m})$} \\
\hline & $18 / 10 / 93$ & $19 / 10 / 93$ & 20710793 & $21 / 10 / 93$ & $22 / 10 / 93$ & $24 / 10 / 93$ & $26 / 10 / 93$ & $28 / 10 / 93$ & $30710 / 93$ \\
\hline $\begin{array}{l}0,0007 \\
0,0021 \\
0,0035 \\
0,0049 \\
0,0063 \\
0,0077 \\
0,0091 \\
0,00105 \\
0,0119 \\
0,0133 \\
0,0147 \\
0,0161 \\
0,0175 \\
0,0189 \\
0,0203 \\
0,00217 \\
0,0231 \\
0,0245 \\
0,0259 \\
0,0273 \\
0,0287 \\
0,0301 \\
0,0315 \\
0,0329 \\
0,0343 \\
0,0357 \\
0,0371 \\
0,0385 \\
0,0399 \\
0,043 \\
0,0427 \\
0,0441 \\
0,0455 \\
0,0469 \\
0,0483 \\
0,0497 \\
\end{array}$ & $\begin{array}{l}0,23157 \\
0,24839 \\
0,23045 \\
0,24159 \\
0,25901 \\
0,24880 \\
0,26438 \\
0,25976 \\
0,23618 \\
0,25679 \\
0,23159 \\
0,23212 \\
0,26985 \\
0,24079 \\
0,22243 \\
0,26081 \\
0,22685 \\
0,25716 \\
0,24896 \\
0,24820 \\
0,26081 \\
0,25375 \\
0,22034 \\
0,22180 \\
0,25541 \\
0,26511 \\
0,27011 \\
0,26060 \\
0,22349 \\
0,22019 \\
0,24441 \\
0,2549 \\
0,22016 \\
0,23664 \\
0,23230 \\
0,25936 \\
\end{array}$ & $\begin{array}{l}0,22104 \\
0,19441 \\
0,20600 \\
0,19612 \\
0,19197 \\
0,21434 \\
0,20539 \\
0,22773 \\
0,22363 \\
0,23814 \\
0,19339 \\
0,21959 \\
0,23693 \\
0,23842 \\
0,19529 \\
0,21449 \\
0,20664 \\
0,22725 \\
0,22493 \\
0,23736 \\
0,23946 \\
0,24665 \\
0,23499 \\
0,22180 \\
0,23900 \\
0,22258 \\
0,20706 \\
0,20018 \\
0,20816 \\
0,20583 \\
0,25200 \\
0,24907 \\
0,19945 \\
0,24591 \\
0,20066 \\
0,21228 \\
\end{array}$ & $\begin{array}{l}0,21346 \\
0,21187 \\
0,18678 \\
0,18322 \\
0,21362 \\
0,20285 \\
0,20923 \\
0,20530 \\
0,22050 \\
0,20049 \\
0,19726 \\
0,21180 \\
0,18448 \\
0,22426 \\
0,23611 \\
0,18613 \\
0,22610 \\
0,22967 \\
0,20954 \\
0,22194 \\
0,22375 \\
0,19517 \\
0,21872 \\
0,20221 \\
0,21266 \\
0,19996 \\
0,20221 \\
0,22980 \\
0,20173 \\
0,21173 \\
0,20348 \\
0,23559 \\
0,20937 \\
0,22992 \\
0,20775 \\
0,24515\end{array}$ & $\begin{array}{l}0,18035 \\
0,17987 \\
0,19304 \\
0,21303 \\
0,17688 \\
0,18370 \\
0,21693 \\
0,18688 \\
0,21581 \\
0,18369 \\
0,20970 \\
0,19704 \\
0,22372 \\
0,22504 \\
0,21923 \\
0,21053 \\
0,21411 \\
0,21923 \\
0,19499 \\
0,19974 \\
0,21828 \\
0,18591 \\
0,20094 \\
0,19130 \\
0,19575 \\
0,19594 \\
0,21111 \\
0,20692 \\
0,24461 \\
0,20752 \\
0,19685 \\
0,19886 \\
0,22932 \\
0,21235 \\
0,23947 \\
0,20064\end{array}$ & $\begin{array}{l}0,16544 \\
0,18673 \\
0,17508 \\
0,18205 \\
0,17650 \\
0,17417 \\
0,20769 \\
0,16858 \\
0,20180 \\
0,21962 \\
0,19649 \\
0,18083 \\
0,21366 \\
0,19459 \\
0,19132 \\
0,18535 \\
0,22460 \\
0,22083 \\
0,21107 \\
0,17999 \\
0,19881 \\
0,18283 \\
0,22928 \\
0,20768 \\
0,20957 \\
0,21691 \\
0,22900 \\
0,19682 \\
0,22430 \\
0,20162 \\
0,24104 \\
0,20218 \\
0,22016 \\
0,20236 \\
0,20696 \\
0,21461\end{array}$ & $\begin{array}{l}0,17699 \\
0,16622 \\
0,17158 \\
0,15952 \\
0,14732 \\
0,17088 \\
0,19849 \\
0,16099 \\
0,19560 \\
0,20123 \\
0,17180 \\
0,20946 \\
0,17761 \\
0,16603 \\
0,19291 \\
0,20106 \\
0,20291 \\
0,18103 \\
0,20417 \\
0,20814 \\
0,19804 \\
0,19749 \\
0,18888 \\
0,18431 \\
0,21420 \\
0,21044 \\
0,18771 \\
0,18843 \\
0,21299 \\
0,22358 \\
0,19025 \\
0,21800 \\
0,22432 \\
0,23244 \\
0,20066 \\
0,22866 \\
\end{array}$ & $\begin{array}{l}0,14913 \\
0,15343 \\
0,15493 \\
0,14217 \\
0,17049 \\
0,16031 \\
0,17713 \\
0,16478 \\
0,18247 \\
0,17496 \\
0,14733 \\
0,19627 \\
0,18143 \\
0,14918 \\
0,16763 \\
0,18770 \\
0,16519 \\
0,20404 \\
0,20187 \\
0,20967 \\
0,20425 \\
0,19826 \\
0,19370 \\
0,21709 \\
0,21497 \\
0,19032 \\
0,17889 \\
0,17506 \\
0,20816 \\
0,20162 \\
0,20763 \\
0,19389 \\
0,20441 \\
0,18993 \\
0,19281 \\
0,21851 \\
\end{array}$ & $\begin{array}{l}0,14102 \\
0,13317 \\
0,15338 \\
0,15064 \\
0,13878 \\
0,16942 \\
0,14541 \\
0,15343 \\
0,15868 \\
0,14320 \\
0,18103 \\
0,17237 \\
0,18907 \\
0,17757 \\
0,19053 \\
0,20500 \\
0,16666 \\
0,16999 \\
0,18053 \\
0,16415 \\
0,20970 \\
0,20058 \\
0,18567 \\
0,16653 \\
0,21574 \\
0,18151 \\
0,21435 \\
0,17256 \\
0,21380 \\
0,18486 \\
0,19107 \\
0,22887 \\
0,18055 \\
0,20985 \\
0,21723 \\
0,21072\end{array}$ & $\begin{array}{l}0,13733 \\
0,14705 \\
0,16887 \\
0,16223 \\
0,16936 \\
0,15014 \\
0,15745 \\
0,18382 \\
0,17093 \\
0,18733 \\
0,14429 \\
0,17007 \\
0,19673 \\
0,19149 \\
0,15039 \\
0,18378 \\
0,19473 \\
0,16135 \\
0,16162 \\
0,16339 \\
0,19494 \\
0,18514 \\
0,18327 \\
0,18664 \\
0,18809 \\
0,21853 \\
0,17809 \\
0,20440 \\
0,172119 \\
0,20920 \\
0,18777 \\
0,21049 \\
0,21351 \\
0,22824 \\
0,18811 \\
0,21306\end{array}$ \\
\hline
\end{tabular}


Solo LE, profundidade $0,04 \mathrm{~m}, 2^{\mathrm{a}}$ repetição, lado A.

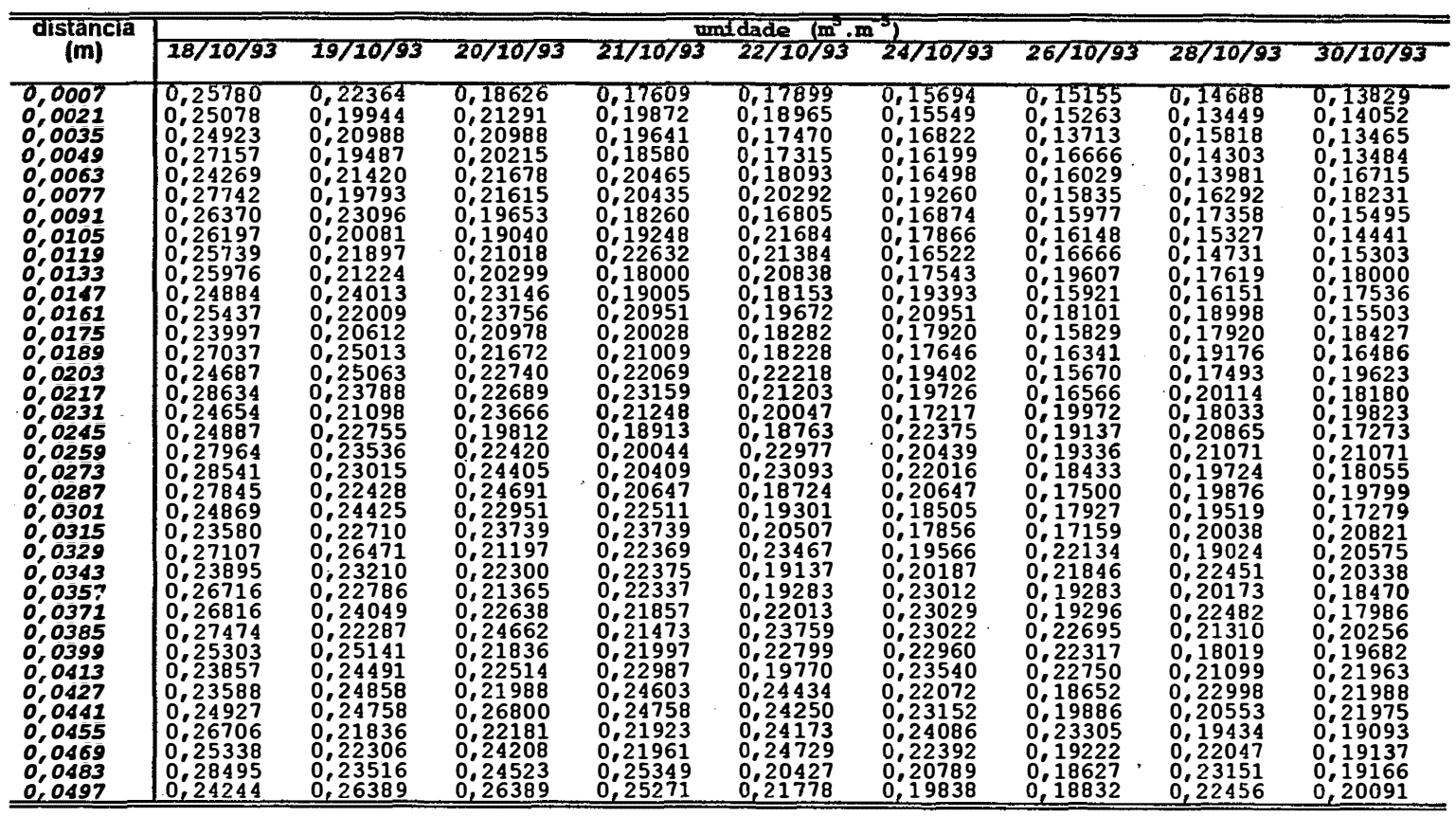

Solo LE, profundidade $0,04 \mathrm{~m}, 2^{\mathrm{a}}$ repetição, lado B.

\begin{tabular}{|c|c|c|c|c|c|c|c|c|c|}
\hline $\begin{array}{c}\text { distăncia } \\
\text { (m) }\end{array}$ & \multicolumn{9}{|c|}{ 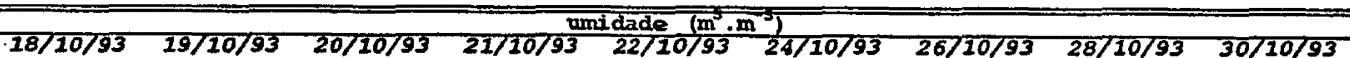 } \\
\hline $\begin{array}{l}0,0007 \\
0,0021 \\
0,0035 \\
0,0049 \\
0,0063 \\
0,0077 \\
0,0091 \\
0,0105 \\
0,0119 \\
0,0133 \\
0,0147 \\
0,0161 \\
0,0175 \\
0,0189 \\
0,0203 \\
0,00217 \\
0,0231 \\
0,0045 \\
0,0259 \\
0,0273 \\
0,0287 \\
0,0301 \\
0,00315 \\
0,0329 \\
0,0343 \\
0,0357 \\
0,0371 \\
0,0385 \\
0,0399 \\
0,0413 \\
0,0427 \\
0,0441 \\
0,0455 \\
0,0469 \\
0,0483\end{array}$ & $\begin{array}{l}0,25149 \\
0,26682 \\
0,28654 \\
0,27140 \\
0,28363 \\
0,25189 \\
0,24917 \\
0,28702 \\
0,27846 \\
0,28818 \\
0,28106 \\
0,25766 \\
0,24875 \\
0,26043 \\
0,24157 \\
0,27035 \\
0,25515 \\
0,28645 \\
0,27125 \\
0,28352 \\
0,25662 \\
0,27582 \\
0,25294 \\
0,23737 \\
0,24264 \\
0,24804 \\
0,26183 \\
0,24281 \\
0,25715 \\
0,25661 \\
0,28216 \\
0,27193 \\
0,25245 \\
0,28770 \\
0,26858\end{array}$ & $\begin{array}{l}0,21833 \\
0,21090 \\
0,21100 \\
0,22880 \\
0,23876 \\
0,23612 \\
0,22513 \\
0,23817 \\
0,24520 \\
0,21159 \\
0,20393 \\
0,23098 \\
0,21301 \\
0,20384 \\
0,23406 \\
0,22468 \\
0,24383 \\
0,25563 \\
0,20514 \\
0,26241 \\
0,25035 \\
0,24225 \\
0,24160 \\
0,21532 \\
0,24037 \\
0,25335 \\
0,24835 \\
0,24837 \\
0,21966 \\
0,26511 \\
0,24010 \\
0,23100 \\
0,22772 \\
0,24367 \\
0,23959\end{array}$ & $\begin{array}{l}0,18718 \\
0,20458 \\
0,20706 \\
0,20222 \\
0,20987 \\
0,18864 \\
0,19242 \\
0,22416 \\
0,18882 \\
0,21159 \\
0,19361 \\
0,20967 \\
0,19928 \\
0,23054 \\
0,20051 \\
0,19964 \\
0,24308 \\
0,22515 \\
0,24522 \\
0,21762 \\
0,20376 \\
0,20398 \\
0,23783 \\
0,22975 \\
0,23356 \\
0,23218 \\
0,20753 \\
0,25235 \\
0,22521 \\
0,26433 \\
0,25862 \\
0,25766 \\
0,26333 \\
0,25445 \\
0,24139\end{array}$ & $\begin{array}{l}0,19765 \\
0,19081 \\
0,20156 \\
0,17785 \\
0,20224 \\
0,20594 \\
0,18873 \\
0,18867 \\
0,21026 \\
0,18911 \\
0,23362 \\
0,21480 \\
0,21809 \\
0,22691 \\
0,21686 \\
0,21392 \\
0,19681 \\
0,23730 \\
0,20889 \\
0,22606 \\
0,24409 \\
0,19960 \\
0,24462 \\
0,21911 \\
0,24264 \\
0,22165 \\
0,22865 \\
0,20574 \\
0,24753 \\
0,21526 \\
0,23529 \\
0,23017 \\
0,21009 \\
0,24620 \\
0,20913\end{array}$ & $\begin{array}{l}0,20655 \\
0,18493 \\
0,19019 \\
0,18255 \\
0,20296 \\
0,17932 \\
0,19686 \\
0,19020 \\
0,22139 \\
0,18072 \\
0,19067 \\
0,21553 \\
0,22900 \\
0,21391 \\
0,21313 \\
0,21607 \\
0,20348 \\
0,23046 \\
0,20438 \\
0,22069 \\
0,19147 \\
0,21350 \\
0,24311 \\
0,20549 \\
0,22752 \\
0,22466 \\
0,22629 \\
0,20731 \\
0,23475 \\
0,19935 \\
0,23129 \\
0,22603 \\
0,24237 \\
0,22412 \\
0,20735\end{array}$ & $\begin{array}{l}0,14726 \\
0,16348 \\
0,17927 \\
0,15953 \\
0,18164 \\
0,16361 \\
0,16596 \\
0,17490 \\
0 ; 17508 \\
0,18491 \\
0,17091 \\
0,19144 \\
0,19137 \\
0,16606 \\
0,20644 \\
0,18685 \\
0,18868 \\
0,21079 \\
0,20288 \\
0,22299 \\
0,19837 \\
0,22452 \\
0,20041 \\
0,23203 \\
0,19381 \\
0,23595 \\
0,23179 \\
0,20652 \\
0,20702 \\
0,22745 \\
0,20344 \\
0,22934 \\
0,21851 \\
0,22978 \\
0,21805\end{array}$ & $\begin{array}{l}0,14171 \\
0,16659 \\
0,152114 \\
0,15099 \\
0,14801 \\
0,15295 \\
0,17328 \\
0,18331 \\
0,15664 \\
0,17237 \\
0,18627 \\
0,19726 \\
0,16633 \\
0,17528 \\
0,17911 \\
0,16285 \\
0,18942 \\
0,16299 \\
0,19989 \\
0,17281 \\
0,18841 \\
0,21937 \\
0,19744 \\
0,21305 \\
0,20575 \\
0,22165 \\
0,18272 \\
0,20104 \\
0,18660 \\
0,19935 \\
0,18215 \\
0,20460 \\
0,19030 \\
0,23734 \\
0,17962\end{array}$ & $\begin{array}{l}0,14765 \\
0,15147 \\
0,17071 \\
0,15371 \\
0,15370 \\
0,17145 \\
0,16669 \\
0,16121 \\
0,14984 \\
0,18841 \\
0,19582 \\
0,15677 \\
0,17632 \\
0,18381 \\
0,16007 \\
0,16285 \\
0,21016 \\
0,20477 \\
0,19989 \\
0,21839 \\
0,17238 \\
0,20837 \\
0,21083 \\
0,18145 \\
0,20650 \\
0,18292 \\
0,21612 \\
0,19012 \\
0,23157 \\
0,21298 \\
0,19633 \\
0,19150 \\
0,21085 \\
0,21847 \\
0,19198\end{array}$ & $\begin{array}{l}0,16355 \\
0,17594 \\
0,16528 \\
0,15138 \\
0,14765 \\
0,17288 \\
0,14700 \\
0,16425 \\
0,17097 \\
0,15849 \\
0,16145 \\
0,16396 \\
0,18347 \\
0,18667 \\
0,16591 \\
0,20605 \\
0,16372 \\
0,18529 \\
0,20814 \\
0,17281 \\
0,16934 \\
0,17780 \\
0,19077 \\
0,19570 \\
0,21624 \\
0,21716 \\
0,19820 \\
0,18623 \\
0,22125 \\
0,19483 \\
0,19317 \\
0,20296 \\
0,20551 \\
0,21158 \\
0,21627\end{array}$ \\
\hline
\end{tabular}


Solo LE, profundidade $0,05 \mathrm{~m}, 2^{\mathrm{a}}$ repetição, lado $\mathrm{A}$.

\begin{tabular}{|c|c|c|c|c|c|c|c|c|c|}
\hline $\begin{array}{l}\text { distancia } \\
\text { (m) }\end{array}$ & $18 / 10793$ & 19710793 & $20710 / 93$ & $21 / 10 / 93$ & $\frac{1 \text { dade }(\mathrm{m}}{22710 / 93}$ & $\frac{5}{24 / 10 / 33}$ & $26710 / 93$ & $28710 / 93$ & $30 / 20 / 93$ \\
\hline $\begin{array}{l}0,0007 \\
0,0021 \\
0,0035 \\
0,0049 \\
0,0063 \\
0,0077 \\
0,0091 \\
0,0105 \\
0,0119 \\
0,0133 \\
0,0147 \\
0,0161 \\
0,0175 \\
0,0189 \\
0,0203 \\
0,0217 \\
0,0231 \\
0,0245 \\
0,0259 \\
0,0273 \\
0,0287 \\
0,0301 \\
0,0315 \\
0,0329 \\
0,0343 \\
0,0357 \\
0,0371 \\
0,0385 \\
0,0399 \\
0,043 \\
0,0427 \\
0,0441 \\
0,0455 \\
0,0469 \\
0,0483 \\
0,0497 \\
\end{array}$ & $\begin{array}{l}0,24263 \\
0,28774 \\
0,25494 \\
0,27389 \\
0,26426 \\
0,27434 \\
0,24877 \\
0,23877 \\
0,26710 \\
0,26709 \\
0,24103 \\
0,23830 \\
0,25907 \\
0,26620 \\
0,24127 \\
0,25455 \\
0,25946 \\
0,25794 \\
0,24287 \\
0,26393 \\
0,26710 \\
0,28421 \\
0,27531 \\
0,28826 \\
0,24825 \\
0,24429 \\
0,26439 \\
0,24859 \\
0,28223 \\
0,27144 \\
0,24899 \\
0,26149 \\
0,25411 \\
0,25517 \\
0,26032 \\
0,26398 \\
\end{array}$ & $\begin{array}{l}0,23678 \\
0,21218 \\
0,20600 \\
0,21220 \\
0,21565 \\
0,22806 \\
0,22886 \\
0,22848 \\
0,19995 \\
0,23901 \\
0,22034 \\
0,21914 \\
0,21515 \\
0,21080 \\
0,23738 \\
0,22798 \\
0,22288 \\
0,25331 \\
0,24820 \\
0,25404 \\
0,22045 \\
0,22949 \\
0,24595 \\
0,23892 \\
0,25770 \\
0,24045 \\
0,23342 \\
0,26773 \\
0,24662 \\
0,21492 \\
0,24659 \\
0,24907 \\
0,22293 \\
0,22853 \\
0,23640 \\
0,23605 \\
\end{array}$ & $\begin{array}{l}0,19153 \\
0,19895 \\
0,21609 \\
0,19900 \\
0,20530 \\
0,21411 \\
0,18434 \\
0,21165 \\
0,23333 \\
0,21267 \\
0,19616 \\
0,20377 \\
0,21982 \\
0,23985 \\
0,24361 \\
0,23967 \\
0,23882 \\
0,24486 \\
0,23754 \\
0,20738 \\
0,22348 \\
0,24479 \\
0,23101 \\
0,21959 \\
0,23024 \\
0,22516 \\
0,22857 \\
0,22711 \\
0,23104 \\
0,21735 \\
0,22985 \\
0,22277 \\
0,24258 \\
0,21811 \\
0,26552 \\
0,24533 \\
\end{array}$ & $\begin{array}{l}0,19189 \\
0,19120 \\
0,18002 \\
0,19717 \\
0,20493 \\
0,20663 \\
0,21142 \\
0,18120 \\
0,22894 \\
0,19308 \\
0,19252 \\
0,22208 \\
0,22763 \\
0,19455 \\
0,22419 \\
0,23889 \\
0,22818 \\
0,20524 \\
0,23830 \\
0,20664 \\
0,20005 \\
0,22263 \\
0,20434 \\
0,22036 \\
0,23102 \\
0,24813 \\
0,19801 \\
0,21643 \\
0,24498 \\
0,23853 \\
0,23462 \\
0,22032 \\
0,23684 \\
0,23577 \\
0,23318 \\
0,22518 \\
\end{array}$ & $\begin{array}{l}0,19045 \\
0,16807 \\
0,18186 \\
0,19170 \\
0,19829 \\
0,20735 \\
0,20915 \\
0,20364 \\
0,18128 \\
0,18370 \\
0,19179 \\
0,22355 \\
0,20274 \\
0,18206 \\
0,20567 \\
0,18861 \\
0,18380 \\
0,18715 \\
0,19759 \\
0,20291 \\
0,22804 \\
0,20821 \\
0,21987 \\
0,23892 \\
0,19226 \\
0,23356 \\
0,24642 \\
0,19927 \\
0,24827 \\
0,22792 \\
0,22429 \\
0,22686 \\
0,24587 \\
0,24384 \\
0,20632 \\
0,24588 \\
\end{array}$ & $\begin{array}{l}0,17186 \\
0,16462 \\
0,17743 \\
0,16955 \\
0,15266 \\
0,18538 \\
0,18884 \\
0,15680 \\
0,17913 \\
0,19815 \\
0,19033 \\
0,19284 \\
0,16659 \\
0,16671 \\
0,20336 \\
0,19091 \\
0,21004 \\
0,18489 \\
0,22466 \\
0,21785 \\
0,20231 \\
0,19386 \\
0,18378 \\
0,19047 \\
0,21390 \\
0,19860 \\
0,18843 \\
0,20743 \\
0,22532 \\
0,22385 \\
0,20611 \\
0,20240 \\
0,20100 \\
0,21252 \\
0,22740 \\
0,22301 \\
\end{array}$ & $\begin{array}{l}0,13610 \\
0,15544 \\
0,16675 \\
0,13363 \\
0,14724 \\
0,16255 \\
0,16719 \\
0,17616 \\
0,17556 \\
0,15220 \\
0,16498 \\
0,15745 \\
0,16736 \\
0,17328 \\
0,17129 \\
0,20013 \\
0,17635 \\
0,20675 \\
0,20433 \\
0,21485 \\
0,18729 \\
0,20065 \\
0,18012 \\
0,18058 \\
0,18458 \\
0,17679 \\
0,22049 \\
0,19276 \\
0,23104 \\
0,19714 \\
0,20139 \\
0,21623 \\
0,22293 \\
0,20216\end{array}$ & $\begin{array}{l}0,14385 \\
0,12999 \\
0,13350 \\
0,15548 \\
0,16572 \\
0,16815 \\
0,13982 \\
0,17544 \\
0,16344 \\
0,15790 \\
0,17581 \\
0,19211 \\
0,18576 \\
0,18647 \\
0,17509 \\
0,18478 \\
0,17561 \\
0,16768 \\
0,18564 \\
0,21186 \\
0,17310 \\
0,18184\end{array}$ & $\begin{array}{l}0,14209 \\
0,15735 \\
0,14223 \\
0,16341 \\
0,15339 \\
0,15591 \\
0,18734 \\
0,16324 \\
0,17913 \\
0,15078 \\
0,16570 \\
0,20085 \\
0,17654 \\
0,19014 \\
0,17053 \\
0,17638 \\
0,17635 \\
0,17590 \\
0,17523 \\
0,21411 \\
0,21439 \\
0,20518 \\
0,17428 \\
0,17149 \\
0,17845 \\
0,22439 \\
0,20602 \\
0,18546 \\
0,19690 \\
0,22060 \\
0,23064 \\
0,20078 \\
0,22620 \\
0,21092 \\
0,21014 \\
0,22844 \\
\end{array}$ \\
\hline
\end{tabular}

Solo LE, profundidade $0,05 \mathrm{~m}, 2^{\mathrm{a}}$ repetição; lado $\mathrm{B}$.

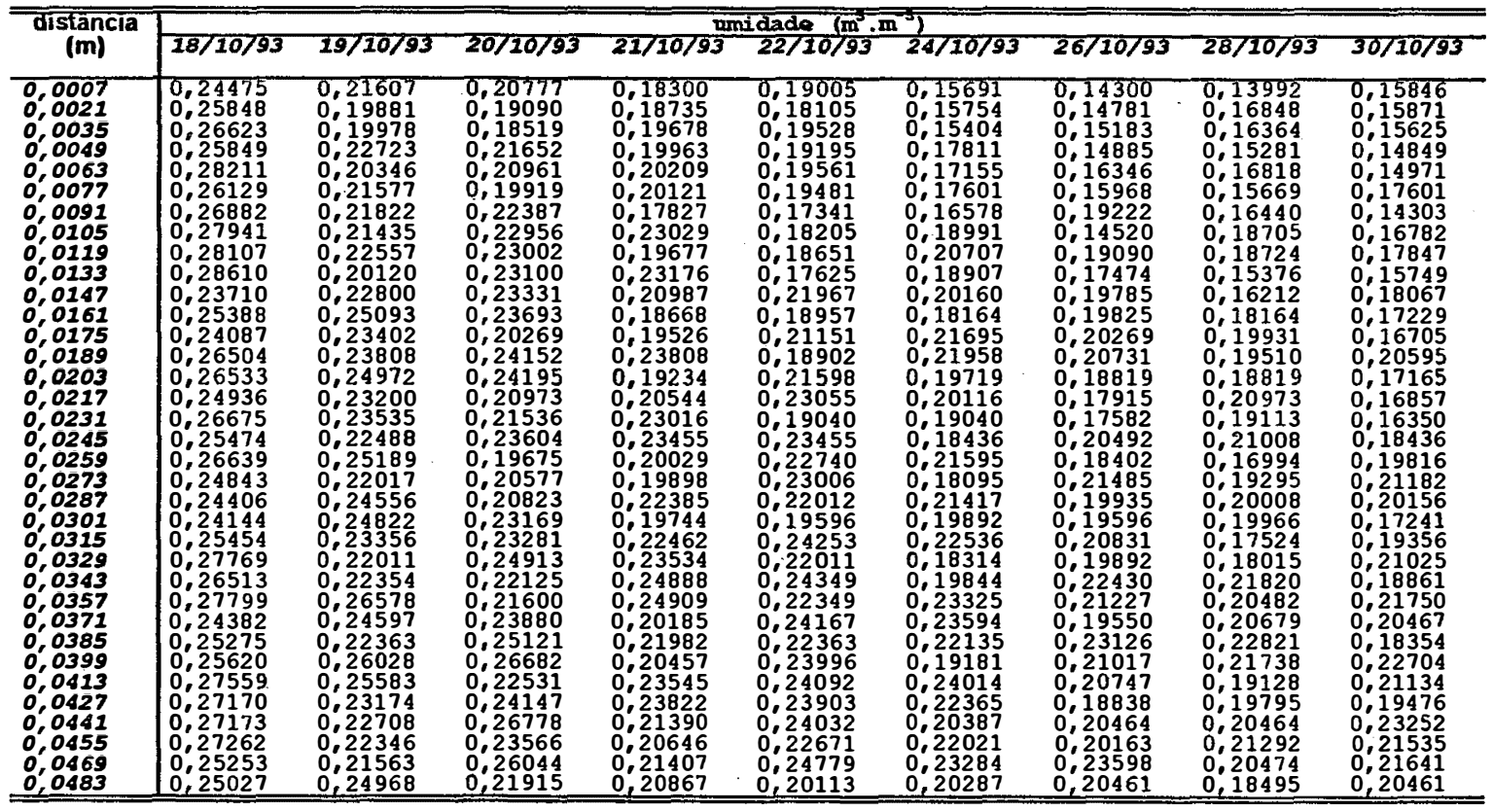


Solo LE, profundidade $0,06 \mathrm{~m}, 2^{\underline{a}}$ repetição, lado $A$.

\begin{tabular}{|c|c|c|c|c|c|c|c|c|c|}
\hline $\begin{array}{l}\text { distancia } \\
\text { (m) }\end{array}$ & $18 / 10 / 93$ & 19710793 & $20 / 10 / 93$ & $21 / 10 / 93$ & $\frac{\text { idade }(\mathrm{m} .1}{22 / 10 / 93}$ & $24 / 10 / 93$ & $26 / 10 / 93$ & $28 / 10 / 93$ & 30710793 \\
\hline $\begin{array}{l}0,0007 \\
0,0021 \\
0,0035 \\
0,0049 \\
0,0063 \\
0,0077 \\
0,0091 \\
0,0105 \\
0,0119 \\
0,0133 \\
0,0147 \\
0,0161 \\
0,0175 \\
0,0189 \\
0,0203 \\
0,0217 \\
0,0231 \\
0,0245 \\
0,0259 \\
0,0273 \\
0,0287 \\
0,0301 \\
0,0315 \\
0,0329 \\
0,0343 \\
0,0357 \\
0,0371 \\
0,0385 \\
0,0399 \\
0,0413 \\
0,0427 \\
0,0441 \\
0,0455 \\
0,0469 \\
0,0483 \\
0,0497\end{array}$ & $\begin{array}{l}0,26024 \\
0,25089 \\
0,25010 \\
0,28207 \\
0,27039 \\
0,27821 \\
0,27544 \\
0,26836 \\
0,26687 \\
0,27359 \\
0,25826 \\
0,27396 \\
0,27857 \\
0,25271 \\
0,25296 \\
0,26059 \\
0,25234 \\
0,23474 \\
0,26426 \\
0,26348 \\
0,23284 \\
0,28490 \\
0,25493 \\
0,24183 \\
0,25204 \\
0,26016 \\
0,26657 \\
0,28419 \\
0,27353 \\
0,28452 \\
0,27832 \\
0,25686 \\
0,25240 \\
0,28458 \\
0,25902 \\
0,27598 \\
\end{array}$ & $\begin{array}{l}0,19813 \\
0,19857 \\
0,22571 \\
0,21377 \\
0,20505 \\
0,23532 \\
0,21206 \\
0,22073 \\
0,20449 \\
0,23686 \\
0,21584 \\
0,20809 \\
0,22957 \\
0,24646 \\
0,20911 \\
0,20284 \\
0,23318 \\
0,25130 \\
0,23064 \\
0,25227 \\
0,25735 \\
0,21823 \\
0,23736 \\
0,23054 \\
0,21611 \\
0,21979 \\
0,23204 \\
0,23719 \\
0,21398 \\
0,23140 \\
0,23305 \\
0,23429 \\
0,23556 \\
0,22017 \\
0,25902 \\
0,21344 \\
\end{array}$ & $\begin{array}{l}0,18853 \\
0,18621 \\
0,19620 \\
0,20920 \\
0,21664 \\
0,20898 \\
0,22204 \\
0,22223 \\
0,19337 \\
0,23608 \\
0,18594 \\
0,23929 \\
0,19816 \\
0,20007 \\
0,19439 \\
0,21623 \\
0,23089 \\
0,23946 \\
0,21797 \\
0,20946 \\
0,19998 \\
0,19637 \\
0,22976 \\
0,24669 \\
0,23401 \\
0,24638 \\
0,25329 \\
0,21623 \\
0,22306 \\
0,24209 \\
0,23001 \\
0,21988 \\
0,23636 \\
0,22646 \\
0,22267 \\
0,26410 \\
\end{array}$ & $\begin{array}{l}0,20665 \\
0,18024 \\
0,18100 \\
0,20464 \\
0,19536 \\
0,18256 \\
0,22276 \\
0,19240 \\
0,21790 \\
0,17698 \\
0,18296 \\
0,22479 \\
0,19816 \\
0,19777 \\
0,22001 \\
0,18804 \\
0,21339 \\
0,23081 \\
0,23764 \\
0,23872 \\
0,24151 \\
0,19248 \\
0,23736 \\
0,228112 \\
0,24027 \\
0,24791 \\
0,21457 \\
0,20062 \\
0,22685 \\
0,23674 \\
0,21108 \\
0,23992 \\
0,24757 \\
0,21467 \\
0,21898 \\
0,24731 \\
\end{array}$ & $\begin{array}{l}0,19222 \\
0,21137 \\
0,17872 \\
0,18647 \\
0,18423 \\
0,19706 \\
0,17249 \\
0,20355 \\
0,20672 \\
0,19068 \\
0,21659 \\
0,18850 \\
0,21114 \\
0,20007 \\
0,21455 \\
0,21921 \\
0,18925 \\
0,19107 \\
0,20898 \\
0,20946 \\
0,21871 \\
0,22765 \\
0,23280 \\
0,22009 \\
0,19909 \\
0,19646 \\
0,21603 \\
0,21921 \\
0,20418 \\
0,19580 \\
0,21410 \\
0,24717 \\
0,22200 \\
0,22017 \\
0,24859 \\
0,22264 \\
\end{array}$ & $\begin{array}{l}0,18044 \\
0,17242 \\
0,16965 \\
0,17143 \\
0,19648 \\
0,17961 \\
0,20211 \\
0,16144 \\
0,18377 \\
0,20982 \\
0,19338 \\
0,19150 \\
0,17013 \\
0,17110 \\
0,16597 \\
0,20730 \\
0,17053 \\
0,18257 \\
0,22366 \\
0,19378 \\
0,19842 \\
0,20337 \\
0,20708 \\
0,20490 \\
0,22077 \\
0,20998 \\
0,20516 \\
0,23418 \\
0,21021 \\
0,23521 \\
0,21939 \\
0,21350 \\
0,20535 \\
0,23119 \\
0,22119 \\
0,22755 \\
\end{array}$ & $\begin{array}{l}0,14975 \\
0,13513 \\
0,15910 \\
0,14568 \\
0,16394 \\
0,15771 \\
0,18726 \\
0,18870 \\
0,15225 \\
0,16864 \\
0,18000 \\
0,15565 \\
0,16335 \\
0,15900 \\
0,19671 \\
0,19321 \\
0,20583 \\
0,16719 \\
0,16313 \\
0,17198 \\
0,17598 \\
0,21118 \\
0,20784 \\
0,20091 \\
0,17911 \\
0,20472 \\
0,18644 \\
0,19988 \\
0,18768 \\
0,20485 \\
0,18479 \\
0,20396 \\
0,23316 \\
0,22961 \\
0,23005 \\
0,20245 \\
\end{array}$ & $\begin{array}{l}0,14866 \\
0,15574 \\
0,14224 \\
0,14679 \\
0,13725 \\
0,15511 \\
0,18303 \\
0,18870 \\
0,16174 \\
0,19297 \\
0,19413 \\
0,16755 \\
0,18221 \\
0,15372 \\
0,16291 \\
0,20284 \\
0,16085 \\
0,21281 \\
0,19744 \\
0,19769 \\
0,16752 \\
0,19792 \\
0,18385 \\
0,18900 \\
0,18141 \\
0,22130 \\
0,19578 \\
0,21176 \\
0,20043 \\
0,19355 \\
0,23229 \\
0,21829 \\
0,23396 \\
0,22095 \\
0,20504 \\
0,21099 \\
\end{array}$ & $\begin{array}{l}0,13237 \\
0,15021 \\
0,15685 \\
0,15349 \\
0,15733 \\
0,17403 \\
0,18867 \\
0,16290 \\
0,15955 \\
0,19450 \\
0,18074 \\
0,16159 \\
0,18524 \\
0,20161 \\
0,16138 \\
0,20953 \\
0,16606 \\
0,19959 \\
0,215115 \\
0,17586 \\
0,21401 \\
0,18241 \\
0,21236 \\
0,17555 \\
0,21455 \\
0,17333 \\
0,17998 \\
0,19543 \\
0,20418 \\
0,21544 \\
0,19228 \\
0,21909 \\
0,21644 \\
0,21232 \\
0,19991 \\
0,18968 \\
\end{array}$ \\
\hline
\end{tabular}

Solo LE, profundidade $0,06 \mathrm{~m}, 2^{\underline{a}}$ repetição, lado B.

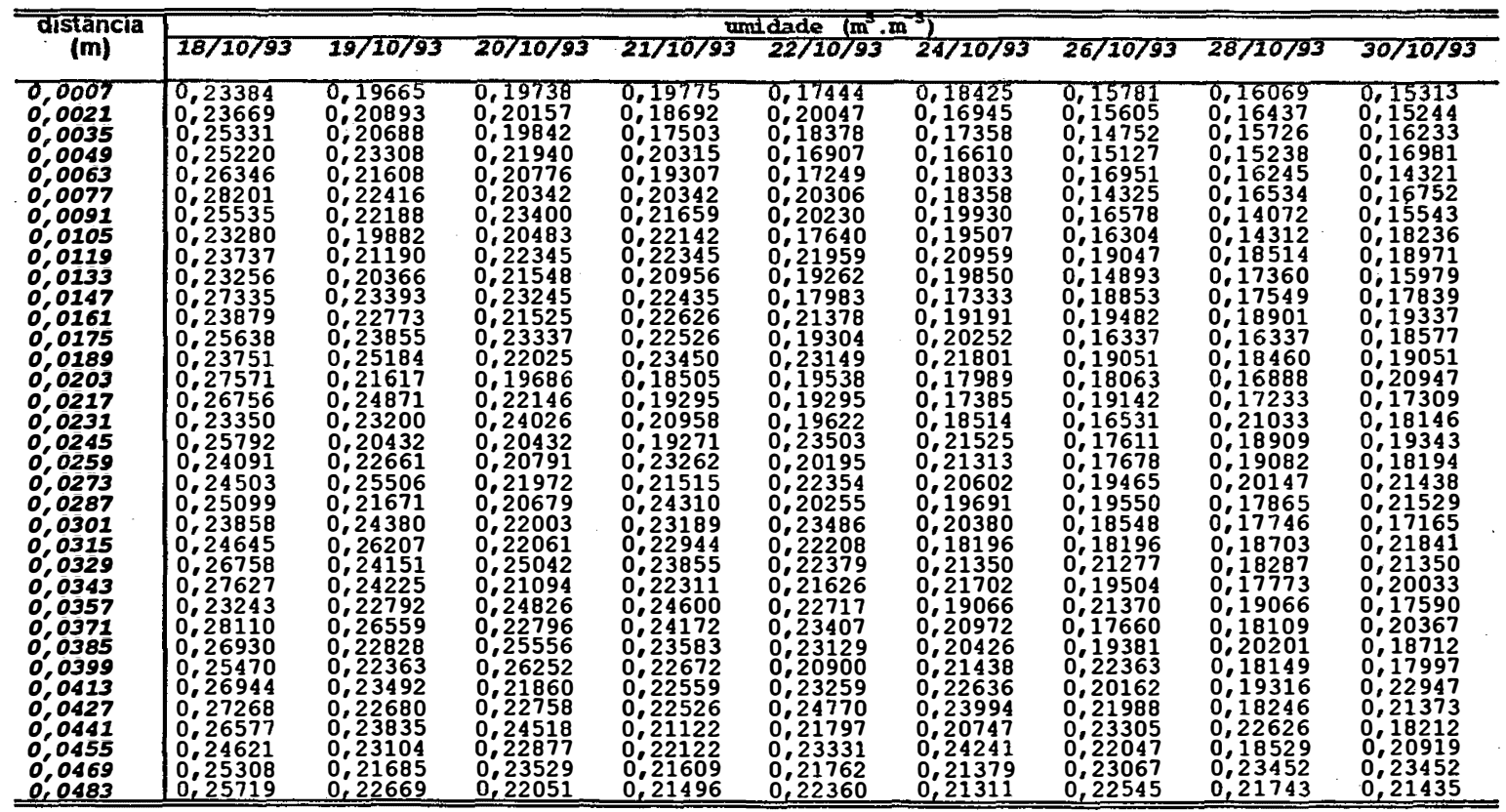

